\title{
Competitiveness of Polish Milk Processing Industry During the Integration to the European Union - Analysis of Dynamic Comparative Advantages
}

\author{
Doctoral Dissertation \\ submitted for the degree of Doctor of Agricultural Sciences \\ of the Faculty of Agricultural Sciences \\ Georg-August-University Göttingen (Germany)
}

\author{
by \\ Waldemar Guba \\ born in Inowroclaw (Poland)
}

Göttingen, May 2000 
D7

$1^{\text {st }}$ examiner: $\quad$ Prof. Dr. S. Tangermann

$2^{\text {nd }}$ examiner: $\quad$ Prof. Dr. S. v. Cramon-Taubadel

Day of oral examination: 20 June 2000 


\section{ACKNOWLEDGEMENTS}

The study in hand has been written at the Institute of Agricultural Economics (IfA) of the Göttingen University and financially supported by the ACE Phare programme of the European Union, which I thankfully acknowledge.

I am grateful to Prof. Dr. Stefan Tangermann, my "Doktovater", who supported this study with many constructive discussions and comments and who has truly inspired me with his writings and lectures in economics. In a way, this study is a consequence of a fruitful co-operation between the team of researches of IfA and the Agricultural Policy Analysis Unit (SAEPR/FAPA) in Warsaw (where I have been working since 1994) in the field of agricultural policy reform in Poland and Poland's integration with the European Union. This study has also benefited from comments by Prof. Dr. Monika Hartmann from IAMO in Halle, Prof. Dr. Stephan von Cramon-Taubadel from IfA and comments by other participants of my "Doktorandenseminars" at IfA.

I would like to sincerely thank all colleagues and staff at the IfA for kind support and cooperative atmosphere during my stay in Göttingen. Thanks to them I could not only explore new economics problems in an efficient and joyful way, but also get acquainted with the German culture and language.

I dedicate this work to my parents.

Wa ld emar Guba 


\begin{abstract}
To analyse competitiveness of Polish milk processing industry during Poland's integration to the EU the study employs the concept of comparative advantage of international trade theory. It has been shown that the mechanism of comparative advantage can explain much of the competitive performance both in the recent past and in the near future, given the technological and structural characteristics of the industry (technological gap and pending restructuring) as well as the properties of the macroeconomic environment associated with the recent market reforms, realized economic growth and ongoing integration with the European Union (appreciating real exchange rate, rising wages and high real interest rates). Empirical tools used involve: domestic resource cost ratio (DRC), private cost ratio (PCR) and policy analysis matrix (PAM). These have been used first to estimate and decompose recent comparative advantages for the industry (as a whole and its selected product-specific activities), and then, to project future (dynamic) comparative advantages up to 2010. The later is based on a set of consistent assumptions as regards future macroeconomic performance as well as sector-specific assumptions concerning the prospected harmonization of domestic market policies with the Common Agricultural Policy of EU and conditions for the industry to realize necessary improvements in factor productivity and product quality.
\end{abstract}

\title{
ZUSAMMENFASSUNG
}

Mit Hilfe des Konzeptes der komparativen Kostenvorteile der internationalen Handelstheorie wird in dieser Studie die Wettbewerbsfähigkeit der polnischen Milchverarbeitungsindustrie während Polens Integration in die EU untersucht. Bei der Untersuchung werden einerseits technologische und strukturelle Charakteristika des Industriezweiges (technologischer Rückstand und anstehende Restrukturierungen), andererseits makroökonomische Rahmenbedingungen im Zusammenhang mit den Marktreformen, dem realisierten wirtschaftlichen Wachstum und der fortschreitenden Integration mit der Europäischen Union (Aufwertung des realen Wechselkurses, steigende Löhne und hohe Realzinsen) berücksichtigt. Es konnte gezeigt werden, dass das Konzept der komparativen Kostenvorteile wesentliche Erklärungsbeiträge für die Entwicklung der Wettbewerbsfähigkeit sowohl in der Vergangenheit als auch für die nahe Zukunft liefert. Die dabei angewendeten empirischen Methoden umfassen Berechnungen des domestic resource cost ratio (DRC), des private cost ratio (PCR) und der policy analysis matrix (PAM). Diese wurden erstens eingesetzt, um jüngste komparative Vorteile des gesamten Industriezweiges und ausgewählter Molkereiprodukte zu schätzen und zu analysieren. Zweitens wurden zukünftige dynamische komparative Vorteile bis 2010 prognostiziert. Letztere Untersuchung basiert auf konsistenten Annahmen zur zukünftigen makroökonomischen Entwicklung und auf sektorspezifischen Annahmen hinsichtlich der Anpassung der heimischen Agrarmarktpolitiken an die Gemeinsame Agrarpolitik der EU und hinsichtlich der Möglichkeiten der milchverarbeitende Industrie, notwendige Verbesserungen in Faktorproduktivität und Produktqualität zu erreichen. 


\section{TABLE OF CONTENTS}

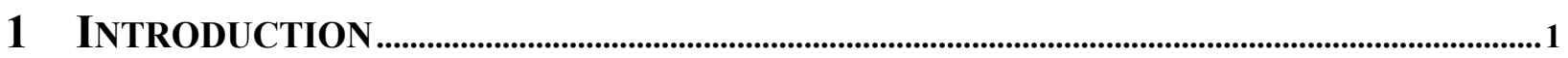

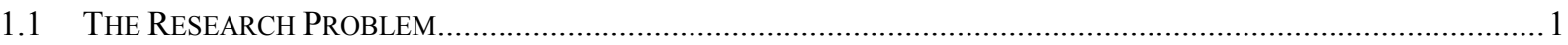

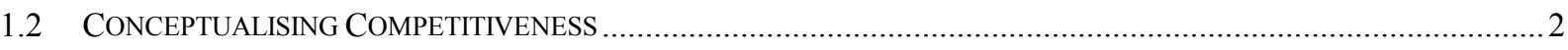

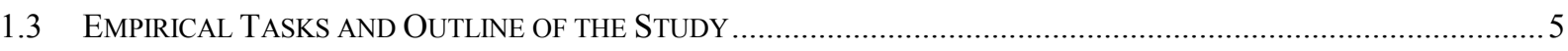

\section{Technology and Technological Change in the Milk}

PROCESSING INDUSTRY ...................................................................................................................

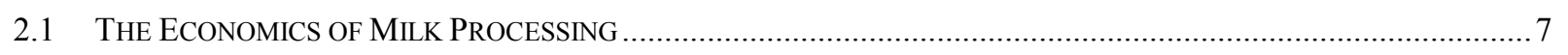

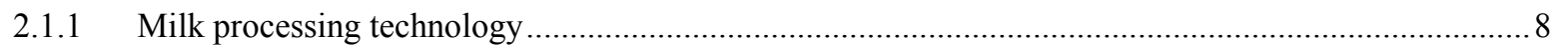

$2.1 .2 \quad$ Determinants of processing costs ...........................................................................................

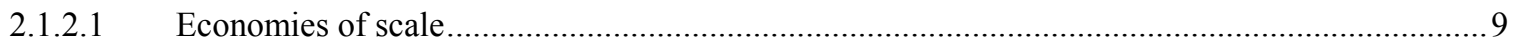

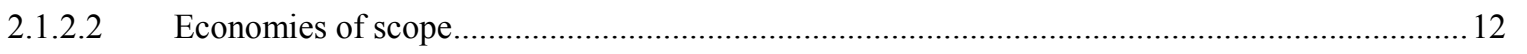

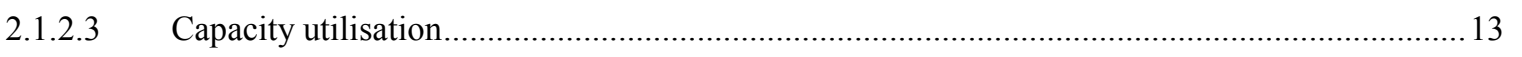

$2.2 \quad$ STRUCTURE OF THE MILK PROCESSING INDUSTRY IN POLAND ...................................................

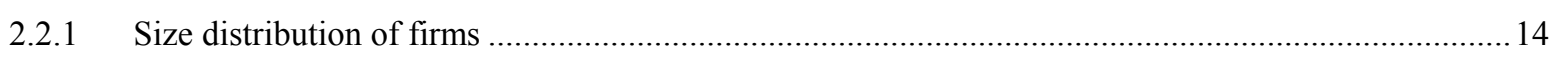

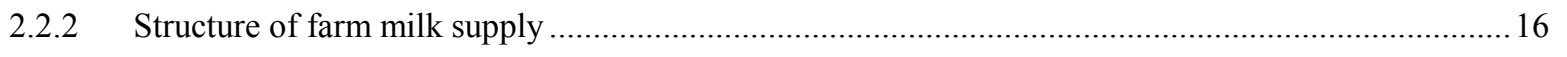

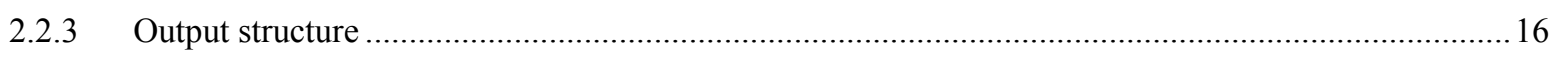

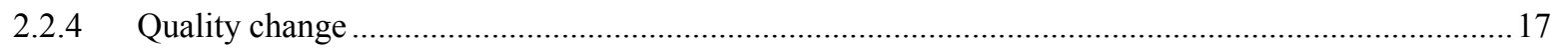

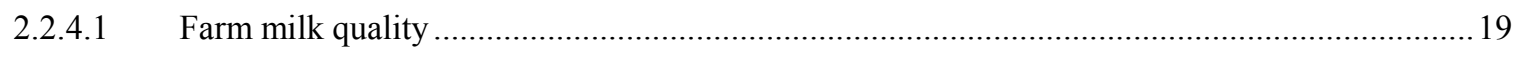

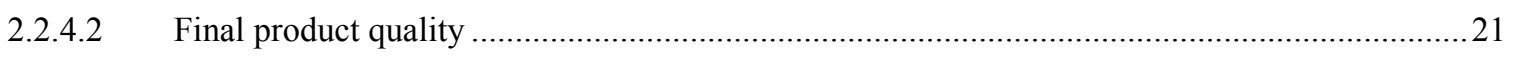

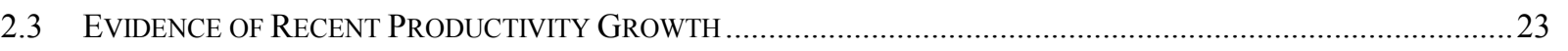

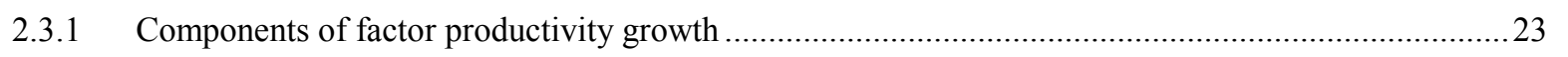

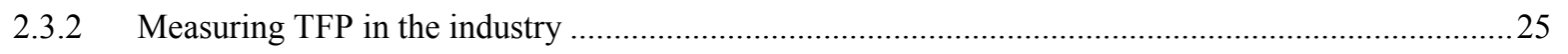

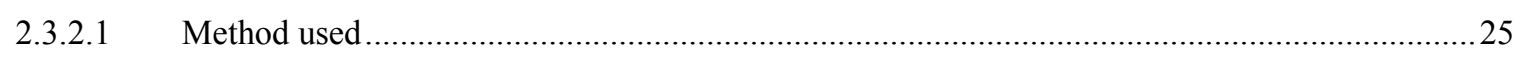

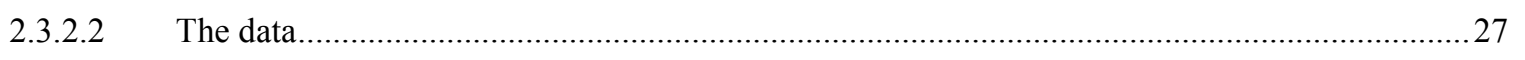

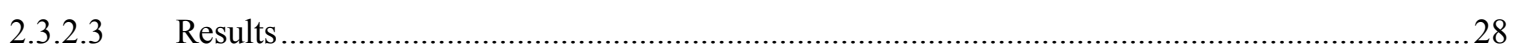

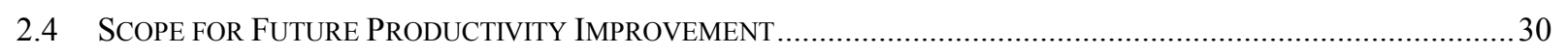

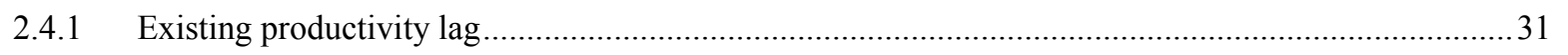

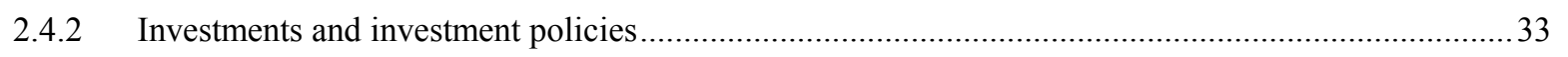

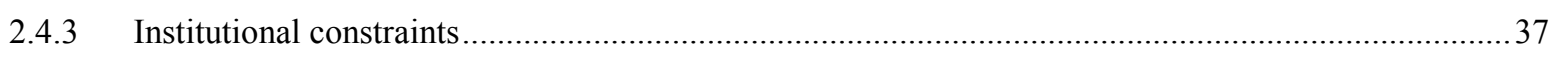

$3 \quad$ RECENT COMPARATIVE ADVANTAGES .................................................................................39

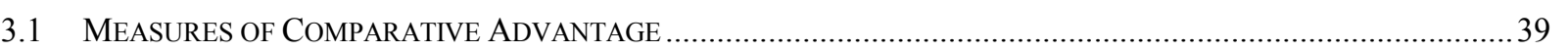

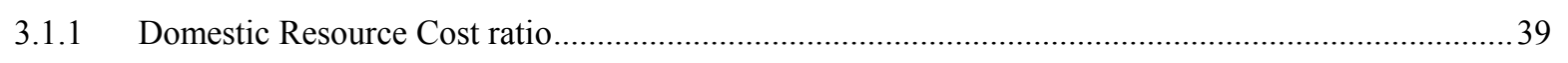

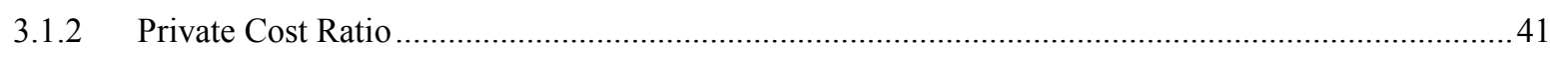

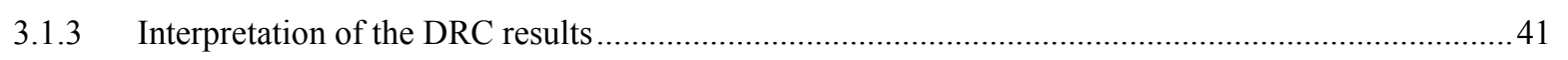

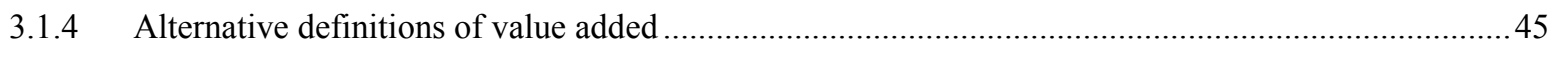

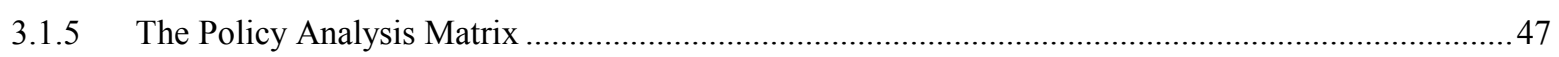




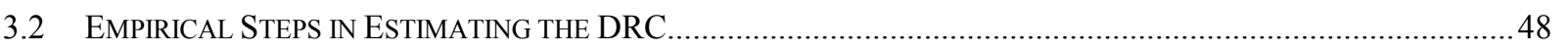

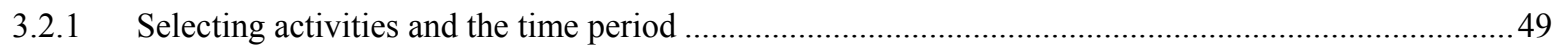

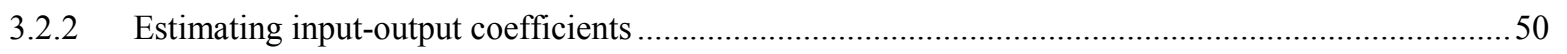

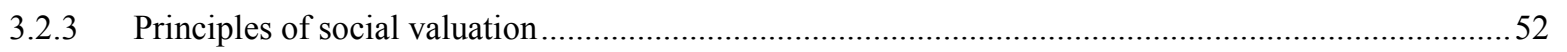

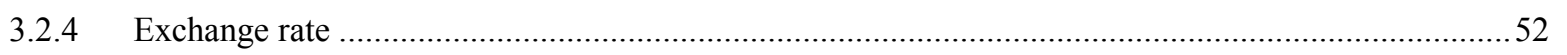

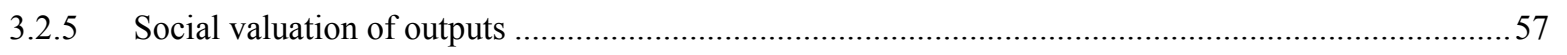

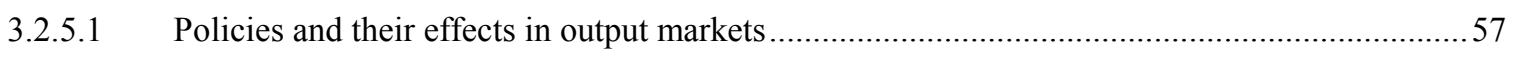

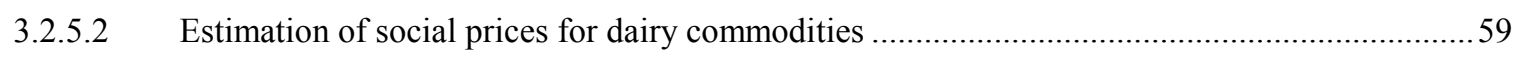

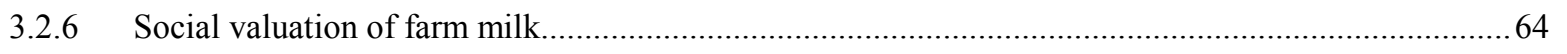

3.2.6.1 Effect of sectoral policies on farm milk prices ..........................................................65

3.2.6.2 Effects of fragmented farm structure ............................................................................67

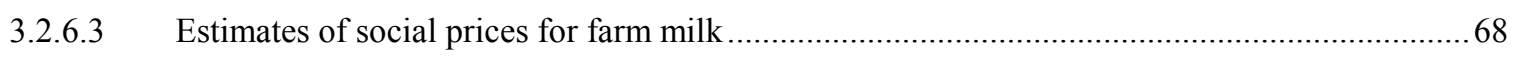

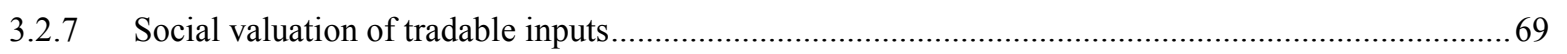

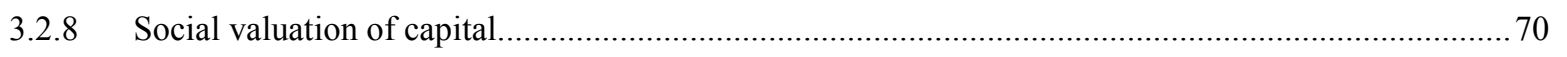

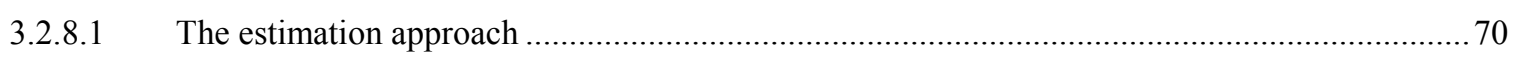

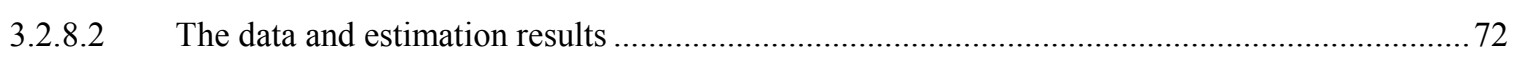

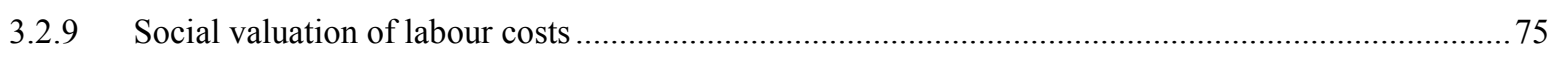

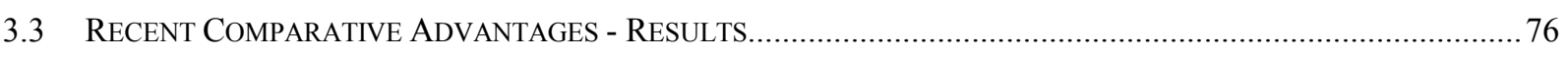

\section{DYNAMIC COMPARATIVE AdVANTAGES - EFFECTS OF INTEgRATION} WITH THE EU.

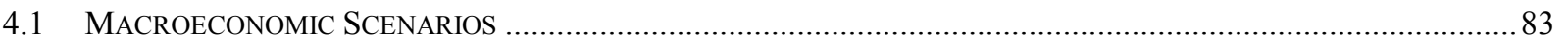

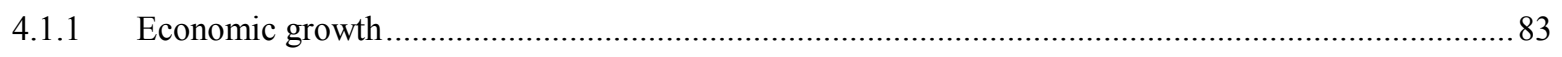

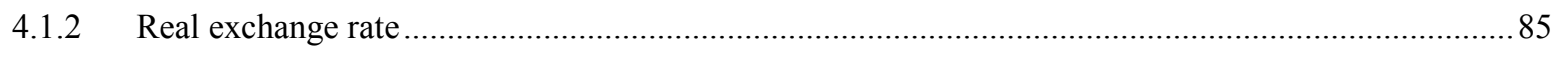

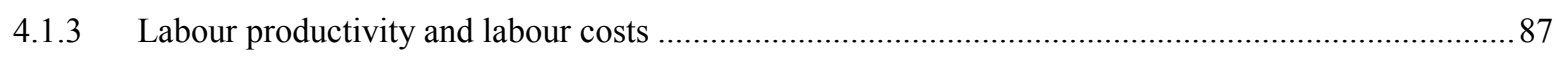

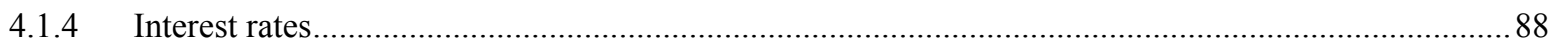

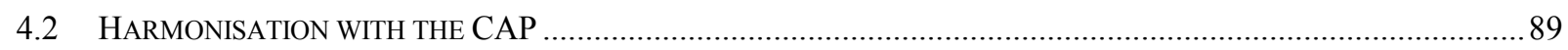

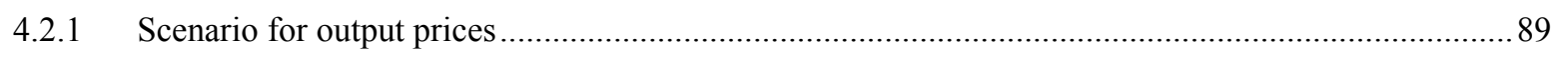

$4.2 .2 \quad$ Future disparities between private and social values ........................................................ 92

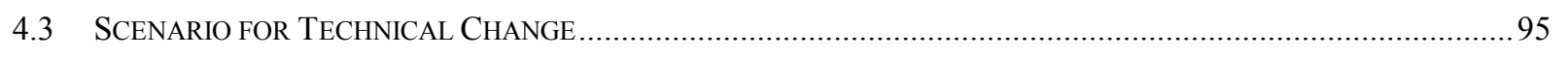

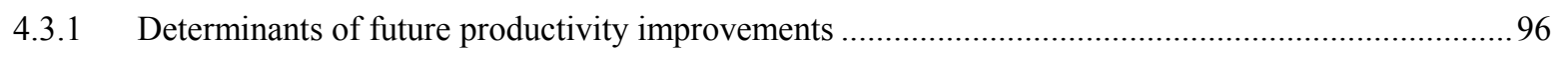

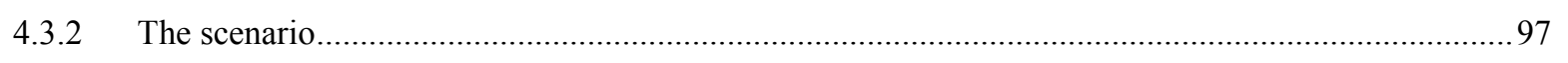

4.3 .3 Decomposing contributions to dynamic comparative advantages........................................... 98

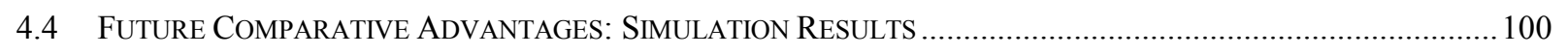

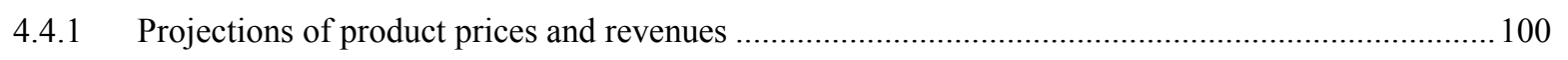

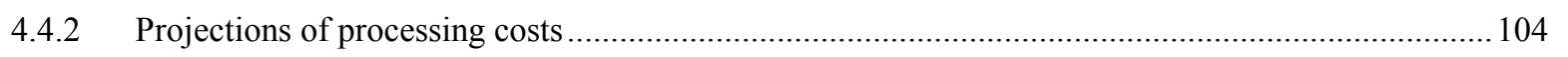

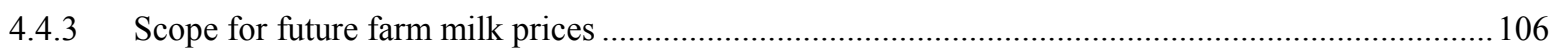

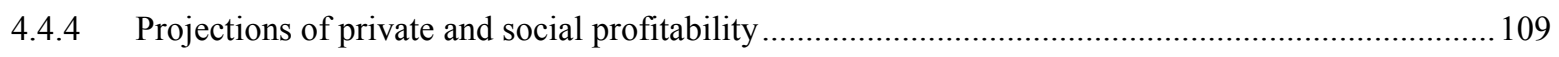

5 Broadened View of Dynamic Comparative Advantage - A case

STUDY OF THE YOGHURT MARKET .................................................................................116

5.1 CHARACTERISTICS OF YOGHURT AND YOGHURT TECHNOLOGY ....................................................... 117

5.2 DEVELOPMENTS IN THE YOGHURT MARKET IN POLAND (1990-1999) ................................................. 117

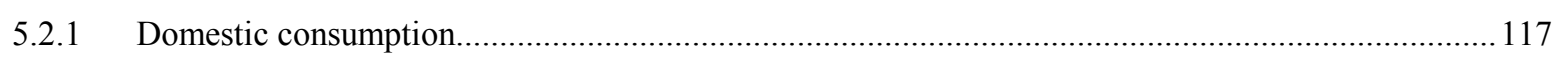




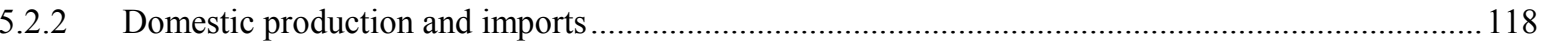

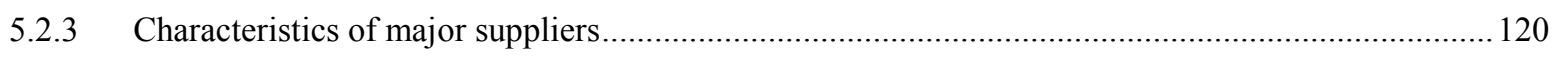

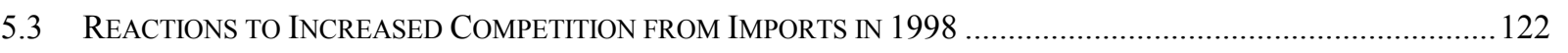

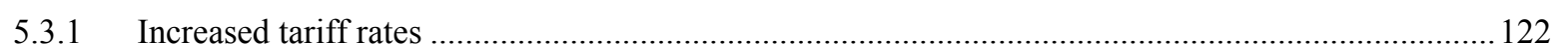

5.3 .2 Response of the major importer (Zott) to the new tariff rates ................................................ 124

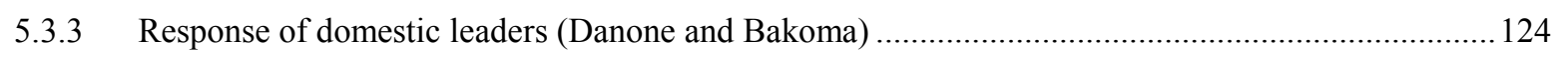

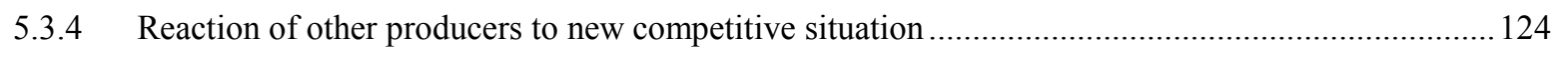

$5.4 \quad$ SALIENT FACTS ON DEVELOPMENTS IN THE YOGHURT MARKET IN POLAND .......................................... 125

5.5 EXPLAINING THE COMPETITIVENESS OF YOGHURT PRODUCTION IN POLAND ...................................... 126

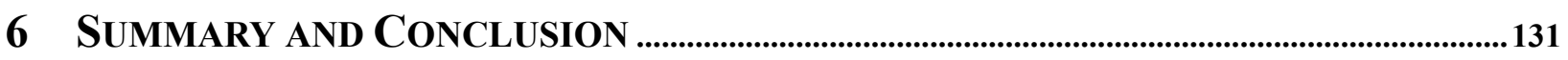

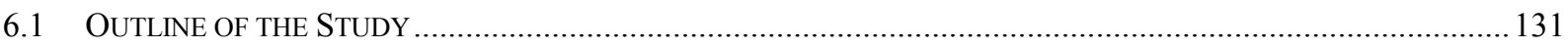

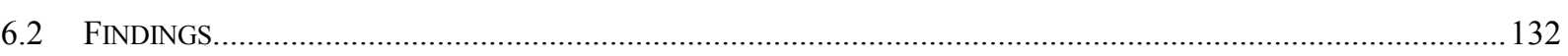

$6.3 \quad$ GENERAL CONCLUSIONS .................................................................................................................... 137

$7 \quad$ REFERENCES ...............................................................................................................................139

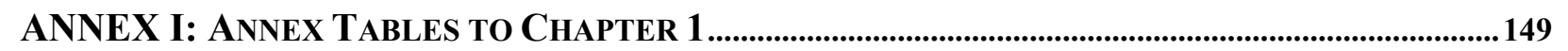

ANNEX II: ANNEX TABLES TO CHAPTER 2 ....................................................................................................152

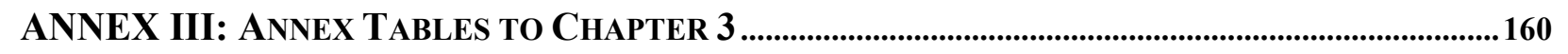

ANNEX IV: ANNEX TABLES TO CHAPTER 4 .........................................................................................171 


\section{LIST OF TABLES}

Table 2.1. Changes in input intensity resulting from an increase in capacity size and improvement in capacity utilisation, selected product-lines (in \%),..................................................................... 11

Table 2.2. $\quad$ Changes in the product structure of output of the milk processing industry, Poland, 1992-1998

(production in thousand tons, per year)........................................................................................ 17

Table 2.3. $\quad$ Regulatory quality standards for farm milk in Poland and in the EU, and the quality of milk deliveries in Poland, 1998-1999.

Table 2.4. Conformity with regulatory standards for dairy product quality (1997, value weighted shares of fon-random cases violating the standards, in \%) ............................................................................22

Table 2.5. Components of revenue growth in the milk processing industry, 1993-1997 (in \% per year)..............28

Table 2.6. $\quad$ Selected data on investment in the milk processing industry, 1992-1997...........................................

Table 2.7. Profitability and investment rates in the milk processing industry (by ownership status) and in the food processing industry, 1994-1998 (1n \%).

Table 3.1. $\quad$ The Policy Analysis Matrix................................................................................................ 48

Table 3.2: $\quad$ Product share in the industry revenues, and share of farm milk in total cost, 1997..........................49

Table 3.3. $\quad$ Private-social divergence of dairy product prices (in \% of private producer price)............................61

Table 3.4. Prices of milk and fat and non-fat components under alternative prices for butter and SMP, and alternative processing margins, 1996-1998.

Table 3.5. $\quad$ Lending interest rates faced by the milk processing industry, 1993-1998 (in \%).............................. 73

Table 3.6. $\quad$ Distribution of gross domestic product and rates of return on capital, Poland, 1995-1998_................74

Table 3.7. $\quad$ Conversion factors for capital cost in the milk processing industry, 1997.......................................75

Table 3.8. $\quad$ Estimates of coefficients of profitability and distortion, Poland 1997 ............................................... 77

Table 3.9. PAM and the corresponding indices of policy effects and profitability for selected commodities in the industry, 1997 ................................................................................................................ 82

Table 4.1. $\quad$ Summary of assumptions for macroeconomic variables and the corresponding convergence properties, relative to OECD average .................................................................................. 89

Table 4.2. $\quad$ Policy Analysis Matrix for projected efficiency....................................................................... 95

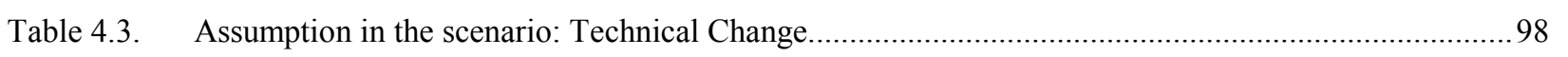

Table 4.4. The matrix of dynamic comparative advantage......................................................................... 99

Table 4.5. Projections of changes in milk processing costs at industry level, in 2002 and 2007, at private prices, in real terms (total processing costs in 1997=100)....................................................... 106

Table 4.6. $\quad$ Projections of private and social profitability, 2007, under alternative scenarios for

macroeconomic development and technical change.

Table 4.7: Matrix of dynamic comparative advantage, under Base scenario, in real terms (1997 revenues =

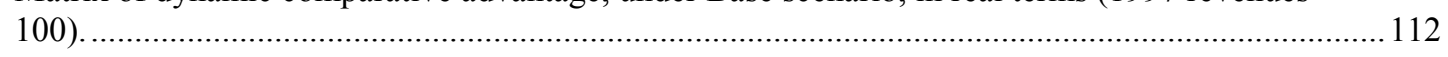

Table 4.8: $\quad$ Matrix of dynamic effects on private profitability, under Base scenario, in real terms (1997 revenues $=100)$.

Table 4.9. Sensitivity analysis: impact of variation in farm milk price on private profitability (PCR) in 2007 under alternative scenarios (Farm milk price as percentage of SMP and butter price equivalent under the current processing costs)

Table 5.1. $\quad$ Major suppliers' shares in the domestic yoghurt market in Mai-June 1999........................................119

Table 5.2. $\quad$ Poland's foreign trade in yoghurts, 1994-1998....................................................................... 119

Table 5.3. $\quad$ Net profitability of yoghurt producers compared to that of the entire milk processing industry (in \% of revenue) .............................................................................................................................. 12 


\section{LIST OF ANNEX TABLES}

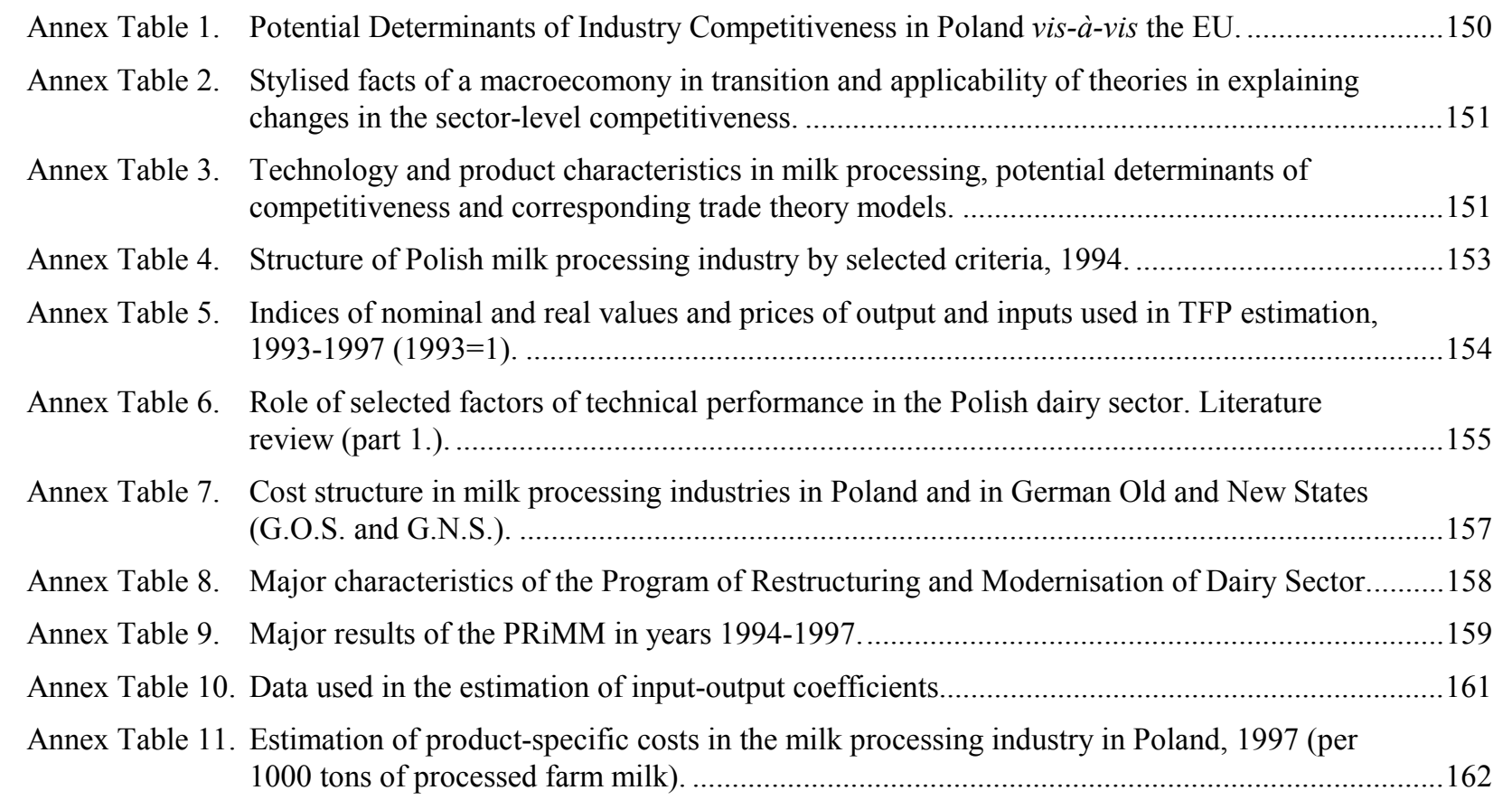

Annex Table 12. Budget data used in PAM analysis, 1997.............................................................................163

Annex Table 13. Nominal, real and effective real exchange rates, Poland, 1993-1998 (1993=1) .......................164

Annex Table 14. Producer prices of dairy products, 1993-1998 (PLZ/kg, in current prices).(1) ...........................165

Annex Table 15. Data and assumptions used in the estimations of social prices for tradables: taxes, subsidies

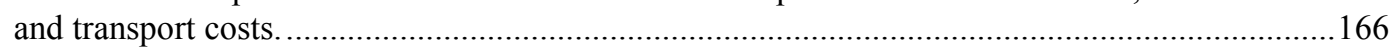

Annex Table 16. Data used in the estimation of social values for tradables: unit values in the trade for representative dairy commodities.....................................................................................167

Annex Table 17. Estimation of implicit prices of fat and non-fat components of farm milk, example of Polish market prices in the years 1995-1997 and alternative processing costs..........................................168

Annex Table 18. Costs of direct capital in milk processing industry, Poland, 1993-1997 ....................................169

Annex Table 19. Hypothesised effects of economies of rapid growth on the desired product structure of the industry, stylised representation based on production-possibility curve...................................170

Annex Table 20. Development of selected macroeconomic variables of Polish economy, 1990-1998...................172

Annex Table 21. Deriving the Relation Between GDP Growth and the Change in the RER ....................................173

Annex Table 22. Projections of world market prices for dairy products, 1997-2010 (FOB. export price, northern Europe).

Annex Table 23. Milk processing industry, ex-post and ex-ante PAMs and decomposition of dynamic effects

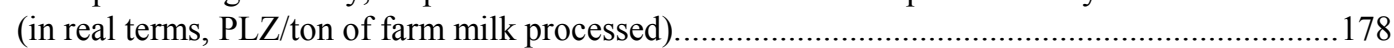

Annex Table 24. Skimmed milk powder, ex-post and ex-ante PAMs and decomposition of dynamic effects (in real terms, PLZ/ton of product) ................................................................................179

Annex Table 25. Ripening cheese, ex-post and ex-ante PAMs and decomposition of dynamic effects (in real terms, PLZ/ton of product) ........................................................................................... 180

Annex Table 26. Butter, ex-post and ex-ante PAMs and decomposition of dynamic effects (in real terms,

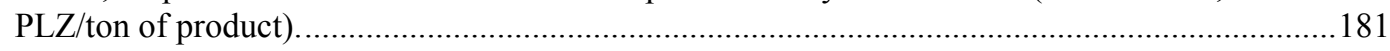

Annex Table 27. Yoghurt, ex-post and ex-ante PAMs and decomposition of dynamic effects (in real terms, PLZ/ton of product) 


\section{LIST OF FigURES}

Figure 2.1. Structure of milk processing industry in Poland (1994) France and Germany (1988) (share of enterprise size classes in total industry output)........................................................................ 15

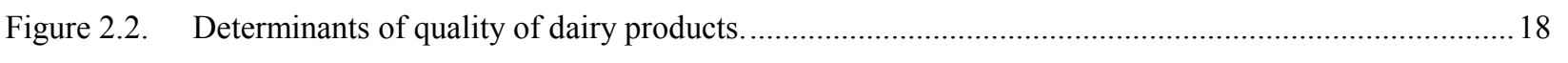

Figure 2.3. $\quad$ Decomposition of productivity growth using cost functions.............................................................

Figure 2.4. $\quad$ Development of real prices and quantities in the milk processing industry, 1993-1997....................29

Figure 2.5. Stylised comparison of production techniques in Poland and German New and Old States G.N.S and G.O.S) using factor space (factor intensity per 1000 tons of milk processed)...................32

Figure 3.1: $\quad$ Breakdown of costs and alternative definitions of the DRC used in the analysis..............................45

Figure 3.2. $\quad$ Real exchange rates in Poland, United States and Germany, alternative measures, 1989-1998_...........54

Figure 3.3. $\quad$ Effective real exchange rates estimated with alternative trade weights, 1993-1998. …...................56

Figure 3.4. $\quad$ Butter prices and intervention procurement quantities, 1992-1998.................................................58

Figure 3.5. $\quad$ SMP prices and intervention procurement quantities, 1992-1998. ...............................................58

Figure 3.6. $\quad$ FOB-minus, CIF-plus and import entry prices for selected dairy commodities, 1996-1998...............61

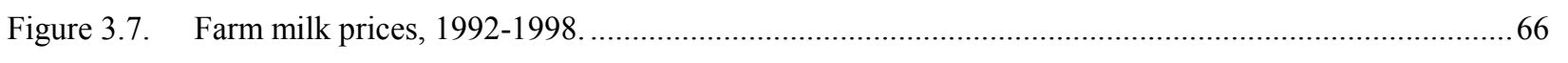

Figure 3.8. Relationship between farm milk prices and milk delivery per farm in a region (voivodship),

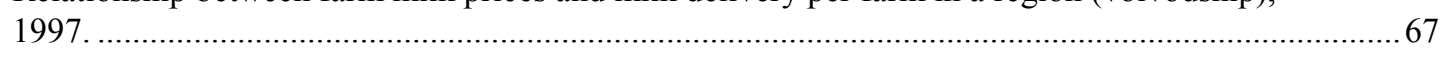

Figure 3.9. $\quad$ Milk Prices Derived from Butter and SMP Prices, 1997. ..........................................................6 69

Figure 4.1. Benchmark levels for alignment of dairy product prices, effects of Agenda 2000, under the

Base scenario and Technical Change, in real terms. ................................................................... 101

Figure 4.2. $\quad$ Projections of revenues at industry-level at alternative price levels, 1997-2010, under the Base scenario and Technical Change, in real terms................................................................................. 102

Figure 4.3. $\quad$ Projections of revenues at industry-level, 1997-2010, under alternative macroeconomic scenarios and Technical Change, at private prices, in real terms. .

Figure 4.4. $\quad$ Export subsidies of the EU relative to WTO commitments, average for the marketing years $1995-1998 \ldots$

Figure 4.5. Cost structure of Polish milk processing industry, in private prices, sums of direct and indirect inputs, 1997.

Figure 4.6. $\quad$ Projections of processing costs at industry level, 1997-2010, under alternative macroeconomic scenarios and No Technical Change, at private prices, in real terms.

Figure 4.7: Projections of processing costs at industry level, 1997-2010, under alternative macroeconomic scenarios and Technical Change, at private prices, in real terms.

Figure 4.8. $\quad$ Projections of revenue minus processing margin at industry-level (left-hand scale) and the

implicit farm milk price (right-hand scale), 1997-2010, under No Technical Change scenario, at

private prices, in real terms.

Figure 4.9. $\quad$ Projections of revenue minus processing margin at industry-level (left-hand scale) and the implicit farm milk price (right-hand scale), 1997-2010, under Technical Change scenario, in private prices, in real terms.

Figure 4.10. $\quad$ Milk prices derived from alternative SMP and butter prices, under Base scenario, in real terms.......108

Figure 5.1. $\quad$ Production and consumption of yoghurts in Poland 1996-1999, yearly........................................ 118

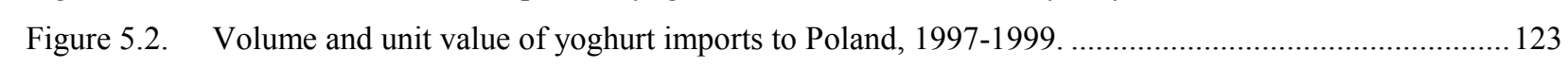

Figure 5.3. Concentration of yoghurt producers as a response to changing competitive conditions.....................125 


\section{List OF ABbREVIATIONS}

ARMR

ARR

CAP

CEEC

CIF

$\mathrm{CN}$

DDFC

DRC

ECU

EPC

$\mathrm{EU}$

EUROSTAT

FAMMU

FAO

FAPA

FAPRI

FDI

FOB

FSU

GATT

GDP

GISIPAR

GUS

HACCP

H-O-S

IERiGŻ

IfBML

KPSM
Agencja Restrukturyzacji i Modernizacji Rolnictwa, Agency for Restructuring and Modernisation of Agriculture, Warsaw Agencja Rynku Rolnego, Agricultural Market Agency, Warsaw Common Agricultural Policy

Central and Eastern European Countries

Cost, Insurance, Freight

Combined Nomenclature

Distortion of Domestic Factor Cost (coefficient)

Domestic Resource Cost (ratio)

European Currency Unit

Effective Protection Coefficient

European Union

Statistical Office of the European Communities

Foreign Agricultural Markets Monitoring Unit, Warsaw

Food and Agriculture Organisation (of the United Nations)

Foundation of Assistance Programmes for Agriculture, Fundacja Programów Pomocy dla Rolnictwa, Warsaw

Food and Agriculture Policy Institute

Foreign Direct Investment

Free on Board

Former Soviet Union

General Agreement on Tariffs and Trade

Gross Domestic Product

Główny Inspektorat Skupu i Przetwórstwa Artykułów Rolnych, Inspection of Procurement and Processing of Farm Products, Warsaw

Główny Urząd Statystyczny, Central Statistical Office, Warsaw

Hazard Analysis of Critical Control Points

Heckscher-Ohlin-Samuelson (model)

Instytut Ekonomiki Rolnictwa i Gospodarki Żywnościowej, Institute of Agriculture and Food Economics, Warsaw

Institut für Betriebswirtschaft und Marktforschung der Lebensmittelverarbeitung, Bundesanstalt für Milchforschung, Kiel

Krajowe Porozumienie Spółdzielni Mleczarskich,

National Board of Dairy Co-operatives, Warsaw 


\begin{tabular}{|c|c|}
\hline MAFE & $\begin{array}{l}\text { Ministry of Agriculture and Food Economy, } \\
\text { Ministerstwo Rolnictwa i Gospodarki Żywnościowej, Warsaw }\end{array}$ \\
\hline MES & Minimum Efficient Scale \\
\hline Mio & Million \\
\hline NEB & Net Economic Benefit \\
\hline NER & Nominal Exchange Rate \\
\hline NOBE & $\begin{array}{l}\text { Niezależny Ośrodek Badań Ekonomicznych, } \\
\text { Independent Centre of Economic Studies, Warsaw }\end{array}$ \\
\hline OECD & Organisation for Economic Co-operation and Development \\
\hline PAIZ & $\begin{array}{l}\text { Państwowa Agencja Inwestycji Zagranicznych, } \\
\text { National Agency for Foreign Direct Investments, Warsaw }\end{array}$ \\
\hline PAM & Policy Analysis Matrix \\
\hline PCR & Private Cost Ratio \\
\hline $\mathrm{PIH}$ & Państwowa Inspekcja Handlowa, National Trade Inspection, Warsaw \\
\hline PLZ & Polish złoty (New) \\
\hline PPP & Purchasing Power Parity \\
\hline PRMM & $\begin{array}{l}\text { Program Restrukturyzacji i Modernizacji Mleczarstwa, } \\
\text { Programme for Restructuring and Modernisation of Dairy Sector }\end{array}$ \\
\hline PSE & Producer Subsidy Equivalent \\
\hline RER & Real Exchange Rate \\
\hline SAEPR & $\begin{array}{l}\text { Sekcja Analiz Ekonomicznych Polityki Rolnej, } \\
\text { Agricultural Policy Analysis Unit, Warsaw }\end{array}$ \\
\hline $\mathrm{SCB}$ & Social Cost Benefit (coefficient) \\
\hline SMP & Skimmed Milk Powder \\
\hline TFP & Total Factor Productivity \\
\hline WMP & Whole Milk Powder \\
\hline WTO & World Trade Organisation \\
\hline ZMP & Zentrale Markt- und Preisberichtstelle GmbH, Berlin \\
\hline
\end{tabular}




\section{INTRODUCTION}

\subsection{The Research Problem}

The ability to compete on the Single Market of the European Union (EU) is both a formal and an informal prerequisite of Poland's prospected EU membership (EU Commission, 1998). The problem has attracted much public attention since the signing of the Poland-EU Association Agreement in 1991. Many economic studies have dealt with the possible impact of Poland's accession to the EU on the economic structures and future competitive position of Poland's agro-food sector. The notion of competitiveness has been broadly used only recently in association with the narrowing of initially high EU-Poland price gaps for agricultural and food products. At the same time the focus of the public debate has gradually been shifting from the primary agriculture alone to a wider view of rural and agro-food economy, with an increasing stress on post-farm activities.

Out of a series of concerns related with the competitiveness of post-farm activities in Poland during the process of integrating with the EU two conditions are of a particular importance. The first one is the ability to conform to the EU hygienic, food safety, environmental and other standards, which are required by the EU law and increasingly demanded by the EU consumers. The second one, partly related to the former one, is the economic viability of these activities given the farm input prices reflecting full transmission of the support to farm producers intended by the Common Agricultural Policy (CAP). This concern arises from the modus operandi of the CAP in several sectors, where price support is provided at a higher level of marketing chain with an expectation that low processing and transaction costs and competitive market conditions guarantee full transmission of such price support to farm producers. Failure of Poland's food processing industry to meet the first condition may result in an outright market loses in the pre-accession period or a delay of accession, either due to the violation of acquis communautaire or ignorance of consumer preferences. Failure to meet the second condition means that, in some sectors, objectives of CAP, i.e. farm price support will, at least partly, be missed.

Several real developments in the recent years have fuelled the worries about the competitiveness of Polish agro-food sector, and its processing industries in particular, in relation to the EU competitors. These events included: (i) the deterioration of Poland's balance of agro-food trade with the EU, contradicting the intended asymmetric nature of preferences under the Association Agreement, (ii) the growth of geographical specialisation of Polish agree-food trade including an 
eastwards flows of processed (EU-Poland-FSU) and westward flows of basic commodities, (iii) selective and unsatisfactory progress in the restructuring of both agriculture and processing industry in Poland, and (iv) implementation of new trade barriers by the EU (the 1998 ban on dairy imports due to sanitary reasons), and by Poland (the increase in tariff rates in 1999).

This study undertakes to analyse the prospects of competitiveness in Polish agro-food processing industry over the period of Poland's economic and political integration with the EU. To enable satisfactory insight into the problem the study will focus on one selected industry - milk-processing industry. This choice is arbitrary, but not a random one. Milk processing industry represents several crucial features of the entire food-processing industry. In particular it is characterised by the following:

i. High relative importance of farm input (milk) for the total farm income, and the importance of dairy products in consumer expenditures on food;

ii. Associated with the above, a high political rank; in Poland the sector is one of the three most influenced by the farm policy (but not the most protected); in the EU dairy farm production belongs to the most protected ones, and traditionally absorbs high share of total budgetary expenditures on farm policy;

iii. Farm milk is a non-traded (internationally) input, which in combination with daily delivery to processing plant provides for a high interdependence of the two marketing stages. This explains great importance of farm co-operatives as a form of ownership in milk processing;

iv. Associated with the above, is the reliance of farm milk price support systems on the intervention in markets for processed dairy products. Since only the prices of processed dairy products are directly controllable by policy, the efficiency of processing determines the transmission of policy effects to the farm level;

v. The quality of consumer (final) dairy products is extremely susceptible to mishandling at any stage of farm-consumer chain. Regardless of the degree of processing, the actual or perceived levels of compliance with quality standards represent an important competitiveness factor. In addition, the obligation to adjust to legal or market standards in this respect may impose a significant constraint on the choice of production technique and path (and pace) of modernisation.

\subsection{Conceptualising Competitiveness}

Competitiveness has not a definition in the neo-classical theory. Some authors even regard competitiveness as merely a political concept (Sharples, 1990). Krugman (1994) argues that in many situations the use of the concept, e.g. in reference to national level, makes little sense. As far as sector level is concerned, he postulates more frequent use of the concepts of productivity and comparative 
advantage, which have more precise economic meaning. The widespread use of 'competitiveness' notion in the empirically oriented economic literature gives rise to a variety of definitions. One of the widely quoted definitions describes a competitive industry as 'one that posses the sustained ability to profitably gain and maintain market share in domestic and/or foreign markets' (Agriculture Canada, 1991).

\section{Theoretical background and approaches to competitiveness analysis}

Most insights into the issue of competitiveness are offered by the international trade theory explaining patterns of international specialisation in production and related patterns of trade flows. Most empirical studies, however, focus on selected aspects of competitiveness depending on a question asked and a situation at hand. These studies can be divided into two broad categories. The first category deals with an ex-post analysis by investigating the 'degree' of competitiveness and ranking activities in terms of competitiveness. The second one involves ex-ante analyses investigating determinants of competitiveness and projecting a future competitive position of a sector or an industry. A critical discussion of approaches and indicators used to analyse competitiveness in agrofood sector can be found in Abbott and Bredahl (1994), Ethier (1994), Frohberg and Hartmann (1997) or van Berkum and van Meijl (1998a,b).

In the previous studies on current and future competitive position of Polish dairy sector different approaches have been used. Most studies conclude that the dairy sector as a whole or at least some of its product-specific activities are internationally competitive. This conclusion is made both on the basis of trade-based indicators such as Revealed Comparative Advantage (Misala, 1997), and the analysis of social opportunity cost of generating unit value added based on Domestic Resource Cost ratio (DRC) (Münch et al., 1997; Banse et al., 1998). Comparative advantage implied by these studies appears to be attained despite absolute disadvantages. For example, NOBE (1998) estimates that labour productivity in milk processing in Poland is as much as tenfold lower compared to the corresponding industry in the EU.

Given the current CAP regime in the dairy sector, the integration with the EU is expected to significantly raise farm milk prices in Poland, however, at output volumes constrained by milk quotas. Aside from price effects, the ability to conform to hygienic and other EU standards may be crucial for the future competitiveness on the single European market (EU Commission, 1998). Relying on most recent developments, some analysts point at challenges arising from macroeconomic changes accompanying fast economic growth, including an appreciating tendency of real exchange rate of domestic currency against the currencies of EU member states and upward tendency in real wages (Banse et al., 1998; Bonjec et al., 1998 and Münch et al., 1997). 


\section{Procedure to select methodology}

The choice of relevant theoretical basis and empirical method in this study is based on the following rationale. The starting point is the literature on international trade theory and the question about the relevance of this theory to analyse competitiveness in the economic context considered herein. The major problem faced is that this theory involves a variety of seemingly competing hypotheses based on different assumptions about the characteristics of countries, technologies and markets. This variety creates a practical problem of choosing the most adequate approach to conceptualise competitiveness in a real-life situation. For example, new-trade models have extended the comparative advantage (Ricardo) and factor proportionality (Hekscher-Ohlin-Samuelson) concepts. Nevertheless, in most of these theoretical developments the principle of comparative advantage, rather than absolute advantage, appears as a dominant determinant of trade and competitiveness patterns (e.g. van Berkum and van Meijl, 1998a,b or Markusen et al., 1995). At the same time, the new theoretical extensions point non-comparative advantage determinants of specialisation and trade, mostly, related to increasing returns and imperfect competition (Annex Table 1).

To select a relevant theoretical concept to describe and to study the competitiveness in the agrofood sector, van Berkum and van Meijl (1998a,b) recommend an eclectic approach. In this approach, features and stylised facts of an analysed economic context, i.e. country, technology, product, market, etc., are confronted with the assumptions of each model and on this basis the most promising one can be selected. Such an approach has been taken in this study.

\section{Macroeconomic properties of the period under consideration}

The greatest promise associated with the economic reforms of Poland's transition and with the harmonisation of law and policy with these of the EU is a sustainable economic growth. High growth rates, which have already been experienced and which are expected in the time span covered herein, find explanation in economic theories (Annex Table 2 and Chapter 4). These high growth rates, however, imply changes in relative factor endowments and, expectedly, in relative factor productivity among economy sectors. These changes, in turn, are manifested through changes in the major relative prices, such as real exchange rate, wage rates, interest rates, and other. In terms of trade theory language, these changes are interpretable as changes in (dynamic) comparative advantages. The significance of this effect for industry competitiveness consists in that high speed of accompanying changes in relative prices imposes the need for fast adjustments in technology and structure on the one hand and renders considerable investment uncertainty on the other hand. Therefore, it seems both justified and recommendable to take account of the comparative advantage effects in the analysis of industry-level competitiveness during the considered period. 
Features of the analysed products, markets, and technology

Although comparative advantage is a universal mechanism of determining country specialisation in production and trade, nevertheless, under specific conditions, effects such as economies of scale, imperfect competition or sustainable and high technological gaps can overshadow this effect. As far as milk processing industry is concerned, the characteristics of products and technology and the corresponding characteristics of market structure provide for a high potential importance of the comparative advantage mechanism, although different 'basis' for comparative advantage can be expected in different products. At the same time, competitiveness of several traditionally processed dairy products, such as butter, SMP or ripening cheeses seems to rely more on comparative advantage than other, 'more' processed items, such as yoghurts or ice-cream (Annex Table 3). The general conclusion is that cost competitiveness, i.e. competitiveness determined to a large extent by comparative advantage dominates in the Industry. Accounting for other competitiveness determinants may require a modification of the analytical approach.

\section{Working hypothesis}

On the basis of the above presented rationales a working hypothesis can be formulated that changes in comparative advantages in the entire economy and in the milk processing industry will play a crucial role in determining competitive performance of this industry over the period of under consideration. Therefore, the concept of comparative advantage is used here to investigate international competitiveness of the industry.

\subsection{Empirical Tasks and Outline of the Study}

The subsequent empirical part of the study focuses on the measurement of comparative advantages in five selected economic activities within the milk processing industry: butter, SMP, ripening cheese, yoghurt and milk processing industry treated as one multi-product activity. To take account of competitiveness relying on more complex and less quantifiable effects, the analysis is complemented with a descriptive case study of a market of selected dairy product.

Chapter 2 deals with the current state of technology and factor productivity in the Industry. The ultimate objective of Chapter 2 is to assess prospects for productivity/technology change and to provide information for constructing a relevant scenario for a simulation analysis. Three major questions are asked. First, what progress in terms of factor productivity has the industry made in recent (transition) years? To this end non-parametric estimation of TFP change using Tornquist approximation of Divisia index will be used for industry (aggregated) data. Second, what scope for factor productivity improvement exists in the industry? This will be answered through a comparison of cost structure and input-intensity with those in the neighbouring German milk industry. Third, what 
are the policy and institutional forces determining the pace of modernisation and restructuring in the industry? This will be answered through a descriptive analysis of recent investments and investment policies as well as institutional factors.

In the subsequent two chapters comparative advantages are first estimated for the year 1997 (Chapter 3), while dynamic comparative advantages are projected for the period 1997-2010, (Chapter 4). Domestic Resource Cost ratio (DRC) is used as a measure of comparative advantage. DRC is a measure of social opportunity cost of generating a unit of value added, i.e. a measure of social profitability of an activity. This differs from the private profitability, which is measured by the counterpart of DRC estimated in private prices, i.e. Private Cost Ratio (PCR). The PCR diverge from the DRC by the net effect of policy and other distortions, measured by the Effective Protection Coefficient (EPC) and Coefficient of Distortion in Domestic Factor Cost (DDFC). Changes in the comparative advantage over time, i.e. dynamic comparative advantage, and in the private profitability are represented by the changes in the value of DRC and PCR. Comparative advantages evolve due to the changes in prices and changes in input-output coefficients entering the DRC.

Potential importance of various determinants of past and future competitiveness, other than comparative advantage, is addressed in Chapter 5 by a case study of yoghurt market in Poland. The analysis starts from a description of recent dynamic development in terms of domestic demand, trade and trade policy responses, domestic industry responses, the role of foreign direct investments, quality aspects of competitiveness and potential for imperfect competition. These developments are interpreted in terms of hypotheses of the (new) trade theories.

Chapter 6 summarises and concludes the study. 


\section{Technology and TeChNological Change in the MILK PROCESSING INDUSTRY}

This chapter presents a survey of milk processing technology and technological and structural change in the milk processing industry in Poland. It starts from an introduction of the general characteristics of milk processing and the corresponding costs determinants. In the next step major dimensions of the industry structure are analysed: the product structure of output, size distributions of firms, structure of the dairy farm suppliers and quality. The subsequent section focuses on detecting recent productivity change in the industry. The Tornquist approximation of Divisia indices has been used. The last section tries to evaluate the prospects for the factor productivity growth by examining productivity gaps between Poland and the neighbouring Germany, and by discussing existing constraints on the productivity catch-up.

\subsection{The Economics of Milk Processing}

The dairy sector involves milk production on farms and its industrial processing into consumer or intermediate products. The sector shares many characteristics with other agro-industrial branches. Farm production of milk is spatially dispersed, while processing takes place in centrally located factories. Unlike in any other case, the delivery of farm input to the processing plant takes place on a daily basis. High perishability of milk imposes special requirements with regard to treatment before, during and after transportation to the factory. Assembly costs (a function of logistic organisation, milk handling, and means of transport) tend to be high compared to other sectors. The technically determined need for co-ordination between dispersed farm milk producers and processors bears consequences for the transaction costs between the two marketing chain levels. Vertical integration in the sector usually takes the form of farm producer co-operatives or contracting arrangements.

Milk processing yields a range of products, which differ in terms of farm input content, proportions between fat and non-fat components of farm milk, shelf life, and absolute and relative intensity in non-farm inputs (labour, capital, energy, packaging, R\&D and others).

This section presents the economics of milk processing in some detail. It covers the characteristics of the processing technology, major factors affecting processing costs and product quality and the major direction of technological progress in the industry. 


\subsubsection{Milk processing technology}

Milk processing involves microbiological and physical treatments and packaging. Final products obtain their ultimate form: liquid (milk, cream, yoghurts, kefirs, whey), solid (butter, cheeses, milk powders, ice cream) and other characteristics (texture, flavour, acidity etc.) as a result of a sequence of treatments including: heating (pasteurisation, ultra-high temperature treatment), concentration and separation of solid components (buttering, cheese making), separation of fat and non-fat components (cream and skimmed milk), evaporation (concentrated milk and milk powder), fermentation (yoghurt, kefir, cheeses). The addition of components in the processing involves commercial microbiological starters and secondary flora (e.g. LAB - lactic acid bacteria), mineral compounds (salt, $\mathrm{CaCL}_{2}$ ), organic compounds (sugar) and fruits (yoghurts). Apart from the beneficial microbiological activity of flora naturally present in milk or added during the process there is risk of microbiological contamination that deteriorates the quality of milk as a raw material by modifying the desired path of microbiological processes or/and representing a direct hazard to consumer health.

Farm milk consists of two basic components: fat and non-fat (mostly proteins) occurring in a fixed proportion, however, used in various proportions in the production of various dairy products. This imposes a major constraint on flexibility in adjusting the product mix of the industry output. Dairy products compete for the same components: fat and non-fat. In some cases products also compete for specialised production capacity (e.g. a typical line for hard cheese production can serve for the production of several other sorts of cheese, milk powered line can be used to produce SMP). The fixed proportion between fat and non-fat delivered with farm milk leads to the complementarity relation among pairs of final products which are intensive in one of the two components: cream and skimmed milk, butter and SMP. There is also an input-output relationship including e.g.: cream and butter, skimmed milk and SMP, hard cheeses and fried and melted cheeses. Intermediate products may be used directly in same factory/enterprise or may be passed to another factory/enterprise via market exchange. Apart from the above relationships dairy products are more or less closely related in marketing, in trade channels and in consumption.

Although all dairy products can be regarded as internationally tradable, only butter, SMP and hard cheeses dominate the international dairy trade. Products with shorter shelf lives, mostly milk, milk drinks and non-ripening cheeses (so called fresh products) are typically marketed domestically. An important difference between the two groups exists also in that the latter reveal a higher seasonal stability of production. The former, in turn, especially butter and SMP, tend to follow a highly seasonal production pattern associated with the seasonality in farm milk supply.

1 This section draws on selected handbooks on milk processing technology including Early (1998) and Obrusiewicz (1994).

2 In the long-term certain modification of proportions of milk components is possible through breeding effort. 
Dairy processing plants show a different degree of product specialisation. There is a tendency for factories specialising in fresh products to be localised in the proximity of consumer markets while those specialising in storable, generic products tend to be localised in the proximity of abundant farm milk supply. With the progress in the packaging and transport technologies these tendencies, however, appear to be less marked.

In the internal organisation of a typical product-diverse factory one can separate activities specific to each final product (product line) and common to some or to all of them. The dairy processing activity starts with the assembly of raw material from farm producers, either directly by tanker or with intermediate collection points, which pre-collect and bulk milk from small and dispersed farms. After the delivery to a processing location farm milk is subject to initial treatments including cooling, cleaning, heat treatment (pasteurisation) and storing. Next, cream and skimmed milk are separated during skimming process. Up to this point the activities are common to all products. The subsequent treatments are usually carried out in separate departments using specialised, product-specific equipment.

Other unspecific (to products) activities include: management as well as 'production' of steam, water, cold and sewage cleaning. The existence of a set of processing steps, that are common to several final products, limits the separability of cost and make calculations of product specific costs feasible only on a basis of various allocation criteria.

Many enterprises generate a substantial share of their value added from the re-sale of collected farm milk and also engage in distribution of their output. These downstream activities, including even retail sale, are in many cases fully internalised, which means that the industry also produces value added from trade. In this study, revenue income from these activities will be referred to as a margin from trade.

\subsubsection{Determinants of processing costs}

Processing costs are a function of technology used, economic efficiency (with which the technology and production factors are applied), quality of factors and their prices. The shape of a typical longterm cost curve indicates that the scale of processing plant/enterprise can represent an important cost determinant. This section focuses on the sources and importance of the economies of scale, scope and capacity utilisation in the industry. Technological change, efficiency, factor quality and prices will be the subject matter of other sections.

\subsubsection{Economies of scale}

Economies of scale can be distinguished into the real and pecuniary. The real economies of scale are those associated with a reduction in physical quantity of inputs, raw materials, various types of labour 
and capital. Pecuniary economies are economies realised from paying lower prices for factors used in the production or higher prices received in the distribution of the product, e.g. due to bulk-buying by the firm as the size increases (Koutsoyiannis, 1980). The pecuniary economies may further be divided into effects associated with reduction of costs (e.g. lower risk and transaction costs incurred by banks) or may arise from ability to exert (or countervail) bargain power on product and factor markets.

The optimal size of milk processing capacity is a result of two conflicting forces: increasing returns to scale in processing and unit cost progression in raw milk assembly. The latter reflects the increase in the average distance from which farm milk needs to be delivered with the increase in the size of plant. The effect also depends on the density of milk production in the neighbourhood of the factory (more milk available in the proximity of processing capacity) and on the number of milk producers (having fewer but bigger farms limits transaction costs, saves time and shortens the distance milk needs to be transported). With the fragmented supply of farm milk the assembly costs may also be increased by the necessity to maintain the collection points where pre-bulking takes place to enable

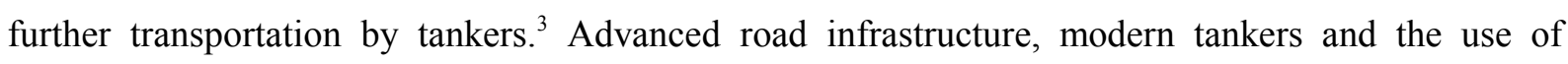
computerised techniques to optimise the logistics of milk assembly can partly compensate for the adverse effects of fragmented farm structure (Pimpicki et al., 1999).

Milk processing itself reveals increasing returns to scale: unit costs of processing tend to be lower in bigger plants. Major sources of these returns include unit cost decreases in capital, and other cost components. Moreover, the larger the capacity, the greater is the scope for specialisation of both capital equipment and labour. Returns to scale in the industry are also associated with the increasing scope for (technically determined) superior techniques or better organisation of production process (management). An example is the substitution of manually for automatically operated machinery or methods of batch for flow production (e.g. in butter or cheese production). Typically, such a technology switch is not only conducive to the reduction of unit costs but also to better control of product quality and hence higher output prices.

The rate of unit cost decreases, however, has a diminishing character, which leads to a concept of a minimum efficient scale (MES) defined as the scale of which the doubling brings unit costs decrease lower than 5\% (EU Commission, 1988). The following points provide more or less direct evidence of the importance of the economies of scale in milk processing.

\section{Engineering cost analysis}

One of the empirical methods used in industrial cost analysis is the engineering method. The method consists of studying the technical relationship between input and output levels using available engineering information (mainly technical parameters of machinery or experimental measurements in

\footnotetext{
${ }^{3}$ Additional cost consequences associated with quality aspects will be considered in one of the later sections.
} 
functioning product-lines). These technical relationships obtained for a range of output levels are combined with the set of corresponding prices and then used to estimate production functions. For the case of the milk processing industry, results of such analysis have been published by the IfBML in

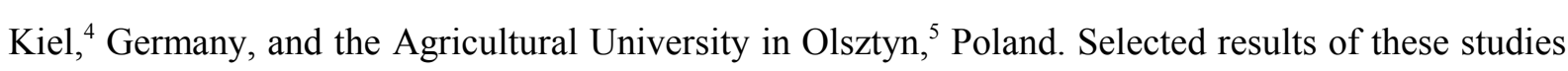
have been used here to arrive at the approximate magnitudes of cost saving resulting from the doubling of processing capacity for selected product lines (Table 2.1). The results suggest that the costs of a typical processing line (i.e. costs limited to product-specific departments of a factory) for butter, SMP and ripening cheese show substantial decreases within the range of sizes typical (or above that) of Polish milk processing plants. In most of considered cases these decreases exceed the trigger value of $5 \%$.

Table 2.1. Changes in input intensity resulting from an increase in capacity size and improvement in capacity utilisation, selected product-lines (in \%).

\begin{tabular}{|c|c|c|c|c|c|c|c|c|c|}
\hline \multirow[b]{2}{*}{ Product } & \multirow{2}{*}{ Change in capacity } & \multicolumn{4}{|c|}{ Material input } & \multicolumn{3}{|c|}{ Labour } & \multirow{2}{*}{ Capital } \\
\hline & & & Electricity & $\begin{array}{l}\text { Water and } \\
\text { sewage }\end{array}$ & Steam & Skilled & Unskilled & Total & \\
\hline \multicolumn{10}{|c|}{ Capacity size effects } \\
\hline Ripening cheese & $\begin{array}{c}\text { from c.a. } 2 \text { to c.a. } 5 \\
\cdot 000 \text { tons }\end{array}$ & (1) & -20 & -23 & 3 & -47 & -4 & -26 & -19 \\
\hline Butter & $\begin{array}{r}\text { from c.a. } 4 \text { to c.a. } 8 \\
\cdot 000 \text { tons }\end{array}$ & (2) & -13 & -22 & -13 & -45 & -7 & -33 & -18 \\
\hline SMP & $\begin{array}{c}\text { from c.a. } 16 \text { to c.a. } 31 \\
\cdot 000 \text { tons }\end{array}$ & (3) & -9 & -11 & 0 & -47 & -35 & -43 & -19 \\
\hline \multicolumn{10}{|c|}{ Capacity utilisation effects } \\
\hline \multirow[t]{2}{*}{ Ripening cheese } & from $66 \%$ to $100 \%$ & (4) & -12 & -13 & -6 & -16 & -5 & -6 & -38 \\
\hline & from $33 \%$ to $100 \%$ & (4) & -30 & -30 & -16 & -36 & -13 & -16 & -67 \\
\hline \multirow[t]{2}{*}{ Butter } & from $66 \%$ to $100 \%$ & (4) & -2 & -5 & -7 & -10 & -7 & -4 & -38 \\
\hline & from $33 \%$ to $100 \%$ & (4) & -6 & -12 & -16 & -25 & -17 & -10 & -67 \\
\hline \multirow[t]{2}{*}{ SMP } & from $66 \%$ to $100 \%$ & (4) & -2 & -24 & -2 & -18 & -5 & -12 & -38 \\
\hline & from $33 \%$ to $100 \%$ & (1) & -6 & -46 & -5 & -41 & -13 & -29 & -67 \\
\hline \multicolumn{10}{|c|}{$\begin{array}{l}\text { (1) Average for 'older' (Brehm, K.P and E.Krell, 1976) and 'newer' (Krell, E. and H. Wietbrauk, 1993) vintages of technology. } \\
\text { Increase from size ca. } 2 \text { to ca. } 4.5 \text { thousand tons per year for the 'older' and from } 2.4 \text { to } 5.4 \text { thousand tons per years for the 'newer' } \\
\text { technologies (at } 66 \% \text { of capacity utilisation). } \\
\text { (2) For 'older' technology vintage (Brehm, K.P and E.Krell, 1976). Increase from size ca. } 4 \text { thousand tons of output per year to ca. } 8 \\
\text { thousand tons per year (values for } 66 \% \text { capacity utilisation). } \\
\text { (3) For 'older' technologies (Behme, G. and H. Wietbrauk, 1975). Increase from size of ca. } 16 \text { thousand tons of output per year to ca. } 31 \\
\text { thousand tons per year (values for } 66 \% \text { capacity utilisation). } \\
\text { (4) Average for } 5 \text { various technologies. Source: Brehm, K.P and E.Krell, (1976); Gornowicz, M. and T. Stachowski (1991); Krell, E. and } \\
\text { H. Wietbrauk, (1993); Behme, G. and H. Wietbrauk, } 1975 \text { and author's calculation. }\end{array}$} \\
\hline Source: quoted abc & and author's calculation & & & & & & & & \\
\hline
\end{tabular}

\section{The survivor technique evidence}

The survivor technique to the analyse economies of scale is based on the Darwinian doctrine of the survival of the fittest. The doctrine implies that the firms with the lowest costs should survive through

\footnotetext{
4 See Behme and Wietbrauk (1975); Brehm and Krell (1975, 1976); Krell and Wieterbrauk (1993).

5 See Gornowicz (1983); Gornowicz and Stachowski (1991).
} 
time (Koutsoyannis, 1980). Evidence corresponding to the survival criterion is provided by the study of Traill and Gilpin (1998), who show that the milk industry is the most concentrated among the European food and drink industries: $2.13 \%$ of firms generate $55.6 \%$ of output. It is important to bear in mind that this study is concerned with the concentration of ownership structure (capital concentration), and not directly with the concentration of processing capacities. . $_{\text {Hence the results }}$ may suggest importance of other than only technically determined size advantages in areas like R\&D and marketing as well as pecuniary economies of scale. The latter may include the size-related possibility of control over market. The gains to firms involve not only the 'improved' private prices faced (higher output prices and lower factor prices) but may also contribute to a lower risk of output fluctuation, reduction in costs of over-capacities and a higher propensity to invest and hence the use of more efficient technologies.

\section{Evidence from restructuring the East German milk processing industry}

The restructuring of the milk processing industry in the East German states after the reunification of the country in 1989 provides unique, almost experimental, evidence on the importance of the economies of scale. The restructuring has been carried out with a high capital subsidy and in a relatively short time. On the basis of engineering studies, the IfBML has predicted that an optimal structure would require a reduction in the number of processing plants from the initial 264 units (with an average volume of milk processed equal to 30 Mio kg per year) to only 6 units (with an average capacity 1040 Mio kg milk per year) (Glöer, et al., 1997, and Hülsemeyer and Glöer, 1998). In reality the restructuring resulted in the reduction of the number of plants to 33 units (with a capacity of 180 Mio kg milk per year).

\subsubsection{Economies of scope}

The term economies of scope applies to a situation where the production of two or more products reduces costs or raises revenues compared to the position where each product is produced separately in similar quantities. As dairies vary in terms of product specialisation the question emerges of what are the sources of economies of scope in the industry. Several such potential sources can be listed. First are the inherent complementarity relations among products. Second, a certain part of processing machinery is not specific to any of products, which means that in some situations reaping gains from economies of scale is possible by increasing the throughput of farm milk by widened range of final products. Third, relatively short shelf life of many dairy products, in combination with increasing demand for traceability and quality may limit the willingness of buyers to bulk the variety of products from several distanced producers. Fourth, the portfolio of products may play an important role in

${ }^{6}$ See comprehensive discussion of the scale-effects gains due to the single market of EU in EU Commission 
coping with market risk - in periods characterised by enhanced price volatility (e.g. during economy liberalisation) tendency to lower specialisation may be observed. However, the actually observed product portfolios of firms may also reflect the lags in adjustment of product structure of output to new relative profitability, whereby presently less attractive product-lines are maintained merely due to the lengthy depreciation of fixed capital.

\subsubsection{Capacity utilisation}

The tendency to seasonality in farm milk production leads to swings in the seasonal volume of milk processed and under-utilisation of capacity $\mathrm{E}_{\mathrm{At}}$ the farm level the factors determining the degree of seasonality include feeding and calving patterns. In the countries with extensive low-cost production based on grass as a major feeding component the majority of calving takes place in spring: this leads to high seasonal swings in milk supply with peaks falling in summer, with downs in winter months. Moderate climate, greater share of feeding concentrates and incentive policy (winter milk bonuses) promote less seasonal milk supply. The seasonality does not affect all products to the same extent: butter and SMP and to lesser extent ripening cheeses account for the major share of summer increases in the volume of processed milk. Effects of capacity utilisation on the unit cost are presented in Table 2.1. Magnitude of seasonality can be diminished by provision of financial incentives to farmers to change the calving pattern (reflection of the trade off between the increased processing costs and decreased milk production costs). These incentives (e.g. in the form of higher winter prices or another premium) must compensate for associated increases in feeding costs.

While the seasonality is an inherent cause of capacity under-utilisation and is difficult to avoid, there are other potential causes. In particular, under-utilisation may be a side effect of rapid unexpected changes in market conditions due to policy, or policy-neutral reasons, e.g. the transitionrelated shifts in the relative prices. Over-capacities in the 'declining' products may lead to the increased detected costs due to the increased fixed costs and decelerated rate of technological progress (diminished rate of replacement investment).

\subsection{Structure of the Milk Processing Industry in Poland}

The concept of industry structure is used here in a broad sense. According to Boehlje (1990) the structure of an industry includes the following dimensions: (i) the size distributions of firms, (ii) the technology and production specialisation, (iii) the characterisation of the workforce (managers and

(1988).

7 The upper boundaries for estimates of capacity utilisation can be achieved by dividing the yearly output by the output in the peak month multiplied by twelve. See Pitts (1983).

8 For a detailed discussion of economic aspects of seasonality of milk production in Ireland, including effects 
employees), (iv) the resource ownership and (v) the inter- and intra-sector linkages including horizontal and vertical integration. This section focuses on recent changes and the state of the following aspects of the industry structure: size distribution of firms (indicative of the magnitude of scale in-efficiency), structure of farm supply (indicative of efficiency and costs of raw material assembly), product structure of industry output (indicative of the recent changes in value added and technology) and product quality issue.

\subsubsection{Size distribution of firms}

According to the IERiGŻ (1999), in the first half of 1999 there were 382 firms processing farm milk, each employing at least 6 workers. Of this number, 342 enterprises dealt with the milk processing and/or cheese production, and another 40 with ice-cream production. Among about 350 enterprises with employment exceeding 50 persons there are 280 co-operative enterprises, about 50 joint stock companies and between 10 and 20 other private firms. There were also about 30 other private enterprises each employing less than 50 workers. Co-operatives represent dominant ownership and an organisational form that accounted for 70\% of the total turnovers in 1997.

More insight into the structure of the industry, including the size distribution in major product lines as well as the comparison with the corresponding structures in selected EU countries delivers the data reported by the IERiGŻ (Smoleński and Wigier, 1997). The situation in the dairy co-operative sector in Poland in 1994 is compared with that in the entire dairy processing in Germany (only the western states) and France in 1988. The results are presented in Figure 2.1 and in Annex Table 4.

The average sizes of the processing capacity in Poland appear to lie below the minimum efficient sizes of processing lines. This conclusion follows from the comparison with the engineering data on scale effects in Table 2.1 - for all products considered here average sizes lie below the capacity levels, which showed cost savings from capacity doubling higher than 5\%.

However, the conclusion does not directly apply for the optimality of the processing plants, as these are also affected by the assembly costs. The fragmented structure of farm milk production in Poland may strengthen the adverse effect of the assembly costs progression on the optimal size of processing plant. The study by Gornowicz (1987) shows that for the available technologies and milkfarm structure in Poland the optimum size for butter production much exceeded the existing capacities for butter. ${ }^{0}$ For other products the adverse effect of assembly costs (and fragmented structure) on the optimal scale may even be weaker due to the lower share of milk in total costs. This may suggest that the conclusion about the sub-optimality of the average production capacity is plausible.

on processor's cost, see Pitts (1983).

9 This conclusion can be assumed to hold true for the more recent situation because both farm and industry structures have not substantially changed since 1987 while the realised technological change must have increased the optimum concentration. 
Figure 2.1. Structure of milk processing industry in Poland (1994) France and Germany (1988) (share of enterprise size classes in total industry output).
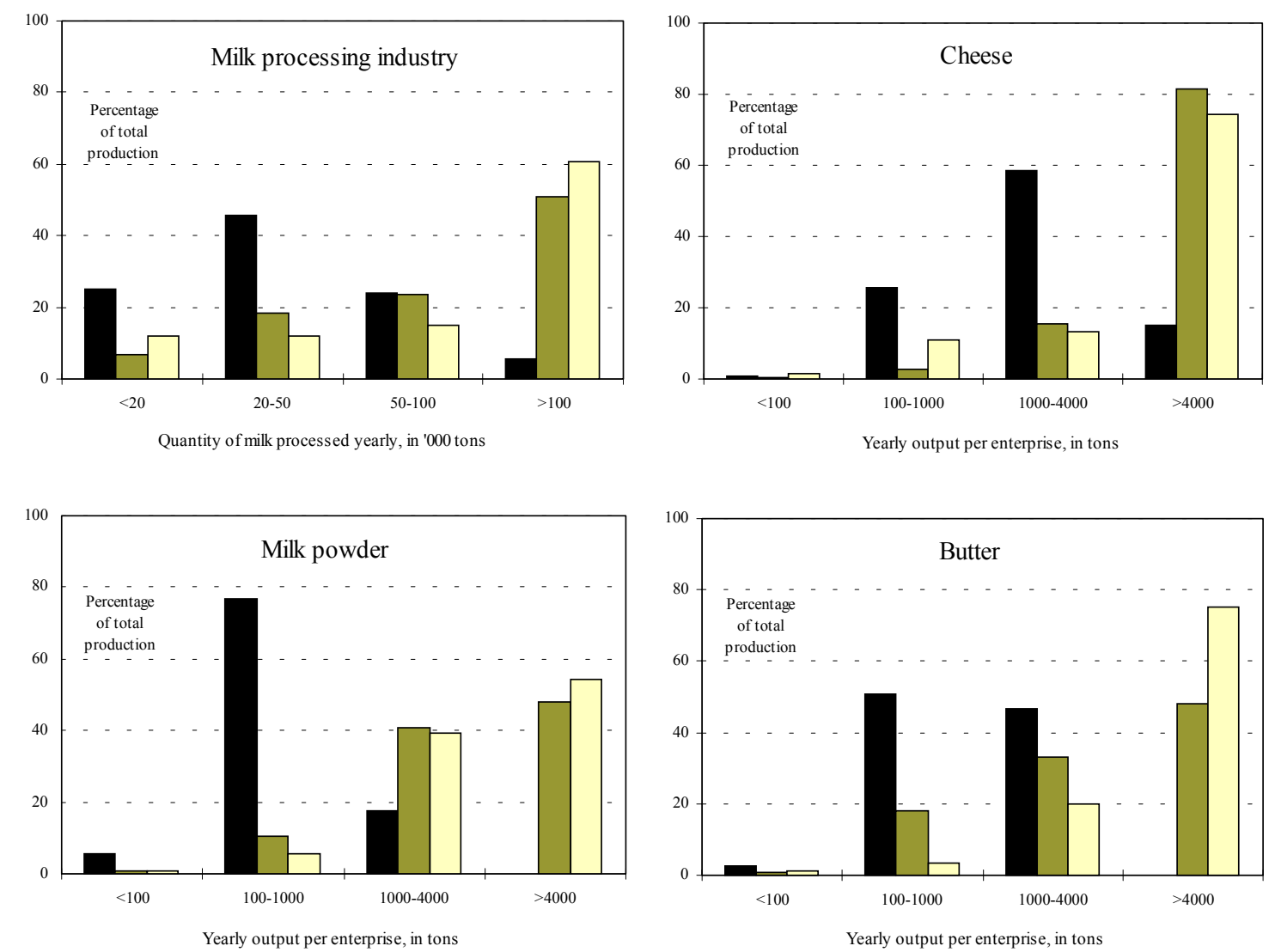

Poland

$\square$ Germany

France

Source: Smoleński and Wiger, (1997) (based on data from EC Dairy Facts\&Figures, Milk Marketing Board UK, 1993) and author's calculations.

The international comparison in Figure 2.1 suggests significant structural differences between Polish milk processing industry and the two industries from the EU countries. For all analysed cases Polish milk processing is characterised by higher shares of smaller enterprises in the total volumes of milk processed and in the total production of particular products. Relatively small structural disparities between Poland and the two reference countries have been detected in butter production, which may have to do with the specific role of butter production - butter production often provides a reserve processing capacities to deal with the seasonality in milk supply. In turn, relatively big structural disparities have been detected for milk powder production. The foregoing international comparison, however, is subject to several qualifications:

i. The fact that the data for the EU reflect the situation in 1988 but that of Poland in 1994 does not undermine the conclusion of structural differences between the compared countries. This is because substantial structural changes are reported for the EU dairy sector in that time period, which are conducive to an even further widening of the size disparities between the countries; 
ii. The firm size difference alone may not necessarily suggest scale inefficiency in Poland, because the older and less capital- but more labour-intensive production technologies typically used in Poland may, in fact, be characterised by a smaller minimum efficient scale.

It is important to remember that the industry structure in Poland, even several years after the liberal reforms of 1989, still remained (in 1994) mainly the outcome of the non-market allocation processes during the central-planning policy of the past. As reported by Zalewski and Nierzurawski (1994), in the seventies and eighties the spatial allocation of the processing capacities in the dairy sector followed the 'principle' of self-sufficiency of administrative regions (17 voivodships in seventies, and 49 in eighties), which imposed a serious constraint on concentration and specialisation in the industry.

\subsubsection{Structure of farm milk supply}

With $21 \%$ of green pasture in arable land and about $600 \mathrm{~mm}$ of yearly precipitation, natural conditions of farm milk production in Poland can be categorised as moderate: poorer than north-west Europe, but better compared to south European countries. Milk productivity of merely 31141 per year per cow is significantly below the EU average, 4663 in 1994, which indicates a technological and structural gap (extensive production technology with low capital and knowledge input).

Degree of concentration of milk supply (or herd structure) is a function of general farm size structure and the level of farm specialisation. In 1996 about 1.3 million farms in Poland (about 65\% of all holdings above 1 ha) reared 3.4 million cows, which yields an average of 2.6 cows per farm. As many as $88.6 \%$ of dairy farms kept less than 5 cows producing daily less than 40 litres of milk. The IERiGŻ (1999) estimates that in 1998 about 800 thousand farms delivered milk for processing, which means that the average daily delivery per farm is between 201 and 301 .

As far as the technology of milk assembly is concerned, it is estimated that in 1998 about $40 \%$ of milk were collected by tankers directly from dairy farms (KPSM, 1998). Increase in direct collection is only partly constrained by the fragmentation of milk supply; even with current farm structure, milk pre-bulking could take place in selected neighbouring farms (co-operative purchases of cooling equipment would be possible). The use of collection points leads to increases in the assembly costs and loss of milk quality.

\subsubsection{Output structure}

Between 1992 and 1998 substantial changes occurred in the product mix of the milk industry output (Table 2.2). Over that time period the general trend was towards reduction of butter and milk powders in favour of 'higher value added' products such as milk drinks, mainly yoghurts and kefirs (increase 
by $488 \%$ ), ice-creams (increase by $314 \%$ ), ripening and fresh cheeses (increase by $67 \%$ and $61 \%$, respectively).

Table 2.2. Changes in the product structure of output of the milk processing industry, Poland, 19921998 (production in thousand tons, per year).

\begin{tabular}{|lrrrrrrrr}
\hline \multirow{2}{*}{ Product } & 1992 & 1993 & 1994 & 1995 & 1996 & 1997 & 1998 \\
\cline { 2 - 8 } & & & & & & & $1992=$ \\
& & & & & & & \\
\hline \\
Milk drinks (incl. yoghurts) & 53.9 & 64.7 & 119.5 & 149.6 & 208.2 & 265.6 & 317.1 & $\mathbf{5 8 8}$ \\
Ice-creams & 28.7 & 35.7 & 50.0 & 74.8 & 87.2 & 136.9 & 118.8 & $\mathbf{4 1 4}$ \\
Processed cheeses & 16.5 & 28.5 & 29.0 & 29.6 & 36.8 & 42.5 & 41.1 & $\mathbf{2 4 9}$ \\
Ripening cheeses & 97.9 & 113.4 & 129.5 & 122.2 & 136.8 & 158.3 & 163.5 & $\mathbf{1 6 7}$ \\
Fresh cheeses & 162.0 & 169.0 & 186.4 & 197.5 & 216.4 & 236.7 & 261.4 & $\mathbf{1 6 1}$ \\
Creams & 157.1 & 160.7 & 166.9 & 174.7 & 189.0 & 200.5 & 194.6 & $\mathbf{1 2 4}$ \\
Drinking milk & 1240.5 & 1240.0 & 1311.6 & 1260.6 & 1356.1 & 1339.7 & 1350.4 & $\mathbf{1 0 9}$ \\
SMP & 132.9 & 156.5 & 112.0 & 128.4 & 120.6 & 119.9 & 131.3 & $\mathbf{9 9}$ \\
Butter & 153.8 & 146.4 & 119.8 & 122.9 & 131.7 & 139.0 & 146.0 & $\mathbf{9 5}$ \\
WMP & 42.2 & 37.5 & 39.2 & 40.5 & 35.2 & 39.8 & 39.3 & $\mathbf{9 3}$ \\
Casein & 11.9 & 8.6 & 3.0 & 3.1 & 2.2 & 1.3 & 6.9 & $\mathbf{5 8}$ \\
\hline Farm milk processed & 6696 & 6562 & 6149 & 6059 & 6315 & 67700 & 6943 & $\mathbf{1 0 4}$ \\
\hline Source: IERiGŻ (1999) and author's calculations. & & & & & \\
\hline
\end{tabular}

This development reflects the relative profitability of various product lines reported in studies based on an enterprise sample by Stachowski et al. (1999), Gornowicz (1996) as well as Doradztwo Mleczarskie (1997). Possible causes of this development will be discusses in Chapter 3, where determinants of private profitability of selected products (SMP, butter, ripening cheese and yoghurts) will be analysed, and in Chapter 5 where a case study of a high value added product will be carried out.

This evolution may imply important consequences for the technological change. Namely, the extend of the output increases in such product-lines as milk drinks, ice-creams or processed cheeses was mainly possible by investments in the new production capacities, rather than by the use of (underutilised) existing capacities (Smoleński, 1997). This means that in these expanding product lines new technology vintages may have been installed and economies of rapid growth attained (see Annex Table 19 for a closer definition of this phenomena). By the same token, incentives for technological change in the 'declining' product lines may have been diminished.

\subsubsection{Quality change}

The notion of quality refers to the combination of constituent product characteristics (Pearce, 1995). Quality change is associated with a change in the absolute amount of all (or most) of these characteristics and also is referred to as a vertical product differentiation. This needs to be distinguished from the horizontal product differentiation associated with a far-reaching change in 
selected characteristics (Philips, 1983). Price differences due to the quality differences can be regarded as a function of the implicit (shadow) prices of the particular characteristics (hedonic prices) and their intensities in a product (Pearce, 1995).

Quality differences in the final output can reflect the input quality (e.g. farm milk or machinery) or efficiency of the input use (e.g. managerial control over technological process). Hence quality improvement may necessitate either: (i) higher costs due to a switch to better quality input (milk quality premia or investment in new assembly or processing technology) or (ii) merely enforcement of better managerial practices (induced by competitive pressure or more rigid legislation). Figure 2.2 outlines taxonomy of characteristics of dairy products responsible for the quality (vertical product differentiation) and variety (horizontal product differentiation).

Figure 2.2. Determinants of quality of dairy products.

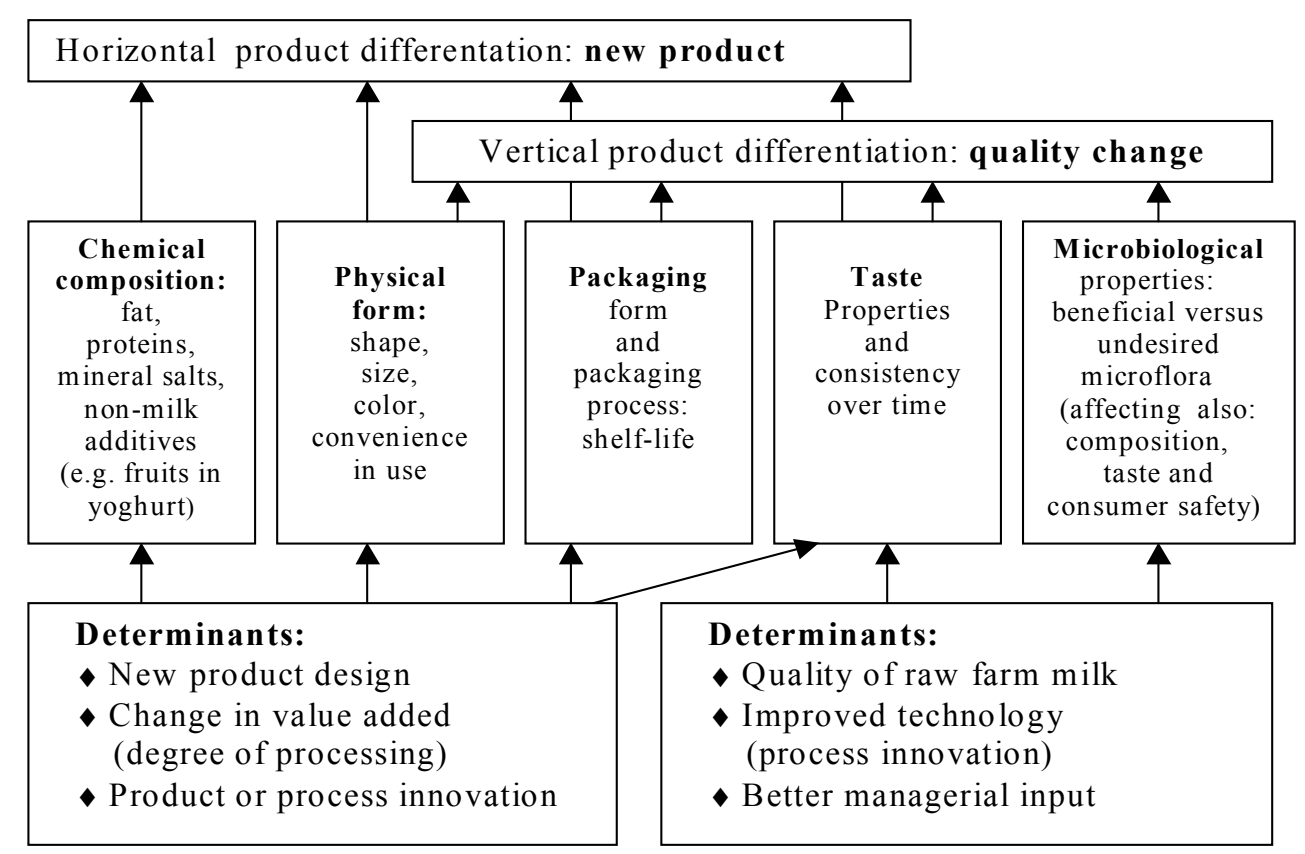

Source: author's compilation based on sources quoted in text.

In the discussion on the competitiveness of the Polish agro-food sector against the EU market, quality has been playing an increasingly important role. As far as the EU consumer market is concerned, food safety issues have constantly been moving to the forefront of public interest. In Poland the structural and technological lag exacerbate the problems of quality control both at farm and processing levels. The issue was manifested most acutely when the EU Commission imposed a ban on Polish dairy imports in December 1997 (Rzeczpospolita, 17.05.1999). There are also suspicions that the quality gap leads to overestimation of the apparent price competitiveness of the Polish ago-food sector against the EU (USDA ERS, 1999). 


\subsubsection{Farm milk quality}

The quality of farm milk is influenced by a number of factors associated with the technology of farm production. ${ }^{10}$ The most common sources of failures include wrong feeding, healthiness of milk-cow herds and wrong methods of milking and post milking treatment. The most widespread problems with assuring high quality of milk include mastitis, hygienic quality and adulteration. Mastitis is defined as inflammation of the mammary gland in response to the injury or infection of tissue associated with the increase in the level of white blood cells or leukocytes, which causes an increase in somatic cell counts of milk. The effects of mastitis on the quality of milk consist of increased levels of enzymes decomposing fats and proteins and thus changing the technological properties of milk.

The health and cleanliness of the cow, the standard of milking and the hygienic conditions of milking equipment influence the hygienic quality of farm milk. The microbiological contamination of raw milk during the production on farm may result in the presence of a variety of microorganisms, some of them pathogenic. Equipment enabling the immediate lowering of temperature of milk freshly drawn from the cow down to $4^{\circ}$, and ideally $2^{\circ} \mathrm{C}$, to reduce the growth of contaminant bacteria is a prerequisite for assuring the hygienic quality of raw milk. Adulteration of milk may occur by accident or by design (to increase volume, mask evidences of spoilage etc.) and covers cases of: extraneous water, chemical compounds or antibiotics. Malpractice leads to serious perturbations in the processing adversely affecting the quality of final products.

To limit the incidence of quality failure, minimum standards and surveillance procedures are set in legislation. Table 2.3 presents such regulatory quality norms in Poland and in the EU and reports on the results of recent quality controls in Poland. The average quality of farm milk delivered to processors in Poland between 1997 and 1999 was, in general, low. In 1998 and 1999, when new EUcomplied quality standards were introduced, only $47 \%$ and $30 \%$ (respectively for both years) of farm milk was classified as the Class Extra corresponding to the quality standard acceptable in the EU. Only dairy products produced from milk of this quality grade were allowed to be exported to the EU market after the partial abolition of the import ban in January 1999. Even in the enterprises, which received the renewed licences to export, only part of the milk processed $(60 \%-70 \%)$ meets this requirement 1 (Rzeczpospolita, 23.09.1998).

10 This section is based on Early (1998) and Ziajka and Dzwolak (1998).

11 The licensed enterprises were obliged to separate the production from lower quality milk, which can only be sold domestically. 
Table 2.3. Regulatory quality standards for farm milk in Poland and in the EU, and the quality of milk deliveries in Poland, 1998-1999.

I. Quality norms for farm milk in Poland and EU (1.1.1998)

\begin{tabular}{|c|c|c|c|c|c|}
\hline Quality criteria & Units & \multicolumn{4}{|c|}{ Quality categories } \\
\hline \multicolumn{6}{|c|}{ European Union (EU Directive 92/46/EEC) (1) } \\
\hline & \multicolumn{2}{|r|}{ Acceptable } & \multicolumn{3}{|c|}{ Unacceptable } \\
\hline Limits for the bacteria number & 1000 per $\mathrm{ccm}$ & $<=100$ & & & \\
\hline Limits for the somatic cells & 1000 per $\mathrm{ccm}$ & $<400$ & & & \\
\hline Inhibiting substances & & 'traces' & & & \\
\hline Freezing point & $\mathrm{C}^{\mathrm{O}}$ & $<=-0.515$ & & & \\
\hline Density & $\mathrm{g} / \mathrm{ccm}$ & 1.028 & & & \\
\hline \multicolumn{6}{|c|}{ Poland (PN-A-86002:1995) (2) } \\
\hline & & Class Extra & Class I & Class II & Class III \\
\hline Limits for the bacteria number & 1000 per $\mathrm{ccm}$ & $<100$ & $100-400$ & $400-1000$ & $>1000$ \\
\hline Limits for the somatic cells & 1000 per $\mathrm{ccm}$ & $<400$ & $400-500$ & $500-1000$ & $>1000$ \\
\hline Results of Whiteside's test & & - & - & $-/+$ & + \\
\hline Water dilution & & \multicolumn{4}{|c|}{ unacceptable } \\
\hline Inhibiting substances & & \multicolumn{4}{|c|}{ unacceptable } \\
\hline Freezing point & $\mathrm{C}^{\mathrm{O}}$ & \multicolumn{4}{|c|}{$<-0.512$} \\
\hline Density & $\mathrm{g} / \mathrm{ccm}$ & \multicolumn{4}{|c|}{1.028} \\
\hline
\end{tabular}

II. Results of quality control in Poland in 1998 and 1999 (3)

\begin{tabular}{|cccccc|}
\hline & & Class Extra & Class I & Class II & Class III \\
\hline First half 1998 & Percentage & 47.9 & 17.4 & 15.1 & 16.6 \\
\hline First half 1999 & Percentage & 30.1 & 28.9 & 23.3 & 15.1 \\
\hline
\end{tabular}

(3) Random controls covering 8720 samples (in 1998) and 4509 samples (in 1999). In 1999 altogether 74 firms were covered including 66 dairy co-operatives. Samples have been collected at various stages of farm milk transportation between farm and processor.

Source: (1) and (2) Zalewski (1998), (3) Główny Inspektorat Skupu i Przetwórstwa Artykułów Rolnych (1999).

Poor quality of farm milk is considered to be the major factor of quality problems envisaged by the milk processing industry. The most obvious culprit is the fragmentation of farm milk production. The adverse effects of fragmented farm structure on milk quality include:

i. Lack of adequate cooling equipment on the smallest farms. IERiGŻ (1999) estimates that investment in such equipment is economically justified only on farms with at least 5-6 cows (about $30 \%$ of all cows in farms delivering milk to processing);

ii. Lack of adequate veterinary control related to high unit fixed costs of this input on smallest farms;

iii. Still a high share of milk not being collected directly from farms by tankers but through collection points.

Related with this structural factor has been the postponement by the Government of the enforcement of new quality standards and the adequate institutional controlling arrangement. The underlying policy debate indicates that the timetable for enforcement of the new regulation reflected a 
trade-off between the need to upgrade the quality to meet the EU standards and the possibility that new more rigorous regulations may limit the milk production in the short term, thus: undermining the rationales for demanding a high milk quota during accession negotiation and triggering problems with milk availability at processing level.

Despite the implementation of the new legal standards in January 1998, many processing enterprises have received temporary exemptions. The establishing of quality control laboratories independent of farmers and producers, which is a prerequisite to the enforcement of the law, started in 1998, but has proceeded sluggishly (Rzeczpospolita, 17.05.1999). Although the adjustment to the new standards requires increased investment, nevertheless substantial improvement has been recorded in 1999 merely due to the higher scrutiny of processors faced with the new legal obligations and with the threat of losing EU exports outlets. This suggests that, to a degree, fears about the drop in milk production (due to the higher legal requirements) have been exaggerated.

\subsubsection{Final product quality}

Processing technology used has an important contribution to the final quality of processed milk products. Of importance is machinery equipment as well as the applied alternative solution to consecutive treatments during the processing. Major potential improvement envisaged in the Polish milk processing include:

i. Implementation of CIP - clean-in-place cleaning system (Nitecka, 1998; Early, 1998);

ii. Implementation of modern quality management technologies like HACCP - Hazard Analysis of Critical Control Points (Nitecka, 1998);

iii. Other technological advancements such as: automated control of technological processes including (e.g. microprocessor technologies), substitution of batch for flow techniques (enhancing uniformity of product composition), introduction of new technologies of milk cleaning and pasteurisation (microfiltration, bactofugation and superpasteurisation), implementation of vacuum and control atmosphere packaging prolonging shelf life of final products.

Most of the recent innovations in milk processing technologies are directly targeted at quality improvements and only some of them require completely new machinery (Hülsen, 1996 and Caraveli and Traill, 1998). For example, new management and quality control systems require only adaptive investments rather than replacement of all existing capital stock. For this reason, managerial technologies like the HACCP advocated by the EU Council Directive 92/46/EEC are seen as a costefficient way of quality upgrading and their propagation is being promoted by the Government (Nitecka, 1998).

The National Trade Inspection (PIH) is conducting controls of the compliance of dairy products with the regulatory standards at producer, wholesale and retail levels. The data for the second half of 
1997 indicate at a rather high incidence of quality failures either in terms of consistency with the norms concerning the proportions of components (composition, organoleptic properties etc.) or packaging (Table 2.4). Controls carried out in about a hundred processing enterprises (however, preselected in a non-random manner, i.e. of the lower than average performance in terms of quality) revealed quality failures in about $40 \%$ to $50 \%$ samples (weighted by value) (PIH, 1998). The report points out the producers' difficulty with assuring uniformity of various product lots. One of the major reasons indicated is the tendency of even small producers to diversify the range of products and to follow a strategy of product differentiation. Other barriers to quality improvements indicated include: low quality of farm milk, errors in processing procedures, and only to a lesser extent outdated machinery.

Table 2.4. Conformity with regulatory standards for dairy product quality (1997, value weighted shares of non-random cases violating the standards, in \%).

\begin{tabular}{|c|c|c|c|}
\hline \multirow{2}{*}{ Product } & \multirow{2}{*}{$\begin{array}{c}\text { Share of } \\
\text { questioned samples (1) }\end{array}$} & \multicolumn{2}{|c|}{ Including samples with failures in: } \\
\hline & & Composition & Packaging \\
\hline Consumption milk & 40.0 & 13.1 & 23.4 \\
\hline Milk drinks & 46.3 & 21.0 & 33.7 \\
\hline Creams & 38.2 & 27.6 & 15.8 \\
\hline Butter & 52.9 & 15.9 & 24.5 \\
\hline Cottage cheese & 52.1 & 47.5 & 19.9 \\
\hline Hard cheeses & 43.5 & 33.1 & 17.2 \\
\hline \multicolumn{4}{|c|}{$\begin{array}{l}\text { (1) The analysis is not based on a random sample, as the enterprises for the control are pre-selected so as to } \\
\text { target the worse performing. This means that results are not representative for the entire industry. The } \\
\text { controls covered about one third of all processing firms (and approximately about } 20-30 \% \text { of the industry } \\
\text { output). } \\
\text { Source: PIH (1998). }\end{array}$} \\
\hline
\end{tabular}

\section{Prospects for quality upgrade}

The above evidence points out major obstacles to quality improvements in the analysed industry. Fragmented farm structure seems to contribute a great deal since investments in the necessary equipment reveals a minimum efficient scale that lies significantly above the average size of commercial dairy farm. Sub-optimal structure of processing may affect the quality by inhibiting technological change and promoting low specialisation of relatively small enterprises. An important role is played by the incentive structure shaped by market forces and trade policy (competitive pressure) and by the institution policy (Government's determination to implement legal quality standards and surveillance system). As for the latter, an important stimulus resulted from the EU ban on imports from Poland maintained between December 1997 and January 1999. 


\subsection{Evidence of Recent Productivity Growth}

This section surveys recent factor productivity changes in the analysed industry. To this purpose, a non-parametric estimation of total factor productivity (TFP), based on index numbers, is used. The section starts from a presentation of basic concepts related to the productivity and efficiency analysis. Next, the method of TFP estimation is introduced and applied for the period 1993-1997.

\subsubsection{Components of factor productivity growth}

The basic concept in measurement of productivity growth is total factor productivity (TFP), the ratio of an index of (aggregate) output to an index of (aggregate) input. Growth in TFP occurs, for example, when output grows without an increase in input or input decreases without a decline in the output. Changes in the TFP can be decomposed into three components: (i) technological change, (ii) changes in technical efficiency, and (iii) changes in scale (efficiency) (Kalaitzandonakes et al., 1994; Piesse, 1997). This decomposition can be illustrated using the cost function (Figure 2.3).

Figure 2.3. Decomposition of productivity growth using cost functions.

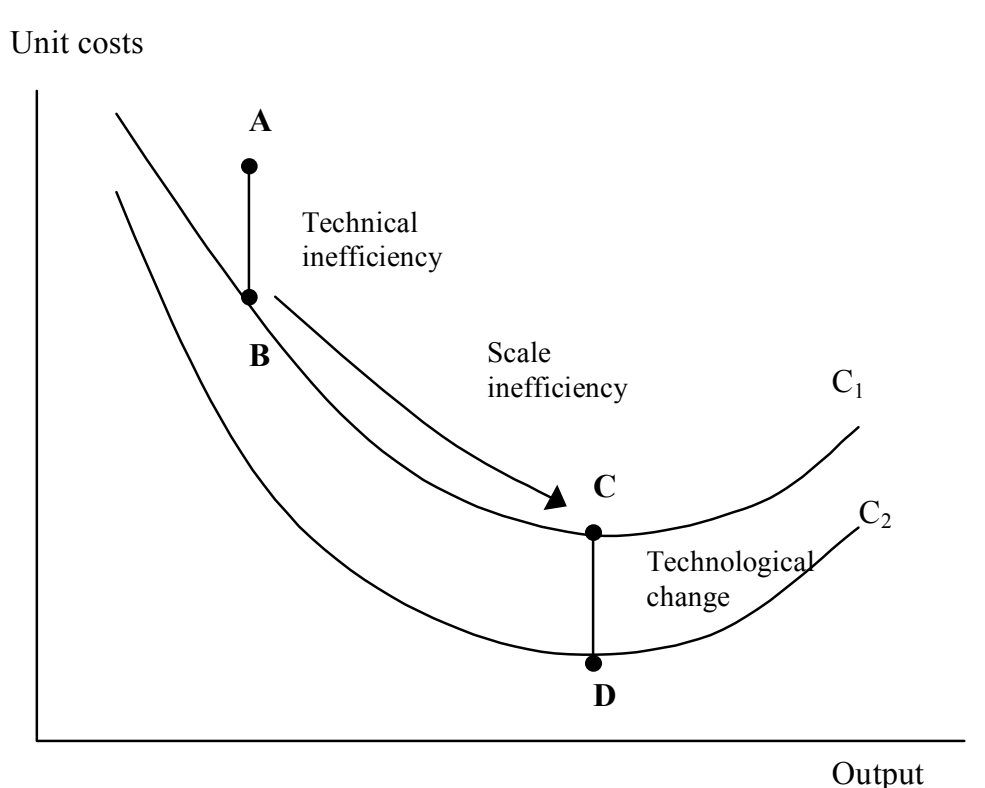

Source: Kalaitzandonakes et al. (1994).

The figure shows a firm, which step-wise increases its total factor productivity by eliminating its technical inefficiency (movement from point A to B), then, by eliminating its scale inefficiency (movement from the point $\mathrm{B}$ to $\mathrm{C}$ and by technological change (movement from point $\mathrm{C}$ to $\mathrm{D}$ ). Firms composing an industry may differ both in terms of TFP and in terms of the combination of these three components of TFP. In order to improve productivity, firms can follow different strategies. At the aggregate level, productivity growth reflects the net outcome of changes in technical or scale 
efficiency, adoption of new technologies, exit of least efficient firms or entry of new firms characterised by high efficiency.

Conceptualising differences between efficiency change and technological change is important since they are determined by fundamentally different phenomena, and can be addressed by different policies (Piesse, 1997). Definitions of concepts, which are often used in the analysis of technical change, are presented in Box 1.

\section{Box 1. Major Concepts Related to Technical Change}

Technological change refers to the advances in the state of knowledge. It consists of three inter-linked forces: research and development, (R\&D), adoption and diffusion (A\&D) and institutional component. For a firm the strategy for realising technological change may thus consist of innovation and/or imitation. Existence of a technological gap between countries implies scope for innovation while countries at the technological forefront can mainly realise technological progress by innovation.

Technological change is characterised by several important properties. First one pertains to whether new technologies are biased against any of the production factors. Technological change can result in a greater saving of labour factor or capital, i.e. it changes the optimum factor ratio. Technological change is said to be neutral if it leaves the optimum factor ratio unchanged. Since in the industrial sectors technological change is usually an endogenous process, i.e. induced primarily by relative resource endowments, most technological advances tend to be of labour saving type. The second property of technological change refers to whether it requires adaptation of an existing process via acquisition of new inputs (usually mechanical) (embodied technological change) or whether it makes use of existing labour and capital to produce more of the same product (disembodied technological change). The third property of technological change, closely related to the previous ones, is its scale bias. This may exist because certain technologies may be better tailored to firms of a particular size. In principle, new mechanical technologies tend to favour larger operations. Another important distinction in the literature on technological change, which becomes increasingly apparent in the agro-food industries, is focus of innovation on product or process. Product innovations reflect the recent tendency to the increasing role of noncost competitiveness (product proliferation and differentiation) while process innovations mainly reduce costs enabling cost advantages and competitiveness gains.

Related to technical change is the concept of economic efficiency. This can be defined as how 'effectively' resources (factors and possessed technology) are used for the purpose of profit maximisation. One possible empirical procedure in measuring efficiency is to estimate a frontier production function (for an industry), which is assumed to represent a set of best available techniques - current advancement in the technological progress available to an industry. The distance between this and an average production function is indicative of the degree of inefficiencies that exist in the industry.

Technical efficiency decides how effectively the resources are used with a given technology and scale. Potential explanations for this kind of inefficiency are described by the $\boldsymbol{x}$ - (in-) efficiency theory. According to this theory, the observed efficiency gaps between firms (and sectors in a country or in the international perspective) may be explained by several factors internal to the firm, such as: management and workers' personality traits, work norms, motivational factors and transaction costs as well as external to the firm, including: regulations, property rights and ownership form and, above all, the extent of the competitive pressure faced that enforces the elimination of sub-optimal use of inputs and technologies.

One possible explanation for the usually observed co-existence of scale inefficient and scale efficient firms is that scale efficiency represents only one productivity component, which means that scale under-efficiency can be 'compensated for' by superior technical efficiency (e.g. better management or limited principal-agent problems) or ability to faster adopt new technology (e.g. easier raising of capital for new investment, if capital market is malfunctioning) (see Figure 2.3).

Source: author's compilation based on Fratz (1988), Leibenstein (1966) and OECD (1995a). 


\subsubsection{Measuring TFP in the industry}

Of two general approaches to the measurement of technical change: estimation of an industry production function with time variable (parametric estimation) and index number estimation of TFP (non-parametric estimation) the latter one is applied here. It is based on superlative indices. The Tornquist approximation of Divisia Index is used to arrive at a rate of total factor productivity changes. Implicit to the estimation procedure is the decomposition of the industry revenue growth into the price effect, input deepening effect and TFP effect, which provides an insight into structural changes accompanying the changes in the TFP.

\subsubsection{Method used}

Empirical analyses of technological change have traditionally used the concept of factor productivity, comparing its changes over time or conducting cross-sectional analysis (inter-industry or international comparative analyses) (Chambers, 1988). Partial productivity measurements (usually labour productivity) have been extended by a concept of TFP, defined as the ratio of output $\mathrm{Q}$ to the index of all inputs $\mathrm{X}$, i.e. $\mathrm{Q} / \mathrm{X}$. Differentiating this expression with respect to time gives: $\dot{T F P}=\dot{Q}-\dot{X}$, where $\dot{T F P}, \dot{Q}, \dot{X}$ denote rates of change in the TFP, Q and X (e.g. $\dot{T F P}=d \ln T F P / d t)$.

For an index estimation of total factor productivity aggregate output and input indices are needed. One commonly used specification is the Divisia input and output index based on revenue shares of outputs and cost shares of inputs (Chambers, 1988). In calculations using discrete yearly data the most commonly used is the Törnqvist approximation of the Divisia Index of TFP. This index has been used here. ${ }^{12}$ The underlying definitions and indices are as follows:

$$
\begin{aligned}
& \text { TF } \dot{P}_{t}=\dot{Q}_{t}-\dot{X}_{t}, \\
& \dot{Q}_{t}=\sum_{i=1}^{n} \frac{1}{2}\left(r_{i, t}+r_{i, t-1}\right)\left(\ln q_{i, t}-\ln q_{i, t-1}\right), \\
& \dot{X}_{t}=\sum_{j=1}^{m} \frac{1}{2}\left(s_{j, t}+s_{j, t-1}\right)\left(\ln x_{j, t}-\ln x_{j, t-1}\right),
\end{aligned}
$$

where $\dot{Q}$ and $\dot{X}$ are output and input Tornquist approximation of Divisia indices at each time $t$

$$
r_{i, t}=\frac{q_{i, t} p_{i, t}}{\sum_{i=1}^{i=n} q_{i, t} p_{i, t}} \quad \text { is the revenue share of output } q_{i} \text { in period } t
$$

12 The analysis draws on the approach used by Gopinath et al. (1996) who studied the components of U.S. food processing GDP growth, and Gopinath et al. (1997) who studied agricultural competitiveness in the U.S. and EU countries. 
$s_{j, t}=\frac{x_{j, t} w_{j, t}}{\sum_{j=1}^{j=m} x_{j, t} w_{j, t}}$ is the cost share of input $x_{j}$ to total costs in period $t$

where:

$q_{i}$ is the quantity of output $i$ in the industry,

$x_{j}$ is the quantity of input $j$ in the industry,

$p_{i}$ and $w_{j}$ are corresponding output and input prices,

$n$ is the number of output categories,

$m$ is the number of input categories.

In this study, the calculation procedure depended on the primary data available. This included yearly observations of:

aggregate output revenues:

$\sum_{i=1}^{i=n} q_{i, t *} p_{i, t}$

expenditure on single input categories: $\quad x_{i, t} * w_{i, t}$,

output quantities: $\quad q_{i, t}$,

prices for particular outputs: $\quad p_{i, t}$,

price indices for particular input categories: $w_{j, t}$.

On the basis of this data implicit quantities of output and input can be calculated. The calculation involves the following steps:

i. Conversion of all values and prices (i.e. output revenues, input expenditures and output and input prices) from nominal into real terms using the GDP deflator (see Annex Table 5);

ii. Estimation of the Tornquist approximation of the output price index using the output quantity and price data:

$$
\dot{P_{t}}=\sum_{i=1}^{n} \frac{1}{2}\left(r_{i, t}+r_{i, t-1}\right)\left(\ln \frac{p_{i, t}}{p_{i, t-1}}\right)
$$

where $r_{i, t}$ is calculated according to the formula (2.4);

iii. Estimation of the implicit output quantity index:

$$
\dot{Q}_{t}=(Q * P)_{t}-\dot{P}_{t},
$$

where:

$$
(P * \dot{Q})_{t}=\ln \left(\frac{\sum_{i=1}^{i=n} q_{i, t} p_{i, t}}{\sum_{i=1}^{i=n} q_{i, t-1} p_{i, t-1}}\right)
$$

iv. Calculation of the implicit quantity indices for each input category:

$$
\dot{x}_{j, t}=\left(x_{j, t} \dot{w}_{j, t}\right)-\dot{w}_{j, t},
$$

where: 


$$
x_{j, t} \dot{w}_{j, t}=\ln \left(\frac{x_{j, t} w_{j, t}}{x_{j, t-1} w_{j, t-1}}\right)
$$

v. Calculation of the quantity index for the aggregate input:

$$
\dot{X}_{t}=\sum_{j=1}^{m} \frac{1}{2}\left(s_{j, t}+s_{j, t-1}\right) \dot{x}_{j, t}
$$

vi. Calculation of index of the TFP growth for each year $t$ :

$$
T \dot{F} P_{t}=\dot{Q}_{t}-\dot{X}_{t}
$$

vii. Average effects in the analysed period (1993-1997) have been estimated as geometric averages.

For the TFP:

$$
\dot{T F P}=\ln \left(\sqrt[4]{\prod_{1}^{4} \exp \dot{F F P}_{t}}\right),
$$

where 4 is the number of periods for which separate yearly indices have been estimated.

\section{Decomposition of revenue growth}

Implicit to the estimating of TFP growth according to the procedure used here is the decomposition of the industry revenue growth into the price, input deepening and TFP effects. The price effect, positive or negative, takes place when the index of nominal output prices diverge from the GDP price index (used here as the deflator). Input deepening contributions are changes in the quantities of an input, which bring about a change in quantity of output; they equal to the percentage changes in input quantities weighted by their cost shares. Along with the estimates of TFP growth, these price and input effects are of interest here because they deliver information, which helps interpret the estimates for the TFP and shed light on the structural changes in the industry. The relation between revenue growth, price effect, input deepening contribution and TFP growth, derived from equations (2.1) and (2.7) is as follows:

$(Q * P)_{t}=\dot{P}_{t}+\dot{Q}_{t}=\dot{P}_{t}+\dot{X}_{t}+T \dot{F F} P_{t}$

\subsubsection{The data}

Several data sources have been used. The backbone of the data used is income statement reports of dairy enterprises submitted (and aggregated for the industry-level) by the GUS (1998b). This data set involves aggregate output revenues and cost expenditure for major input categories in current prices. Producer output prices for 15 dairy products published by the IERiGŻ (1999) have been used. Price indices for 8 input categories are either sector specific (capital, labour, farm milk, fuels) or economy wide (electricity, services, material inputs, other costs). For some input categories directly observed 
quantities are available (farm milk, employment). The GDP deflator as well as the indices of input prices comes from the GUS (1999c). Capital quantities are calculated on the basis of gross stock of capital for major categories (buildings, machinery, vehicles) (GUS, 1998e), price indices for each fixed capital category and own estimates of interest rates (including effects of credit policy). Quantities of capital (implicit quantities of capital services) are calculated as periodised values of capital stock using the annuity method (for details see section 3.2.8).

\subsubsection{Results}

Intermediate results including the nominal and real price indices and quantity indices are presented in Annex Table 5 and, in part, in Figure 2.4. Final results, which are presented in Table 2.5, include price and input deepening effects and TFP effects in each year and averages for the whole period.

Over the analysed period the revenue growth in the milk processing industry averaged $5.93 \%$ annually. A major contribution to this growth was from the growth in the non-farm inputs $(4.29 \%$ annual average) of which the majority is accounted by the category 'other materials' including packaging materials and other (3.80\% annual average). On average, the (real) price effect appears almost neutral $(0.09 \%)$. TFP growth explains $1.16 \%$ of annual average growth, while growth in the farm milk input only $0.38 \%$.

The results point at the remarkable difference in the relative contributions of various growth components in the years 1996 and 1997 compared to the two previous years. Although in the years 1996 and 1997 the contribution of other materials appears dominant, (real) prices declined remarkably $(-5.11 \%$ and $-3.28 \%$ respectively), use of farm milk has recovered $(2.29 \%$ and $3.68 \%$ respectively) while TFP growth was boosted (2.32\% and $4.52 \%$, respectively).

Table 2.5. Components of revenue growth in the milk processing industry, 1993-1997 (in \% per year).

\begin{tabular}{|c|c|c|c|c|c|}
\hline & 1994 & 1995 & 1996 & 1997 & Average \\
\hline Revenue of industry including: & -7.67 & 14.42 & 6.23 & 10.72 & 5.93 \\
\hline Price effect & -1.26 & 10.01 & -5.11 & -3.28 & 0.09 \\
\hline Implicit quantity effect & -6.40 & 4.41 & 11.34 & 14.01 & 5.84 \\
\hline Farm milk input contribution & -3.62 & -0.81 & 2.29 & 3.68 & 0.38 \\
\hline Non-farm input contribution including: & 1.46 & 3.18 & 6.72 & 5.81 & 4.29 \\
\hline Labour & -0.97 & -0.37 & -0.11 & 0.11 & -0.33 \\
\hline Capital & 0.30 & 0.52 & 0.21 & 0.27 & 0.33 \\
\hline Services & -0.58 & 0.29 & 0.37 & 1.30 & 0.34 \\
\hline Other materials & 3.06 & 2.96 & 6.00 & 3.17 & 3.80 \\
\hline Fuels & -0.05 & -0.05 & -0.04 & -0.04 & -0.05 \\
\hline Electricity & -0.06 & 0.20 & -0.07 & 0.16 & 0.06 \\
\hline Other costs & -0.25 & -0.37 & 0.36 & 0.85 & 0.15 \\
\hline TFP growth & -4.24 & 2.05 & 2.32 & 4.52 & 1.16 \\
\hline
\end{tabular}

Source: author's calculation based on methods and data described in the text. 
Characteristic is also the switch in the performance of almost all indices in the year 1995: first of all, a significant 'positive' price impulse (10\% annual price effect) accounting for the majority of the revenue growth in that year. This coincided with a significant change in the performance of the remaining indices (compared to the year 1994) including: a slowing-down in the regression in farm milk input (from $-3.62 \%$ in 1994 to $-0.81 \%$ in 1995), establishing of positive growth rates in TFP (change from $-4.24 \%$ in 1994 to $2.05 \%$ in 1995 ) and a switch to positive implicit output quantity growth (change from $-6.40 \%$ in 1994 to $4.41 \%$ in 1995 ).

Clear trends have been detected in the capital and labour contributions. Labour input contribution to the revenue growth averaged $-0.33 \%$ annually (the labour reduction was stopped in 1997), while capital input explained $0.33 \%$ of the average annual rate of revenue growth. Relatively low contribution of capital growth to the output growth reflects a relatively low share of this input in total cost (only $4.5 \%$ compared to $13.1 \%$ for labour, $15.2 \%$ for other materials and $54.7 \%$ for farm milk averages for 1993-1997). In fact, capital was the second fast growing input: next to other materials (see Figure 2.4).

Figure 2.4. Development of real prices and quantities in the milk processing industry, 1993-1997.

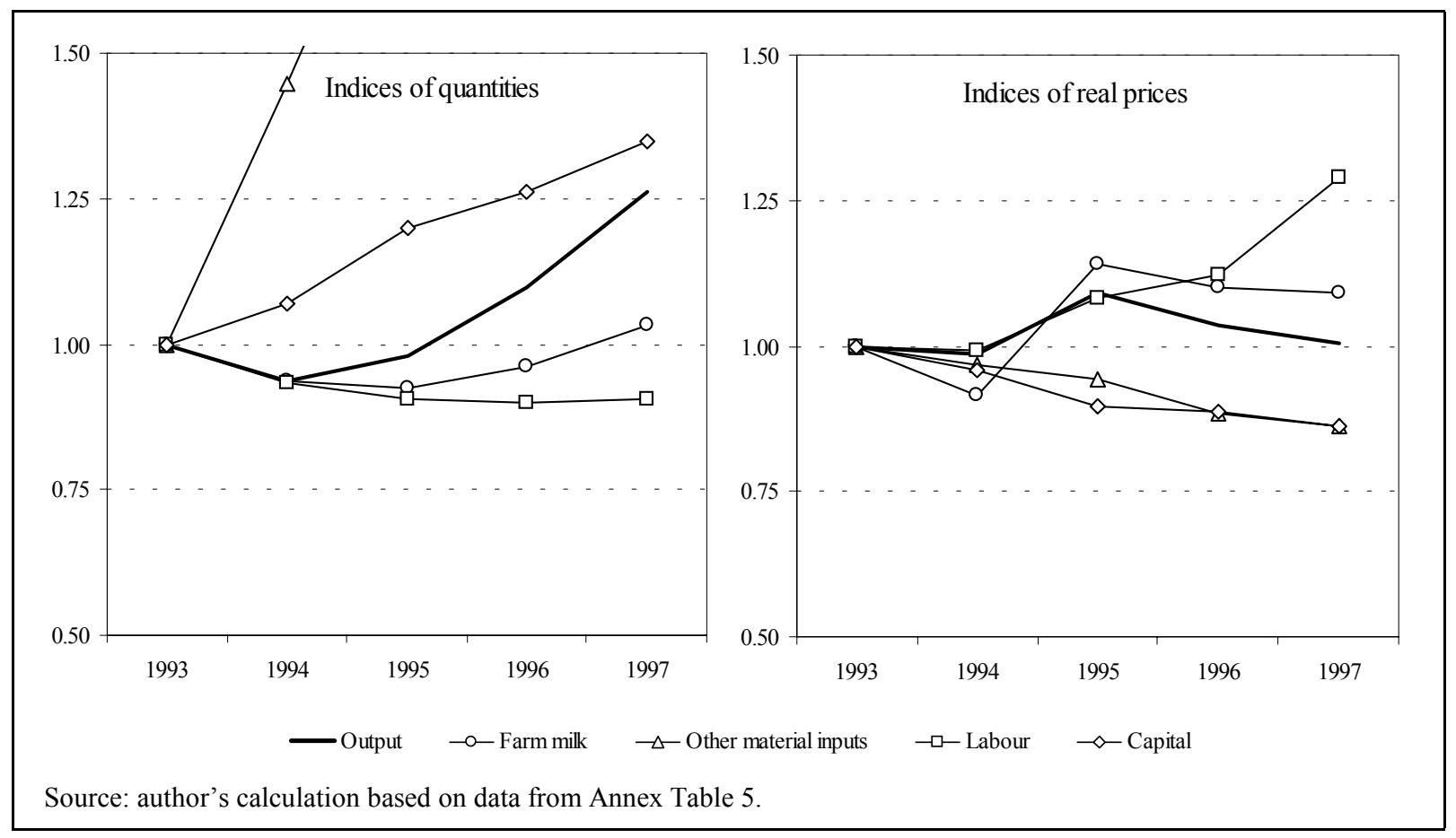

The following further interpretation of results can be put forward:

i. The output quantity growth has mainly occurred through changes in the product composition towards more high value-added items. This has already been evidenced by the data on the changes in the product structure of the industry output in the period under consideration. Here this development is also reflected in the changes in relative contribution of various inputs to the output growth: relatively small increases in the volume of input of farm milk and major 
contributions of input of the other materials (e.g. packaging materials) and less of capital and services;

ii. Over the analysed period, TFP growth showed an increasing trend. This is an important result because TFP is a sustainable source of growth ${ }^{1}$ (this, however, also depends on the source of the TFP growth - see next point). The detected changes in input contributions are rather of a shortterm nature, as they mainly result from the (transitional) adjustment in the product composition in the dairy industry output associated with relative price changes and domestic consumer preference changes;

iii. In the analysed period the changes in the TFP may result from several sources. Their relative importance cannot be separated by this method. Instead, the following hypothetical explanations are proposed and confronted with various descriptive statistics and results of other studies. Rate or investment will be discussed in section 2.4.2 - here the technological change is suggested through the expansion of the new production capacities associated with changes in product composition and increase in the capital input. Only indirect evidence of the improvement of technical efficiency is delivered in Annex Table 6; this source of TFP has itself several aspects, including learning effects, institutional changes (declining share of co-operative as production organisation form) and consequences of competitive pressure resulting from the growing integration with foreign markets and real exchange rate appreciation. Potential gains from the improvements in scale efficiency are considered to be significant, however the gains realised in the analysed period were probably small. Also gains from the improved capacity utilisation were rather small as most output increases occurred by the creation of new capacities while the closing of marginal firms were seldom.

The transitional economic context suggests that efficiency improvements may have made a much higher contribution to TFP growth in the analysed past period than it may make in the future. ${ }^{14}$ Hence, sustainability of the detected TFP growth may require a greater role of technological change through increased investment.

\subsection{Scope for Future Productivity Improvement}

This section discusses the scope for improvement in the factor productivity in the industry in the medium term. The notion of scope embraces two elements. The first one is the existing potential for substituting old equipment for new, changing structure and management practices and eliminating inefficiencies. It can be 'measured' in terms of the productivity gap relative to the competitors with

13 For discussion of links between sectoral growth, TFP, and international competitiveness see Gopinath et al. (1997).

14 According to Piesse (1997): 'The transition may perhaps be viewed mostly as an efficiency problem, with 
up-to-date technologies and operating at a low level of economic inefficiencies. The second one is the set of institutional and policy conditions which shape the incentives for and constraints on modernisation and restructuring. To a degree however, the distinction between the two elements is artificial. For example, high potential gains (reduction in costs and/or increase in revenues) from acquiring new technology provide an incentive to invest. The point is, however, that the trigger level of such an incentive may be much higher in the presence of structural, institutional and policy constraints. Such constraints can be seen as sources of high transaction costs, increased risk and uncertainty, which must affect investment decisions.

\subsubsection{Existing productivity lag}

The scope for fast productivity improvement may be provided by a comparison with another existing milk industry that is characterised by up-to-date technology and a longer history of operating in a competitive and institutionally mature market economy. To this end the milk processing industry in the neighbouring Germany offers a good example. The relevance of this particular case may be justified by the following rationales:

i. Germany belongs to the countries with the highest unit costs of labour, which should have induced the adoption of the most up-to-date technologies and the reduction of inefficiencies motivated by a pressure to increase labour productivity. The choice of the capital intensive techniques in this industry, due to the relative abundance of this production factor, may not affect this relevance substantially because the question asked here is about the scope for adjustment in the future when relative capital/labour prices in Poland should be moving towards those in Germany today;

ii. As far as economic efficiency is concerned there are two conflicting effects involved. On the one hand, the dairy regime of the CAP may have had a petrifying effect on economic structures and efficiency. On the other hand however, the industry has been operating for a long time in the integrated single European market, which could have had a promoting effect on economic efficiency;

iii. Restructuring of the milk processing industry in the East German states enabled reaping economies of rapid growth, ${ }^{15}$ i.e. tailoring the size of the production units to the technically determined scale effects and employment of the latest technologies.

technical change being a more long term issue...'

15 See EU Commission (1988). Closer definition of this phenomena can be found in Annex Table 19.

16 In this particular case the modernisation has partly been pre-designed and guided by a set of state financial incentives rather than resulted from a lengthy evolutionary market process. This, at least theoretically, has enabled optimisation of the industrial structure and exploitation of economies of scale in processing. As von Alvensleben (1996) argues, this optimisation and the corresponding high industrial concentration have substantially contributed to the unexpected and undesired bias in the bargaining equilibrium between farmers 
Figure 2.5. Stylised comparison of production techniques in Poland and German New and Old States (G.N.S and G.O.S) using factor space (factor intensity per 1000 tons of milk processed).

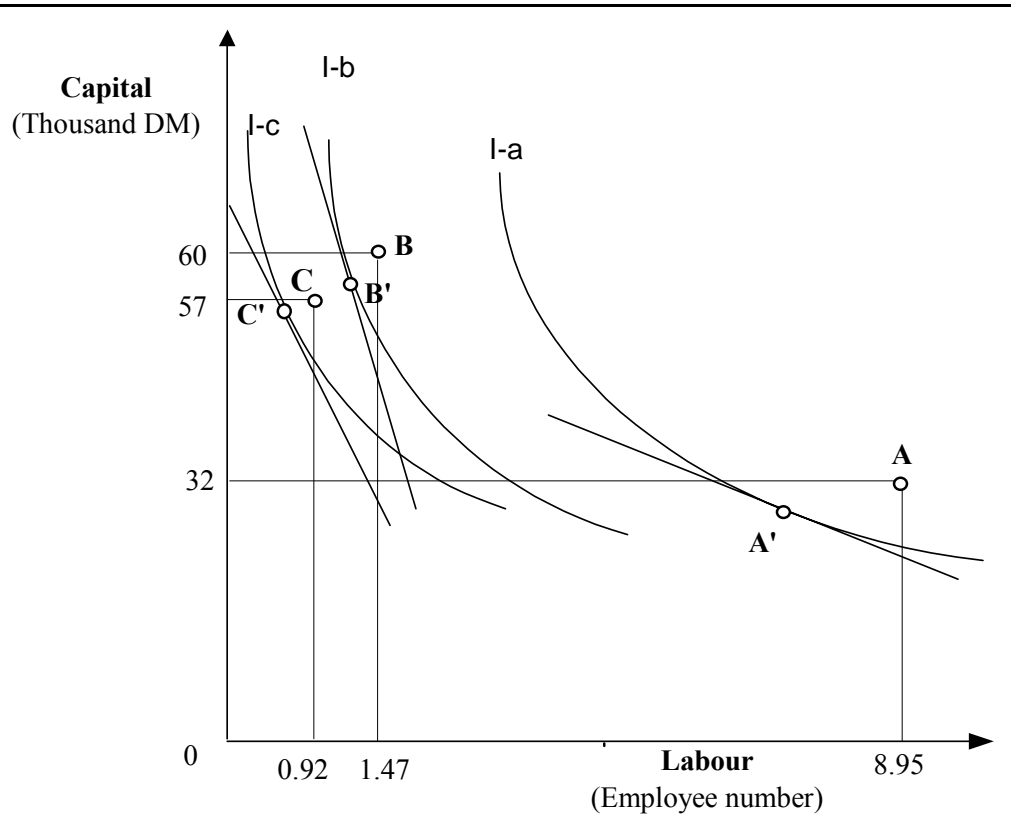

I-a: unit isoquant for current Polish technology;

I-c: unit isoquant for technology in G.N.S.;

I-b: unit isoquant for technology in G.O.S;

B: current factor combination in G.O.S;

A: actual factor combination in Poland;

C: factor combination in G.N.S;

A': factor combination attainable at current technology after removing economic inefficiencies

B': factor combination attainable in G.O.S at current technology after removing economic inefficiencies;

C': factor combination attainable in G.N.S. at current technology after removing economic inefficiencies.

Points A, B and C are estimates. The isoquants and isocost lines, as well as the points A', B' and C', are hypothetical. Drawing separate isoquants for each industry reflects an assumption that they differ not only in terms of relative capital/labour intensities but also in terms of technology advancement (i.e. frontier production functions). Thus the 'distance' between isoquants corresponds to the effect of technological change.

Source: author's compilation based on data from Annex Table 7.

The comparison of Polish milk processing with the German counterpart in terms of capital and labour intensity is demonstrated in Figure 2.5 with the use of factor space. More detailed analysis using statistics on the two industries is provided in Annex Table 7. The following observations can be made:

i. Poland's technology is about ten times more labour intensive than the German one in terms of employee number per unit of farm milk processed. This represents an extremely large margin for future saving in labour costs for the Polish milk processing industry. This labour productivity gap, when confronted with about six-times lower labour costs per employee, results in about $70 \%$ higher labour intensity in Poland when measured in the terms of input expenditure;

and processors on the milk market in the East German states. Mainly due to this additional 'scale effect' in the years 1992-1994 low milk prices in the East German states were observed, whereby the implicit transfers benefited processors with about 1.1 billion DM in addition to about 0.45 billion DM received via 'official' investment grants. 
ii. The capital input measured as a sum of depreciation and interest on the capital funds is about twice as high in the German milk industry, which indicates the differences in the capital/labour mix between the two industries.

This simple comparison suggests that in the Polish milk processing industry there is a substantial scope for applying input saving technology and/or for removing other sources of lower factor productivity. The scope for adjustment also includes the potential for substituting labour for capital in response to possible future changes in relative prices of the two factors.

\subsubsection{Investments and investment policies}

Technological progress in milk processing is closely associated with the new vintages of physical assets (embodied technical change). Therefore intensity of investment can be used as an indicator of the pace of technological change. Investment is defined as a capital formation - the flow of expenditure devoted to increasing or maintaining the real capital stock (Pearce, 1995). In particular, net positive investment i.e. the flow of investment expenditure in excess of the wearing away or depreciation may have several motives associated with the rise in marginal value product of capital. 17

The magnitude and sustainability of productivity gains associated with investments depend not only on the volume of the investment expenditure but also on its allocative efficiency. This efficiency may be affected by several factors related to industrial structure, institutions and industrial policy. Of major importance is the entrepreneurial ability to identify and to assess the investment projects, including the ability to recognise and evaluate the risks and uncertainties of future market conditions. In addition, there are the effects of policy incentives affecting the projections made by potential investors on future profitability and the risks of alternative projects.

\section{Recent investment intensity}

Selected data on recent investment intensity is presented in Table 2.6. Substantial increases in the investment rates were reported between 1995 and 1997: when measured in real value terms, gross investment volume in these three years recovered to the level of that in 1992, and even surpassed it when measured in terms of USD (effect of real appreciation of the Polish zloty - see Chapter 3). This recovery coincides with the operation of the governmental Programme of Restructuring and Modernisation of Dairy Sector (PRMM) in the years 1994-1997. It has been estimated that over that period $24 \%-25 \%$ of total gross and $45 \%$ of net, investment outlays were subsidised. The interest rate

17 This effect may arise from: (i) an increase in industry price index which translates into a shift in the derived demand for all inputs, including capital, (ii) increase in the relative output prices in favour of more capital intensive products in a multi-product industry, (iii) a change in the relative factor prices inducing a change in the optimum input mix in favour of capital, (iv) a change in the relative factor productivity inducing a change in the optimum input mix in favour of capital (e.g. due to a capital-biased technological change embodied in the new equipment). 
subsidies under the Programme accounted for a decrease of about $11 \%-12 \%$ in the value of (periodised) capital costs.

Table 2.6. Selected data on investment in the milk processing industry, 1992-1997.

\begin{tabular}{|c|c|c|c|c|c|c|c|c|}
\hline Characteristic & & Unit & 1992 & 1993 & 1994 & 1995 & 1996 & 1997 \\
\hline Gross investments in current prices & (1) & Mio PLZ & 141 & 84 & 144 & 324 & 366 & 425 \\
\hline Depreciation in current prices & $(2)$ & Mio PLZ & 66 & 83 & 104 & 146 & 181 & 245 \\
\hline Net investment in current prices & (3) & Mio PLZ & 75 & 1 & 40 & 178 & 185 & 180 \\
\hline Gross investment in real prices & (4) & $1992=100$ & 100 & 46 & 61 & 107 & 100 & 101 \\
\hline Gross investment in USD & (5) & $1992=100$ & 100 & 45 & 61 & 129 & 132 & 126 \\
\hline Subsidised credits & (6) & Mio PLZ & 0 & 0 & 26 & 79 & 88 & 107 \\
\hline Share of subs. investment funds & (7) & $\%$ & 0 & 0 & 18 & 24 & 24 & 25 \\
\hline Capital cost decreases due to the subsidies & (8) & $\%$ & 0 & 0 & 9 & 12 & 11 & 12 \\
\hline $\begin{array}{l}\text { (1) and (2) GUS (1998b). } \\
\text { (3) = (1) - (2). } \\
\text { (4) Real investment value calculated by divi } \\
\text { (5) Value in USD calculated with the use of } \\
\text { (6) Domańska (1999). } \\
\text { (7) }=(6) /(1)^{*} 100 \text {. } \\
\text { (8) Decrease in annuity for total investment } \\
\text { estimation presented in the Table } 3.4 \text {. }\end{array}$ & $\begin{array}{l}\text { ling } t l \\
\text { nomir }\end{array}$ & $\begin{array}{l}\text { value in cur } \\
\text { market exch }\end{array}$ & $\begin{array}{l}\text { prices b } \\
\text { e rate. }\end{array}$ & GDP de & idy to tl & credits & nterest & \\
\hline Sources: GUS, (1998b,c,e and 1999c), Dor & & & & & & & & \\
\hline
\end{tabular}

Despite preferential credit policies the attained rates of investment in the industry have been below that of the food industry as a whole (Table 2.7). This result applies, however, only to the dairy co-operatives: other, private enterprises have been investing at a rate similar or even above that for the whole food industry.

Table 2.7. Profitability and investment rates in the milk processing industry (by ownership status) and in the food processing industry, 1994-1998 (in \%).

\begin{tabular}{|lrrrrrr}
\hline \multicolumn{1}{c}{ Indicator } & \multicolumn{1}{c}{ Sector } & 1994 & 1995 & 1996 & 1997 & 1998 \\
\hline \multirow{2}{*}{$\begin{array}{l}\text { Net income share of } \\
\text { revenues }\end{array}$} & Food industry & 0.81 & 1.33 & 1.90 & 1.45 & 0.60 \\
& Milk industry & -0.26 & -0.29 & -0.21 & 0.90 & -0.47 \\
& including: Co-operatives & n.a. & n.a. & -0.62 & 0.16 & -1.44 \\
& \multicolumn{1}{c}{ Other } & n.a. & n.a. & 0.93 & 2.37 & 1.77 \\
\hline Gross investment to & Food industry & 1.56 & 1.94 & 2.02 & 2.21 & 1.87 \\
depreciation & Milk industry total & 1.39 & 2.23 & 1.55 & 1.73 & 1.90 \\
& including: Co-operatives & n.a. & n.a. & 1.16 & 1.63 & 1.44 \\
& $\quad$ Other & n.a. & n.a. & 2.43 & 1.67 & 2.83 \\
\hline Share in total & Co-operatives & n.a. & n.a. & 75 & 70 & 68 \\
net revenues of & Share-holder companies & n.a. & n.a. & 23 & 27 & 28 \\
industry & Other private & n.a. & n.a. & 2 & 4 & 4 \\
& Total & 100 & 100 & 100 & 100 & 100 \\
\hline n.a.- not available. & & & & & & \\
Source: Smoleński (1997) and IERiGŻ (1999) based on GUS data. & & & & \\
\hline
\end{tabular}




\section{Performance differences among firms}

A panel analysis of the industry firms by Smoleński (1998b) and regular monitoring of the profitability of various ownership groups by IERiGŻ (Table 2.7) reveals substantial variation among firms in terms of financial performance. Firms differ in terms of: profitability, and hence the ability to raise own and the access to borrowed investment funds, and the rate of the net investment. Smoleński (1998b) concludes that between 1993 and 1995 in more that half of all firms the replacement investments were much below the physical depreciation. This suggests that a large proportion of firms may not be viable in the long-term and follow a 'survival' rather then a 'development' strategy. From a long-term perspective many of these under-performing firms are in the process of exiting from the industry. In the short term, despite operating with older and less factor-productive technology, they may stay competitive because higher unit costs are compensated for by low expenditure on investments. Transfers, directly or indirectly arising from economic policy, may also sustain their viability.

\section{Program of Restructuring and Modernisation of Dairy Sector (PRMM)}

In 1994, in response to declining production, deteriorating profitability and investment in the dairy sector, a Programme of Restructuring and Modernisation of the Dairy Sector (PRMM) was launched (Domańska, 1994). The Programme was based on an interest rate subsidy to investment credits granted to farm milk producers and processors. Out of an estimated total value of subsidised credits in the period 1994-1997 amounting to 654 million PLZ about 300 million were allocated to milk processing enterprises. Details of the Programme and estimated effects are presented in Annex Table 8. The resulting allocation of the subsidies in terms of the number of beneficiaries and product lines is characterised as follows (see also Annex Table 9):

i. Only $2-3 \%$ of dairy farms delivering milk for processing has directly benefited from the subsidies. The enterprise coverage in the processing industry has been much wider: about 247 out of about 330 enterprises received subsidised credits;

ii. In processing, the allocation of subsidies to different product lines is consistent with the previously evidenced changes in the output structure of the industry: the highest number of projects have been allocated to milk drinks and desserts, fresh cheese production, and ripening cheese production.

Despite the fact that the implementation of the Programme has coincided with an improvement in the sector performance (recovery in farm milk delivery to processing, increase in the investment in processing, fast adjustments in the output structure), several authors cast doubts on the allocative efficiency of the subsidies, pointing at the 'unselective' criteria used (Rzeczpospolita, 17.05.1999), and at the related deficiency as regards the Programme design and monitoring (Kulawik, 1998). In fact, assessment of this policy in terms of its influence on productivity changes has to consider a more 
general dilemma of policy prescription aimed at promoting an industry development, namely, the trade off between: (i) the 'desired' impact of capital cost reduction on the acquisition of new technology, and (ii) the 'undesired' effects of reduction in competitive pressure on incentives to improve efficiency. ${ }^{18}$ On the basis of the material gathered in this chapter, several of the 'undesired' effects arising from the Programme can be hypothesised.

i. The wide coverage of the subsidies in terms of the number of processing enterprises benefited suggests that the 'survival' ability of the marginal, exiting producers has been increased, thus possibly slowing down industrial concentration and restructuring;

ii. The fact that the increased rates of investment in the period 1995-1997 coincided with the implementation of the Programme says little about the actual impact of the scheme on investment intensity during that period, and even less about the competitiveness of the industry in the longterm. First, it is conceivable that the increased number of enterprises operating above long run average costs (probably the exiting firms) has squeezed the profits of other (viable in the longterm) enterprises (by under-utilised capacities, increased market and policy risk), thus probably limiting modernisation investment in viable firms. In this way, subsidised investments in the marginal firms may have displaced a part of private investment in the efficient sub-sector. Second, it is possible that a substantial part of the subsidies to processing enterprises may have been transferred to farm milk producers via higher milk prices. The possibility of such transfers, normally expected in a competitive environment, ${ }^{1}$ is even increased by the domination of farmers co-operatives as the ownership form, 20

iii. There are two kinds of gains associated with economies of scale, which may have been forgone due to the suggested misallocation. First, a direct one, concerns the foregone gains from technical economies of scale offered by the new technologies, although product quality up-grade may have been achieved. Second, a less direct one, is the inhibiting effect on industrial concentration that may affect competitiveness (both at firm and sector level) by restricting the sector bargaining position against foreign competitors (both on domestic and export markets). This aspect gains in importance considering the opening up of the EU markets, where degree of concentration and vertical and horizontal integration (both in milk processing and distribution) is high.

To sum up, the subsidised investments may have brought about factor productivity improvement through technological change, but at the same time they may have diminished incentives for exploiting the scope for productivity gains through eliminating technical and scale inefficiencies.

18 For introduction of the problem see Kalaitzandonakes et al. (1994).

19 Decreased processing costs in a competitive equilibrium shift the derived demand curve, which must increase the price of sector specific non-tradable input (Gardner, 1975, and Tomek and Robinson, 1990).

20 This effect would also contradict the critics (Biegański, 1998) that too small a share of benefits within the scheme has been allocated to farm milk producers. 
Actual lack of capital integration (e.g. mergers or other forms of horizontal integration) among dairy co-operatives during the period of operation of the Programme, despite substantial potential efficiency

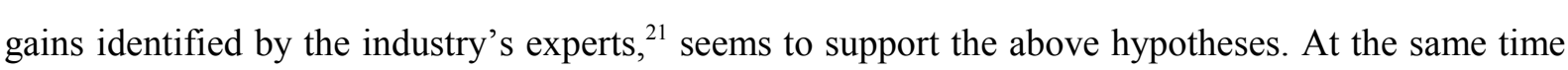
many pitfalls of the Programme have also been recognised by decision-makers, and taken into consideration in designing its new, modified version for future support schemes (Annex Table 8).

\subsubsection{Institutional constraints}

The existing opportunities for technological up-grade and efficiency improvement should be used by the enterprises to maximise profits. It has already been suggested that the pace of the observable restructuring and modernisation differs among firms due to internal and external constraints and incentives, and that such a scope for new profits may not be a sufficient condition for a firm to realise them. One important factor is institutional conditions, and in particular ownership, for that may cause a deviation from the profit maximisation behaviour.

The institutional constraints concern mainly the co-operative firms and have to do with the delayed reform of legislative framework (Nowicki, 1998, Smoleński, 1998a). These constraints refer to the 'subjective' growth factors discussed by Brandes and Odening (1992). The following interrelated issues are involved here:

i. The first one is the capability of the management to identify and carry out the best investment opportunities and to use existing productive resources in an efficient way. The growth of managerial capabilities in the co-operatives is relatively slow because it is based mainly on the learning by doing of existing personnel with limited inflow of new human resources. In such circumstances many opportunities may not be fully exploited, and indeed, the level of managerial skills may constitute a major determinant of a competitive (dis-) advantage of a firm. The existing examples of successful restructuring of dairy co-operatives indicate that this 'human capital' factor is of great significance (see point 11 in Annex Table 6);

ii. The second one is the extent of the principal-agent and asymmetric information problem that may influence decision-making. The former refers to managerial boards of co-ops being able to pursue goals other than profit maximisation of co-operatives. Opportunity for this phenomenon has been enhanced by the legacy of central planning (e.g. distorted ownership attitudes) and sluggish implementation of legal reform on co-operatives (ultimately introduced in 1994). The latter, asymmetric information, stems from the differences among firms and between owners (mainly farmers) and managers, in terms of access to economic and technological information;

iii. The third one are the conflicts of interest between various groups of members. One is the conflict between economically viable and non-viable farm-members, who may have different time

21 For example Smoleński (1997). 
preference with regard to the investable financial surpluses. The high share of small-scale milk producers aggravates the conflict. Only efficient dairy farms, with low-costs production and good development prospects, appear to promote the implementation of rigid quality criteria and are willing to 'scarify' a part of current profits (level of milk price) in order to rise capital necessary to invest in milk processing. Another one is the conflict between farm-members and employeemembers. Employee-members derive most benefits from being employed by the co-operative and hence may block necessary restructuring that is usually associated with labour reduction (see point 10 in Annex Table 6). 


\section{Recent Comparative Advantages}

Between 1993 and 1998 milk processing belonged to the best performing industries in the Polish agro-food sector in terms of the relative export position (Misala, 1997). The purpose here is, among others, to investigate whether this performance actually results from the comparative advantage rather than from incentives provided by policy or other distorting effects. To analyse comparative advantage in the period 1996-1998 domestic resource cost methodology (DRC) is applied. The results are meant to infer efficiency in the industry and to provide for a quantitative model of the industry that can further be used to project 'dynamic' comparative advantages during Poland's integration into the EU.

\subsection{Measures of Comparative Advantage}

Analysis of comparative advantage relies on the concept of opportunity costs. From the national point of view an activity producing internationally tradable goods makes it possible to engage scarce domestic resources (capital, labour, natural resources) to generate value added (revenue net of costs of tradable inputs) that can be used in foreign trade to generate revenues (from exports) or savings (from import substitution). Therefore border prices (equivalents of world-market prices) for tradables (both outputs and inputs) determine the benefit offered by various activities (at given technology), while the costs of domestic resources used represent the opportunity costs for engaging the scarce domestic resources in each activity.

\subsubsection{Domestic Resource Cost ratio}

The domestic resource costs (DRC) compares the opportunity costs of domestic production to the value added at international prices that it generates (Tsakok, 1990). The DRC is the ratio with the numerator comprising total costs of domestic resources measured in shadow (domestic) prices and the denominator equal to the value added measured in international prices. Shadow prices for domestic resources and international prices for tradable outputs and inputs (approximated by border prices adjusted for transport costs) are referred to as the social prices because they represent the opportunity costs and opportunity benefit for the nation of engaging the scarce resources in alternative activities. They may differ from the private prices (financial prices) faced by producers due to the effects of policy distortions and market failures (e.g. monopoly pricing or high transaction costs). The total 
difference between the social and private prices is called here divergence (terminology used by Corden, 1971).

The DRC is calculated as:

$$
D R C_{i}=\frac{\sum_{j=k+1}^{n} a_{i j} V_{j}^{s}}{P_{i}^{s}-\sum_{j=1}^{k} a_{i j} P_{j}^{s}},
$$

where: $a_{i j}, 1$ to $k \quad$ - technical coefficients for traded inputs,

$a_{i j}, k+1$ to $n$ - technical coefficients for domestic resources,

$V_{j}^{s} \quad$ - social (shadow) price for domestic resource,

$P_{i}^{s} \quad$ - social (border) price of traded output,

$P_{j}^{s} \quad$ - border price of traded input.

When the denominator is measured in foreign currency in which international (border prices) are originally reported (USD in this study), the DRC measures the activity-specific exchange rate and the results are interpreted by comparing the DRC value with the official (or other benchmark) exchange rate. An alternative procedure, which is used here, requires converting the border prices in denominator from foreign into the domestic currency, in which case the DRC is the ratio value. Hence the formula 3.1, and the corresponding formulas in this chapter, assumes that border prices are expressed in the domestic currency after applying an appropriate exchange rate. For this purpose one needs to consider whether the observed market exchange rate can be treated as undistorted.

DRC $<1$ indicates comparative advantage - the social opportunity costs in terms of domestic resources used up are smaller that the corresponding social gain in terms of value added generated. The opposite is true for the DRC values exceeding unity. The $\mathrm{DRC}=1$ indicates that the economy neither gains nor loses from employment of resources in an activity.

An alternative representation of the relation between the social costs and benefits is the net economic benefit (NEB) (or net social profit) that can be derived directly from the equation (3.1), namely:

$$
N E B_{i}=P_{i}^{s}-\sum_{j=1}^{k} a_{i j} P_{j}^{s}-\sum_{j=k+1}^{n} a_{i j} V_{j}^{s} .
$$

The net economic benefit represents the social profit per unit of product generated by an activity. Positive NEBs are equivalent to $\mathrm{DRC}<1$, negative $\mathrm{NEB}$ to $\mathrm{DRC}>1$, NEB $=0$ to $\mathrm{DRC}=1$. Unlike the DRC, the NEB is not sensitive to the classification of inputs to tradables or non-tradables. The disadvantage of NEB compared to the DRC, however, lies in that the NEB cannot be used to rank alternative activities.

Another measure of comparative advantage combining some of the advantages of the DRC (a ratio index) and NEB (values independent of input classification to tradables and non-tradables) is the social cost-benefit ratio (SCB) proposed by Maters and Winter-Nelson (1995). As far as the ranking 
of alternative activities is concerned, this ratio is proved to be superior relative to DRC because (unlike DRC) it is free of the bias against the activities intensive in domestic resources. ${ }^{0}$ The SCB is defined as:

$$
S C B_{i}=\frac{\sum_{j=k+1}^{n} a_{i j} V_{j}^{s}+\sum_{j=1}^{k} a_{i j} P_{j}^{s}}{P_{i}^{s}} .
$$

In this study DRC is used as the major measure of comparative advantage. SCBs will also be calculated to check how the ranking of activities is affected by the use of alternative efficiency indicators. NEB is calculated as an implicit component of policy analysis matrices.

\subsubsection{Private Cost Ratio}

The DRC ratio identifies social profitability, in a presence of divergences, policy distortions and market failures in the output and input markets. Hence the social profitability differs from the private one, measured in financial private prices, by the net effect of these divergences. In analogy to the social profitability, private profitability can be detected by a counterpart of the DRC measured in private prices, namely the private cost ratio (PCR) (Monke and Pearson, 1989):

$$
P C R_{i}=\frac{\sum_{j=k+1}^{n} a_{i j} V_{j}^{p}}{P_{i}^{p}-\sum_{j=1}^{k} a_{i j} P_{j}^{p}},
$$

where: $a_{i j}, 1$ to $k \quad$ - technical coefficients for traded inputs,

$a_{i j}, k+1$ to $n$ - technical coefficients for domestic resources,

$V_{j}^{p} \quad$ - private price for domestic factor $j$,

$P_{i}^{p} \quad$ - private price of traded output $i$,

$P_{j}^{p} \quad$ - private price of traded input $j$,

The PCR $<1$ whenever an activity generates positive private profits.

\subsubsection{Interpretation of the DRC results}

Favourable DRC means that at the current input productivity (technology and efficiency) represented by the technical coefficients used in estimation, an activity offers an efficient employment of scarce domestic resources. The exogenous (to the activity) determinants ${ }_{23}$ of this efficiency include: (i) the

22 Consider the following series of three activities only differing in terms of the proportions of domestic resources in total costs:

\begin{tabular}{|c|c|c|c|c|c|}
\hline \multirow{2}{*}{ Social revenues } & \multicolumn{2}{|c|}{ Social costs } & \multirow{2}{*}{ NEB } & \multirow{2}{*}{ SCB } & \multirow{2}{*}{ DRC } \\
\cline { 2 - 3 } & Domestic resource & Tradable inputs & & 0.90 & 0.75 \\
\hline 10.0 & 3.0 & 6.0 & 1.0 & 0.90 & 0.82 \\
\hline 10.0 & 4.5 & 4.5 & 1.0 & 0.90 & 0.86 \\
\hline 10.0 & 6.0 & 3.0 & 1.0 & 0.90 \\
\hline
\end{tabular}

23 This is true under the 'small country' assumption (i.e. changes in the county's export or import volumes have 
shadow prices and exchange rate reflecting the structure of economy and (ii) world prices of tradables reflecting the world market supply-demand conditions. Since the return to domestic resources exceeds the marginal return economy-wide an expansion of the activity up to the level where the DRC would breakeven $(\mathrm{DRC}=1)$ would bring a gain in GDP (interpretable as an improvement in the economy's allocative efficiency).

\section{Average versus marginal DRCs}

This general conclusion is, however, complicated by the average character of the coefficients usually used, which is also the case in this study. Since the industry (or any sample of enterprises) consists of production units differing in terms of technology and efficiency, the desirability of expansion only and always concerns the units for which individual DRC are favourable (DRC $<=1)$, i.e. even in industries with unfavourable average efficiency some firms may have favourable DRCs and in industries with the favourable average values some firms may be inefficient. At the same time, the difficulty in identifying the extent of the desired expansion stems from the simultaneous changes in at least some of the social prices (e.g. for industry-specific non-tradable inputs like farm milk in the milk processing industry). This requires an analysis of DRC at the margin of the industry to spot the breakeven industry size.

Some of these shortcomings can be partly offset by complementing the analysis with descriptive statistics on structural characteristics and on discrepancies among enterprises in terms of economic performance like the data presented in the previous chapter of this study. This provides information about the existing deviation from the considered average and the extent and the nature of the inefficiencies for marginal enterprises. Further discussion, then, will be subject to all the qualification associated with the 'average' character of the technical coefficients used.

\section{Constant technology assumption}

In estimating social costs by accounting only for divergences in prices one makes the assumption that industry would operate at the same technology if the social prices prevailed. In other words, input productivity and input mix are assumed not to be affected by the divergences in prices. Since the information required to account for technology adjustments is virtually not available (technology and efficiency responsiveness, and the substitution elasticities among inputs) in practice the effects are usually ignored ${ }^{24}$ (Valdes and Schaeffer, 1995). Nevertheless, it is possible in certain cases to determine a priori the directions of the underlying biases (Tsakok, 1990).

no influence on the world prices of tradables it faces) and 'small industry' assumption (i.e. changes in the industry's employment of domestic factors have no influence on the factor prices it faces).

24 A recent study of comparative advantages in Poland and Hungary based on combined general equilibrium and partial equilibrium of food market by Banse et al. (1998) have accounted for substitution effects between capital and labour taking an assumption on elasticity of substitution based on literature review. 
For example, enhanced private profits $(\mathrm{PCR}<\mathrm{DRC})$ means that operating under the social prices the entrepreneurs would face higher pressure to improve productivity of inputs. Such adjustment would bring an improvement in the estimates of DRC compared to the values based on the 'observed' coefficients, i.e. in such a case estimates of social profitability tend to understate true social profitability. In analogy, the opposite bias is expected for cases where profits are depressed (PCR $>$ DRC) - social profitability tends to be overestimated. Second, the substitution among inputs is assumed to a have a cost minimising effect at any level of output. For this reason, whenever the coefficients reflect input-mix observed at private prices, neglecting substitution means underestimating the social profitability.

\section{Link between social profitability (DRC) and private profitability (PCR)}

Unfavourable DRC raises the question of what makes the observed activity viable. The first and general answer is suggested by the private profitability demonstrated by the PCR - despite being socially unprofitable the activity may enjoy profitability at financial prices. Private profitability can be seen as a net outcome of the 'level' of comparative (dis-) advantage and the effects of the existing divergences in markets. Hence measures of such divergences must provide for a link between the measures of private and social profitability.

Two indices of distortions in the markets are useful here. First is the nominal protection coefficient (NPC), the ratio of private and social prices measuring a divergence in a single market: for an output or input (it is market specific). Second is the effective protection coefficient (EPC) which measures combined effect of distortions in output and tradable input markets on a given activity (it is activity specific). The effective protection measures the change in the return to the 'value added product', of the domestic resources, resulting from the distortive policies in both product and tradable input markets (Corden, 1971). The NPC and EPC can be presented using the notation from equations (3.1) and (3.4):

$$
\begin{aligned}
& N P C_{i}=\frac{P_{i}^{p}}{P_{i}^{s}} \text { for tradable output } i, \\
& N P C_{j}=\frac{P_{j}^{p}}{P_{j}^{s}} \text { for tradable input } j, \\
& E P C_{i}=\frac{P_{i}^{p}-\sum_{j=1}^{k} a_{i j} P_{j}^{p}}{P_{i}^{s}-\sum_{j=1}^{k} a_{i j} P_{j}^{s}} \text { for activity producing output } i .
\end{aligned}
$$

From equations (3.1), (3.4) and (3.7) the following relationship between the PCR and DRC can be derived: 


$$
P C R_{i}=D R C_{i} * \frac{1}{E P C_{i}} * \frac{\sum_{j=k+1}^{n} a_{i j} V_{j}^{p}}{\sum_{j=k+1}^{n} a_{i j} V_{j}^{s}}
$$

where the last term of the right-hand side of the relation measures the average distortion in the markets for domestic resources (here capital and labour). It can be referred to as a coefficient of distortion in domestic factor costs (DDFC). Like the EPC the DDFC is activity-specific, as it is the function of the price divergence in each factor market and the activity-specific intensities in factor. Hence:

$$
P C R_{i}=D R C_{i} * \frac{1}{E P C_{i}} * D D F C_{i} .
$$

Since private profitability $(\mathrm{PCR}<=1)$ is the necessary condition for an activity to stay viable it follows that:

$$
1 \geq D R C_{i} * \frac{1}{E P C_{i}} * D D F C_{i}
$$

or

$$
\frac{E P C_{i}}{D D F C_{i}} \geq D R C_{i} .
$$

This means that to stay profitable an activity lacking comparative advantage (DRC $>1)$ requires transfers either through tradable output and input markets $(\mathrm{EPC}>1)$ or/and in a form of policy distortions or market failures cheapening (relative to 'shadow' prices) the costs of domestic factors $(\mathrm{DDFC}<1)$. At the same time, in a case of undistorted domestic factor costs 2.5 (DDFC $=1)$ an activity to stay privately profitable must receive effective protection at least equal to the value of the domestic resource cost $(\mathrm{EPC}>=\mathrm{DRC})$.

It seems obvious that unfavourable DRCs suggest two alternative reactions targeted at sustaining economic viability (private profitability). First, an efficient one consists of improving factor productivity (decreasing DRC), by eliminating inefficiencies or adopting new technologies. Second, an inefficient one, is to try to influence the price-determination in output and input markets by political lobbying or imperfect competition practices (increasing EPC or decreasing DDFC).

Equation (3.9) presents the effects of divergences using EPC and DDFC, which aggregate effects in various markets faced by producers. These effects can, however, be presented in a desegregated form using the policy analysis matrix (see section 3.1.5). In this study four groups of inputs are separated in the PAMs: tradables, capital, labour and farm milk. Moreover, in output markets, total

25 Or distortions that balance out. 
divergence is disentangled into direct policy effect (trade policy) and the remaining, unexplained effects (structural and market failure).

\section{A comment on the tradition of DRC analysis}

Traditionally the DRC has been used as an ex-ante measure of project evaluation under conditions of distorted exchange rate and distorted prices (Bruno, 1972), and in an ex-post context as a measure of the costs of maintaining unprofitable activities through trade protection (Krueger, 1972). In some studies it has been used to simulate dynamic comparative advantage during periods of policy liberalisation and regional integration (Pearson et al., 1987 for Portugal, Münch et al., 1997 for Poland). In most uses the DRC serves to rank activities in terms of the comparative advantage for policy-making purposes (Monke and Pearson, 1989).

\subsubsection{Alternative definitions of value added}

Calculation of DRC requires breakdown of costs into domestic resources (alternatively referred to as primary factors: capital, labour, land) and tradable inputs. However, both domestic resources and tradable inputs can be used directly in the considered activity or in and indirect way with the nontraded intermediary inputs (Figure 3.1).

Figure 3.1: Breakdown of costs and alternative definitions of the DRC used in the analysis.

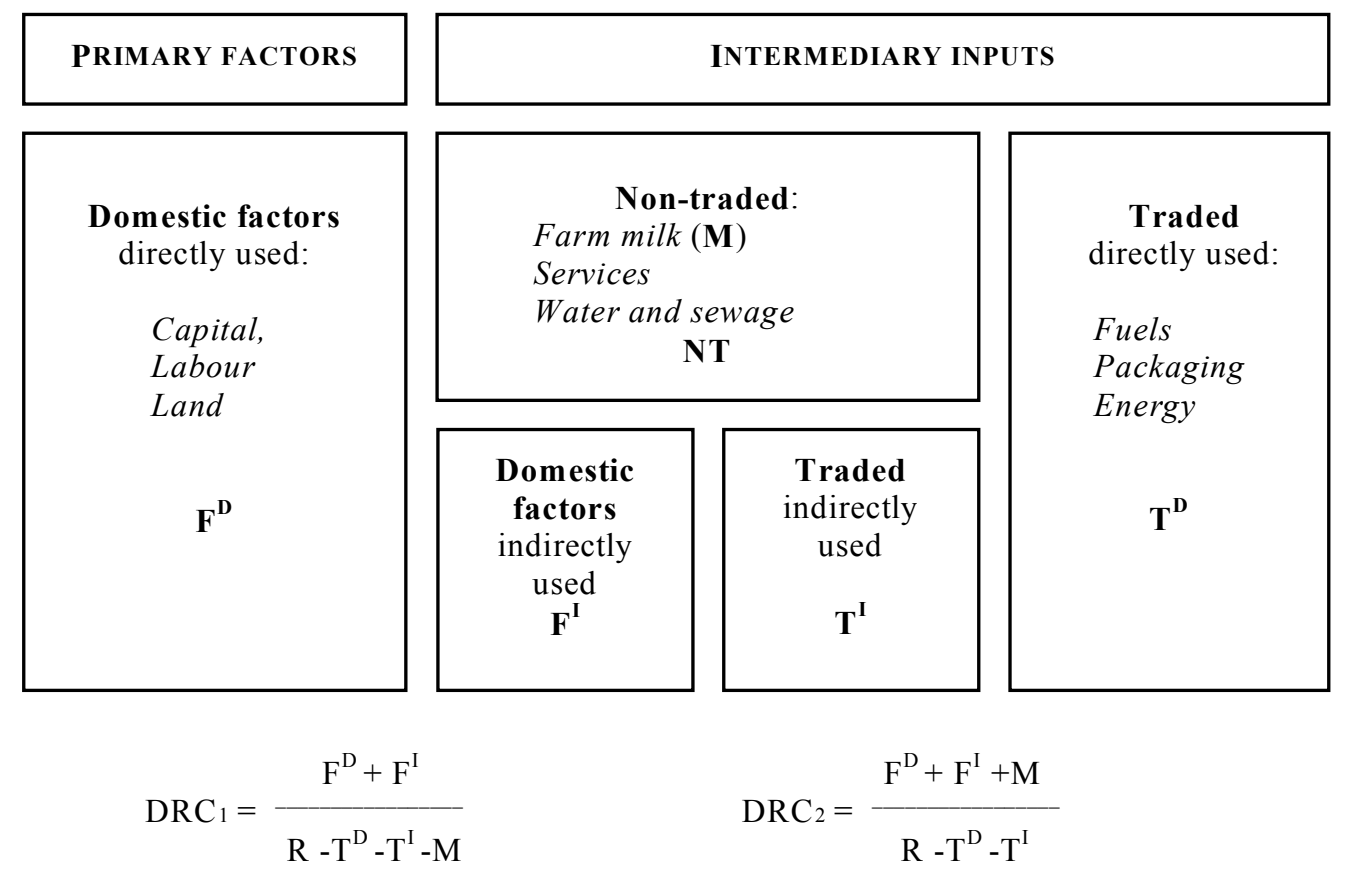

In the DRC definitions R denotes revenue. As in equation 3.1 revenue and costs are valued in social prices. Source: author's compilation based on Tsakok (1990). 
Thus the components of DRC, both numerator and denominator, may vary depending on the definition of value added. In particular, different treatment of non-tradable inputs and the classification of the indirect domestic factors lead to various definitions of activity under consideration (Tower, 1992). Three general cases can be distinguished.

In the so called sophisticated Corden method of estimating the value added, the costs of nontradable intermediary inputs (NT) are decomposed into their tradable elements, i.e. indirect tradable inputs $\left(\mathrm{T}^{\mathrm{I}}\right)$, and domestic resources, i.e. indirect domestic factors $\left(\mathrm{F}^{\mathrm{I}}\right)$ (Tsakok, 1990). In such a case the numerator of DRC involves costs of both direct $\left(\mathrm{F}^{\mathrm{D}}\right)$ and indirect $\left(\mathrm{F}^{\mathrm{I}}\right)$ domestic factors, while both costs of the directly $\left(\mathrm{T}^{\mathrm{D}}\right)$ and indirectly $\left(\mathrm{T}^{\mathrm{I}}\right)$ tradable inputs are in the denominator, and are subtracted from revenues to calculate the international value added. This approach implies that an integrated industry is considered, composed of the one that uses direct resources (e.g. milk processing) and the one producing non-tradable intermediary input (e.g. production of transport and other services, and farm milk). In such a case the DRC represents cost-benefit ratio of using the domestic resources in both industries to transform tradable inputs used in both industries into the final output (e.g. capital and labour used in milk processing, providers of services and agriculture to convert grain, fuel, electricity, packaging materials (and other tradable inputs) in all these activities into processed dairy products.

In the simple Corden method the entire costs of non-tradable inputs (NT) are treated as a part of the value added and enter the nominator of DRC together with the direct domestic factors $\left(\mathrm{F}^{\mathrm{D}}\right)$; the desegregation of non-tradable input costs is thus avoided. The DRC is the cost benefit ratio of using direct domestic resources and non-tradable inputs to convert direct tradable inputs into the final output (e.g. using capital and labour, and farm milk to convert fuel, electricity, packaging and other direct tradables into processed dairy products).

In the simple Balassa method only directly used domestic factors $\left(\mathrm{F}^{\mathrm{D}}\right)$ enter the value added and the numerator of DRC, while the entire costs of non-tradable inputs (NT) are treated in the same way as the direct tradable inputs $\left(\mathrm{T}^{\mathrm{D}}\right)$ - they are subtracted from the value of output in the denominator. In this case the DRC represents a cost-benefit ratio for using direct primary resources to convert tradable inputs and non-tradable inputs into the final output (e.g. using capital and labour in milk processing to convert fuel, electricity, packaging, services and farm milk into the processed dairy products).

As far as this study is concerned, the following approach to the value added estimation has been chosen: costs of all non-tradable inputs except for farm milk have been decomposed into their tradable elements and domestic factors. The resulting indirect domestic factors have been included into the value added (as in the sophisticated Corden method). It is important that the considered categories of

26 Balassa and Schydlowsky (1972) refer to the DRC calculated according to the sophisticated Corden method of value added estimation as 'total' DRC and to the DRC calculated according to the simple Balassa method of the value added estimation as 'direct' DRC. 
the non-tradable inputs involve mainly the services that are almost inherent elements of the milk processing industry (milk transport services, water and sewage, distribution) which makes it reasonable to treat these 'upstream' activities in an integrated way with the 'core' elements of the milk processing activity.

Farm milk, in turn, has been treated in two alternative ways (Figure 3.1):

i. In the first approach milk has been treated as a tradable input - it has been excluded from the value added. The resulting DRC (thereafter referred to as the $\mathrm{DRC}_{1}$ ) gives the cost-benefit ratio for domestic resources directly used in the milk processing industry and indirect domestic resources used in the closely integrated activities producing non-tradable inputs (services) to the milk processing industry, to convert directly and indirectly used tradable inputs and farm milk into processed dairy products. The major rationale underlying this approach is that the focus of the study is on the efficiency of resources used in milk processing - desegregating the costs of farm milk production and calculation of DRC for the integrated farm-processing activity would prevent a conclusion on relative contributions of efficiency in each activity. Thus, the appropriate procedure is to exclude costs of milk from the value added (simple Balassa method). 27

ii. In the second approach milk costs have been included in the value added (simple Corden method). The resulting DRC (thereafter referred to as the $\mathrm{DRC}_{2}$ ) measures the cost-benefit of using domestic resources and farm milk to transfer the tradable inputs into dairy products. The results of this approach must approximate the results from the sophisticated Corden method (not applied here for farm milk) considering that in 1997, in Poland, domestic factors (land, labour, capital) constituted about $80-85 \%$ of total milk production costs and that the engaged domestic factors are to a great extend specific to milk production, 29 i.e. the social cost of farm milk represent mainly the payments to the domestic factors.

\subsubsection{The Policy Analysis Matrix}

Calculation of DRC and protection indices requires extensive data set including private and social prices, and input-output coefficients for analysed activities. The policy analysis matrix (PAM) - the framework for organisation and presentation of intermediate results for estimating these DRC and other policy indices has been proposed by Monke and Pearson (1989). The PAM is a product of two

27 The similarities between farm milk and tradable inputs also include the way in which their social prices are estimated in this study: social price of farm milk has been derived from the prices of SMP and butter, two tradable substitutes of milk (see later sections).

28 Own estimates based on Skarżyńska and Sadowska (1997).

29 This stems from the structural characteristics of milk farming in Poland where, at least in the medium term, labour and capital used in milk production have very limited alternative uses. This is mainly because of labour intensive technology and rural over-employment. Also capital assets used in the animal production are increasingly specialised. 
accounting identities, one defining profitability as the difference between revenues and costs and the other measuring the effects of divergences (distorting policies and market failures) as the difference between observed parameters (private values) and parameters that would exist if the divergences were removed (social values) (Table 3.1). The PAM will be used here as an auxiliary tool in the DRC analysis.

Table 3.1. The Policy Analysis Matrix.

\begin{tabular}{|ccccc|}
\hline & Revenue & \multicolumn{2}{c}{ Costs } & Profits \\
\cline { 3 - 4 } & & Tradable inputs & Domestic factors & \\
\hline $\begin{array}{c}\text { Accounting in Private } \\
\text { (Financial) Prices }\end{array}$ & $\boldsymbol{A}=P_{i}^{P}$ & $\boldsymbol{B}=\sum_{j=1}^{k} a_{i j} P_{j}^{p}$ & $\boldsymbol{C}=\sum_{j=k+1}^{n} a_{i j} V_{j}^{p}$ & $\boldsymbol{D}=\boldsymbol{A}-\boldsymbol{B}-\boldsymbol{C}$ \\
$\begin{array}{c}\text { Accounting in Social } \\
\text { (Economic) Prices }\end{array}$ & $\boldsymbol{E}=P_{i}^{s}$ & $\boldsymbol{F}=\sum_{j=1}^{k} a_{i j} P_{j}^{s}$ & $G=\sum_{j=k+1}^{n} a_{i j} V_{j}^{s}$ & $\boldsymbol{H}=\boldsymbol{E}-\boldsymbol{F}-\boldsymbol{G}$ \\
$\begin{array}{c}\text { Effects of Policy and } \\
\text { Market Failures }\end{array}$ & $\boldsymbol{I}=\boldsymbol{A}-\boldsymbol{E}$ & $\boldsymbol{J}=\boldsymbol{B}-\boldsymbol{F}$ & $\boldsymbol{K}=\boldsymbol{C}-\boldsymbol{G}$ & $\begin{array}{c}\boldsymbol{L}=\boldsymbol{D}-\boldsymbol{H}= \\
=\boldsymbol{I}-\boldsymbol{J}-\boldsymbol{K}\end{array}$ \\
\hline
\end{tabular}

Source: Monke and Pearson (1989).

Description of PAM: $a_{i j}, P_{i}^{p}, P_{i}^{s}, P_{j}^{p}, P_{j}^{s}, V_{j}^{p}, V_{j}^{s}, i$ and $j$ as in the equations 3.1 and 3.4.

Measures of Transfers: output transfers - $\quad$ I input transfers - $\quad \mathrm{J}$, factor transfers - $\quad \mathrm{K}$, net transfers - L.

Measures of Social (Economic) Profitability:

Net Economic Profits - $\quad$ H=E-F-G,

Domestic Resources Cost - DRC $=\mathrm{G} /(\mathrm{E}-\mathrm{F})$,

Social Cost Benefit ratio - $\mathrm{SCB}=(\mathrm{F}+\mathrm{G}) / \mathrm{E}$,

Correspondence among these indices: $\mathrm{H}>0 \Rightarrow \mathrm{DRC}<1 \Rightarrow \mathrm{SCB}<1$.

Measures of Private (Financial) Profitability:

Net Private Profits - $\quad$ D = A-B-C,

Private Cost Ratio - $\quad \mathrm{PCR}=\mathrm{C} /(\mathrm{A}-\mathrm{B})$,

Private Cost Benefit ratio - $\mathrm{PCB}=(\mathrm{B}+\mathrm{C}) / \mathrm{A}$,

Correspondence among these indices - $\mathrm{D}>0=\mathrm{PCR}<1=\mathrm{PCB}<1$.

Measures of Protection:

Nominal Protection Coefficient (for tradable outputs) $-\mathrm{NPCo}=\mathrm{A} / \mathrm{B}$,

Nominal Protection Coefficient (for tradable inputs) - NPCi $=\mathrm{B} / \mathrm{F}$,

Coefficient of Distortion in Domestic Factor Cost - $\quad$ DDFC $=\mathrm{C} / \mathrm{G}$,

Effective Protection Coefficient - $\quad \mathrm{EPC}=(\mathrm{A}-\mathrm{B}) /(\mathrm{E}-\mathrm{F})$.

\subsection{Empirical Steps in Estimating the DRC}

The empirical steps in estimating DRCs and the associated policy effects include the following:

i. Defining activities to be analysed and time period to be covered;

ii. Estimating input-output coefficients for these activities;

iii. Social valuation of revenues and costs; 
iv. Organising the data using the PAM framework and calculating the DRC and the corresponding indices of policy effects.

\subsubsection{Selecting activities and the time period}

To take account of wide range of the product-specific characteristics of milk processing technology and the dairy market, and to make the analysis manageable, five product-specific activities have been selected for the analysis. These involve production of: SMP, butter, ripening cheese, yoghurt and milk processing. The last one is a multi-product activity, defined as an average of the twelve 'major' dairy product categories and an additional thirteenth activity representing the production of wholesale and retail services by the industry (referred to as the 'margin from trade'). The weights correspond to their shares in the industry's revenues and costs (Table 3.2).

Table 3.2: Product share in the industry revenues, and share of farm milk in total cost, 1997.

\begin{tabular}{|c|c|c|c|c|}
\hline \multirow{2}{*}{ Product category } & \multirow{2}{*}{$\frac{\text { 'Representative' product }}{\text { CN code }}$} & \multicolumn{3}{|c|}{ Industry shares in percentage } \\
\hline & & Revenue & Farm milk costs & Other costs \\
\hline 1. Consumption milk & 0401209 & 13.3 & 14.7 & 11.6 \\
\hline 2. Condensed milk and wey & 0402911 & 0.6 & 0.6 & 0.5 \\
\hline 3. Whole milk powder & 040221199 & 4.8 & 5.3 & 4.1 \\
\hline 4. Skimmed milk powder & 040210190 & 7.4 & 9.7 & 4.8 \\
\hline 5. Ripening cheese & 040690780 & 15.6 & 18.8 & 11.9 \\
\hline 6. Non-ripening cheese & 040610200 & 12.8 & 15.9 & 9.2 \\
\hline 7. Processed cheeses & 040630390 & 4.2 & 4.9 & 3.4 \\
\hline 8. Ice-creams & 210500 & 9.6 & 2.5 & 17.8 \\
\hline 9. Creams & 0401303 & 7.8 & 5.1 & 10.9 \\
\hline 10. Butter & 040510190 & 11.9 & 18.3 & 4.4 \\
\hline 11. Yoghurts and kefirs & 040310930 & 8.3 & 3.9 & 13.5 \\
\hline 12. Casein & 350110 & 0.2 & 0.3 & 0.0 \\
\hline 13. Margin from trade & & 3.6 & 0.0 & 7.8 \\
\hline Total & & 100.0 & 100.0 & 100.0 \\
\hline
\end{tabular}

Since the considered twelve product categories are characterised by various degree of heterogeneity, in each case one homogenous product has been identified to represent the entire category. The major criterion used was the share of this 'representative' product in the output/trade within each category. The $\mathrm{CN}$ code definitions have been used, which enabled direct comparability of the prices and other data derived from trade statistics.

The four product-specific activities (SMP, butter, ripening cheese and yoghurt) have been selected so as to take account of: (i) various technological properties (e.g. intensity in farm milk and, respectively, the 'degree' of processing), (ii) significance in terms of the share in the industry's output and trade (these four products account for about a half of the farm milk use), (iii) recent trends in 
production and investments (output of SMP and butter has showed a declining tendency, while the output of ripening cheese and yoghurt a rising tendency).

\subsubsection{Estimating input-output coefficients}

The input-output coefficients have been estimated for the year 1997 for which the most complete data was available at the time of the analysis. The major challenge in this estimation is that costs allocation among various outputs is usually not practised and is difficult to arrive at, even at the enterprise level. This is mainly because of the joint nature of the majority of costs in a typical multi-product dairy factory. Another problem is that only for some items are volumes/quantities of inputs directly observable, while in most cases aggregate expenditure on more or less aggregated input categories are available. Here the estimation is made by combining several kinds of data, including: market statistics, accounting data, engineering/experimental data, studies of enterprise-samples and other kinds of information, most taken from the existing literature.

The estimation relies on the following industry-level data: (i) industry-aggregated accounting data (revenues and expenditures on major input categories), (ii) quantities for various outputs, (iii) quantity of farm milk (for industry-level only), (iv) quantities of several other inputs (number of employees, fuels, electricity, water and sewage), (v) stock of capital in the industry (buildings, machinery, vehicles) and (vi) relative product profitability reported for various enterprise samples. In general, the allocation of costs and inputs to commodity-specific activities has been achieved on the basis of additional information. Most important are engineering-type experimental data. Others include results of various sample analyses of Polish milk processing enterprises from the years 1994-1998.

The data sources and estimates of input-output models are presented in the Annex Tables 10, 11, and 12. Major elements of the estimation procedure are as follows:

i. Product specific revenues. These have been estimated using the product quantity data and price data. Industry output has been presented as the aggregate product composed of 12 different dairy product categories plus the 'margin from trade'. The sum of product-specific revenues has been checked for consistency with the aggregate revenues from the accounting data;

ii. Farm milk costs. Technical coefficients for fat and non-fat components of farm milk have been taken from the textbooks on milk processing technology. Prices of these two milk components are not directly observable and have been derived from: (i) actual prices of farm milk, butter and SMP, (ii) technical coefficients for fat and non-fat in farm milk, butter and SMP and (iii) processing costs (precisely: price margins for butter and SMP);

iii. Product specific private profit margins. These are based on profitability data of various product lines reported in several studies on various enterprise samples between 1994 and 1998. Subtraction of the farm milk cost and private profit margin from the revenue yields the total 
processing costs specific to the product (and the sum of these yields processing costs specific to the entire industry);

iv. Milk assembly costs. The total processing costs of the industry have been split into farm milk assembly costs (collection, transportation and initial handling of farm milk) and costs of 'actual' processing, using the sample data. This separation of assembly costs is only aimed at helping in the allocation of costs to outputs. First, structure of assembly costs is fairly homogenous (among enterprises) and the components of assembly costs can be allocated to products proportionally to the intensities in farm milk. Second, the residual i.e. the remaining costs represent the part of processing costs, which could be allocated to product-specific lines according to the relative intensities taken from engineering studies;

v. Capital cost. Capital costs for the industry level have been derived from the capital asset values and cost of financial capital (interest rate). Capital input reflects the value of depreciation and interest paid (or foregone) on financial capital engaged, and has been calculated with the use of the annuity method (annual replacement cost);

vi. Product-specific input intensities. The industry-level values for inputs used in the product specific part of processing have been allocated to products according to the relative intensities resulting from engineering simulations and sample data. These data correspond to the structures

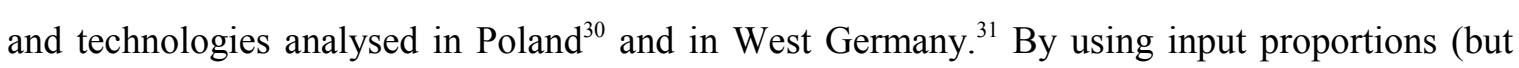
not intensities) from technologies introduced in Germany in late seventies one assumes that they correspond well to technological and structural advancement in Poland in 1997. This assumption is considered to be justified by the technological lag discussed in Chapted 2;

vii. Disaggregating nontradable inputs. To disaggregate non-tradable inputs an approximate approach has been used following the recommendation of Monke and Pearson (1989). In specific cases the authors prescribe the use of the rule of thumb, namely, that separate budgeting of nontradable elements can be avoided (without significant consequences for results) unless the nontradable input represents more than $5 \%$ of total production costs. Here, in the case of services, it is assumed that (indirect) capital, labour and tradables, each contribute one third of the entire costs of a non-tradable. In the case of water and sewage costs, fifty percent of costs have been attributed to capital input and the remaining to the tradable input category;

viii. Expressing technical coefficients. The revenues and costs that in the previous stages of calculations reflect absolute magnitudes for the entire industry have been expressed per unit of output (ton or thousand tons) - for product specific activities, or per unit of farm milk processed

30 Based on data and information from: Budny, et al. (1986); Gornowicz, (1983); Stachowski, et al., (1995); Gornowicz et al., (1999); Gornowicz and Stachowski (1990); Gornowicz (1996); Wojdalski et al. (1998).

31 Based on data and information from: Brehm and Krell, (1975); Brehm and Krell (1976); Behme and Wietbrauk (1975); Longuet and Wietbrauk (1975); Behme (1975a,b); Krell and Wieterbrauk (1993a). 
(ton or thousand tons) - in the case of industry-level activity. Input-output coefficients (quantities of factor/input used per unit of output) have been expressed either in the specific input units (e.g. units of fat and non-fat components, $\mathrm{kWh}$ of electricity, $\mathrm{kg}$ of fuel, coal, $\mathrm{m}^{3}$ of natural gas, $\mathrm{m}^{3}$ of water and sewage, number of employees), or in token units - in the case of entries representing aggregated or uncountable items (services, capital, other costs, other materials).

\subsubsection{Principles of social valuation}

The major empirical task in estimating the DRC is to find the 'social' counterparts of the observed private revenues and costs i.e. to fill in the second row of the PAM. The methodology of social valuation differs among the tradables and domestic factors. It is relatively straightforward in the case of tradable components (both outputs and inputs) because observable border prices can be readily used as a benchmark. Less direct is the estimation of social values for domestic factors mainly because these are represented by unobservable shadow values.

Given sufficient information (and research resources) shadow prices for domestic factors can be calculated and simulated from a computable general equilibrium model. In many empirical analyses, less direct approach is being applied - social prices for factors are estimated instead as residuals between observed market prices and direct effects of polices (Monke and Pearson, 1989). The indirect effects of policies on factor markets can be considered only qualitatively. As a result, profitability analysis is often accompanied by the sensitivity analysis to the changes in the factor price estimates (Monke and Pearson, 1989). This simplified approach to social valuation of domestic resources has been applied in this study.

Social valuation of the quantifiable and homogenous items (most tradables) proceeds by applying social prices to quantities (or technical coefficients). In other cases, i.e. for items which are not quantifiable (i.e. where token units are used) social valuation proceeds by applying a conversion factor, a number which transforms expenditure (costs) in private (financial) prices into their equivalent values at social prices.

\subsubsection{Exchange rate}

Two questions concerning the exchange rate are relevant in this study. In this chapter the question is asked whether exchange rate observed in the recent past, including the year for which the DRC analysis is made, has diverged from its social level. In the next chapter, devoted to the future developments, long-run pattern of the exchange rate in Poland will be closer investigated. Measures used in the analysis of exchange rate are defined in the Box 2. 


\section{BOX 2. Defining Measures of Exchange Rate}

\section{Nominal and real exchange rate}

The nominal exchange rate (NER) is an undeflated conversion factor between one currency and another. Changes in the nominal exchange rate may merely reflect an inflationary trend, which possibly is neutral to the economy's relative prices. An observed nominal exchange rate is socially optimal if it equals the nominal equilibrium exchange rate (NEER). To infer about possible divergence between the two it is useful to consider the real exchange rate (RER), one of the fundamental measures of relative prices in the economy defined as the ratio of the price of tradables to non-tradables:

$\mathrm{RER}=\mathrm{P}_{\mathrm{T}} / \mathrm{P}_{\mathrm{NT}}$

in which $\mathrm{P}_{\mathrm{T}}$ is the price of tradables and $\mathrm{P}_{\mathrm{NT}}$ is the price of non-tradables.

Changes in the RER (and hence the NER) can reflect changes in: (i) the equilibrium real exchange rate (ERER), mostly driven by the factors exogenous to the policy, or (ii) distorting effects including policy-induced ones. The equilibrium real exchange rate is defined as the value of RER at which the economy is accumulating or decumulating foreign assets at the desired rate, and at which the demand for domestic goods (non-tradables) equals supply (Edwards, 1989). According to the alternative formulation of this definition the exchange rate is in equilibrium level when the economy is simultaneously in internal (domestic output, employment and inflation) and external (current and capital account) equilibrium (Halpern and Wyplosz, 1996).

The ERER is driven by macroeconomic fundamentals like productivity changes and technological progress, and such external factors as international prices, international transfers and world interest rates. Domestic policies causing a divergence between the RER and the ERER include: trade policy, exchange and capital controls, other taxes and subsidies as well as the size and composition of government expenditures (Edwards, 1989).

An appreciation of the RER, either due to the appreciation of the ERER or due to a divergence from its (shadow) ERER (and the corresponding shifts in the NER and NEER), is indicative of a decline in the international value added in the tradable activities denominated in the domestic currency (denominator of the DRC), losses in their competitiveness and the pressure to productivity improvement. If the appreciation of the RER is due to a divergence from the ERER it can be interpreted as a tax on tradable sector. In turn, an appreciation caused by a change in the ERER reflects changes in the economy's structure with consequences for the structure of comparative advantages.

\section{Inter-temporal measures of real exchange rate}

Due to the complex nature of the exchange rate determination in empirical estimations are used various 'imperfect' indicators of real exchange rate. To measure inter-temporal changes in the RER the following indices are typically used:

$\operatorname{RER}(1)=\mathrm{P}_{\mathrm{T}} / \mathrm{P}_{\mathrm{TN}}$,

where $\mathrm{P}_{\mathrm{T}}$ is the price index of tradable sectors, while the $\mathrm{P}_{\mathrm{NT}}$ is a price index of domestic non-tradable sector (e.g. Halpern and Wyplosz, 1996).

$\operatorname{RER}(2)=N E R * P_{T}{ }^{\prime} / P_{D}$,

where NER is the index of NER (number of domestic currencies per unit of foreign currencies), $\mathrm{P}_{\mathrm{T}}$ ' is foreign price index for tradables (for example foreign producer price index - PPI) while $\mathrm{P}_{\mathrm{D}}$ is the domestic price index presumably heavily weighted against the home goods sector (as with the CPI or GDP price index) (e.g. Shiff and Valdes, 1998).

$\operatorname{RER}(3)=\mathrm{NER} / \mathrm{PPP}=1 / \mathrm{PL}=\mathrm{ERDI}$,

where PPP is the purchasing power parity (number of units of domestic currency required to buy the same amount of goods and services in the domestic market as 1USD, or other reference currency, would buy in the United States, or other reference country), while NER is the corresponding nominal exchange rate. RER(3) is a reciprocal of Domestic Price Level (PL) (Kravis and Lipsey, 1988), also called a Comparative Price Level (e.g. OECD, 1999). In the literature on international price comparisons this reciprocal is also referred to as Exchange Rate Deviation Index (ERDI) (e.g. Vitrova, 1997). The PPP used in the inter-temporal context indicates at the convergence of the domestic prices on the price level in the reference country.

\section{Effective real exchange rate}

Real exchange rate can be calculated against one foreign currency or many currencies. An effective real exchange rate (EFRER) refers to the average of the rates between the home currency and more than one foreign currency, weights usually being chosen according to the importance of countries in trade (Dutton and Grenees, 1987). 
Trade weights (shares of bilateral trade in total country trade) for various commodity aggregates, ranging from entire trade to single good/sectors can be used. Moreover export or import weights can be applied. In this way sectoral as well as export- or import-specific EFRER can be calculated.

Source: author's compilation based on the sources quoted in the text.

\section{Real exchange rates of PLZ against the USD and the DM}

The defined indices have been used to present development of RER in Poland since the beginning of economic transition in 1989 (Figure 3.2). The 1988 has been chosen for the base year and the USD and the DM have been taken as the major reference currencies ${ }_{22}$. For the purpose of this study two conclusions of Halpern and Wyplosz (1996) are of importance. First, the strong real appreciation observed in Poland since 1990 corresponds to a continuing appreciation of real equilibrium exchange rate. This development can be viewed as the outcome of successful economic transformation, since it is driven by rapid gains in efficiency once markets drive prices and allocation of resources. Second, the equilibrium real exchange rate cannot be known with precision.

Figure 3.2. Real exchange rates in Poland, United States and Germany, alternative measures, 19891998.

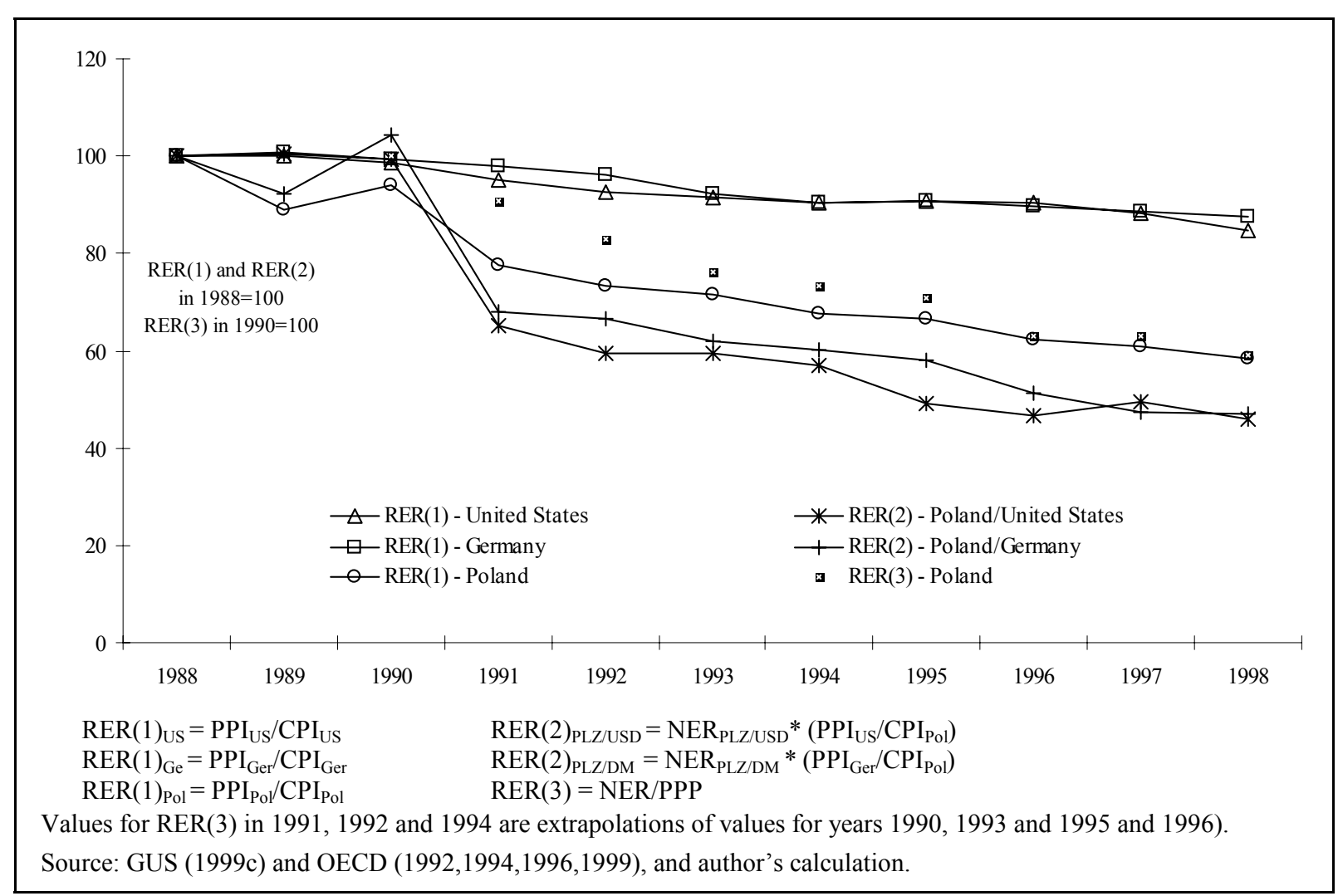

32 NER values for 1998 and 1999 are represented by the estimates of the shadow NER by OECD (1995b) for the purpose of retrospective PSE calculation. These are close to the official rather than to the black market nominal exchange rates. 
The assumption taken in this study that the observed (nominal) exchange rate in the years 19961998 approximate to the equilibrium values can be supported by the following further points:

i. The considered period (1996-1998) has been characterised by high rates of economic growth, a stable unemployment level (mostly structural unemployment) and declining inflation, which suggest that the economy has converged on its internal balance. The external balance has been achieved, since the current account deficits have been compensated by the foreign capital inflows, whose volumes and forms (mostly FDI in privatised enterprises) can be assessed as 'desired';

ii. Proceeding liberalisation of exchange rate policy. After a short time of fixed exchange rate targeted at curbing inflation (January 1990-May 1991) Poland has operated a crawling peg regime with a relatively wide band of movements and a limited number of interventions. 3.3 In June 1999 the crawling peg, and in January 2000 the band, were abandoned and the free exchange rate market has been implemented;

iii. Effects of other policies can be neglected because their net outcome for the real exchange rate is rather ambiguous. For example, the tendency for the wage increases above their social (shadow) level may have increased relative costs (and hence prices) in the non-tradable sector (appreciating effect on RER). In turn, the import protection in tradables sectors, which are characterised by relatively low price elasticity, have had an opposite effect on prices of non-tradables and the relative prices (tradables to non-tradables).

\section{Effective real exchange rates}

Although the USD and the DM are good reference currencies for the majority of Polish exports and imports, however, in the agro-food and dairy industry the geographical patterns of trade were characterised by the relatively high importance of other currencies. To gain insight into the sector specific effects of exchange rate changes during the period 1993-1998 the effective real exchange rates have been calculated for 3 commodity groups (total Polish trade, agro-food trade and dairy trade) using 1997 export and import weights of five distinct trade-partner countries (Russia, the Ukraine, Germany, other EU countries, other countries) and 4 corresponding currencies (the Russian rubel (RUR), the Ukraine hrywna (Hrn), the German mark (DM), the U.S. dollar (USD)) (Figure 3.3 and Annex Table 13). The first important result is that, contrary to the RER changes relative to the

33 Until 1998 the value of the złoty was linked to a basket of western currencies, whose weights in the basket reflected their relative importance in Poland's foreign trading transactions; the basket was made up of the USD (45\%), the DM (35\%), the British Pound (10\%), the Swiss franc $(5 \%)$ and the French franc $(5 \%)$. The monthly crawl was reduced from $1.5 \%$ in 1993 down to $0.5 \%$ in 1988 . The band for allowed fluctuation was widened from $+/-7 \%$ in 1995 , to $+/-10 \%$ in 1998 and $+/-15 \%$ in 1999 . Since 1996 the National Bank of Poland (NBP) has targeted the external balance (money reserve), by allowing for free exchange rate movements (within the band) and flexible interest rate policy.

34 For the group of 'other EU countries' the DM and for 'other countries' the USD have been used. 
western currencies, the Polish złoty has strongly depreciated against the currencies of the two major trade partners from the FSU: the Russian rubel and the Ukraine hrywna.

Figure 3.3. Effective real exchange rates estimated with alternative trade weights, 1993-1998.

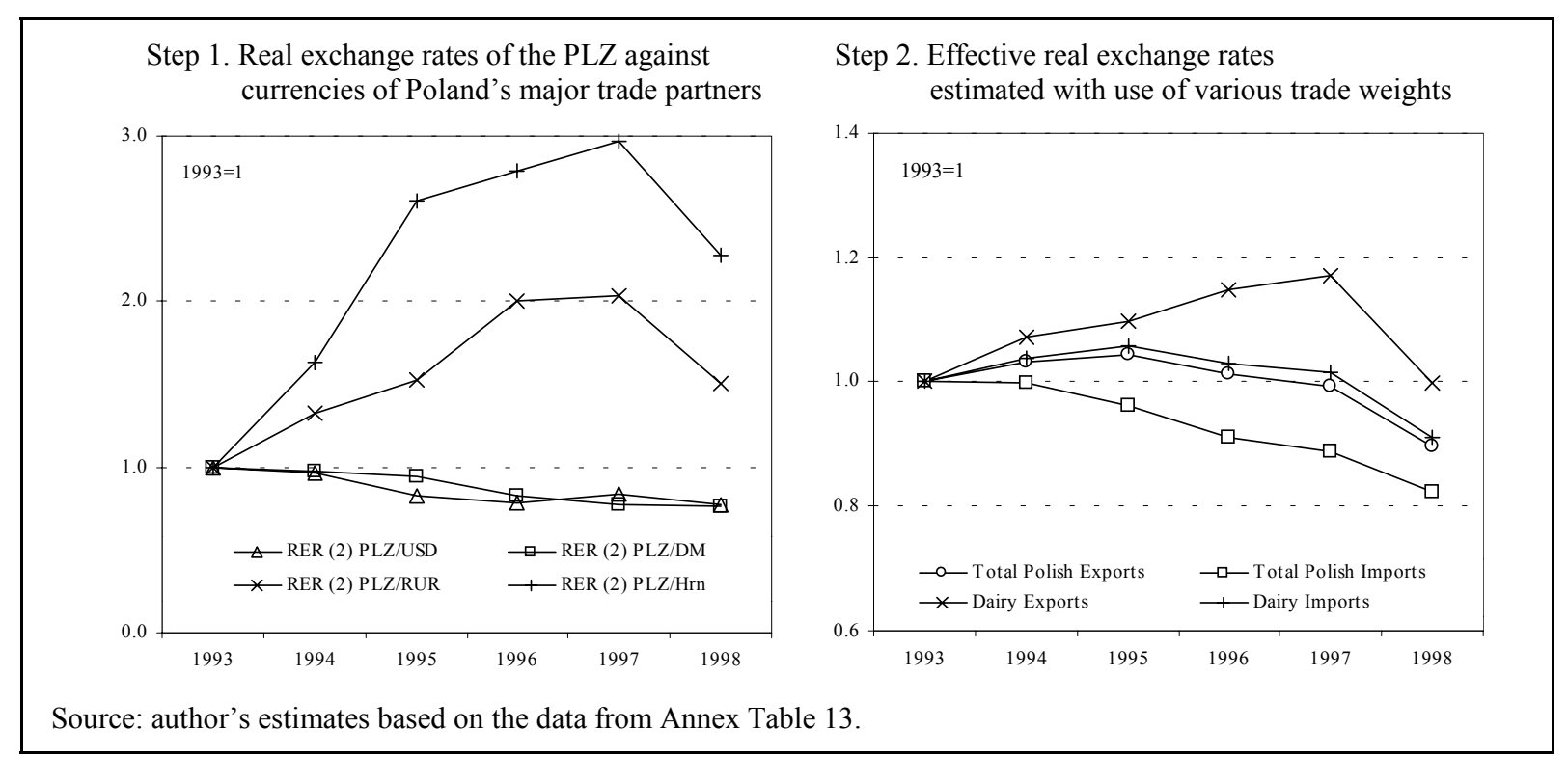

The analysis shows that until the 1997, in terms of export shares, EFRERs have strongly depreciated for agro-food and dairy products and weakly depreciated economy-wide. In terms of import shares, until 1997, there was strong appreciation for both agro-food and economy-wide and depreciation for dairy products. In all cases EFRERs strongly appreciated in 1998 due to the strong depreciation of the Rubel and the Hrywna.

What conclusions can be drawn from this analysis?

i. First, these results are consistent with the fast growth in the Polish net agro-food and dairy exports to the FSU countries observed during the analysed period and with the deterioration in the trade balances relative to the EU countries. The results of EFRER weighted by imports may, however, be underestimated due to the effects of trade barriers. The losses in competitiveness against the EU imports are masked by the protective policies (mainly for agro-food and dairy variants of EFRER) limiting import volumes and leading to the overestimation of the levels of effective exchange rates relative to the free trade situation (underestimation of appreciating tendencies). .5 The latter becomes apparent when one compares the results for agro-food products (i.e. those with relatively high import protection) with those for total trade.

ii. Second, the results pose the question of the long-run exchange rate of Polish zloty relative to the currencies of their export and import markets. As far as the developed countries' markets are concerned, the past appreciation seems to reflect the long-run changes in the equilibrium

35 In a free trade situation the detectable EFRER would appreciate more because the weights of currencies against which the PLZ appreciated would be higher. 
exchange rate (see Chapter 5). In the case of the two FSU countries considered here the problem very much boils down to the question of the prospects for the macroeconomic performance of these countries. Considering the possibility of reform progress (e.g. due to the change in the Russian leadership in spring 2000) and the sustainability of recovered mineral oil prices (Russia's major source of foreign revenues) the real exchange rate levels of the period 1996-1998 (until the financial crisis of 1998) may be taken as indicative of a longer-term equilibrium. This is mainly because the appreciation of these currencies (RUR and Hrn) relative to the PLZ and the USD in the years 1993-1997 has been a typical effect of macroeconomic stabilisation programme which these countries embarked upon, and which will have to be pursued in the future (Halpern and Wyplosz, 1996). Hence, the strong appreciation of these currencies between 1993 and 1997 (and the depreciation of the PLZ relative to these currencies and the resulting exchange rate in 1997) should be seen rather as the shift towards a new equilibrium, though the rate of the past adjustment should not be expected to continue in the near future even in the case of economic recovery in these countries. One can also argue that in the long-run, what matters is the development of real exchange rates relative to the currencies of countries, which are crucial for the equilibrium in the world market (both suppliers and importers). This is because of the possibility of adjustments in a country's exports and imports markets (and hence weights used in the calculation of EFRER) to changes in the long-run RER relative to various currencies.

\subsubsection{Social valuation of outputs}

\subsubsection{Policies and their effects in output markets}

Since 1992 the market for dairy products has been influenced by the state intervention. The state buffer-stock programme has been operated by the Agency of Agricultural Market (ARR) - an institution dealing with market intervention in major farm markets in Poland. Market intervention has been based on purchases and sales of butter and SMP. Intervention prices have been set at levels enabling, at least theoretically, a payment of a minimum price for farm milk. Levels of intervention and minimum prices are an outcome of political bargaining among representatives of the government, farmers and processors. Implicit export subsidies have been used occasionally to dispose of accumulated stocks. $\frac{36}{}$ In general, the importance of subsidies used to be marginal mainly because the intervention operates under the financial constraint imposed through the budget of ARR. The evolution of intervention prices, market and world prices, and magnitude of domestic production involved in the intervention is presented in Figure 3.4 (for butter) and Figure 3.5 (for SMP).

36 This conclusion results from the difference between the intervention procurement price and the export price that must be covered from the budget of the ARR. 
Figure 3.4. Butter prices and intervention procurement quantities, 1992-1998.

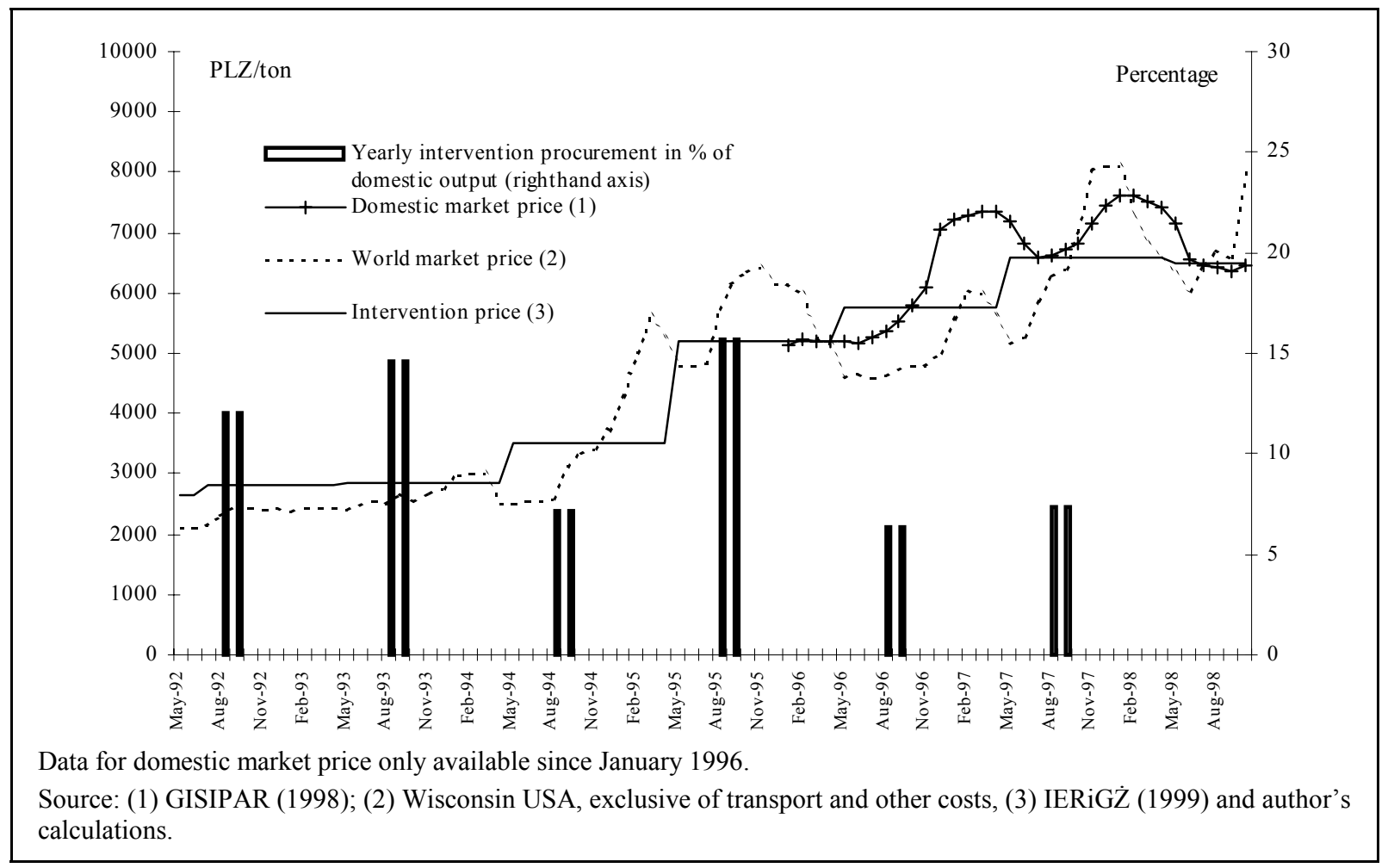

Figure 3.5. SMP prices and intervention procurement quantities, 1992-1998.

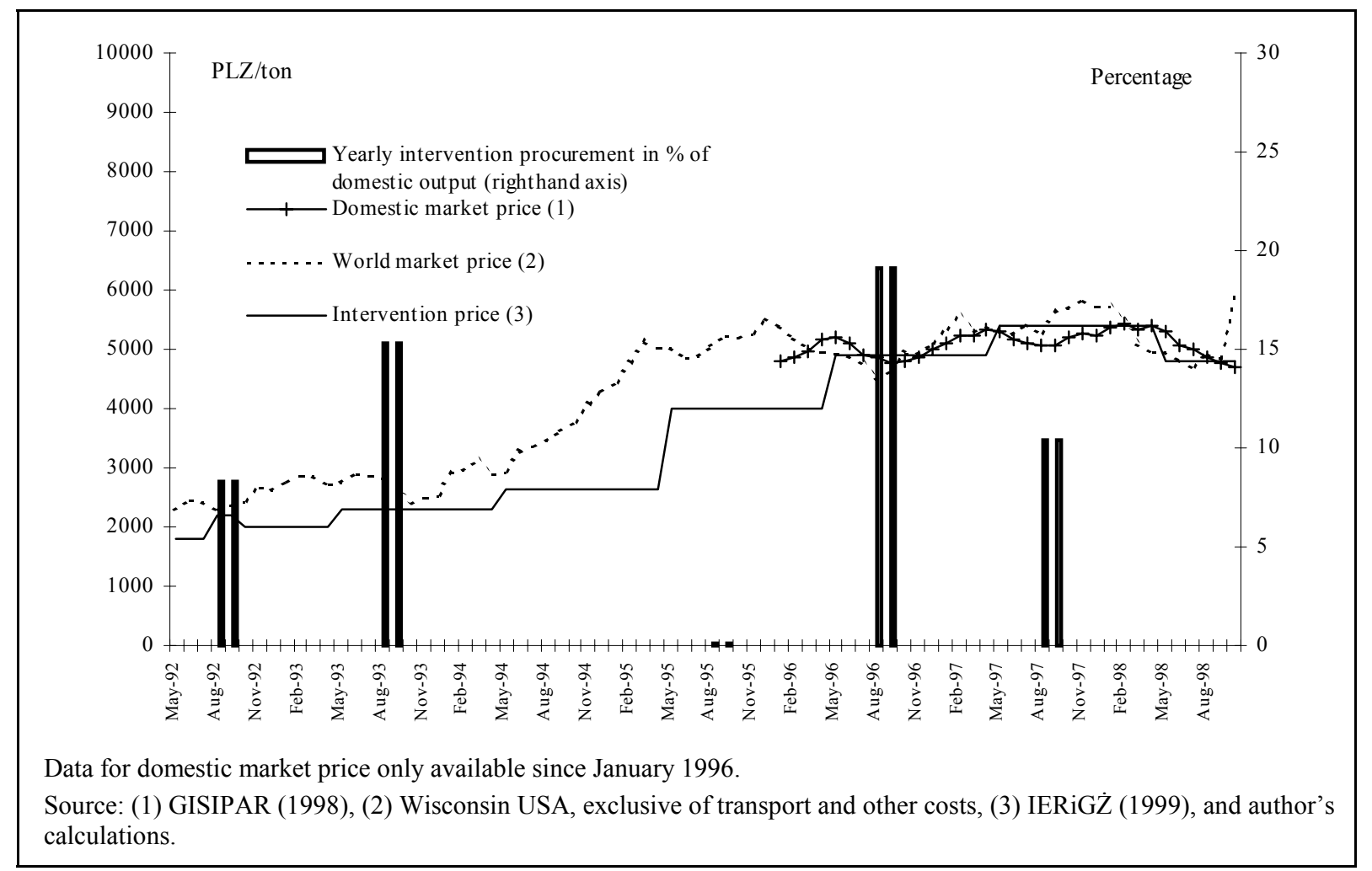




\subsubsection{Estimation of social prices for dairy commodities}

\section{Separating policy effects and other distortions in output markets}

By definition, the detected divergence between the private and the social price for outputs is composed of the effects of direct policy distortions and market failures. To gain additional insight into the functioning of markets for dairy products, a procedure to isolate the two distorting effects has been applied (Kray, 1997 and Glauben et al., 1998). This procedure boils down to the measurement of residual between the observable total divergence and the effect of policy implied by the set of border instruments used. The policy effect consists of specific subsidy or tariff, plus per unit value equivalent of ad valorem export tax or import tariff. The estimation procedure is described by the following formulas:

i. Social prices:

$$
\begin{aligned}
& P^{s}=P^{c i f}+\underset{b \rightarrow p}{t r} \text { for importables (refered to as CIF-plus), } \\
& P^{s}=P^{f o b}-\underset{p \rightarrow b}{t r} \text { for exportables (refered to as FOB-minus); }
\end{aligned}
$$

ii. Total divergence:

$D G^{t o t}=P^{p}-P^{s} \quad$ for importables and exportables;

iii. Direct policy effect:

$D G^{p o l}=P^{c i f} * t_{i m}^{a v}+t_{i m}^{s p} \quad$ for importables,

$D G^{p o l}=P^{f o b} * t_{e x}^{a v}+t_{e x}^{s p}$ for exportables;

iv. Effects of other distortions (remaining unexplained distortions):

$D G^{r e s}=D G^{\text {tot }}-D^{\text {pol }}$ for importables and exportables;

v. All effects $D G^{\text {tot }}, D G^{\text {pol }}, D G^{\text {res }}$ can be expressed in relative terms - here as a percentage of domestic price.

Notation:

$P$ - price, with sub- and superscripts:

$$
\begin{array}{ll}
p & \text { - for private prices, } \\
s & \text { - for social prices, } \\
c i f & \text { - for import unit border value, } \\
f o b & \text { - for export unit border value; }
\end{array}
$$

tr - transport and handling costs, with subscripts:

$\mathrm{b}->\mathrm{p}$ - from border to producer,

$\mathrm{p}->\mathrm{b}$ - from producer to border;

$t$ - border tariffs (taxes) or subsidies, with sub- and superscripts:

$D G$ - divergence, with superscripts:

$$
\begin{array}{ll}
i m & \text { - for imports, } \\
e x & \text { - for exports, } \\
a v & \text { - ad valorem, } \\
s p & \text { - specific; }
\end{array}
$$

tot - for total divergence,

pol - for direct policy divergence, 


$$
\text { res - for residual divergence. }
$$

Additionally, import entry prices have been calculated. These are equal CIF price adjusted for (i.e. increased by): (i) the ad valorem and specific border tariffs payable and (ii) transport costs (to enable comparability with the domestic producer prices). While the difference between the private and social prices represents the utilised protection, the margin between the private and import entry price is indicative of the available (potential) protection and exceeds the level of the utilised protection by a margin of so called 'water' in tariff.

\section{Results of the estimation}

The above procedure has been used to estimate social prices for dairy products and to explain the divergence between these and the prices received by producers. The analysis covers the selected 12 dairy (representative) products defined in terms of CN code. The FOB and CIF prices are represented by unit border values based on Polish trade statistics (SAEPR/FAPA, 1999). The trade data presented in the Annex Table 15 also makes it possible to identify the net trade position i.e. to classify the products into importables and exportables.

The information on direct border measures including the ad valorem and specific tariffs and taxes has been taken from Polish Tariff Schedule (1999) and (SAEPR/FAPA, 1999, for export subsidies). Transport costs are taken from Ziąbrowski, (1997) (see Annex Table 15). Results of this analysis are presented in Figure 3.6, where domestic prices for the selected dairy products are compared with their world market counterparts, CIF-plus or FOB-minus, and with the import entry prices. It turned out that the FOB-minus prices represent social prices for all considered products except for yoghurt, which is the only net imported commodity, and for which CIF-plus represents the social price. Decomposition of the private-social price divergence into direct policy distortion and remaining divergence (unexplained effect) is presented in the Table 3.3. 
Figure 3.6. FOB-minus, CIF-plus and import entry prices for selected dairy commodities, 1996-1998.

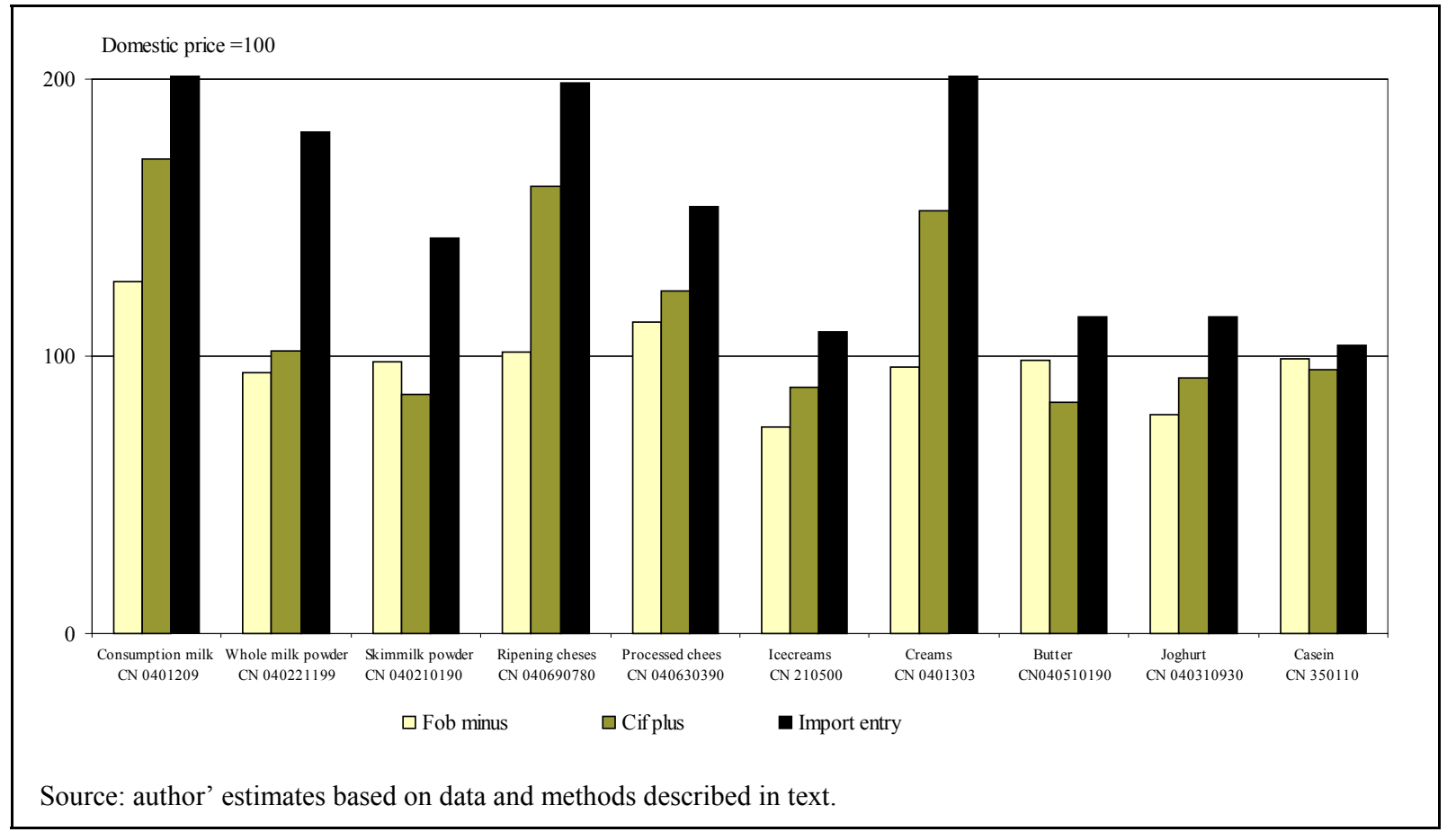

Table 3.3. Private-social divergence of dairy product prices (in $\%$ of private producer price).

\begin{tabular}{|c|c|c|c|c|c|c|c|}
\hline \multirow[b]{2}{*}{ Product } & \multirow[b]{2}{*}{$\mathrm{CN}$ code } & \multicolumn{3}{|c|}{1997} & \multicolumn{3}{|c|}{ Average 1996-1998 } \\
\hline & & $\begin{array}{c}\text { Total } \\
\text { divergence }\end{array}$ & $\begin{array}{l}\text { Policy } \\
\text { effect }\end{array}$ & $\begin{array}{l}\text { Remaining } \\
\text { distortions }\end{array}$ & $\begin{array}{c}\text { Total } \\
\text { divergence }\end{array}$ & $\begin{array}{c}\text { Policy } \\
\text { effect }\end{array}$ & $\begin{array}{l}\text { Remaining } \\
\text { distortions }\end{array}$ \\
\hline Consumption milk & 0401209 & -15 & 0 & -15 & -27 & 0 & -27 \\
\hline Condensed milk & 0402911 & -35 & 0 & -35 & -42 & 0 & -42 \\
\hline Whole milk powder & 040221199 & 7 & 0 & 7 & 6 & 0 & 6 \\
\hline SMP & 040210190 & 2 & 0 & 1 & 2 & 0 & 1 \\
\hline Ripening cheese & 040690780 & 1 & 0 & 1 & -2 & 0 & -2 \\
\hline Fresh cheese & 040610200 & 31 & 0 & 31 & 31 & 0 & 31 \\
\hline Processed cheese & 040630390 & -11 & 0 & -11 & -12 & 0 & -12 \\
\hline Ice-creams & 210500 & 31 & 0 & 31 & 26 & 0 & 26 \\
\hline Creams & 0401303 & 11 & 0 & 11 & 4 & 0 & 4 \\
\hline Butter & 040510190 & 2 & 0 & 2 & 2 & 0 & 2 \\
\hline Yoghurt & 040310930 & 18 & 26 & -8 & 8 & 26 & -18 \\
\hline Casein & 350110 & 5 & 0 & 5 & 1 & 0 & 1 \\
\hline \multicolumn{8}{|c|}{$\begin{array}{l}\text { Positive values: divergence subsidising producer, as a percentage of private producer price. } \\
\text { Negative values: divergences taxing producer, as a percentage of private producer price. }\end{array}$} \\
\hline
\end{tabular}

Several hypotheses interpreting the detected 'remaining' distortions in the output markets can be put forward. First, it must be stressed that the interpretation is constrained by the possible shortcomings of the data used. The detected remaining (and hence total) divergences may originate from the following effects: 
i. Specification error: differences between exports, imports and domestic product, in terms of quality (vertical differentiation) or variety (horizontal differentiation);

ii. Measurement error (e.g. bias in mal-invoicing, underestimation of transport costs);

iii. Imperfect competition and other 'structural' effects such as high transaction costs.

The first presumed effect is related with the heterogeneous nature of the products that cannot be accounted for, even by focusing on such a narrowed product definition as that offered by the 8-digit $\mathrm{CN}$ code. At the same time there may be a good reason for a systematic bias in the quality that may contribute to the observed price effects. Such a bias seems to be implied by the geographical pattern of the Polish dairy trade. The point is that the majority of Polish dairy exports have been sold in the markets of FSU countries while the majority of imports, presumably of higher-priced quality grades, originated from the EU market (Annex Table 16). Assuming significance of the above effect, the employment of FOB-minus for almost all products considered (except yoghurts) in the identification of social prices means that the influence of such a specification error is diminished. This is because the quality of exports can be expected to better reflect 'average' quality of domestic production than the quality of imports.

As Figure 3.6 and Table 3.3 indicate, in all cases of exportable products the detected divergence cannot be explained by direct policies, simply because taxes or subsidies on exports either have not been operated or have been of marginal magnitude. The situation looks different for yoghurts, an importable product, where total divergence is a net outcome of two conflicting forces: high protection, rising domestic price, and remaining distortion, which depresses domestic price. Because of a relatively high scope for differentiation (vertical and horizontal differentiation) this price depressing rest distortion could be explained e.g. by the specification error (e.g. inferior quality of home production). More insight into this effect is gained by the case study of the yoghurt market in Chapter 6.

Remaining distortions detected in other products - exportables - either enhance or depress domestic prices relative to the FOB-minus. Sizable depressing impact, which has been detected for drinking milk, condensed milk and processed cheese may result from: (i) specification error (domestically lower quality or lower value-added assortments are traded) or (ii) the highly competitive conditions on the domestic market associated with the lagged adjustments to a shock on the demand side (e.g. deteriorated conditions in exports markets of FSU) or to a shock on the supply side (e.g. expansion of domestic production capacity due to a biased credit subsidies favouring some product lines). To a degree, this could be interpreted as a transient effect associated with the ongoing structural adjustment in the industry.

Sizable enhancing effect, which has been detected for fresh cheese, ice-creams, and creams can be due to the: (i) specification error (domestically are traded higher quality or higher value added assortments than the exported ones), (ii) price discrimination against domestic consumers (possibly an 
outcome of low price elasticity, oligopolistic structure of domestic market and high protection from imports). An important indication of whether the domestic industry has room for manoeuvre for such a price discrimination is provided in Figure 3.6 by the relative level of import entry prices. It is important that for many products, including the fresh cheeses and creams and ice-creams, these import entry prices lie much above the CIF-plus - a result of high tariff rates or (iii) lagged supply adjustment (a transient effect due to structural change) to an increase in domestic demand.

Among the net exportables, for SMP and butter (and to a lesser extent casein) distinct behaviour is shown in terms of the detected price relation. In both cases the divergence between private and social price (FOB-minus) as well as the rest distortion are of small magnitude, while, at the same time, the CIF-plus lies below the FOB-minus level. The first hypothetical explanation is that the two products show a relatively smaller scope for the three kinds of non-policy effects (measurement and specification errors and imperfect competition). This is because of: (i) their relatively higher homogeneity and (ii) greater transparency/efficiency of their international market also associated with the greater volumes traded. The second reason is that the geographical pattern of Poland's trade in these two commodities differs from that in other dairy commodities, with a consequence for the faced relative CIF- FOB prices.

In the case of the SMP the CIF prices are mainly determined by the imports from the FSU countries, which accounted in the period 1996-1998 for as much as $89 \%$ of total Polish imports. In fact, Poland is a net exporter of SMP with about $36 \%$ of exports directed to the EU. Some of the exports to the EU (equivalent of about 5\% of total Polish exports in the period 1996-1997) enjoy preferential access within a Europe Agreement tariff quota (with in-quota tariff rate equal to $20 \%$ of the MFN tariff rate), which may contribute a fraction of the quota-rent to the Poland's FOB-price. This means that the difference between the FOB and the CIF may reflect a sort of trade margin realised by Polish traders who take advantage of the established position of the country on the international SMP market (barraging position plus preferences in access to the protected EU market).

As far as butter is concerned, the majority of exports between 1996 and 1998 have been sold on the FSU markets (74\%), while $21 \%$ on the EU market. About $75 \%$ of the exports to the EU have been sold within the preferential quota of the Europe Agreement at the tariff rate equal to $20 \%$ of the MFN one. At the same time $66 \%$ of total imports came from the EU at a CIF price $18 \%$ below Poland's FOB in the major export market (FSU), and 25\% below Poland's FOB in export to the EU.

For the main purpose of this study these hypothesised sources of the remaining distortions can be divided into those, which are transient, and more persistent. The former are mainly the effects associated with the mainstream of structural adjustment induced by the reforms of economic transition. This category includes: lagged adjustment in supply and demand, high transaction costs (that might have led to underestimation of the transport and handling costs in the calculation of CIFplus and FOB-minus prices). Quality differences may be expected to disappear with time to the extent 
that they reflect outdated technologies and regulatory standards and quality control system that is too permissive. Horizontal differentiation (variety differences) may persist as the source of specification error in an analysis like that conducted here. Moreover, for a net exporting sector like Polish dairy the structural adjustments of transition mean the time needed to find and establish a position in new export outlets, which, in turn, may have consequences for the attainable prices both in terms of the level and stability. A good example for this aspect is provided by the Russian economic crisis in 1998 that resulted in a drastic reduction in Poland's dairy exports to this country and the subsequent repercussions in the domestic markets (SAEPR/FAPA, 1999).

\subsubsection{Social valuation of farm milk}

Farm milk is a non-tradable input specific to the milk processing industry - the industry is its sole domestic user. In addition, there is rather limited scope for substitution of farm milk for other inputs input-output coefficients for each dairy processed product are fixed. For the industry-level inputoutput coefficient can, in part, be altered by changing the product-mix of the final output of the industry.

Milk prices are determined through derived demand from the milk processing industry and by primary supply from farm milk producers. Hence, solving for effect of policy distortion on milk price would require inclusion of policy effects on other farm activities, which are linked to milk production via competition for scarce farm resources (labour, capital, land) or by a joint-product relation (beef production). In this study these supply-side policy effects will not be explicitly analysed.

Instead, an alternative procedure, focusing on the demand-side of the farm milk market has been applied here. This can be defined as milk price equivalent of social prices of SMP and butter. The prices of these two commodities are determined internationally. In a free trade situation their domestic prices would amount to the CIF-plus or FOB-minus. Being also most important commodities in the world market for dairy products and representing a substantial source of demand for milk fat and nonfat on domestic markets, ${ }^{\text {g }}$ their prices well approximate opportunity costs (either private or social) for these two farm milk components. 38

This principle for social valuation of fat and non-fat components of farm milk, and, thus for farm milk itself and for the farm milk costs in the processing industry has been used here. The implicit prices for both milk components are calculated from the world prices of butter and SMP by applying adequate processing margins and yield factors (technical coefficients for fat and non-fat input in

37 Estimates conducted elsewhere in this study show that in 1997 butter and SMP accounted for about $30 \%$ of milk non-fat used in processing in Poland.

38 This approach for determining opportunity costs of fat and non-fat components of farm milk is not invalidated by the real-life tendency for higher milk prices paid by producers of higher-value added products. This is because such a tendency may only reflect transient supernormal profits (incentives) associated with the ongoing changes in the structure of domestic (and world) demand and supply for various dairy products. 
production of SMP and butter). The estimation procedure has been explained in the Annex table 17 using the example of private implicit prices of fat and non-fat in Poland between 1995 and 1997.

Factors affecting supply schedule for milk are assumed only to result in the adjustments in the quantity of milk and milk products produced domestically and internationally traded. In this framework, a shift in farm milk supply schedule may significantly affect milk price only by causing a switch in the net trade position of the domestic market (CIF-plus - FOB-minus difference), or by affecting the processing margin (positively e.g. by limiting over-capacities, in the short-term, and allowing for economies of scale, in the long-term).

\subsubsection{Effect of sectoral policies on farm milk prices}

\section{Market intervention in dairy sector}

Market intervention policy in the dairy sector operated since 1992 has focused on price stabilisation. In 1997 border measures and non-policy distortions resulted in an average nominal protection rate in the output market of $8 \%$ (see later sections with PAM analysis). These price increases on the output side might have translated into the demand price for farm milk.

Thus, the intervention may have influenced farm milk prices directly, by raising the price of final

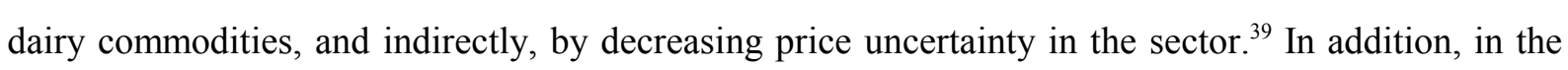
intervention system operated in Poland, the link between the administrative intervention prices of butter and SMP and farm milk price has been enforced through the formal requirement that processing enterprises, which sell to intervention, should pay farmers at least the statutory minimum price. Only until 1993 was the relation between the intervention prices and minimum farm milk prices based on the butter/milk price margin in the 20 best (most efficient in this respect) dairy co-operatives; since 1994 the relation has been established on the basis of the average market prices in the preceding last season (IERiGŻ, 1999).

39 Effects of price instability on processing margin and thereby on the derived demand for farm input have been shown for the US grain market in the study of Brorsen, et al. (1985). For Poland a similar effect has been detected in the pork/pig market during the years 1991-1996 (Wye et al., 1997). 
Figure 3.7. Farm milk prices, 1992-1998.

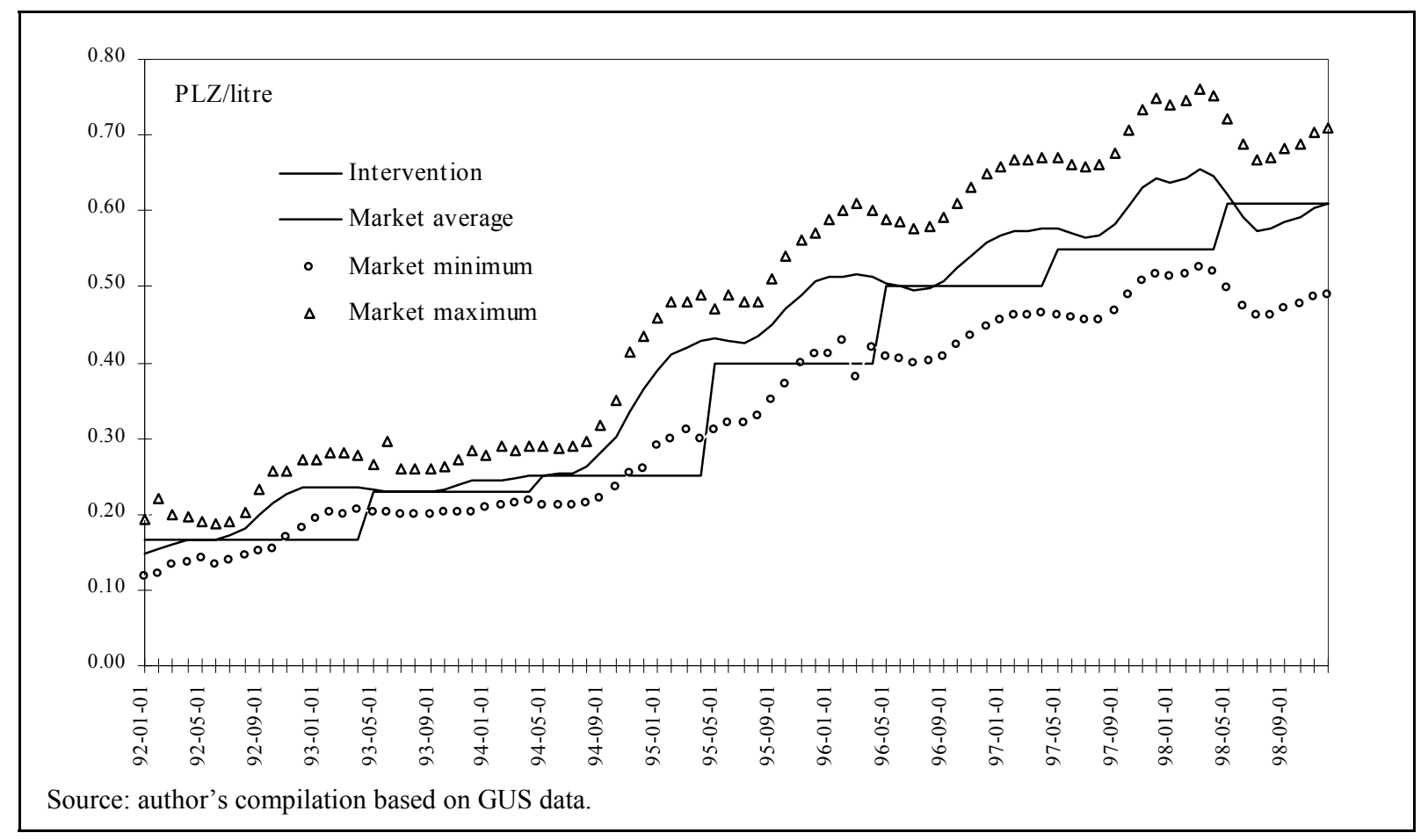

Discussion of the interdependence between the prices at the two market levels starts from Figure 3.7, which shows the average market prices of farm milk and the minimum level set in intervention. The figure shows that over the period 1992-1998 market prices followed a seasonal variation, and the minimum intervention price may have had an influence on market price during seasonal shifts in supply. At the same time the graph shows lower and upper boundaries for the variation in the regional price records.

\section{Effects of other policies}

It can be argued that the investment subsidy scheme (PRMM) has had an ambiguous effect on the farm milk prices. On the one hand, the subsidy may have an enhancing effect on milk prices, in the short term, because it has diminished processing costs (cheaper capital cost and productivity gains from new machinery installed) and, possibly, has also resulted in transfer of a part of the subsidies to the farm sector. On the other hand, however, the flawed system of this subsidy allocation may have slowed down the restructuring (scale effects) and re-organisation at enterprise level, which must have an opposite, i.e. a depressing effect on farm prices in the long run (see also the discussion in Chapter 2). At the same time, the delay in introduction of rigid quality standards may have diminished the quality premium in farm milk price, i.e. it has an enhancing effect on prices of low quality milk and a depressing effect on prices of high quality milk (apart from having an adverse effect on the improvement in the average quality of farm milk delivered). 


\subsubsection{Effects of fragmented farm structure}

The fragmented farm structure in Poland reflects abundant labour resources in this sector and may even suggest a comparative advantage of the country in milk production, given that this activity tends to be relatively labour intensive. At the same time, however, this fragmentation tends to adversely affect the milk prices farmers receive. Three simultaneous and cumulating effects can be hypothesised.

First, there is the quality aspect. Milk pricing is based on a formula system in which fat and nonfat content, microbiological cleanliness and post milking treatment on farms play a decisive role. In Polish conditions, the microbiological quality is potentially the most important factor determining farm milk prices. Milk quality is positively related to farm size due to the significant savings in costs related with quality control within the farm size range typical of Poland. Second, economies of size also play a significant role in milk assembly. Increased assembly costs incurred by processors may be transmitted to farmers via lower milk prices. Third, the deteriorated bargaining position of farmers against the processors in regions with fragmented farm supply has similar consequences.

Figure 3.8. Relationship between farm milk prices and milk delivery per farm in a region (voivodship), 1997.

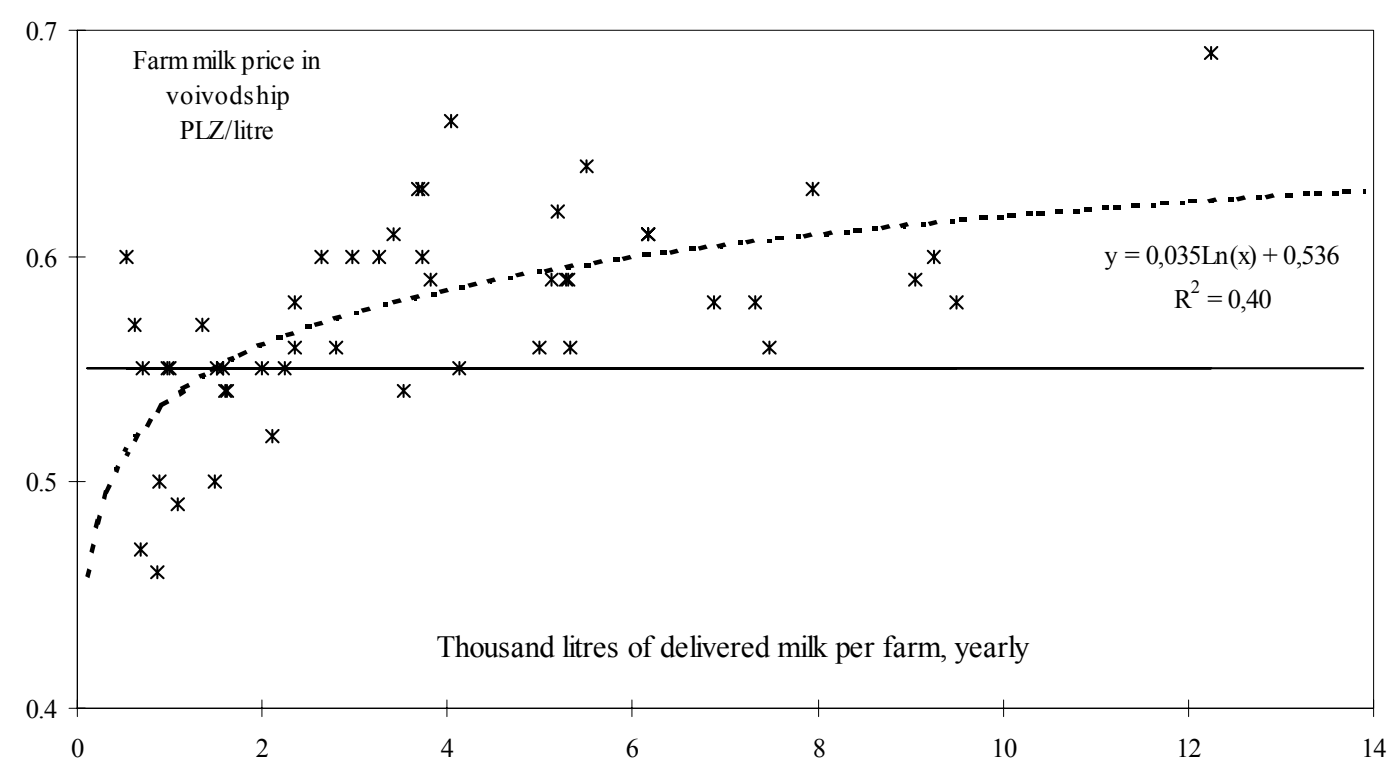

Observations represent averages for voivodships - administrative regions of Poland.

The horizontal bold line denotes statutory minimum for intervention equal to O.55 PLZ/1.

Source: author's estimates based on GUS (1998e).

The potential impact of these structural effects on the farm milk prices has been shown here by a simple cross-sectional analysis using the regional data for Poland (49 observations). Milk prices have been plotted along the scale of average size of milk farm in a region (voivodships) measured by the yearly milk delivery (Figure 3.8). The analysis confirms the above outlined expectation of the strong 
structural effects on farm milk prices: there is a positive relationship between the average size of milk farm in a region and the average milk price received.

\subsubsection{Estimates of social prices for farm milk}

Since Poland is a net exporter of dairy products and SMP and butter in particular, FOB-minus prices for both commodities have been used. Calculations have been conducted for two alternative sets of processing costs - Polish (actually observed price margin derived from prices of milk, butter and SMP and technical coefficients ${ }^{400}$ ) and the EU (indicative EU processing costs used in the calculation of Intervention Farm Milk Equivalen (412). Results are demonstrated in Table 3.4 and Figure 3.9.

Table 3.4. Prices of milk and fat and non-fat components under alternative prices for butter and SMP, and alternative processing margins, 1996-1998.

\begin{tabular}{|c|c|c|c|c|c|c|c|c|c|c|}
\hline \multirow{3}{*}{$\begin{array}{l}\text { Category of } \\
\text { reference prices for } \\
\text { butter and SMP }\end{array}$} & \multirow{2}{*}{\multicolumn{2}{|c|}{$\begin{array}{c}\text { Prices of tradable } \\
\text { equivalents of } \\
\text { farm milk } \\
\end{array}$}} & \multicolumn{4}{|c|}{ Polish margin } & \multicolumn{4}{|c|}{ EU margin } \\
\hline & & & \multicolumn{2}{|c|}{$\begin{array}{l}\text { Prices of milk } \\
\text { components }^{(1)}\end{array}$} & \multirow{2}{*}{$\begin{array}{c}\text { Milk } \\
\text { price } \\
\text { equiv. }\end{array}$} & \multirow{2}{*}{$\begin{array}{c}\text { Fat share } \\
\text { in milk } \\
\text { price }\end{array}$} & \multicolumn{2}{|c|}{$\begin{array}{l}\text { Prices of milk } \\
\text { components (1) }\end{array}$} & \multirow{2}{*}{$\begin{array}{l}\text { Milk } \\
\text { price } \\
\text { equiv. } \\
\begin{array}{c}\text { PLZ/ } \\
\text { ton }\end{array}\end{array}$} & \multirow{2}{*}{$\begin{array}{c}\text { Fat share } \\
\text { in milk } \\
\text { price }\end{array}$} \\
\hline & $\begin{array}{l}\text { Butter } \\
\text { PLZ/ } \\
\text { ton }\end{array}$ & $\begin{array}{c}\text { SMP } \\
\text { PLZ/ } \\
\text { ton }\end{array}$ & $\begin{array}{c}\text { Fat } \\
\text { PLZ/ } \\
\text { unit }\end{array}$ & $\begin{array}{c}\text { Non-fat } \\
\text { PLZ/ } \\
\text { unit }\end{array}$ & & & $\begin{array}{c}\text { Fat } \\
\text { PLZ/ } \\
\text { unit }\end{array}$ & $\begin{array}{c}\text { Non-fat } \\
\text { PLZ } \\
\text { unit }\end{array}$ & & \\
\hline \multicolumn{11}{|c|}{1997} \\
\hline Market. Poland & 7176 & 5188 & 0.068 & 0.330 & 571 & 44 & 0.073 & 0.363 & 620 & 44 \\
\hline FOB-minus & 7152 & 5168 & 0.068 & 0.323 & 564 & 45 & 0.073 & 0.361 & 617 & 44 \\
\hline CIF-plus & 5548 & 4584 & 0.049 & 0.274 & 447 & 41 & 0.054 & 0.313 & 500 & 40 \\
\hline EU intervention & 10945 & 7615 & 0.113 & 0.530 & 927 & 45 & 0.117 & 0.568 & 981 & 44 \\
\hline AGENDA 2000 & 9304 & 6473 & 0.094 & 0.433 & 763 & 45 & 0.098 & 0.471 & 817 & 44 \\
\hline \multicolumn{11}{|c|}{ Average 1996-1998 (2) } \\
\hline Market. Poland & 6690 & 5069 & 0.065 & 0.331 & 558 & 43 & 0.067 & 0.352 & 588 & 43 \\
\hline FOB-minus & 6688 & 5057 & 0.064 & 0.327 & 552 & 45 & 0.067 & 0.351 & 588 & 44 \\
\hline CIF-plus & 4365 & 4365 & 0.050 & 0.255 & 430 & 43 & 0.054 & 0.294 & 483 & 58 \\
\hline EU intervention & 11078 & 7707 & 0.124 & 0.582 & 935 & 45 & 0.130 & 0.627 & 993 & 44 \\
\hline
\end{tabular}

Also, milk price equivalents for a set of alternative prices of butter and SMP have been estimated, including Polish CIF-plus and EU prices (current and under AGENDA 2000). According to this calculation the social price of farm milk lies merely $0.5 \%$ below the current milk price when one uses the current processing technology, and 5.5\% above the current market price when one uses the EU processing margin (EU technology and prices). In the DCR analysis presented in the subsequent

40 In this way it is implicitly assumed that social prices of farm milk are only affected by the distortions in the prices of butter and SMP, but not by the distortions in the price margin. This simplification has been adopted because the distortions in processing costs (due to distorted input prices) are negligible: for SMP social processing costs exceed private level by c.a. $2 \%$ while for butter social processing cost are c.a. $3 \%$ below private level (see Table 3.8). In addition to that, the opposite signs of distortions largely compensate the effects in both products.

41 Agra Europe CAP Monitor (1999). 
section the first option has been used. An inherent part of the estimation procedure is an estimation of implicit (social) prices of fat and non-fat components of milk. This is important as these estimates are used to calculate product specific farm milk costs.

Figure 3.9. Milk Prices Derived from Butter and SMP Prices, 1997.

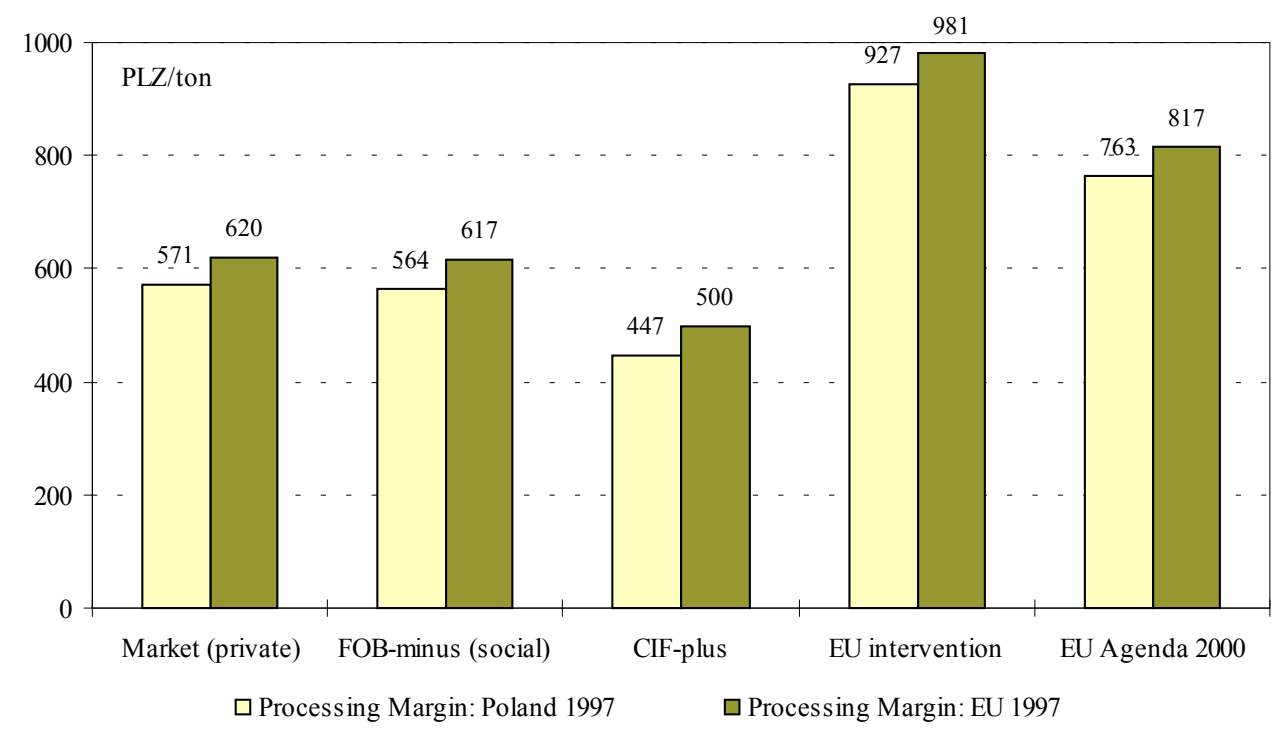

Source: author's estimates based on data described in the text.

\subsubsection{Social valuation of tradable inputs}

The procedure used in social valuation for tradable inputs is based on the assumption that domestic and world prices differ only by the effects of direct policies: import tariffs and taxes in the case of importables, and export subsidies and export taxes in the case of exportables. The social prices are derived from private prices by the use of conversion factors. Conversion factors are calculated from the applied policy measures (Annex Table 15).

This simplifying assumption is justified by the fact that markets for major generic tradable inputs like those for energy and fuels (fuels, coal, and natural gas) are characterised by relatively high transparency and market efficiency. ${ }^{2}$ For industry-specific tradable inputs including packaging and machinery the competitive price arbitrage, with import tariffs as only distorting elements, is being fostered by a small number of transactions: procurement of these inputs takes place with longer time intervals and at smaller unit transactions costs and often with direct contacts between input providers and milk processors. This approach also has practical importance because the heterogeneity of

42 This conclusion is supported by the analysis of pricing efficiency (price transmission) between Polish and world markets for a variety of intermediate goods between 1995 and 1997. See Marczewski and Chojna, (1999). 
industry-specific tradable inputs makes identification of specific price determinants extremely difficult.

\subsubsection{Social valuation of capital}

\subsubsection{The estimation approach}

Capital input is measured as the sum of depreciation, i.e. the reduction in the value of assets arising from wear and tear, and the forgone return on financial capital tied in the value of assets (Corden, 1984; Griliches, 1960). Estimation approaches differ according to method of calculating the depreciation and the data constraints. In this study capital assets are assumed to provide a constant stream of services over the useful (economic) lifetime (Griliches, 1960). Algebraically, this method points to calculation of capital recovery factor, i.e. a number which, when applied to the initial value of assets yields a constant annual payment (user cost of capital). This annuity represents the value necessary to repay the initial value of investment in the assets over a given period of time (equal to the economic life of assets) and at a given interest rate (Tsakok, 1990 and Brandes and Odening, 1992). The underlying formula is:

$$
U C=V *(1+i)^{n} i /\left((1+i)^{n}-1\right)
$$

where

$U C$ - user cost of capital (annuity)

$V \quad$ - initial value of capital assets (investment)

$i \quad$ - real rate of interest

$n$ - economic life of assets

$(1+i)^{n} i /\left((1+i)^{n}-1\right)$ - capital recovery factor for $i$ and $n$.

For the private cost of capital the value of assets should represent private prices of investment goods and the private interest on financial capital engaged. The private interest rate i.e. private opportunity cost of financial capital reflects: (i) the costs of borrowing, in the case of the credit, and/or (ii) the foregone returns from the best alternative, possibly a return to long-term bank deposits or other financial assets, in the case of own financial resources engaged. Calculatory interest rate can be derived as the average of the two interests weighted by their shares in the financing of initial investment.

In social valuation of capital cost one needs to take account of distortions in the market for capital goods, e.g. distortions resulting from tariffs or taxes, and the divergence between private and social interest rates. The procedure to estimate social prices of capital goods is the same as in the case of tradable inputs, namely, it has been assumed that social prices diverge from the private ones by the effect of policy distortions: import tariffs and taxes. The social value of capital assets has been 
derived from the private values by applying a conversion factor based on the information about the applied tariffs and taxes. The social interest rate corresponds to the marginal productivity of capital in the economy, i.e. the return forgone by the economy by engaging the scarce financial resources in the activity under consideration, rather than in the best alternative (e.g. Monke and Pearson, 1989 or Mashayekhi, 1980). Alternative approaches to estimating social opportunity cost of capital funds include (i) estimation of the marginal productivity of capital on the basis of macroeconomic or microeconomic data, and (ii) use of rates on borrowing from representative foreign capital markets e.g. Eurocurrency rates.

After having identified private $\left(V_{p}\right)$ and social $\left(V_{s}\right)$ values of capital assets, and private $\left(i_{p}\right)$ and social $\left(i_{s}\right)$ interest rates on financial capital one can estimate private and social capital costs. This can be done by an application of formula (3.18) for private and social values of capital assets and interest rates. For technical reasons, it is more convenient to use a conversion factor for capital costs, a number which when multiplied by the private capital costs $\left(U C_{p}\right)$, yields the social value for the capital cost $\left(U C_{s}\right)$. The conversion factor for capital $(C F C)$ is calculated as:

$$
C F C=\frac{U C_{s}}{U C_{p}}=\frac{V_{s}}{V_{p}} * \frac{\left(1+i_{s}\right)^{n} i_{s} /\left(\left(1+i_{s}\right)^{n}-1\right)}{\left(1+i_{p}\right)^{n} i_{p} /\left(\left(1+i_{p}\right)^{n}-1\right)}=C F A * C F I .
$$

The conversion factor for capital costs $(C F C)$ is a product of the conversion factor for capital assets value $(C F A)$ and the conversion factor for capital recovery factor $(C F I)$. Assuming that the divergence in the value of capital assets stems solely from the tariff rate, the $C F A$ is defined as:

$$
C F A=V_{s} / V_{p}=1 /(1+\text { tariff rate }) .
$$

The conversion factor for the capital recovery factor $(C F I)$ can be estimated directly from private and social values for interest rate.

\section{Treatment of foreign direct investment}

Since the DRC serves to evaluate whether an activity represents an efficient (potential) use for domestic scarce resources the presence of foreign capital in the industry does not affect the calculation provided the domestic and foreign capital assets are substitutable in the technological sense. The domestic capital may not be a perfect substitute for FDI if the observed level or efficiency is only possible due to the presence of FDI. Such dependence takes place if the technology used by the FDI is not purchasable/attainable for the (potential) domestic investors, i.e. when FDI contributes some sort of firm-specific assets affecting factor productivity. In such a case the capital attributable to FDI may need to be treated as an imported (tradable) input of which the social cost is determined by the profits repatriated (profits net of corporate taxes paid in a host country). At the same time benefits from the FDI accrued by the host country (here Poland) should be accounted for by the use of FDI- 
influenced technical coefficients and/or by the (higher) social revenues from the quality gains, or from improvement in the bargaining position on the world market.

Here these effects have been neglected. Even if the scope for the gains from FDI due to transfer of non-purchasable technologies were high, they have not been exploited to a significant degree in the year 1997. The share of FDI in the industry was relatively low and the existing FDIs concentrated on the selected product-lines (ice creams, milk drinks). There is some evidence that even in product-lines with the most up-to-date technology and with relatively high FDI share (like the yoghurt production see Chapter 6) there existed successful enterprises based on domestic capital, which may suggest that, as far as the milk processing technology is concerned, the investment capital of FDI has been substitutable by the domestic one. In this case, however, the contributions of FDI may have a less tangible character as they may involve a range of indirect effects such as: demonstration effects and offsetting of institutional and policy constraints on the development of domestic-capital-based firms (e.g. by exerting competitive pressure that forces them to take active business strategies despite the mitigating effects stemming from trade and investment policies).

\subsubsection{The data and estimation results}

The gross value of assets taken from GUS (1999c) has been assumed to represent the cost of replacement investment for which annuity value has been calculated. The structure of assets (i.e. the share of buildings, machinery equipment and vehicles) has been used to take account of specific economic lifetimes of various types of assets.

Economy-wide, capital goods belong to the least protected category of imports. The nominal protection rate declined from $9.2 \%$ in 1995 to $3.35 \%$ in 1998 (Marczewski, 1998). These rates are even lower for some specialised machinery used in the milk processing industry (see Annex Table 16). The average rate of protection and taxes has been used to calculate the conversion factor for value of asset in the industry (CFA).

\section{Private interest rate}

Estimates of the private real interest rate have been based on the information about nominal interest rates, inflation and interest rate subsidy operated under the Programme of Restructuring and Modernisation of the Dairy Sector (see also Annex Table 18). The share of own capital has been estimated by combining income statement data (value of long-term credits) (GUS, 1998b) with the data on interest rates under the subsidy scheme. By using the subsidised interest rate as private interest rate (i.e. adjusted for the own versus borrowed capital fund structure), it has been implicitly assumed that all future payments during the considered economic lifetime will proceed at the same interest rate (Table 3.4). This assumption is consistent with the projection of future development of 
real interest rates in Poland (Chapter 4). The private interest rate for indirect capital (capital embodied in the non-tradable inputs) has been assumed to equal the market interest rate.

Table 3.5. Lending interest rates faced by the milk processing industry, 1993-1998 (in \%).

\begin{tabular}{|c|c|c|c|c|c|c|c|c|}
\hline & & 1993 & 1994 & 1995 & 1996 & 1997 & 1998 & 1996-1998 \\
\hline \multicolumn{9}{|l|}{ Nominal interest rates: } \\
\hline Official discount & (1) & 29.0 & 28.0 & 25.0 & 22.0 & 24.5 & 18.2 & 21.6 \\
\hline Commercial credit & (2) & 45.0 & 41.0 & 36.0 & 25.0 & 24.9 & 24.5 & 24.8 \\
\hline Subsidised credit (PMRM) & (3) & 10.9 & 10.5 & 9.4 & 8.3 & 9.2 & 6.8 & 8.1 \\
\hline CPI & (4) & 35.3 & 32.2 & 27.8 & 19.9 & 14.9 & 11.2 & 15.3 \\
\hline \multicolumn{9}{|l|}{ Real interest rates (IR): } \\
\hline Market real IR & (5) & 7.2 & 6.7 & 6.4 & 4.3 & 8.7 & 12.0 & 7.8 \\
\hline \multicolumn{9}{|l|}{ Private IR: } \\
\hline Subsidised credit (PMRM) & (6) & -18.1 & -16.4 & -14.4 & -9.7 & -5.0 & -3.9 & -8.3 \\
\hline Share of sub. cred. in funds & (7) & 0.0 & 18.3 & 24.3 & 24.1 & 25.2 & 23.0 & \\
\hline Private IR & (8) & 7.2 & 2.4 & 1.3 & 0.9 & 5.3 & 8.3 & 4.0 \\
\hline $\begin{array}{l}\text { (1) GUS (1999b). } \\
\text { (2) Twelve moth moving averag } \\
\text { (3) Equal to } 0.25 \% \text { of } 1.5 \text { of offi } \\
\text { (4) GUS }(1999 a) \text {. } \\
\text { (5) IR }{ }^{(\text {real })}=\left(100+\mathrm{IR}^{(\text {nominal })}\right) /(10 \\
\text { (6) See point }(5) \text {. } \\
\text { (8) Average of market and subsi } \\
\text { Source: author's estimates. }\end{array}$ & $\begin{array}{l}\mathrm{f} \sin \\
\text { ldis }\end{array}$ & $\begin{array}{l}\text { verages } \\
\text { rate }(\mathrm{N}\end{array}$ & $\begin{array}{l}\text { m lowe } \\
\text { E, } 199 \\
\text { and Od } \\
\text { in inv }\end{array}$ & $\begin{array}{l}\text { dd high } \\
\text { g (199 }\end{array}$ & ates for & nmerci & edits. & \\
\hline
\end{tabular}

\section{Social interest rates}

The social rate of return to capital can be estimated in an approximate way using the macroeconomic data on gross domestic product (GDP) distribution (Monke and Pearson, 1989). Such analysis has been conducted here for the period 1995-1998 (Table 3.6). Under assumption of competitive conditions the ratio of marginal to average value products should be equal to the share of the factor in the total income. ${ }^{3}$ Capital's shares of GDP were on average 55 percent over the considered time period (GUS, 1999c). Gross marginal rates of return are therefore 55 percent of the average rate of return; the estimates vary between 10.0 percent in 1995 and 13.7 percent in 1998. After accounting for the capital assets depreciation the average net marginal rate of return (return to investment capital) in the years 1996-1998 equals to 7.7 percent.

43 This relationships is based on the marginal productivity theory and the 'Euler's product exhaustion" theorem (see e.g. Koutsoyiannis, 1979). The former predicts that in competitive conditions factor prices should be equal marginal value product. According to the latter, for production functions with constant returns to scale, factor payments (factor income); exhaust the total value of product. Consequently, for two factor case, capital and labour, and prices of: product, capital and labour denoted, respectively, as P, r and w, and quantities of: product, capital and labour denoted, respectively, as $\mathrm{Q}, \mathrm{K}$ and $\mathrm{L}$ it is true that:

$\mathrm{P}^{*} \mathrm{Q}=\mathrm{w}^{*} \mathrm{~L}+\mathrm{r}^{*} \mathrm{~K}$, i.e. $1=\mathrm{w}^{*} \mathrm{~L} / \mathrm{P} * \mathrm{Q}+\mathrm{r}^{*} \mathrm{~K} / \mathrm{P}^{*} \mathrm{Q}$, where $\mathrm{r}^{*} \mathrm{~K} / \mathrm{P} * \mathrm{Q}=$ capital share of total value of product and $\mathrm{r}^{*} \mathrm{~K} / \mathrm{P}^{*} \mathrm{Q}=\mathrm{r} /\left(\mathrm{P}^{*} \mathrm{Q} / \mathrm{K}\right)=$ ratio of marginal to average product of capital. 
Table 3.6. Distribution of gross domestic product and rates of return on capital, Poland, 1995-1998.

\begin{tabular}{|c|c|c|c|c|c|c|c|c|}
\hline \multirow[t]{2}{*}{ Year } & GDP & Labour & Capital & Land & $\begin{array}{c}\text { Value of } \\
\text { capital } \\
\text { stock }\end{array}$ & $\begin{array}{c}\text { Average } \\
\text { Rate of } \\
\text { Return }\end{array}$ & $\begin{array}{l}\text { Gross } \\
\text { marginal } \\
\text { rate of } \\
\text { return } \\
\end{array}$ & $\begin{array}{c}\text { Net } \\
\text { marginal } \\
\text { rate of } \\
\text { return }\end{array}$ \\
\hline & $\begin{array}{c}\text { Mio PLZ } \\
\text { (1) }\end{array}$ & $\begin{array}{c}\text { Mio PLZ } \\
\text { (2) } \\
\end{array}$ & $\begin{array}{c}\text { Mio PLZ } \\
\text { (3) }\end{array}$ & $\begin{array}{c}\text { Mio PLZ } \\
\text { (4) }\end{array}$ & $\begin{array}{c}\text { Mio PLZ } \\
(5) \\
\end{array}$ & $\begin{array}{l}\% \\
(6) \\
\end{array}$ & $\begin{array}{l}\% \\
(7) \\
\end{array}$ & $\begin{array}{l}\% \\
(8) \\
\end{array}$ \\
\hline 1995 & 306318 & 128183 & 174829 & 3306 & 893131 & 19.6 & 11.2 & 7.4 \\
\hline 1996 & 385448 & 167234 & 212895 & 5319 & 1086491 & 19.6 & 10.8 & 6.9 \\
\hline 1997 & 469372 & 207323 & 257345 & 4704 & 1158653 & 22.2 & 12.2 & 7.7 \\
\hline 1998 & 549467 & 239337 & 305822 & 4308 & 1243436 & 24.6 & 13.7 & 8.8 \\
\hline $\begin{array}{l}\text { (1) and (5) } \\
\text { (2) Labour } \\
\text { (3) Capital } \\
\text { (4) Return } \\
\text { (6) }=(3) /(5) \\
\text { (7) }=(3) /(1) \\
\text { (8) After s } \\
\text { which } \\
\text { Source. }\end{array}$ & $\begin{array}{l}\text { S (1999c). } \\
\text { ome calcula } \\
\text { ome calcula } \\
\text { and calculat } \\
\text { action of an } \\
\text { esponds to }\end{array}$ & $\begin{array}{l}d \text { as the sha } \\
d \text { as the resi } \\
\text { as the aver } \\
\text { tisation cos } \\
\% \text { of capita }\end{array}$ & $\begin{array}{l}\text { of compen } \\
\text { al after sub } \\
\text { e rental use } \\
\text { Here assu } \\
\text { tock value }\end{array}$ & $\begin{array}{l}\text { ion of empl } \\
\text { acting labou } \\
\text { in tenure of } \\
\text { d } 11 \% \text { of }\end{array}$ & $\begin{array}{l}\text { ees in GDP } \\
\text { ind land inc } \\
5 \text { ton of wh } \\
\text { (assumpti }\end{array}$ & on a total & $\begin{array}{l}18.5 \text { millio } \\
\text { nbush and }\end{array}$ & $\begin{array}{l}\text { ectares. } \\
\text { her, 1994), }\end{array}$ \\
\hline
\end{tabular}

The calculated rates may be influenced by the divergence in the wage rates. Such a wage rate effect may, however, be compensated by the change in the employment level, i.e. decreased employment in the case of policies, and other distortions, increasing unit labour cost. If, however, in the considered years the increased wages (see next section) have resulted in the higher labour share of total factor income (e.g. due to a lagged adjustment in employment level), then the estimated rates of return to capital underestimates 'actual' social marginal productivity of capital.

Relying on the above discussion it has been assumed that the social interest rate equals 8 percent, the value close to the estimate of the market lending rate and the marginal return calculated from macroeconomic data.

\section{Conversion factors for capital costs - results}

Estimation results of conversion factors for the capital costs in the year 1997 are presented in Annex Table 18 (private and social capital costs for the entire industry) and in Table 3.7.

44 In a recent study on Polish agriculture Münch et al. (1997) used the 7.5\% rate for the social interest rate for the years 1994-1995. In studies on developing countries the choice of the social opportunity rate is often made in a rather arbitrary way. These rates range between $8 \%$ (Pearson, et al., 1987, for Portugal) and 12\% (Barzelay and Pearson, 1982, for Brazil). Such relatively high values reflect the fact that less developed countries, which are the subject of most of the cost-benefit studies, are characterised by higher marginal productivity of capital compared to developed countries), e.g. due to the low relative endowments in this factor. 
Table 3.7. Conversion factors for capital cost in the milk processing industry, 1997.

\begin{tabular}{|llcc|}
\hline & & Symbol & Values \\
\hline \multirow{4}{*}{ Direct capital } & Conversion factor for capital assets & $\mathrm{CFA}_{\mathrm{d}}$ & 1.03 \\
& Conversion factor for capital recovery factor & $\mathrm{CFI}_{\mathrm{d}}$ & 1.28 \\
& Conversion factor for capital cost & $\mathrm{CFC}_{\mathrm{d}}$ & 1.31 \\
\hline \multirow{4}{*}{ Indirect capital } & Conversion factor for capital assets & $\mathrm{CFA}_{\mathrm{i}}$ & 1.06 \\
& Conversion factor for capital recovery factor & $\mathrm{CFI}_{\mathrm{i}}$ & 1.00 \\
& Conversion factor for capital costs & $\mathrm{CFC}_{\mathrm{i}}$ & 1.06 \\
\hline Source: author's calculation based to data and method described in the text. & & \\
\hline
\end{tabular}

\subsubsection{Social valuation of labour costs}

The private labour cost used in the analysis consists of gross wages plus social security taxes paid by the employer (health-care and pension fund). The rationale for treating these taxes as non-distortive is that they affect all economy sectors in the same way (they have a character of ad valorem taxes) and can, in fact, be seen as a part of the wages that is saved by employees to finance current (health care) or future (pension) services (Monke and Pearson, 1989). Taking, however, into consideration that the pension system, which absorbs the majority of these taxes, is to a substantial degree an instrument of income redistribution biased against the present generation ${ }^{45}$ the 'magnitude' of this bias can be treated as the distortive element in present labour costs. This magnitude, however, can only be crudely assessed. First, one needs to consider that the share of obligatory contributions to the social security fund in Poland amounted to $40 \%$ of gross wages, being substantially above the level in most other European countries (e.g. 30.5\% in Hungary, $27 \%$ in the Czech Republic, 17.7\% in Germany). Second, the guaranteed level of pension payment was set at $68 \%$ of wages, also exceeding the level applied in most other European countries (62\% in Hungary. 44\% in the Czech Republic, 50\% in Germany, 40\% in Great Britain).

Additional distortive influence may arise from two labour-market institutions: (i) the minimum wage and (ii) the unemployment insurance system. Between 1995 and 1998 the legally set minimum wage amounted to $43 \%$ of the average wage. In turn, the unemployment insurance system has been characterised by the average unemployment benefit level amounting to $36 \%$ of the minimum wage and duration of 18 months. Garibaldi and Brixiowa (1997) estimated that these policies in Poland have been characterised by the second highest (after Hungary) degree of generosity among the transition economies.

45 Until the reform of 1999 the system was completely based on the pay-as you-go rule, i.e. the entire volume of currently paid taxes was used to finance the current pensions. In addition, the pension fund needed to be subsidised from the state budget, i.e. from other taxes (e.g. value added and income taxes) or from the budget deficit (i.e. the income of future generations).

46 Data quoted after Filas et al. (2000). 
Other policy and non-policy impacts with potential distorting effect on labour costs have also been in place. These involve:

i. The relatively high level of unionisation in those state-owned economy sectors which require fast modernisation and restructuring, or which are 'declining' sectors such as coal mining, steel production, agriculture. The unionisation has resulted in effective political pressure to increase wages and to limit lay-off of redundant labour;

ii. Economy-wide bias in the degree of subsidising (import protection of direct subsidies) towards labour-intensive activities (mainly agriculture) that may have enhanced the average wage rate.

iii. Distorting effects specific to the milk processing industry include the dominance of the cooperative form of ownership with the majority of employees being the co-operative members. This factor has a labour cost enhancing effect by creating pressure either to elevate wage rates or limit the reductions in redundant employment;

iv. Regional segmentation of the labour market due to the high costs of migration (relative to average wage) accompanied by considerable regional discrepancies in the economic growth. Decreased labour mobility leads to over-payment of labour in privileged regions (and sectors) and underpayment in the regions, which are a reservoir of potential migrants. This factor may have led to depressing the private wage rate in the milk processing industry because most capacities are in rural locations facing above average levels of unemployment;

v. The statistics of recent years indicate the effective indexation of wages (especially in the public sector), which have led to high real increases in the labour costs, exceeding the productivity gains (Kopits, 1999).

The above arguments suggest that it is impossible to make a precise quantitative estimation of the social opportunity cost of labour. However, they made it apparent that numerous factors have been affecting the private labour cost, and that most of them were conducive to the elevation of the private cost above the social, shadow level. In this way the milk processing activity has been taxed. In the further calculation it has been assumed that the over-compensation of both direct and indirect labour input amounts to $15 \%$ of the observed private labour cost. Consequently, the conversion factor for labour costs of 0.85 has been used.

\subsection{Recent Comparative Advantages - Results}

\section{Social and Private Profitability}

Estimated indicators of social and private profitability, DRCs and PCRs, and indicators of market distortions, EPCs and NPCDFs, are displayed in Table 3.8. All estimates have been made in two versions corresponding to alternative definitions of value added, differing in terms of farm milk 
classification. In addition social and private cost-benefit ratios (SCB and PCB) have been calculated to demonstrate possible implications of the choice of indicator for ranking of activities.

\section{Differences among the VA formulations}

Comparing the results for alternative VA formulations it becomes clear that estimates of $\mathrm{DRC}_{1}$ and $\mathrm{PCR}_{1}$ are characterised by higher variation than estimates of $\mathrm{DRC}_{2}$ and $\mathrm{PCR}_{2}$. Exclusion of milk from $\mathrm{VA}$ in $\mathrm{DRC}_{1}$ and $\mathrm{PCR}_{1}$ means that this variation reflects variations in returns only to capital and labour used in processing. In turn inclusion of milk in the VA in $\mathrm{DRC}_{2}$ and $\mathrm{PCR}_{2}$ means that this variation reflects variation in returns to both the capital and labour, and farm milk. The rationale for choosing one of the two approaches hinges upon the question asked. Since the efficiency in using scarce domestic resources in processing farm milk into dairy processed products has been the focus of this study, therefore $\mathrm{DRC}_{1}$ and $\mathrm{PCR}_{1}$ are preferable indices here. Indeed, comparison of estimates based on alternative approaches shows that not only the relative returns to VA differ (the differences in variation) but also different ranking of activities arises - butter appears least socially profitable in terms of $\mathrm{DRC}_{1}$ while yoghurt in terms of $\mathrm{DRC}_{2}$.

Table 3.8. Estimates of coefficients of profitability and distortion, Poland 1997.

\begin{tabular}{|c|c|c|c|c|c|c|}
\hline \multirow[t]{2}{*}{ Description of coefficients } & & Industry & SMP & $\begin{array}{c}\text { Ripening } \\
\text { cheese }\end{array}$ & Butter & Yoghurt \\
\hline & \multicolumn{6}{|c|}{ Farm milk as a tradable input } \\
\hline Domestic Resource Cost & $\mathrm{DRC}_{1}$ & 1.13 & 0.91 & 0.76 & 2.03 & 1.32 \\
\hline Private Cost Ratio & $\mathrm{PCR}_{1}$ & 0.92 & 0.86 & 0.84 & 1.84 & 0.77 \\
\hline Effective Protection Coefficients & $\mathrm{EPC}_{1}$ & 1.26 & 0.99 & 0.98 & 1.12 & 1.65 \\
\hline $\begin{array}{l}\text { Coefficient of Distortion } \\
\text { in Domestic Factor Costs }\end{array}$ & $\mathrm{DDFC}_{1}$ & 1.03 & 0.93 & 1.08 & 1.02 & 0.95 \\
\hline \multicolumn{7}{|c|}{ Farm milk as a domestic resource } \\
\hline Domestic Resource Cost & $\mathrm{DRC}_{2}$ & 1.04 & 0.98 & 0.93 & 1.10 & 1.16 \\
\hline Private Cost Ratio & $\mathrm{PCR}_{2}$ & 0.97 & 0.97 & 0.95 & 1.09 & 0.85 \\
\hline Effective Protection Coefficient & $\mathrm{EPC}_{2}$ & 1.09 & 1.01 & 1.00 & 1.01 & 1.33 \\
\hline $\begin{array}{l}\text { Coefficient of Distortion } \\
\text { in Domestic Factor Costs }\end{array}$ & $\mathrm{DDFC}_{2}$ & 1.02 & 1.00 & 1.03 & 1.00 & 0.98 \\
\hline Social Cost Benefit Ratio & $\mathrm{SCB}$ & 1.03 & 0.98 & 0.93 & 1.09 & 1.10 \\
\hline Private Cost Benefit Ratio & PCB & 0.98 & 0.97 & 0.96 & 1.08 & 0.90 \\
\hline \multicolumn{7}{|c|}{$\begin{array}{l}\text { Subscripts (1) and (2) refer to the definitions of value added. The (1) stands for value added including farm milk while } \\
\text { (2) stands for value added excluding farm milk. }\end{array}$} \\
\hline \multicolumn{7}{|c|}{ Source: author's calculations based on methods and data described in text. } \\
\hline
\end{tabular}

According to the argument extended by Masters and Winter-Nelson (1995), ranking of activities arising from various indicators of comparative advantage stems from their algebraic properties: lower variation of estimates based on indicators with a higher share of total costs in nominator leads to 
different rankings. Variation in $\mathrm{DRC}_{1}$ estimates tends to be higher than variation in $\mathrm{DRC}_{2}$ estimates, which in turn tend to be higher than variation in SCB estimates.

Further discussion in this study will focus on the estimates based on value added from which farm milk is excluded, i.e. $\mathrm{DRC}_{1}, \mathrm{PCR}_{1}$ and respective indices of distortions, $\mathrm{EPC}_{1}$ and $\mathrm{DDFC}_{1}$.

\section{General results}

The activity 'milk processing industry' proved to be competitive only in private prices. Private profitability $(\mathrm{PCR}<1)$ is mainly achieved by the 'positive' effective protection $(\mathrm{EPC}>1)$ which compensates both for the lack of comparative advantage (DRC $>1)$ and for the implicit taxation of the industry through increased factor costs (DDFC $>1)$.

Of the four product-specific activities, two - SMP and ripening cheese - appear to be socially profitable. All activities are privately profitable except butter. The contributions of various components to private profitability are different in each case. Milk processing industry, ripening cheese and SMP are enjoying effective protection, the extent of which depends on: (i) the divergence in the specific output market, (ii) the specific intensities in tradable inputs and (iii) nominal protections in the respective input market. Net subsidisation through decreased factor costs (capital and labour), has only been detected in yoghurt and SMP; other activities are taxed through factor markets. Net transfers through factor markets evidenced by the DDFC vary according to the capital/labour proportions (see also PAM analysis in the subsequent section); the net subsidisation in the case of yoghurt and SMP reflects relatively high capital intensity in VA of the two products.

\section{Sources of differences in efficiency}

The question emerges of how the differences among the product-specific DRCs can be explained. Previous sections, in particular Chapter 2, have already delivered a set of relevant information. Indices estimated here add other evidence in that they quantify effects of policy and non-policy influences on the incentives faced in the industry.

The comparative advantage of ripening cheese may have been fostered by the investment-driven expansion of this activity in recent years. Another influence promoting the efficiency of this activity comes from competitive market conditions, evidenced here by the lack of effective protection and taxation through the factor market (effect of a high labour share in VA). The former may have contributed to the favourable performance by embodied technological change (economies of rapid growth), while the latter may have limited technical and scale inefficiencies.

As far as the yoghurt is concerned, its recent enormous output expansion appears to have occurred under high effective protection and net subsidy through factor markets (effect of a high capital share in VA). Therefore the observed lack of social profitability could be a net outcome of the positive effects of technological progress, and adverse effects on technical and scale efficiency 
resulting from low competitive pressure. According to the argument put forward in Chapter 2, subsidisation of capital cost carried out with allocation criteria neglecting the importance of scale efficiency may have been particularly detrimental for competitiveness in activities where economies of scale are increasingly important, as in the case of yoghurt production. Detailed analysis of this phenomenon will be the subject matter of Chapter 6 .

SMP appears socially profitable. The activity faces almost neutral effective protection $(\mathrm{ECP}=0.99)$, however it received substantial net transfers through factor costs. In recent years, the output of SMP showed weak declining tendency, which suggests that there were no contributions from the economies of rapid growth. Nevertheless, there are other factors, which may help explain the favourable performance of this activity. First, in the pre-transition past, the activity has, probably, suffered much less from politically determined constraints on industrial concentration (Łoś, 1985). Substantial investments in this activity have been carried out in the late eighties. In the more recent past the product enjoyed a good reputation for it represented a major source of export earnings, while in 1992 it became the direct target of market stabilisation policy in the sector.

Butter turned out to be socially unprofitable. Its output showed a declining tendency in 19921997. Low efficiency $(\mathrm{DRC}=1.89$ ) is probably a consequence of relatively low modernisation investments and low technical and scale efficiency. A relatively low level of specialisation may explain the last factor in this activity while the low technical efficiency may be associated with relatively high over-capacities. Both may have a similar explanation, namely, despite low, or even negative, profitability the majority of enterprises engage in butter production and even maintain some reserve capacities, which is because butter production is often treated as a buffer to manage seasonal swings in milk supply and unforeseeable shocks in the markets for other dairy products. Hence, possibly, the DRC may underestimate the social profitability unless other benefits from maintaining the butter capacity are explicitly taken into account.

On the whole, the results seem to be consistent with general expectations of the structure of comparative advantages in Poland, where relatively low wages and relatively high capital costs should have favoured a comparative advantage of products relatively intensive in labour (ripening cheese) and disfavour those which are relatively capital-intensive (yoghurt).

47 These benefits include e.g. the avoided costs of not being able to process the milk in periods of its increased supply from farms or due to the market-enforced limited use for production of other dairy products. An important element of this "insurance" mechanism is played by the storability of butter and the state intervention system for butter. Alternatively, one could charge other products with some of the costs related to maintaining the reserve butter capacity. This issue also demonstrates the general problem of separating product specific costs. 


\section{Implications for modernisation and restructuring policy}

The evidenced lack of comparative advantage at the industry level, in conjunction with the varying degree of social and private profitability for product-specific activities, implies that the industry requires modernisation and restructuring. The following points can be made to interpret the results in terms of the desired adjustments to the evidenced incentives.

First, the industry may need to further change product composition of output by limiting the capacities of non-profitable products and expanding capacities of profitable ones. Such restructuring would require reallocation of resources and would be time consuming because fixed assets need to be used-up and new investments accomplished. ${ }^{6}$ This process would lead to some new equilibrium product composition implied by relative private profitability.

Second, due to the economies of rapid growth and dynamic changes in prices, relative profitability and the subsequent target structure of such reallocation may, however, change over time. For example, embodied technological change can reinforce relative profitability of products favoured by initial incentive structure (see Annex Table 19). The point is that in such dynamic circumstances current incentive structure may not suffice to efficiently guide investment allocation among activities. Knowledge may be lacking about (i) price trends over the lifetime of alternative investment projects in the industry, as well as (ii) productivity gains associated with new technologies. As for the former, an important contribution to closing this information gap can be expected from the analysis in the following chapter.

Third, the discrepancy among shadow incentives, depicted by DRC, and actual ones, depicted by PCR, implies a danger that policy-induced and other transfers may be perceived by firms as a reliable 'instrument' for dealing with low efficiency, which may weaken the motivations to modernise and restructure. The importance of current policy and non-policy distortions in industry restructuring and modernisation can be assessed by examining the results in terms of consistency between the socially desirable incentive structure and that actually driving the industry restructuring suggested by private profitability. It turns out that industry-wide, net subsidising mitigates the pressure for efficiency upgrade - private profitability exceeds social ones. As previously argued, although policy transfers through decreased capital costs have been designed to upgrade productivity by helping to finance new investments they also may induce a number of undesirable effects.

Fourth, using Government intervention to cope with the low efficiency can also be evidenced by the relationship between the structure of comparative advantages and the structure of protection. For this purpose, of the two indices of protection the EPC is more appropriate because the index of transfers in factor costs, DDFC, is very much influenced by the inherent factor intensity of activities.

48 The speed of such reallocation is influenced by the costs of external financing to credit net investments and the perceived risk and uncertainty of the faced incentives. Hence the efficiency of financial intermediation, price stability in output markets and reliability of policies are crucial determinants. 
It appears that the highest effective protection is received by yoghurt, the product displaying the worst performance in terms of DRC. The fact that as an importable activity yoghurt is 'easier' to protect does not undermine the argument, because one could reason that this only implies that the Government would react to lobbying pressure if the 'conditions' for support policy were as favourable as in the case of yoghurt. As a matter of fact, in the recent past, on occasions of particularly adverse market development, the industry has quite clearly articulated the demand for more extensive market support.

\section{Further disaggregation of distortions using Policy Analysis Matrices}

Policy Analysis Matrix has been used to further disentangle the components of social and private profitability and the sources of divergence between the two efficiency measures. Divergence for each category has been calculated in a way described in previous sections. Only for outputs is the total divergence broken down into the direct policy effects and remaining distortions. Results are presented in the Table 3.9.

The results for milk processing industry indicate that total divergence in the value of revenues corresponds to the average nominal protection rate of $8 \%$ (nominal protection coefficient equals 1.08). This result is a net outcome of protective policy distortion and the 'protective' effect of the remaining distortion. The industry is taxed through protection of tradable inputs (amounting to the 6\% nominal rate of protection). The industry is significantly taxed through a distorted labour market: transfers from the industry through this distortive effect amount almost to one third of 'gains' incurred via total distortion in the output market. Capital market distortion represents a transfer to the industry - the net effect of credit subsidies and taxation of import of investment goods. As a result of all detected effects the industry appears to receive a net transfer of 55 PLZ per ton of processed farm milk, which corresponds to about $5 \%$ of its revenues and about $20 \%$ of the social value of domestic resources engaged. Of these transfers only 11 PLZ represents the net outcome of direct policy distortions while the remaining 44 PLZ is contributed by the 'remaining' distortion in the product market. 
Table 3.9. $\quad$ PAM and the corresponding indices of policy effects and profitability for selected commodities in the industry, 1997.

Milk processing industry (in PLZ per ton of processed farm milk).

\begin{tabular}{|c|c|c|c|c|c|c|}
\hline & \multirow[t]{2}{*}{ Revenues } & \multicolumn{4}{|c|}{ Costs } & \multirow{2}{*}{ Profits } \\
\hline & & Tradables & Farm Milk & Labour & Capital & \\
\hline Private Prices & 1062 & 188 & 571 & 186 & 92 & 25 \\
\hline Social Prices & 981 & 178 & 564 & 158 & 112 & -30 \\
\hline Total divergence & 81 & 10 & 7 & 28 & -20 & 55 \\
\hline Direct Policy Distortion Total & 36 & 10 & 7 & 28 & -20 & 11 \\
\hline Remaing distortion & 44 & 0 & 0 & 0 & 0 & 44 \\
\hline NPC & 1.08 & 1.06 & 1.01 & 1.18 & 0.82 & \\
\hline & Prv. VA/T & Soc. VA/T & EPC & $\overline{\mathrm{DRC}}$ & PCR & DDFC \\
\hline Milk as non-tradable $\quad\left(\mathrm{DRC}_{1}\right)$ & 874 & 804 & 1.09 & 1.04 & 0.97 & 1.02 \\
\hline Milk as tradable $\quad\left(\mathrm{DRC}_{2}\right)$ & 303 & 240 & 1.26 & 1.13 & 0.92 & 1.03 \\
\hline
\end{tabular}

Skimmed milk powder (in PLZ per ton of output).

\begin{tabular}{|c|c|c|c|c|c|c|}
\hline & \multirow[t]{2}{*}{ Revenues } & \multicolumn{4}{|c|}{ Costs } & \multirow[t]{2}{*}{ Profits } \\
\hline & & Tradables & Farm Milk & Labour & Capital & \\
\hline Private Prices & 5188 & 463 & 3711 & 501 & 371 & 142 \\
\hline Social Prices & 5089 & 429 & 3635 & 426 & 512 & 87 \\
\hline Total divergence & 98 & 34 & 76 & 75 & -142 & 54 \\
\hline Direct Policy Distortion Total & 24 & 34 & 76 & 75 & -142 & -20 \\
\hline Remaing distortion & 74 & 0 & 0 & 0 & 0 & 74 \\
\hline \multirow[t]{2}{*}{ NPC } & 1.02 & 1.08 & 1.02 & 1.18 & 0.72 & \\
\hline & Prv. VA/T & Soc. VA/T & EPC & $\mathrm{DRC}$ & PCR & DDFC \\
\hline Milk as non-tradable $\left(\mathrm{DRC}_{1}\right)$ & 4725 & 4661 & 1.01 & 0.98 & 0.97 & 1.00 \\
\hline Milk as tradable & 1014 & 1026 & 0.99 & 0.91 & 0.86 & 0.93 \\
\hline
\end{tabular}

Ripening cheese (in PLZ per ton of output).

\begin{tabular}{|c|c|c|c|c|c|c|}
\hline & \multirow[t]{2}{*}{ Revenues } & \multicolumn{4}{|c|}{ Costs } & \multirow{2}{*}{ Profits } \\
\hline & & Tradables & Farm Milk & Labour & Capital & \\
\hline Private Prices & 8287 & 672 & 5375 & 1454 & 418 & 367 \\
\hline Social Prices & 8213 & 620 & 5301 & 1236 & 505 & 552 \\
\hline Total divergence & 74 & 53 & 74 & 218 & -87 & -185 \\
\hline Direct Policy Distortion Total & 0 & 53 & 74 & 218 & -87 & -258 \\
\hline Remaing distortion & 74 & 0 & 0 & 0 & 0 & 74 \\
\hline \multirow[t]{2}{*}{ NPC } & 1.01 & 1.08 & 1.01 & 1.18 & 0.83 & \\
\hline & Prv. VA/T & Soc. VA/T & EPC & $\mathrm{DRC}$ & PRC & DDFC \\
\hline Milk as non-tradable $\quad\left(\mathrm{DRC}_{1}\right)$ & 7614 & 7593 & 1.00 & 0.93 & 0.95 & 1.03 \\
\hline Milk as tradable $\quad\left(\mathrm{DRC}_{2}\right)$ & 2239 & 2292 & 0.98 & 0.76 & 0.84 & 1.08 \\
\hline
\end{tabular}

Butter (in PLZ per ton of output).

\begin{tabular}{|c|c|c|c|c|c|c|}
\hline & \multirow[t]{2}{*}{ Revenues } & \multicolumn{4}{|c|}{ Costs } & \multirow[t]{2}{*}{ Profits } \\
\hline & & Tradables & Farm Milk & Labour & Capital & \\
\hline Private Prices & 7176 & 685 & 5784 & 823 & 481 & -597 \\
\hline Social Prices & 7044 & 641 & 5769 & 699 & 585 & -651 \\
\hline Total divergence & 132 & 44 & 15 & 123 & -104 & 54 \\
\hline Direct Policy Distortion Total & 0 & 44 & 15 & 123 & -104 & -79 \\
\hline Remaing distortion & 132 & 0 & 0 & 0 & 0 & 132 \\
\hline \multirow[t]{2}{*}{ NPC } & 1.02 & 1.07 & 1.00 & 1.18 & 0.82 & \\
\hline & Prv. VA/T & Soc. VA/T & EPC & DRC & PCR & $\mathrm{DDFC}$ \\
\hline Milk as non-tradable $\quad\left(\mathrm{DRC}_{1}\right)$ & 6491 & 6403 & 1.01 & 1.10 & 1.09 & 1.00 \\
\hline Milk as tradable $\quad\left(\mathrm{DRC}_{2}\right)$ & 707 & 634 & 1.12 & 2.03 & 1.84 & 1.02 \\
\hline
\end{tabular}

Yoghurt (in PLZ per ton of output).

\begin{tabular}{|c|c|c|c|c|c|c|}
\hline & \multirow[t]{2}{*}{ Revenues } & \multicolumn{4}{|c|}{ Costs } & \multirow[t]{2}{*}{ Profits } \\
\hline & & Tradables & Farm Milk & Labour & Capital & \\
\hline Private Prices & 2630 & 877 & 659 & 427 & 411 & 257 \\
\hline Social Prices & 2150 & 836 & 649 & 363 & 517 & -215 \\
\hline Total divergence & 480 & 41 & 10 & 64 & -106 & 472 \\
\hline Direct Policy Distortion Total & 679 & 41 & 10 & 64 & -106 & 671 \\
\hline Remaing distortion & -199 & 0 & 0 & 0 & 0 & -199 \\
\hline \multirow[t]{2}{*}{$\mathrm{NPC}$} & 1.22 & 1.05 & 1.01 & 1.18 & 0.79 & \\
\hline & Prv. VA/T & Soc. VA/T & EPC & $\overline{\mathrm{DRC}}$ & PCR & DDFC \\
\hline Milk as non-tradable $\left(\mathrm{DRC}_{1}\right)$ & 1753 & 1314 & 1.33 & 1.16 & 0.85 & 0.98 \\
\hline Milk as tradable $\quad\left(\mathrm{DRC}_{2}\right)$ & 1095 & 665 & 1.65 & 1.32 & 0.77 & 0.95 \\
\hline
\end{tabular}




\section{Dynamic Comparative AdVANTAges - EfFECTS OF INTEGRATION WITH THE EU}

This chapter investigates dynamic comparative advantages in the industry between the base year, 1997, and 2010. The chapter is divided into four major sections. In the first one, scenarios for macroeconomic development are defined. The second one discusses the scenario for harmonisation of sectoral policy with the CAP. The third section outlines the scenario for technical change. The fourth one presents the results of simulations - projected development of dynamic comparative advantages in the industry.

\subsection{Macroeconomic Scenarios}

Macroeconomic development and macro-policies influence sectoral competitiveness in several ways. Real exchange rate affects the relative prices of tradable outputs and inputs and non-tradable components. Economic growth is related to an increase in labour productivity (capital accumulation and technological change), which cause an increase in the real wages. Macroeconomic stabilisation decreases the general investment risk and makes investment projects more accountable. Real interest rates may decline due to the improved efficiency of financial intermediation. These changes coming from outside the sector are manifested through changes in the relative prices faced. They bring about the pressure for modernisation and restructuring and at the same time improve the feasibility of such adjustment in the activities where the scope for productivity gains is high. Therefore, macroeconomic development induces changes in comparative advantages, the process which is referred to as dynamic comparative advantages.

\subsubsection{Economic growth}

Developments of all macro-variables relevant here are closely related to the rate of economic growth. ${ }^{-9}$ For the CEECs, which are candidates for EU membership, the prospects for fast growth and the resulting economic convergence on the EU development level (usually measured by the GDP per 
capita) can be evaluated on the basis of the most recent trends and projections of economic growth theories. While the ability to sustain economic convergence is an implicit condition of the EU membership, it is also true that the prospective member-countries hope that the EU membership itself would contribute positively to the pace of convergence (Orłowski, 1998).

Seen from the perspective of neo-classical growth theory (e.g. Barro, 1997), Poland's prospects for economic convergence on the high-income members of the EU are based on the negative relationship between the initial level of real per capita GDP and the attainable growth rate. The convergence property is derived from the neo-classical model of diminishing returns to capital: economies that have less capital per worker (relative to their long-term level) tend to have higher rates of return and higher growth rates. However, the convergence and the growth rates are conditional on the 'quality' of government policy and several other crucial initial conditions (i.e. apart from the initial level of the GDP per capita) including: schooling, life expectancy, government consumption, rule of law, the inflation rate and potential for improving terms of trade (Barro, 1997; Frenkel and Hemmer, 1999). Evidence provided by Barro and Sala-I-Martin (1991) shows that regions (and countries) which are economically and politically integrated, as in the case of U.S. states or regions of the EU, experience economic convergence at a rate of $2 \%$ per year (the rate of making the gap vanish between the poor and rich regions).

Using two models of growth estimated from the cross-country data and control variables describing both the initial conditions and the policy prerequisites for the attainment of sustained growth rates, Fisher et al. (1998) projected for Poland per capita growth rate of 5.42\%, using the Barro (1991) equation, and 4.75\%, using the Levine-Renelt (1992) equation. The authors have estimated that it should take Poland, respectively, 18 or 23 years to converge to low-income EU levels. 1 However, the estimates only reflect the proxy variables for advancements in the transitional reforms observed in 1995, and could not predict whether future policies would improve the convergence conditions.

49 It does not mean that economic growth can be simply seen as a determinant of the exchange rate, labour costs and interest rates. In fact the flow of causalities is complex and involves policy influences. As discussed later, the attainable growth rates are manifestations of other fundamental forces: capital accumulation, technological change and reduction of technical and other inefficiencies. Between growth rates and major macroeconomic variables there is, however, a structural relationship, which enables to see their paths of development as closely correlated.

50 Based on empirical evidence the preconditions for economic convergence have been identified, which have led to the formulation of the so-called 'Washington Consensus' (Williamson, 1993) a list of recommendations for economic policy. These include: (i) low budget deficits and targeting public money to education, science and infrastructure, (ii) a low tax rate and a broad tax base, (iii) liberalisation of the financial sector, the exchange rate policy and foreign trade in goods and capital, (iv) privatisation and protection of the private property law.

51 They have also estimated that it may take Poland 21-24 years to make up for GDP per capita 'lost' during the socialism era. 
The 1999 were for Poland the eighth year of consecutive growth. Average growth rate during that period averaged $5.0 \%$. Significant improvement in the institutional reforms and in such macroeconomic variables such as: inflation rate, rate of gross capital formation and budget deficit have been experienced since 1995 (see Annex Table 20). The year 1999 was especially critical since broad economic reforms (health care, social security, education systems, administration) were implemented. These conditions can be expected to enhance opportunities for sustained and fast growth in the medium term.

EU membership is bound to significantly influence growth prospects. Banse (1999) estimates that between 2000 and 2010 the cumulative effect of EU accession on Poland's GDP may amount to about 8 percentage points. First, the beginning of accession negotiations in 1998 spurred the pace of reform implementation. The prospect of EU membership is also believed to have positively influenced foreign investors' attitudes. Future full accession may affect the growth rate in several ways, of which the net long-run effect should be positive. Positive consequences involve pro-competitive effects and gains from regional liberalisation of trade in goods, and to a large degree, in factors. In particular the increase in capital transfers in the form of FDI can accelerate the productivity improvements in the manufacturing sector. Experience from previous rounds of EU enlargements suggests that budgetary transfers may also have a positive growth effect, provided they are effectively allocated (e.g. to improve general and rural economic infrastructure) and not used up to increase domestic consumption (Orłowski, 1996). Nevertheless, in the short term, the membership requirements, for example, may be associated with increased administrative costs. There are also fears that social and labour standard policy may 'artificially' increase the costs of labour.

The most recent strategic documents of the Polish government outlining growth prospects clearly stress the 'conditionality' aspects and foresee three possible scenarios including: the 'active' one with a $7-8 \%$ growth rate, the 'passive' with a $4-5 \%$ growth rate and the 'warning' with a $3-4 \%$ growth rate (Ministry of Finance, 1999).

Relying on the above conclusions, three scenarios for economic growth have been assumed in this study, namely: the Low-growth with a $3 \%$ growth rate, the Base - with a $5 \%$ growth rate and the High-growth with a $7 \%$ growth rate.

\subsubsection{Real exchange rate}

It is commonly agreed that further transition and economic growth in Poland will be accompanied by appreciation of the real exchange rate (EU Commission, 1997; Orłowski, 1997; Bonjec et al., 1998; Krajnyak and Zettelmeyer, 1997). However, the pace of this process is difficult to predict. In economic literature there are two approaches used to quantify such predictions. In the first, one treats the absolute purchasing power parity (PPP) as a core reference point for the long-run equilibrium exchange rate and derives the rate of appreciation, making an assumption about the pace of the 
convergence to this 'equilibrium' (e.g. Bonjec, et al., 1998). The second is based on the notion that there is an identifiable structural relationship between (equilibrium) price levels (and hence the RER) and basic economic characteristics, such as per capita income, openness to international trade, share of nontradables in output and others (Kravis and Lipsey, 1988). To a large extend the relationship between the RER and these structural characteristics are based on the so called Ballasa-Samuelson effect ${ }^{22}$ (see also Annex Table 21). The latter approach seems more suitable for the present study, as it promises a way in which assumptions on various macroeconomic variables can be synchronised and made consistent with those on exchange rate development.

Studies focused on the forces driving the real exchange rate in the transition economies (Halpern and Wyplosz, 1996; Kopits, 1999) indicate at the core function played by the productivity improvements in the tradable sector explainable by the investment-led technological improvements, as well as improvements in the allocative and x-efficiencies attributable to the economic reforms of transition (internal and external liberalisation, privatisation, institutional change and others). Transition economies are characterised by high potential for such productivity improvements because the technological gaps and initial inefficiencies are high.

\section{Assumption for the RER changes}

For the simulation analysis intended in this study one needs to know how, in a numerical sense, the RER will influence the relative prices in the analysed industry. The analysis of dynamic comparative advantage will use domestic real value (purchasing power) of PLZ in 1997 as a numeraire. This is equivalent to the assumption of nominal exchange rate changes, for example appreciation (fewer units of Polish currency per unit of a reference currency, the USD) in an non-inflationary condition, whereby a decline in the nominal (and hence real) prices of tradables is accompanied by an increase in the nominal (and hence real) prices of nontradables. Such a situation leads to the rise in the Polish price level in the sense that: (i) the USD-denominated value of the basket of goods that can be purchased in Poland for 1 PLZ increases, or, (ii) the comparative price level, ratio of PPP to NER, increases.

The approach to estimating the relationship between the changes in the GDP and the changes in RER and hence the changes in the prices of tradables is presented in the Annex Table 4.2. Crosssectional comparison based on data for the OECD countries quoted in the 'Main Economic Indicators' (OECD 1999$)$ and recent trends in the price and the GDP development in Poland have been used. It

\footnotetext{
${ }^{52}$ The Balassa-Samuelson theory explains why prices of nontradables are lower in poor countries. The theory is based on an observation that income differences among countries mainly result from the differences in productivity in the tradables sectors. Economic growth and accompanying growth in productivity in the tradables sector are conductive to higher incomes (economy-wide) and to higher prices of nontradables (hence to appreciation of RER), because of the relatively lower scope for labour productivity improvements (thus for preventing labour cost increases) in nontradables sector.
} 
has been concluded that in the investigated time horizon one may reasonably assume that real prices of tradables (the prices of which are fully transmitted from the world market by the NER) will decline proportionately to the changes in the GDP (per capita) with a constant elasticity of -0.76 . Thus the yearly rates of appreciation for the three macroeconomics scenarios amount to $-2.28 \%,-3.80 \%$ and $5.32 \%$, respectively for the Low-growth, Base and High-growth scenarios. These rates represent changes in real prices of tradable components in relation to the base year situation (i.e. 1997).

It has been assumed that the long-term, equilibrium, RER between EURO and USD will remain at its 1997 level.

\subsubsection{Labour productivity and labour costs}

The economy-wide gains in labour productivity are a major factor behind the expected increases in the costs of labour in the industry. Other forces include the labour market institutions, policies and development of general infrastructure (road network, telecommunication, housing market etc.) responsible for divergence of private labour costs from their shadow values. Major characteristics of the labour market in Poland in recent years have been described in Chapter 3. As far as future development is concerned, labour costs are expected to be mainly driven by the productivity gains related with economic growth. The prospects for the contribution of distorting components are rather ambiguous. On the one hand, the broad economic reforms implemented until 1999 should limit the scope for pulling up the general wage level in the state sectors above the level justified by productivity gains. On the other hand, compliance with the employment and social standards of EU may, at least in the short-term, induce an increase in the labour costs.

One can argue, however, that the functional efficiency of the labour market in terms of employment and wage flexibility is indispensable for a successful accession to the EU because of the great demand for economy restructuring. Such flexibility may further be necessitated given Poland's intention to converge to the conditions of the European Monetary Union (EMU). Among the conditions of the EMU the exchange rate stability may impose the greatest challenge, which not only translates to a need for faster restructuring and but also requires flexible factor markets (Orłowski, 1998; Kopits, 1999). Moreover, wage flexibility and smooth labour re-allocation among economy sectors should enable adjustments to external shocks in order to avoid increases in unemployment.

Consequently, the future increases in labour costs are assumed to follow the rate of productivity increases, measured in terms of the GDP per employee, at least in the Base and High-growth scenarios. In the Low-growth scenario the labour costs are allowed to increase at a rate $0.5 \%$ higher than the productivity improvements, which may be regarded as a reason for the slower growth rate (due to lower effective returns to investments) and/or a higher unemployment rate (due to substitution for labour-saving technologies). 
In turn, economy-wide, the improvement in labour productivity is assumed to be $2 \%$ below the rate of GDP growth in the High-growth scenario, $1 \%$ in the Base scenario and equal to the GDP growth in the Low-growth scenario. This means that higher rates of growth are associated with higher rates of employment growth. This assumption is based on 'Okun's Law', predicting, that for every percentage point of growth in the GDP above the trend rate (assumed here to amount 5\%) the unemployment rate is expected to decline by one half percentage point (Dornbusch and Fischer, 1994). This assumption embedded here in the simulation scenarios corresponds to one of the greatest challenges of economic policy to be faced by Poland, namely, curbing the unemployment level during the time of deep economy restructuring (Orłowski, 1998).

\subsubsection{Interest rates}

The same rationales behind the expectations of growth rates underlie the projections of future real interest rates. This is because the interest rate reflects the marginal productivity of capital in the economy - the demand side of the financial capital market.

Opportunity costs for investment capital will also be affected by the efficiency of financial intermediation. Improved efficiency of the banking system may have two contradictory effects. First, it diminishes the margin between the saver and borrower interest rates, which results in the tendency to a lower borrower interest rate. Second, it improves the allocation of financial resources economywide, thus enhancing the marginal productivity of capital.

The integration of domestic capital market with the foreign ones (here associated with liberal reforms and the EU-accession) is not sufficient to expect the elimination of the interest rate gap in a short time (Hirshleifer, 1970). Although observed real interest rates may differ from the marginal return to capital in the short term, because of monetary and fiscal policy adjustments, assuming competitive financial intermediation, they must converge on its true opportunity cost in the long-term.

The estimated real interest rate for the years 1995-1998, equal to $8 \%$, is assumed to represent the true social opportunity costs of financial capital in the years of simulation. The rates will not be differentiated among the three scenarios, mainly because the net effect of various factors associated with the growth rate is rather ambiguous and difficult to predict.

\section{Summary of macroeconomic assumptions}

Macroeconomic assumptions are summarised in the Table 4.1. These assumptions suggest that in the medium term Poland will sustain its status of converging economy. These relatively high rates of macroeconomic changes are expected up to 2010 but not necessarily beyond 2010 . 
Table 4.1. Summary of assumptions for macroeconomic variables and the corresponding convergence properties, relative to OECD average. (1)

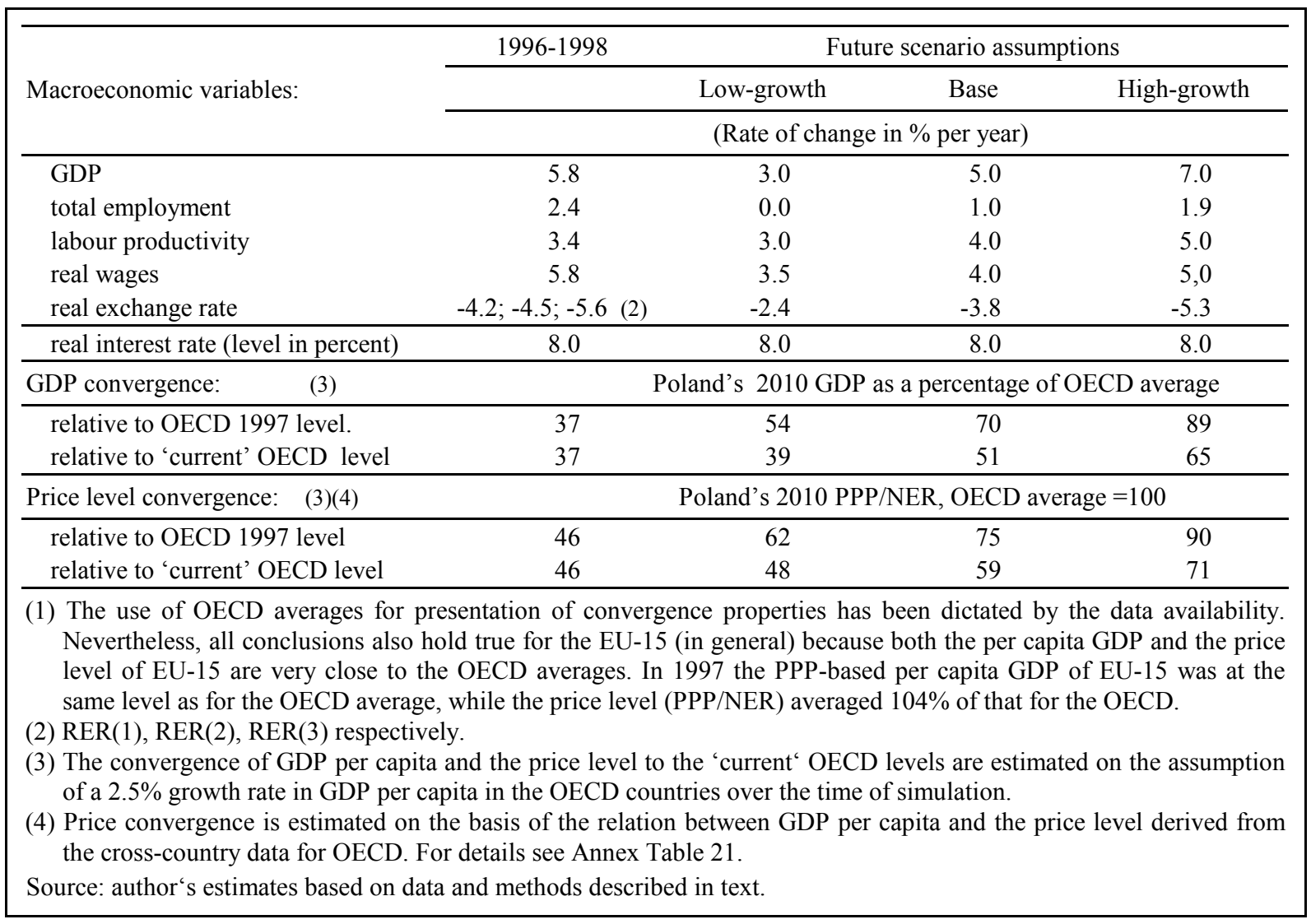

\subsection{Harmonisation with the CAP}

\subsubsection{Scenario for output prices}

Although the exact date of Poland's accession to the EU remains an open question, the projections most often expressed fall between 2003 and 2005. It is important for the scenario formulation that the moment of prospected accession can (more or less) coincide with the implementation of Agenda 2000 reform in the dairy sector. An early accession without a transition period would mean that Polish dairy prices would need to be fully adjusted to the EU price levels before the beginning of the EU's price reduction (i.e. in a case of accession before 30.06.2005) or before the full accomplishment of the reductions (i.e. in a case of accession between 01.07.2005 and 30.06.2007). Because of this uncertainty a working assumption is applied here, namely, it is assumed that the accession takes place in 2004, and that alignment of prices will be carried out in a gradual manner, starting in 2004 (the first year with partly adopted prices) and ending in 2007, i.e. after full implementation of the intervention price cuts in the EU. This assumption suggests a transition period for implementation of market policies. 


\section{Price changes by the 2003}

Between 1997 and 2003 the private producer prices will be driven by the world market prices (Annex Table 22) and domestic policies and other distortions. It is assumed that the extent of divergences in terms of their tariff/subsidy equivalents will stay at their 1997 level, which means that domestic prices will move with the changes in the world market prices (including the effects of RER).

\section{Price harmonisation with the EU}

The adjustment to the EU price levels is to begin in 2004, and end in 2007. The year 2007 is also the year of the accomplishment of the AGENDA 2000 price cuts in the EU dairy sector. $\frac{53}{\text { Hence the full }}$ implementation of the price cuts in the dairy regime of CAP and Poland's alignment to the CAP prices are assumed to coincide. The appropriateness of the assumed timing of price alignment will not be discussed in detail because of its minor relevance for this study. 54 The focus is on the ultimate outcome of the policy harmonisation under a full-integration scenario, which is assumed to be accomplished by 2007.

The scenario for price harmonisation assumes the elimination of price gaps between the two markets. For this purpose the base period's (1997) prices in the EU and Poland are first compared. The EU prices are represented by intervention prices for SMP and butter and the EU market prices for the remaining dairy commodities. However, because of the assumed timing of price alignment the new reformed EU prices represent the relevant target for the harmonisation process. To identify the relevant future price gaps for the full range of commodities used in the simulation two questions needed to be answered. The first is: what the new price levels of the 'non-intervention' dairy commodities will be (only the new intervention prices for SMP and butter are known with precision). The second is: what the positioning of the Polish prices relative to the prices realised by producers from other member states will be.

\section{Benchmark levels for price harmonisation}

As a result of the Agenda 2000 reform intervention prices of SMP and butter are to be reduced by $15 \%$ to the predetermined levels. ${ }^{65}$ These new prices have been used as the target prices for Polish producers of butter and SMP. This assumption derives from the expectations that (i) at least for

53 O.J. of the EC (1999) or Agra Europe (1999).

54 Alternative options for policy harmonisation have their own merits, threats and constraints (economic and political). For example, given the established timetable for the Agenda 2000 reform in the dairy sector, in the case of an "early accession", the transition period for full price harmonisation assumed here enables to avoid the confusion of economic incentives which would follow from the increase of prices in Poland already in 2004 (i.e. in the assumed accession year), exactly one year before the Agenda 2000 price cuts are due to phase in. For a discussion of the various options of price alignment strategy faced by the new accession countries see Tangermann and Josling (1994).

55 O.J. of the EC (1999) or Agra Europe (1999). 
several years after accession, Polish producers may find it difficult to access market channels guaranteeing prices of these two commodities above intervention levels and (ii) Poland's net export supply in SMP and butter may even increase, because the possible difficulties with access to marketchannels in other dairy commodities may make these two products with administrative prices attractive substitutes.

The issue of benchmark prices for price harmonisation in other dairy products is less straightforward. According to the market effects of the CAP dairy regime the expected price adjustments for 'non-intervention' dairy commodities are likely to reflect the changes in the costs of farm milk input implied by the cuts in intervention prices. Like butter and SMP, all non-intervention products in the EU are exportables, which means that under restrictive import access arrangements (import entry prices being much in excess of domestic prices and small minimum access tariff quotas 5 domestic market prices are determined by the export subsidies and prices on the world market. The export subsidies are, in general, aimed to just compensate for the increased costs of farm milk - the major factor in the procedure for establishing the export subsidy is specific fat and non-fat content (Agra Europe CAP Monitor, 1999). Despite high tariff protection price discrimination against domestic consumers (i.e. in excess of the margin of export subsidy) is prevented by a high degree of competition within the EU market. Consequently, it can be expected that: (i) a reduction in intervention prices for SMP and butter will result in the reductions of export subsidies just to a degree reflecting reductions in the costs of farm milk input, while (ii) the competitive conditions should guarantee the reduction in the domestic prices to a degree just equal to this (marginal) cost reduction.

Other effects involved in price formation include: (i) technological change and consumer preferences that shift the supply and demand curves in markets for specific dairy products (which are not followed by adjustments in export subsidy), (ii) constraints imposed on price policy such as limits on volumes of and expenditures on export subsidy set by the WTO. The latter effect may, in fact, be important at least for cheeses and the group of 'other dairy products' for which export subsidies already in 1997 reached the WTO limits.

Future prices for non-intervention dairy products are estimated using the approach described above, i.e. by adjusting base-year (1997) prices for the milk cost reductions resulting from the reduction in the implicit prices of fat and non-fat components due to the cuts in SMP and Butter prices (Annex Table 23). Two kinds of 'representative' EU producer prices are used. For such homogenous commodities as selected sorts of ripening cheeses (Gouda), casein and WMP, EU market

56 This expectation is supported by in the experience of Germany's new states where problems with access to market channels persisted for several years after Germany's reunification and despite the fact that most firms were subsidiaries of West German dairy companies, Göler et al. (1997).

57 The study by the USDA ERS (1999) reports more than 50\% water in the EU tariff rates for SMP and butter in the years 1995-1997. This means that further tariff reductions due to the UR GATT commitments for market access are not restrictive. 
notations were taken. Of the market prices reported by ZMP (1999), prices in the Netherlands, a net exporter, have been used. ${ }^{6 s}$ For the remaining commodities, the unit values in intra-EU trade have been used as an approximation of the EU market wholesale prices.

The estimated EU market prices are relevant as targets for the price alignment provided other influences, including quality differences or imperfect competition, can be neglected. This is assumed to be the case only for the scenario of progressive technical change in Poland, where new technologies bring a necessary quality upgrade, while the associated restructuring and concentration of the industry guarantees an improvement of the bargaining position of Polish producers versus the EU competitors. In contrast, in the scenario of no technical change the target EU prices for Polish producers are to amount to $95 \%$ of the EU prices, except for SMP and butter for which no quality effects have been assumed in all the cases considered.

\subsubsection{Future disparities between private and social values}

In the ex-post analysis the opportunity costs and benefits diverged from the private values due to the direct effects of policies and due to the divergences that could result from domestic policies in an indirect way (e.g. by neglecting the need for intervention in areas of competition policy, market institutions, investments in public goods). In all cases the decision to influence the magnitude of divergence was endogenous to domestic policy making. This, however, will change on accession to the EU because many common EU policies will have to be accepted by Poland as given - the set of policies that can be freely chosen by Polish decision-makers will become limited. The constrained set of policies will give rise to new social prices, which can be referred to as Euro-social prices (Pearson et al., 1987). In such a new policy context the divergences between the Euro-social prices and private prices reflect only the effects of direct and indirect policies that Poland will be allowed to apply sovereignly.

\section{Disparities in revenues and costs}

As far as output prices received by Polish producers are concerned, the estimated benchmark prices will represent new private prices. From the perspective of Poland's social cost-benefit analysis, the new social prices will be represented by the Euro-social prices, which will amount to the new producer (private) prices net of: Poland's budgetary contributions (per unit of product) to the maintenance of the CAP dairy prices above the world market level. Considering Poland's relatively small share of the EU budget after accession, and other relevant information, one can estimate that the share of Poland's corresponding contribution to the dairy CAP prices would amount to less than

58 In 1997 Gouda cheese price in Holland (5.62 DM) was below the levels reported by ZMP (1999) for Germany (6.06 DM) and Belgium (5.89 DM). 
$0.2 \%$ For simplicity, it is assumed that the Euro-social prices for dairy products will equal to the benchmark prices estimated in section 4.2.1. Given the working assumption about the date of accession, the Euro-social prices will already start to substitute for the social ones in 2004. Moreover, implicit to the method of estimating the benchmark prices for price alignment is the assumption that all non-policy divergences detected in the ex-post analysis will be removed.

The EU accession will also be associated with an imposition of certain constraints on policies in the factor markets. In the labour market several effects of conflicting influences on the level of real wages and labour costs can be expected. First, as already mentioned, Poland has to improve the functioning of the labour market to cope with the challenge of structural adjustment resulting from economic integration with the EU. Progress in this respect should limit the divergence between the private and social wage rates detected in the ex-post analysis. At the same time, however, the EU membership imposes the obligation to comply with the acquis communautaire in the field of employment and social affairs, which may have an enhancing impact on wages. ${ }^{6}$ The liberalisation of intra-EU labour flow (even partial) can be conducive to an increase in the domestic wage rates in Poland. Considering the above effects, it is assumed that the previously described rates of growth in real wages accompanying the future economic growth (Table 4.1) can also represent the social (and from 2004 to Euro-social) values, and that between 1997 and 2004 the private labour costs will fully converge on the social levels through a gradual adjustment. This means that between 1997 and 2004 rates of real private wage growth are below those for social/shadow ones.

The private/social divergence in the capital costs will be affected by the EU accession in two major ways. First, Poland will have to align its State aid award provisions with the competition policy of the EU. This harmonisation is to impose stricter rules on capital subsidisation from the State budget, but will not prohibit such measures. Nevertheless, it is assumed that Poland may have to give up the past scheme of credit subsidies, which has been in operation since 1994, merely because of the constraints on the State budget associated with the macroeconomic convergence conditions. Second, already in the pre-accession years, starting from 2001, the industry may benefit from the capital

59 In 1996 the budgetary expenditure on the CAP in the dairy sector amounted to 3775 Mio ECU, i.e. 33.3 ECU per ton of farm milk. This sum corresponds to $11.4 \%$ of the farm milk price, or to about $6 \%$ of milk industry revenues, i.e. $6 \%$ of the price of an 'average' dairy product (assuming that farm milk, on average, accounts for about $50 \%$ of the price). Considering that contributions to the EU budget are, in general, proportional to the GNPs of the member states and that Poland's GNP amounted to about $1.4 \%$ of the EU-15 GNP in 1995, it follows that Poland's contribution to the EU's expenditure on the dairy regime of CAP, per unit of output, would lie below $0.2 \%$ of the price of an 'average' dairy product. The exact future contribution will depend on the following effects: (i) Poland's economic convergence that would increase Poland's share of the EU's GNP, (ii) the impact of Poland's accession on the EU's expenditure on the CAP in the dairy sector, (iii) changes in EU dairy policy (Agenda 2000) and (iv) development in world market prices.

60 For example, one important obligation is to guarantee workers' representation in all undertakings where there are no trade unions. This and other provisions may sustain the existing bias in the bargaining between workers and employers in favour of the former. 
subsidies within the SAPARD ${ }^{6}$ programme. The scheme is to be financed both by the EU budget transfers (in $75 \%$ ) and by the Polish budget (in 25\% - both central and regional) contributions. As far as the agro-food processing is concerned, the SAPARD is aimed specifically at the improvement in sanitary and hygienic conditions in the dairy and meat sector. In such a case, the Euro-social level of capital costs will differ from that based on the projected economy-wide social interest rate by the (per unit) value of subsidy financed by the EU budget (less the part of this subsidy that will stem from Poland's contribution to the EU budget after accession to the EU). The private level of capital cost will in turn differ from the Euro-social one by the amount of SAPARD subsidies co-financed from the domestic budget (per unit of capital costs). It is assumed that the Euro-social level of capital costs will diverge from the level implied by the economy-wide interest rate by the capital cost reduction equivalent to a $3 \%$ decline in this economy-wide interest rate (i.e. decline from $8 \%$ to $5 \%$ ). In turn, the level of private capital cost will diverge from the Euro-social level by the capital cost equivalent to a $1 \%$ reduction in the interest rate below the level assumed for the Euro-social level (i.e. from $5 \%$ to $4 \%)$

Future farm milk prices for DRC analysis are derived as equivalents of projected butter and SMP prices. Euro-social prices of these two products will be used to derive Euro-social prices of farm milk using the projected processing margins, i.e. margins resulting from changes in input prices and, in the scenario assuming technical change, in factor productivity. Moreover, it is also assumed that for a certain time after accession, milk prices paid to farmers, i.e. private milk prices will only achieve $95 \%$ of their Euro-social level. This is merely a working assumption, however, supported by some important rationales. First, there is the experience from the New German states where significantly lower milk prices (than expected) were paid for several years after accession to the CAP. Second, given the possibility of an increase in the concentration of the milk processing industry and an increase in the share of non-co-operative firms, the bargaining position of farmers may decline in the near future, which may adversely affect milk prices. Third, milk (and beef) belong to products which are expected to significantly 'benefit' from the changes in relative prices that are to follow after the

61 SAPARD (the Special Accession Programme for Agriculture and Rural Development) aims at helping candidate countries deal with the problems of the structural adjustment in their agricultural sectors and rural areas, as well as in the implementation of the acquis communautaire concerning the CAP and related legislation. SAPARD was to come into effect on January 1, 2000, and is budgeted until the end of 2006 (EU Commission, 1999). 
adoption of the CAP. This may enhance farmers' readiness to 'accept' lower milk prices, at least for certain time period. Since this assumption may have serious consequences for the projected private profitability, the analysis will be complemented by a sensitivity analysis of projected private profitability (PCR) to the degree of price transmission between SMP and butter and farm milk.

For tradable cost elements, the Euro-social prices will substitute for the social prices in the same way as in tradable outputs, given the common custom system on these commodities. For many of these tradables, including the specialised materials and machinery, the EU is a net exporter and the major supplier on the world market (DRI Europe, 1996). For these goods the Euro-social prices equal the internal EU prices (and in most cases Poland's present social prices). For mineral oils, which constitute an important element of energy costs in the dairy industry, the Euro-social values result from the obligatory minimum levels of the excise tax, which Poland will have to conform with. The Euro-social values are, however, calculated by excluding from the after-tax price levels the value of these excise taxes, because they are payable to the national budget.

\section{Accounting Matrix for Projected Efficiency}

The projected private and social values can be presented in a PAM framework (Table 4.2).

Table 4.2. Policy Analysis Matrix for projected efficiency.

\begin{tabular}{|c|c|c|c|c|c|c|}
\hline & \multirow{2}{*}{ Revenues } & \multicolumn{4}{|c|}{ Costs } & \multirow{2}{*}{ Profits } \\
\hline & & Tradables & Farm Milk & Labour & Capital & \\
\hline Private values & A & B & $\mathrm{C}$ & $\mathrm{D}$ & $\mathrm{E}$ & $\mathrm{F}$ \\
\hline Euro-social values & $\mathrm{G}$ & $\mathrm{H}$ & I & $\mathrm{J}$ & K & $\mathrm{L}$ \\
\hline $\begin{array}{l}\text { Effects of sovereign Polish } \\
\text { polices and market failures }\end{array}$ & $A-G$ & B-H & C-I & D-J & E-K & F-L \\
\hline
\end{tabular}

Source: author's compilation based on Pearson et al. (1987).

\subsection{Scenario for Technical Change}

Future improvements in factor productivity may result from the adoption of new technologies (technological change) and from improved efficiency with which inputs are used at any level of technological advancement. In projecting the pace of these improvements two factors are considered.

62 The underlying cost reductions can be approximated in the following way: the 1997 social, periodised, value of capital components eligible for the subsidy within the SAPARD (in the classification used here these include both direct capital and capital in the services like that of farm milk assembly) amounted to 670 Mio PLZ. The cost reduction equivalent to the reduction of the interest rate from $8.0 \%$ to $4.0 \%$ amounts to about 154.2 Mio PLZ. The cost reduction equivalent to the interest reduction from $5.05 \%$ to $4.0 \%$ amounts to 38.6 Mio PLZ, i.e. about $25 \%$ of the total reduction, which also corresponds to the share of Poland's contribution to the SAPARD. In addition, since the value of contributions of the EU has been set to 168.7 Mio EURO yearly, i.e. the total volume of the subsidies including Poland's share amounts to 210.9 Mio EURO, i.e. about 850 Mio PLZ (at 1999 NER). Consequently it is implicitly assumed that the milk processing industry receives $18.1 \%$ of the total subsidies under the SAPARD scheme. 
First, there is the scope for such improvements as evidenced by the productivity lag. The second are the determinants of the catching-up process. Both factors have been investigated in Chapter 2. It has been shown that, indeed, the productivity lag promises substantial gains from technology transfers and from eliminating existing inefficiencies. This section extends previous discussion by summarising the major determinants of the productivity improvements in the medium term and by constructing a 'feasible' scenario for such improvements over the time horizon until 2010.

\subsubsection{Determinants of future productivity improvements}

Future changes in relative prices of inputs may enhance technological change by promoting investments. Two effects can be distinguished. The first one is caused by the increase in the price of labour (and non-tradable inputs) relative to capital. This is expected to induce a substitution effect (labour for capital) by an increase in net investment. Hence, it can be argued that implicit to the previously made assumptions on macroeconomic developments is the expectation that both the demand for, and the affordability of new (net) investments may increase and, in this way, accelerate the (embodied) technological change.

In fact, the expectation of the positive relationship between the future economy growth rates and the productivity improvements in the industry has another important rationale. One can argue that the forces expected to accelerate the economy-wide growth, i.e. enhancing capital accumulation and technological change, such as economic policy reforms, international transfers of capital and technology, and other, should also apply to the milk processing industry, at any degree of specific constraints maintained in this industry. Of course, the question to be asked here is, whether the considered industry is able to exploit these opportunities.

Next important factor is the future level and volatility of real product prices. From the outlined scenarios for the macroeconomic developments and sectoral policies it is clear that real output prices in the milk processing industry are going to be a net outcome of the depressing effect of RER and the enhancing effect of harmonising domestic policies with the CAP. The inclusion in the CAP would only provide dairy processing with an advantage over other tradable industries (i.e. those which do not 'benefit' from the CAP) in terms of attractiveness for investors if the enhancing effects of the CAP were not to be fully passed to farm milk prices. However, the CAP may positively influence both volume and allocative efficiency of investment merely by diminishing the level of price uncertainty. The price stabilisation effect may provide for a significant advantage in this respect given the volatility of world market prices of dairy products experienced during the recent past.

Substantial improvements in terms of policy incentives to structural change in the industry can be expected. First, it seems that past experience with regard to the efficiency of investments that have been induced by the support programmes operated since 1994 may yield better designed policies in the near future. Second, the policy change including, for example, stricter quality standards and 
quality controls, has already been stimulated by problems faced in legalisation of exports to the EU in 1998 and 1999. In fact, the future support for modernisation (e.g. the SAPARD Programme) may provide the Government with an opportunity to promote structural changes (including various forms of horizontal integration, and concentration) by applying an adequate set of criteria for the aid distribution.

The flexibility of investment timing is one of the standard explanations for observed fluctuations in investment intensity both at macroeconomy- and sectoral level (Dornbusch and Fisher, 1994). This argument seems to apply here. Namely, it may not be reasonable to judge future investments on the basis of recent or even current records. The potential reasons for postponing investment projects in the industry (which for all other reasons may appear justified and financially feasible), include: (i) widespread over-capacities, (ii) pending outcomes of the EU-membership negotiations, which should remove many of the current uncertainties about the future sectoral and macroeconomic policies, (iii) past investment policies and many official declarations sustaining optimistic expectations about the future availability of subsidised capital funds. A plausible conclusion is that once there are fewer political uncertainties about the future economic environment, investment intensities may increase, either due to the materialising of hopes of potential investors or merely because of a removal of illusions.

\subsubsection{The scenario}

Whether this progress is to be realised depends on the pace of investment and its (allocative) efficiency. In the neo-classical theory, investment activity is, however, a derivative of a more fundamental process of adjusting the production technique to changing pressures and opportunities manifested by the changes in prices (Penson and Lins, 1980). By creating scenarios for future price development there is an attempt here to take account of these new opportunities and pressures. It cannot, however, be predicted whether in the considered time horizon the industry will be able to respond sufficiently (or with sufficiently short time lag) to new challenges and opportunities in order to stay competitive, i.e. stay profitable (if such challenges emerge). The procedure followed here is a simple one. It is based on confronting various information gathered in the foregoing analysis including: technological gap, pace of recent adjustment, recent and expected policy incentives, and other investment constraints. It leads to formulations of a 'best guess', about which scenario is feasible. Hence, this scenario should not be seen as a forecast but merely as a working hypothesis used to steer the discussion. Details of the scenario are presented in Table 4.3.

Important qualifications need to be made with regard to the interpretation of the technical change effects. Namely, it concerns the fact that the same extent of factor productivity has been assumed for all analysed activities. While the discussion in Chapters 2 and 3 has suggested that the scope for the change in factor productivity at industry levels is, in general terms, high, it may, in fact, vary across 
the products. One could therefore argue that the different technical progress achieved in the years before 1997 due to, among other things, the effect of the expansion of some activities (i.e. the economies of rapid growth effect) may have limited the scope for further fast improvements in such expanding activities in the medium term. Here, however, by applying this scenario for technological change in some way, another view is being supported. Despite the improvements achieved in the past, the magnitude of the productivity gap, in particular the labour productivity gap, detected at the industry level is considered to be large enough to guarantee scope for further improvement in all product-specific activities and beyond the levels assumed in the scenario.

Table 4.3. Assumption in the scenario: Technical Change.

\begin{tabular}{|c|c|c|}
\hline Inputs & Assumed change by 2007 & Rationale and data source \\
\hline Raw cow milk input & $3 \%$ decrease & Sokołowski and Bazydło (1999). \\
\hline \multicolumn{3}{|l|}{ Materials: } \\
\hline - packaging materials & $5 \%$ increase & $\begin{array}{l}\text { Net effect of improved efficiency in the use of packaging materials } \\
\text { (Sokołowski and Złotkiewicz-Krasnodębska, 1999) and increased } \\
\text { intensity due to the adjustment in market and standards. }\end{array}$ \\
\hline - other materials & no change & \\
\hline Electricity & $10 \%$ increase & $\begin{array}{l}\text { New technologies use more electric power } \\
\text { (Author's interview with experts from Olsztyn University). }\end{array}$ \\
\hline \multicolumn{3}{|l|}{ Energy: } \\
\hline - coal & $50 \%$ decrease & $\begin{array}{l}\text { Improvement in efficiency of heating (steam and warm) systems is } \\
\text { the priority of modernisation projects. Also result of shift towards } \\
\text { use of other fuels such as natural gas and oil (Weiss and Budny, } \\
\text { 1999). }\end{array}$ \\
\hline - mineral oil & $10 \%$ increase & Effect of changing structure of energy sources (see previous point). \\
\hline - natural gas & $10 \%$ increase & Effect of changing structure of energy sources (see previous point). \\
\hline - fuel (diesel) & $30 \%$ increase by 2007 & $\begin{array}{l}\text { Net effects of increased direct milk collection: priority of } \\
\text { modernisation projects and result of improved efficiency in milk } \\
\text { transport (Pimpicki et al., 1999). }\end{array}$ \\
\hline Water and sewage & $200 \%$ increase & $\begin{array}{l}\text { Effects of increased environmental standards. This represents an } \\
\text { increase in costs on this input category. }\end{array}$ \\
\hline External services & no change & \\
\hline Employment & $30 \%$ decline & $\begin{array}{l}\text { Effect of substitution of labour for and capital associated with the } \\
\text { technological change. }\end{array}$ \\
\hline Depreciation & $50 \%$ increase & Effect of intensified investments. \\
\hline Other costs & no change & \\
\hline
\end{tabular}

\subsubsection{Decomposing contributions to dynamic comparative advantages}

Dynamic comparative advantages are projected by applying the scenarios for: macroeconomic variables, sector policy and technical change to simulate future values of DRC and PCR. These intertemporal changes in the comparative advantage can be decomposed into the partial effects. First, the total effects can be decomposed according to the 'place' of origin i.e. output and input components. Second, each such component can be split into the effect of technical change and price effect. Results can be conveniently presented in matrix form, similar to the PAM. They can also be standardised 
using, for example, the value of revenues in the base year as a numeraire. The structure of such a matrix and calculation procedure is proposed in Table 4.4).

Table 4.4. The matrix of dynamic comparative advantage.

\begin{tabular}{|c|c|c|c|c|c|c|}
\hline & \multirow{2}{*}{ Revenues } & \multicolumn{4}{|c|}{ Costs } & \multirow{2}{*}{ Profits } \\
\hline & & Tradables & Farm Milk & Labour & Capital & \\
\hline $\begin{array}{l}\text { Future (2007) private (or social) values with the new } \\
\text { future technical coefficients (Technical Change) }\end{array}$ & A & B & $\mathrm{C}$ & $\mathrm{D}$ & $\mathrm{E}$ & $\mathrm{F}$ \\
\hline $\begin{array}{l}\text { Future (2007) private (or social) values with the base } \\
\text { year technical coefficients (No Technical Change) }\end{array}$ & $A^{6}$ & $\mathrm{~B}^{6}$ & $\mathrm{C}^{6}$ & $D^{4}$ & $E^{6}$ & $\mathrm{~F}^{6}$ \\
\hline Base year (1997) private (or social) values & G & $\mathrm{H}$ & I & $\mathrm{J}$ & $\mathrm{K}$ & $\mathrm{L}$ \\
\hline Total change & $\mathrm{M}$ & $\mathrm{N}$ & $\mathrm{O}$ & $\mathrm{P}$ & $\mathrm{R}$ & $\mathrm{S}$ \\
\hline Price effect & AA & $\mathrm{AB}$ & $\mathrm{AC}$ & $\mathrm{AD}$ & $\mathrm{AE}$ & $\mathrm{AF}$ \\
\hline Technical change effect & BA & $\mathrm{BB}$ & $\mathrm{BC}$ & $\mathrm{BD}$ & $\mathrm{BE}$ & $\mathrm{BF}$ \\
\hline
\end{tabular}

A. Disentangling effects according to the place of origin:
$\mathrm{M}=\mathrm{A}-\mathrm{G}=\mathrm{AA}+\mathrm{BA}$
- price and technical change effect on revenues,
$\mathrm{N}=\mathrm{B}-\mathrm{H}=\mathrm{AB}+\mathrm{BB}$
- price and technical change effect on costs of tradables,
$\mathrm{O}=\mathrm{C}-\mathrm{I}=\mathrm{AC}+\mathrm{BC}$
- price and technical change effect on costs of farm milk,
$\mathrm{P}=\mathrm{D}-\mathrm{J}=\mathrm{AD}-\mathrm{BD}$
- price and technical change effect on costs of labour,
$\mathrm{R}=\mathrm{E}-\mathrm{K}=\mathrm{AE}+\mathrm{BE}$
$\mathrm{S}=\mathrm{F}-\mathrm{L}=\mathrm{AF}+\mathrm{BF}$
- price and technical change effect on costs of capital,
- net effect on profits.

B. Disentangling the effects of price changes and technical change:

Price effect: change in the corresponding entries induced by the change in the (social or private) prices measured with the 'average' technology (average from the technical coefficients in the base year and in the future).

Technical change effect: change in the corresponding entries induced by the technical change measured with 'average' price (i.e. average from prices in the base year and in the future).

Calculation procedure: the total effect is the difference between the future values (products of future volumes $\mathrm{a}_{2}$ and future price $\mathrm{p}_{2}$ ) and base year values (products of base year volumes $\mathrm{a}_{1}$ and base year prices $\mathrm{p}_{1}$ ). For the case of revenues in the above table the entries $\mathrm{A}, \mathrm{A}^{*}, \mathrm{G}$, and $\mathrm{M}$ are defined as:

$\mathrm{A}=\mathrm{a}_{2} * \mathrm{p}_{2}, \mathrm{~A}^{\prime}=\mathrm{a}_{1} * \mathrm{p}_{2}, \mathrm{G}=\mathrm{a}_{1} * \mathrm{p}_{1}, \mathrm{M}=\mathrm{a}_{2} * \mathrm{p}_{2}-\mathrm{a}_{1} * \mathrm{p}_{1}$.

However, $a 2 * p_{2}-a_{1} * p_{1}=\left[\left(a_{2}+a_{1}\right) / 2\right] *\left(p_{2}-p_{1}\right)+\left[\left(p_{2}+p_{1}\right) / 2\right] *\left(a_{2}-a_{1}\right)$, where two components of summation correspond to the above given definitions of the price effect and technical change effect. The two components can be calculated directly from $A, G$ and $A^{*}$ because:

$\left[\left(a_{2}+a_{1}\right) / 2\right] *\left(p_{2}-p_{1}\right)=\left(a_{2}^{*} p_{2}+a_{1} * p_{2}-a_{2} * p_{1}-a_{1} * p_{1}\right) / 2=\left[A+A^{*}-\left(A^{*} G / A^{*}\right)-G\right] / 2=A A=$ price effect,

$\left[\left(\mathrm{p}_{2}+\mathrm{p}_{1}\right) / 2\right]^{*}\left(\mathrm{a}_{2}-\mathrm{a}_{1}\right)=\left(\mathrm{a}_{2} * \mathrm{p}_{2}+\mathrm{a}_{2} * \mathrm{p}_{1}-\mathrm{a}_{1} * \mathrm{p}_{2}-\mathrm{a}_{1} * \mathrm{p}_{1}\right) / 2=\left[\mathrm{A}+\left(\mathrm{A}^{*} \mathrm{G} / \mathrm{A}^{*}\right)-\mathrm{A}^{*}-\mathrm{G}\right] / 2=\mathrm{AB}=$ technical change effect.

C. Standardising the matrix:

Each entry can be expressed in terms of the percentage of revenue in the base year. This can be achieved by dividing each entry by the entry $(\mathrm{G})$ and multiplying by 100 .

Source: author's compilation.

The matrix can be referred to as the matrix of the dynamic (inter-temporal) comparative advantages. This empirical tool, designed specially for the purpose of this study, is an extension of the standard PAM. It is a policy analysis matrix, in so far as the dynamic effects which are traced out are either directly affected by economic policy (e.g. sectoral price policies, interest rate policy) or in an indirect way (e.g. effects of macroeconomic policies on relative prices in the economy, effects of trade liberalisation on elimination of $\mathrm{x}$-inefficiencies etc.).

The matrix represents a framework for summarising the effects of assumed changes in prices and productivity so as to make clear their relative importance as drivers of dynamic comparative advantages. The matrices calculated for social and private values will be used to help interpret intertemporal changes in PCR and DRC. The decomposition concerns the changes that are projected to occur between the base period (year 1997) and the future target year (2007). 


\subsection{Future Comparative Advantages: Simulation Results}

Using the assumptions described above future revenues, costs, profits, and the corresponding indices of comparative advantages have been projected. The projections are made in real terms reflecting the value of the Polish złoty in 1997.

Projections have been made by applying the assumed rates of change presented in Table 4.1 to the base-year levels of prices, revenues and costs. For labour, the rates of change in the wages are applied. For capital, both interest rates and changes in the prices of investment goods have been considered. Future prices of tradables are determined by the future world or Euro-social prices, domestic policies and changes in the real exchange rate. Future farm milk prices are calculated on the basis of the projected prices of SMP and butter (private or social) and projected processing costs, i.e. processing costs at projected input prices (private or social) and, in the case of the 'technical change' scenario, at changed factor productivity.

Estimates of future private revenues and costs are presented as a time series for the years 19972010. Estimates of future DRC and PCR are made only for the year 2007, i.e. the first year after full policy alignment with the CAP. Future developments of revenues and costs for the industry level are based on the initial product structure of output. This means that only inter-temporal changes in the prices are taken into consideration, i.e. without their consequences for the product structure of output and cost structure.

To help the discussion on the projected levels for revenues and costs, a supplementary scenario of Constant RER has been used. In this scenario all variables except for RER, which is assumed to stay unchanged, are the same as in the Base scenario. This additional scenario has been applied here only to picture the magnitude of the RER contribution to the projected changes. Unlike the three core macroeconomic scenarios this one cannot be interpreted in isolation, because it lacks consistency between involved macroeconomic variables.

\subsubsection{Projections of product prices and revenues}

The first bar of Figure 4.1 demonstrates price gaps between Polish and EU markets in 1997 for the selected products. In general, the gap tends to be higher for products with high farm milk content and low for the products with higher shares of non-farm cost components. The second bar of the figure depicts the benchmark prices arising from the Agenda 2000 price cuts, however, related to the Polish prices using the initial, 1997, RER. The third bar of the figure depicts the benchmark prices resulting from the Agenda 2000 price cuts and related to the Polish prices using the projected RER (under the Base scenario) in the year 2007. 
Figure 4.1. Benchmark levels for alignment of dairy product prices, effects of Agenda 2000, under the Base scenario and Technical Change, in real terms.

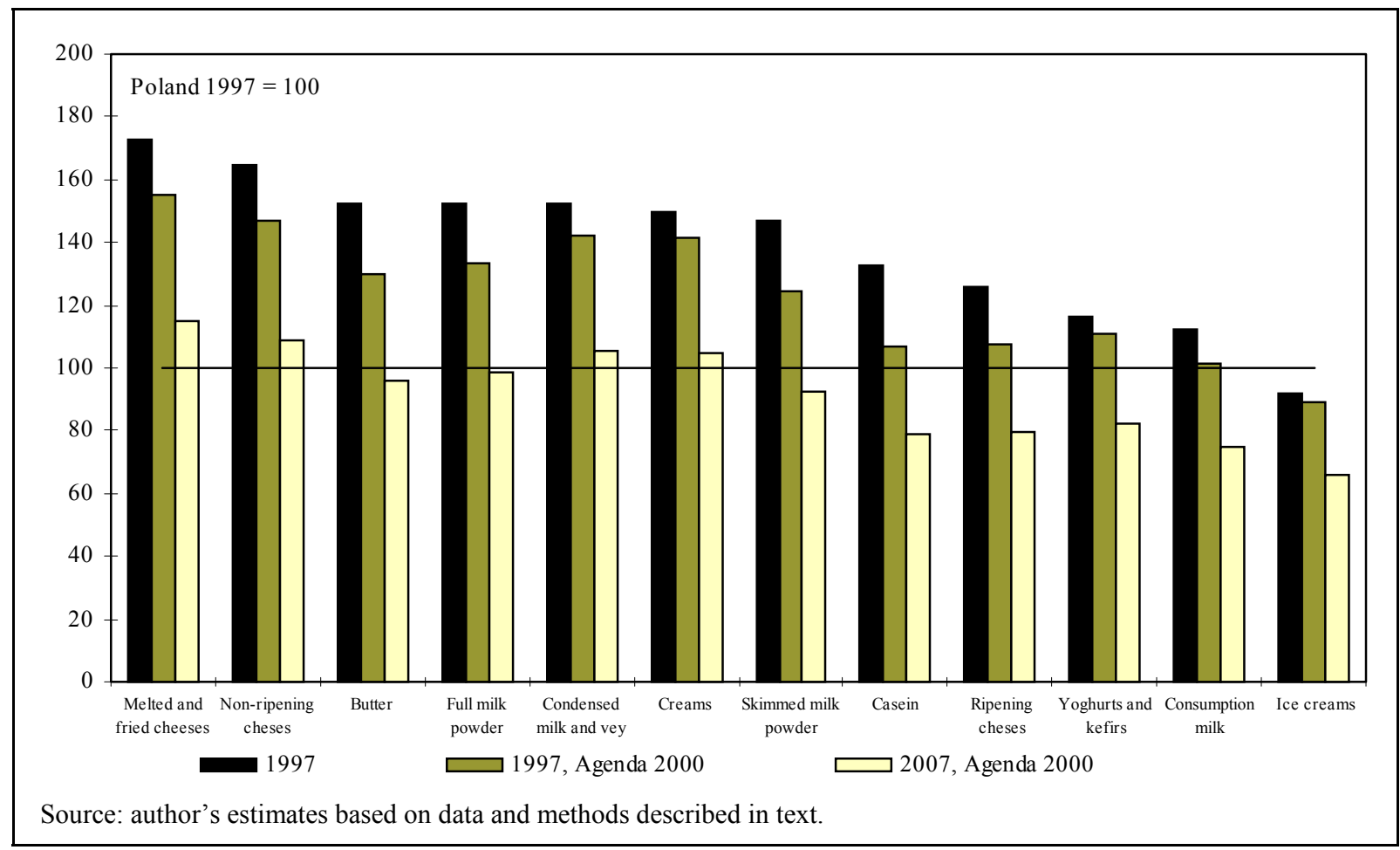

The industry-level price gap and its projected development, weighted with the initial product structure of industry revenues, for Base scenario and Technical Change, are presented in Figures 4.2. and 4.3. The industry revenue is expressed per ton of milk processed. The figures make it clear how significant the effect of macroeconomic development, and RER changes in particular, may be. They also show that, given the price cuts of the Agenda 2000 reform and the appreciating trend of the Polish currency, the policy alignment to CAP between 2004 and 2007 will give rise to relatively small increases in the real product prices and revenues.

Despite the policy harmonisation with the reformed CAP, the dairy real prices in 2007 and in several years later can be expected to decline below the 1997 level. Only for certain products including SMP, butter, fresh cheese, and creams will these declines be smaller. For other products, including such important items (in terms of the revenue share) as ripening cheese, yoghurts, casein, or ice-creams the declines may be more significant, reaching the magnitude of $20 \%$ (in the Base scenario). These product specific effects are attributable to: (i) factors which have diverged Polish 1997 prices from their free-market and perfect-competition level, (ii) factors which may have affected the EU prices in the 1997, like, for example, product-specific constraints on market policy related to the WTO commitments, or (iii) simply the lower marginal processing costs and high competitiveness of the EU producers in a specific product. Let us consider these effects in more detail. 
Figure 4.2. Projections of revenues at industry-level at alternative price levels, 1997-2010, under the Base scenario and Technical Change, in real terms.

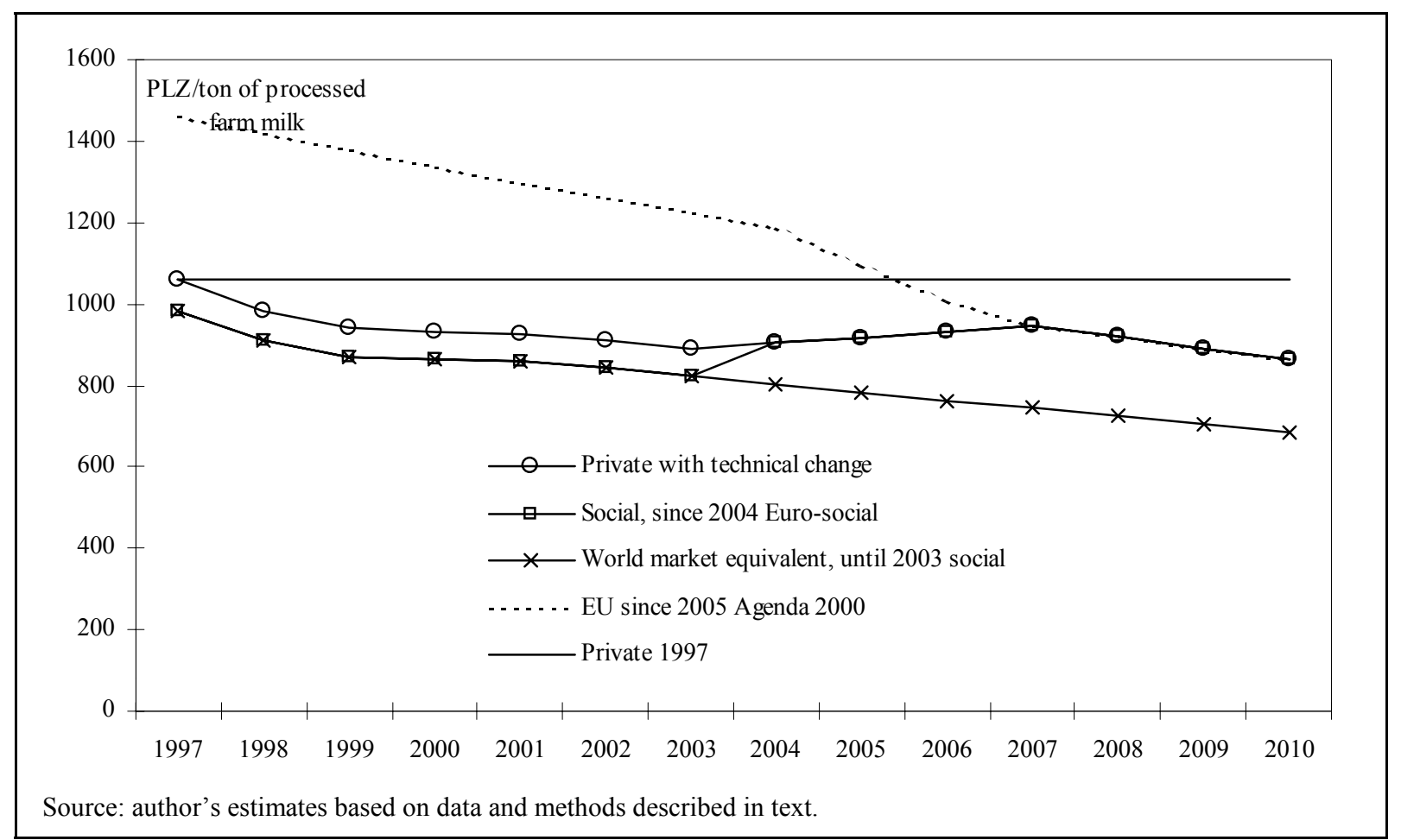

Figure 4.3. Projections of revenues at industry-level, 1997-2010, under alternative macroeconomic scenarios and Technical Change, at private prices, in real terms.

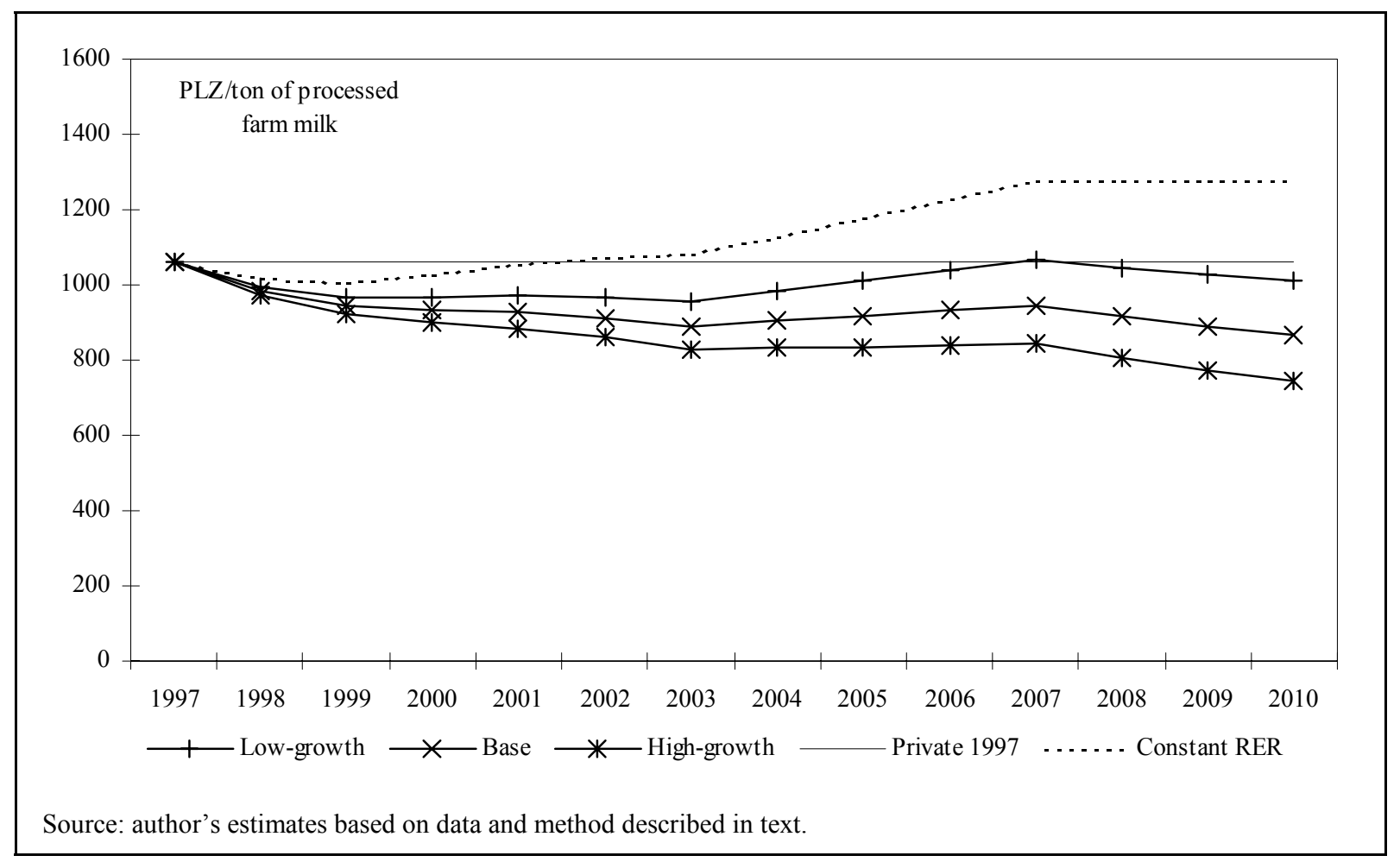

First, it is important to remember that initial price gaps, and hence the magnitude of projected changes in private revenues, are influenced by the policy and other price distortions in Poland, which 
have been discussed in Chapter 3. Of the four products taken to product-specific DRC analysis only for yoghurt is the price gap significantly affected in this way - the detected divergence for butter, ripening cheese and SMP range between $0 \%$ and $3 \%$, while the price enhancing divergence of revenues at industry-level amount to $8 \%$.

Figure 4.4. Export subsidies of the EU relative to WTO commitments, average for the marketing years 1995-1998.

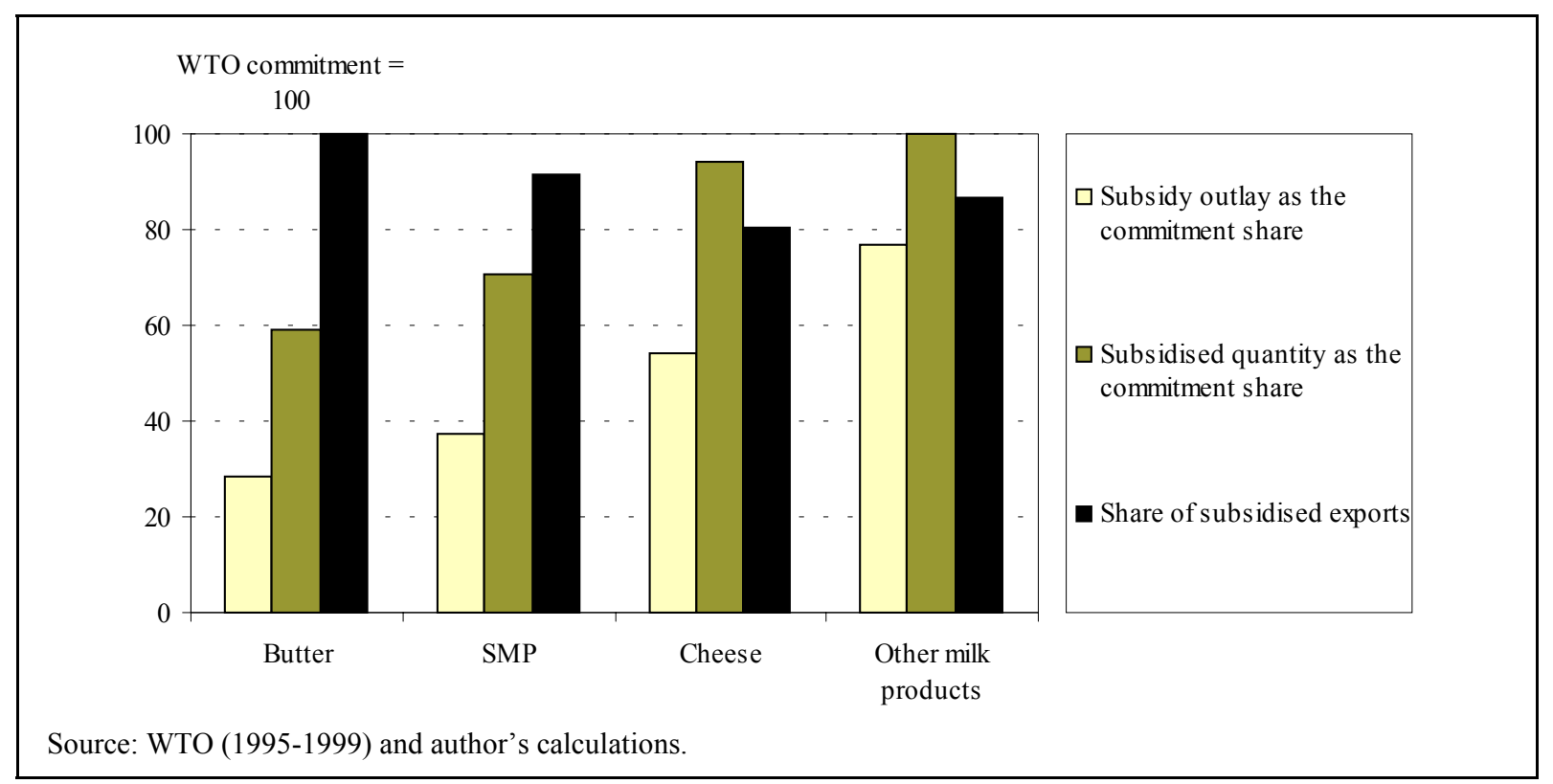

Second, among factors having affected EU prices in 1997, the EU WTO commitments with regards to export subsidy and market access deserve special attention. Figure 4.4 shows that already in the first years of UR GATT implementation export subsidy commitments have become constraining for market policies for cheeses and other dairy products. Consequently, the share of non-subsidised exports in the marketing year 1997/1998 reached as much as $24 \%$ for cheese and $18 \%$ for other dairy products compared to, respectively, $17 \%$ and $16 \%$ in the year $1995 / 1996$. Therefore, the $1997 \mathrm{EU}$ dairy prices for these commodities may have been depressed. These constraints are expected to gain in importance in the medium term not only because of implementing the remaining reductions in export subsidy agreed under the UR GATT, but also due to further reductions expected to be agreed upon in the new round of the WTO negotiations. In addition, merely due to the accomplishing of the UR GATT implementation, commitment on tariff binding may also become constraining for butter (Tangermann, 1999). The major conclusion for the projections on future output prices is that the detected relatively small price gaps for cheeses and several other products, which were observed in 1997, should not be interpreted as a temporary effect. As far as future price development is concerned, the rather optimistic medium-term forecast for the world market situation (e.g. FAPRI, 1999, OECD; 1998) seems to suggest that the pressure for price reductions due to the further increase in the WTO constraints may be (at least partly) offset by an upward trend in World market prices. 
Last but not least, technical change may have a substantial effect on future price levels realised by Polish producers on the EU market. The assumption here of a $5 \%$ price decrease owing to the insufficient quality improvement (despite assumed technical change) may even be seen as a rather modest guess. Should the technical change not be realised, the projected price gaps for nonintervention products would be diminished compared to the magnitudes demonstrated in Figure 4.1.

\subsubsection{Projections of processing costs}

The future development of processing costs depends on three major factors including: (i) input prices, (ii) relative input intensity and (iii) the improvements in factor productivity.

Figure 4.5 shows the structure of total cots of the industry in private prices in1997. The underlying input intensities determine how susceptible the cost competitiveness is to different changes in relative prices. As far as the real appreciation of domestic currency is concerned, the cost structure decides to what extent competitiveness losses, incurred due to the decline in output price and increase in prices of nontradables inputs, can be compensated for through the decline in cost of tradable inputs. It appears that this compensating effect may be quite significant given that the tradables account for $18 \%$ of total costs and that capital costs, accounting for another $9 \%$ of total costs are affected by the changes in the RER in a similar way to the tradable elements.

Figure 4.5. Cost structure of Polish milk processing industry, in private prices, sums of direct and indirect inputs, 1997.

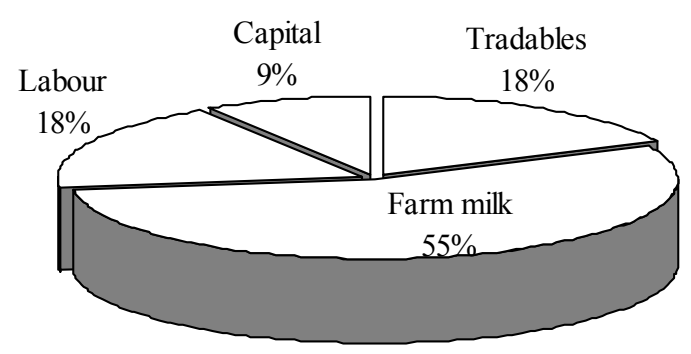

Source: author's estimates based on data and methods described in text.

This compensating effect explains the projected trends in the industry cost (Figures 4.6 and 4.7). The figures suggest that changes in the relative prices accompanying each of the three core macroeconomic scenarios have almost a neutral net effect on the level of processing costs - in all scenarios the real costs remain close to their initial level over the time of projection. The figures show also the magnitude of the compensating effect (location of the cost trajectory for the Constant RER scenario relative to the three core scenarios). The magnitude of the cost reductions arising from the factor productivity improvements in the Technical Change scenario is depicted by the distance between the positions of cost trajectories in Figure 4.6 compared to those in Figure 4.7. 
Figure 4.6. Projections of processing costs at industry level, 1997-2010, under alternative macroeconomic scenarios and No Technical Change, at private prices, in real terms.

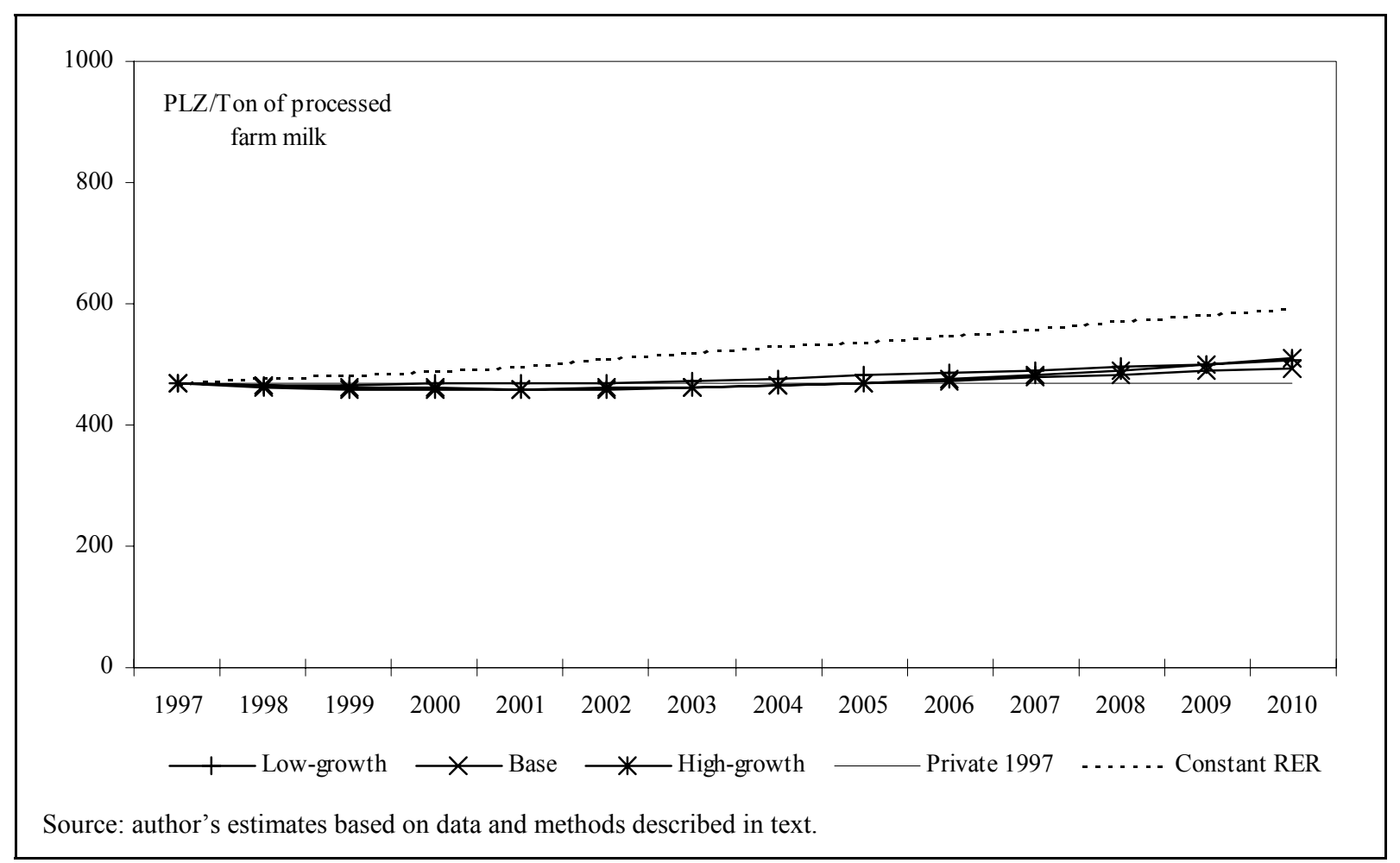

Figure 4.7: Projections of processing costs at industry level, 1997-2010, under alternative macroeconomic scenarios and Technical Change, at private prices, in real terms.

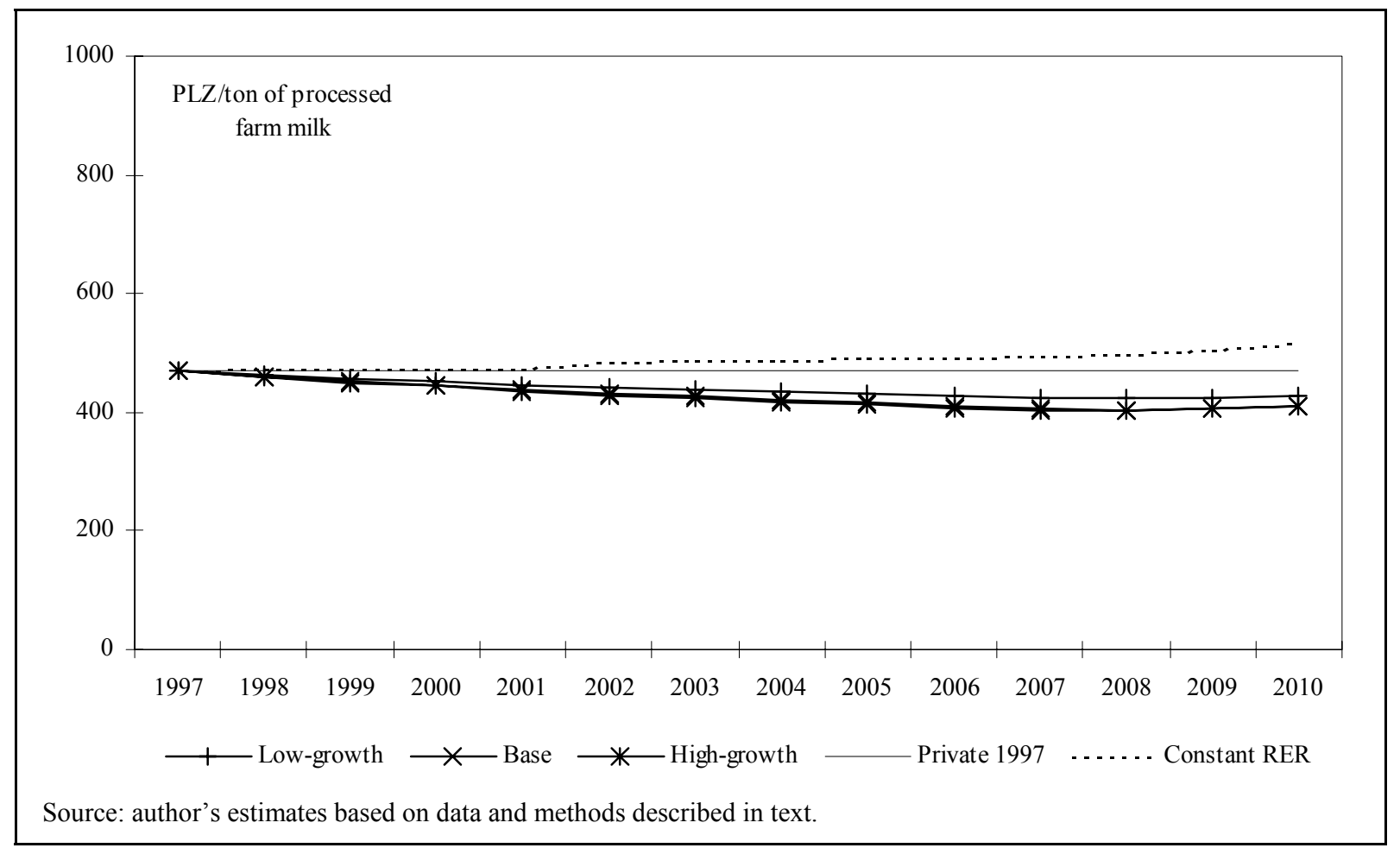


The projected development of various components of processing costs under alternative scenarios is presented in Table 4.5. While reading this table, one needs to remember that the cost category 'services and other costs' is composed both of tradables and nontradable elements (indirect tradables and nontradables), which results in the evolution of this cost category as rather resistant to the macroeconomic changes. The capital costs behave in a similar way to the costs of tradables, 'materials' and 'energy and fuels'. An important result of the analysis in this table is the radical increase in the share of labour costs in the scenario No Technical Change. In the scenario Technical Change this upward trend in the labour costs is, in fact, reversed, though to a degree varying according to the macroeconomic assumptions.

Table 4.5. Projections of changes in milk processing costs at industry level, in 2002 and 2007, at private prices, in real terms (total processing costs in 1997=100).

\begin{tabular}{|c|c|c|c|c|c|c|c|}
\hline \multirow{2}{*}{$\begin{array}{c}\text { Macroeconomic } \\
\text { scenarios }\end{array}$} & \multirow{2}{*}{$\begin{array}{c}\text { Input } \\
\text { category }\end{array}$} & \multicolumn{3}{|c|}{ No Technical Change } & \multicolumn{3}{|c|}{ Technical Change } \\
\hline & & 1997 & 2002 & 2007 & 1997 & 2002 & 2007 \\
\hline \multirow[t]{6}{*}{ Low-growth } & Materials & 34 & 31 & 29 & 34 & 31 & 30 \\
\hline & Energy, fuel and environment & 11 & 10 & 10 & 11 & 11 & 11 \\
\hline & Labour & 30 & 34 & 40 & 30 & 27 & 24 \\
\hline & Capital & 9 & 8 & 7 & 9 & 10 & 11 \\
\hline & Services and other costs & 17 & 16 & 16 & 17 & 16 & 16 \\
\hline & Total & 100 & 99 & 102 & 100 & 95 & 91 \\
\hline \multirow[t]{6}{*}{ Base } & Materials & 34 & 30 & 28 & 34 & 30 & 28 \\
\hline & Energy, fuel and environment & 11 & 10 & 9 & 11 & 10 & 9 \\
\hline & Labour & 30 & 36 & 44 & 30 & 29 & 26 \\
\hline & Capital & 9 & 7 & 6 & 9 & 9 & 10 \\
\hline & Services and other costs & 17 & 16 & 16 & 17 & 16 & 16 \\
\hline & Total & 100 & 98 & 102 & 100 & 94 & 89 \\
\hline \multirow{6}{*}{ High-growth } & Materials & 34 & 29 & 26 & 34 & 29 & 26 \\
\hline & Energy, fuel and environment & 11 & 9 & 8 & 11 & 10 & 8 \\
\hline & Labour & 30 & 38 & 48 & 30 & 30 & 29 \\
\hline & Capital & 9 & 7 & 6 & 9 & 9 & 8 \\
\hline & Services and other costs & 17 & 15 & 16 & 17 & 15 & 16 \\
\hline & Total & 100 & 98 & 103 & 100 & 93 & 88 \\
\hline
\end{tabular}

\subsubsection{Scope for future farm milk prices}

Farm milk prices are determined domestically by a derived demand from the milk processing industry and by primary supply from the farm producers. Under competitive conditions revenues and cost in the milk processing industry are indicative of the demand price of farm milk. Here, the scope for future farm milk prices is estimated in two ways. First, farm milk prices are calculated on the basis of residual of projected revenues and projected costs (private profit margin, in percentage terms, is assumed to remain at its 1997 level). This implicit price is an equivalent of the future price of the industry output, whereby both macroeconomic and sectoral policy effects on revenues and costs are taken into consideration. It also represents the break-even level of milk prices for industry private 
competitiveness. Second, future milk prices have been projected as equivalents of butter and SMP prices and evolving processing costs. This approach serves also to project future social and private levels of farm milk prices.

The presentation of results begins with Figures 4.8 and 4.9 demonstrating the projected development of implicit break-even farm milk prices in various scenarios, derived by the use of the first approach. Figure 4.10 demonstrates the results of the second approach and confronts them with the results of the first. The figure also includes a farm milk price equivalent for EU intervention prices of butter and SMP calculated with EU indicative costs. ${ }^{6}$ As far as the projected development of Polish private farm milk prices are concerned, these embody the assumption that during a certain period after accession the farm prices, i.e. private prices, will only achieve $95 \%$ of the intervention (butter and SMP) milk price equivalent (i.e. of their Euro-social prices).

Figure 4.8. Projections of revenue minus processing margin at industry-level (left-hand scale) and the implicit farm milk price (right-hand scale), 1997-2010, under No Technical Change scenario, at private prices, in real terms.

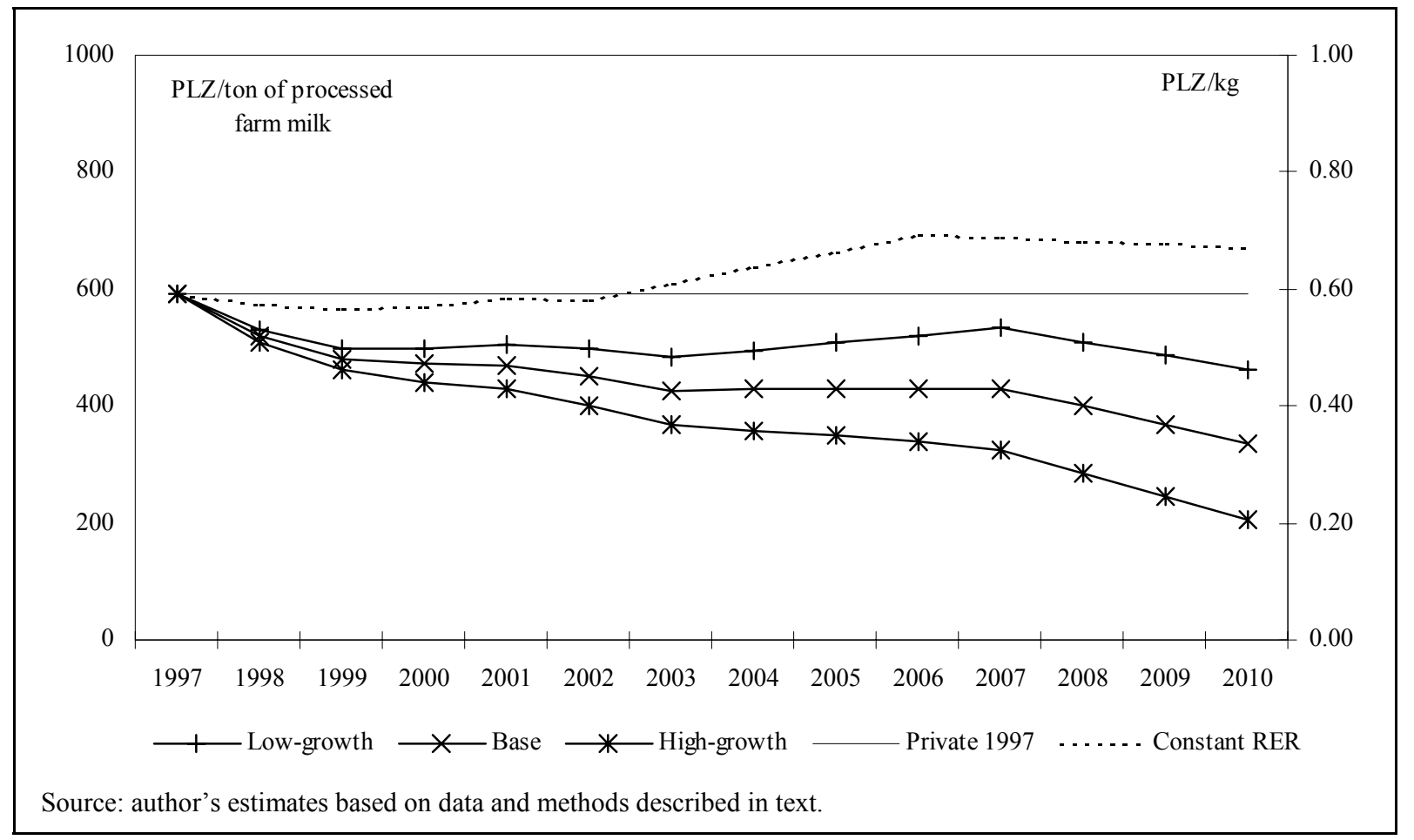

63 See Agra-Europe (1999). 
Figure 4.9. Projections of revenue minus processing margin at industry-level and the implicit farm milk price, 1997-2010, under Technical Change scenario, in private prices, in real terms.

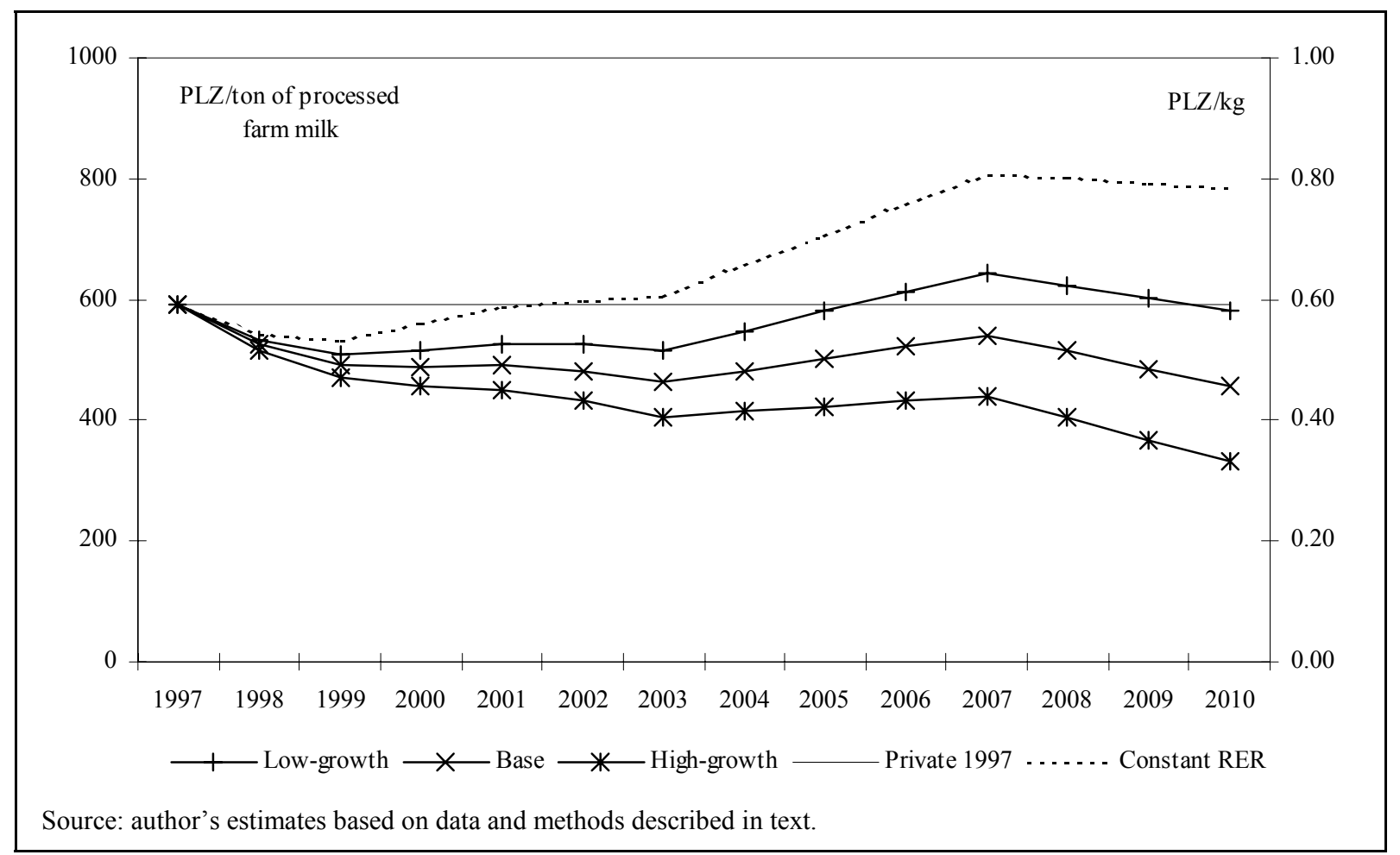

Figure 4.10. Milk prices derived from alternative SMP and butter prices, under Base scenario, in real terms.

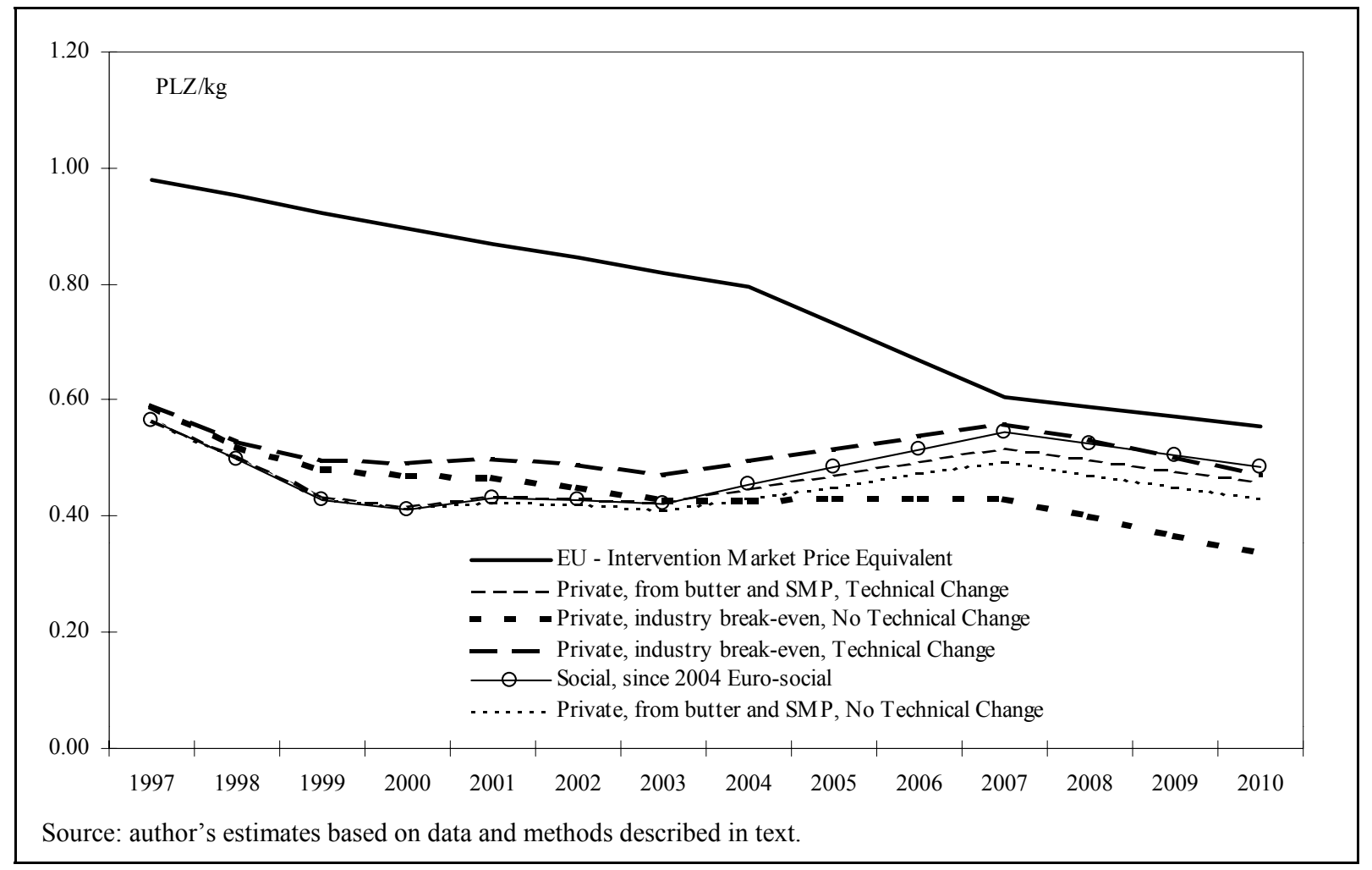

For each analysed combination of revenues and costs (for the total industry and for butter and SMP only) the projected trajectories of farm milk prices represent merely an upper boundary, which 
safeguards profitability in milk processing. The analysis indicates a relatively wide range for such break-even farm milk levels for the first years after accession to the EU. Figure 4.10 also confirms the expectation arising from the analysis of the product-specific revenues, that milk prices derived from the projected prices of SMP and butter (and processing costs) may reach higher values than those derived from projected industry-level revenues and costs, which is because of the higher price gaps faced by the two intervention products relative to most of the remaining products. This result also implies that the opportunity costs of farm milk based on the future Euro-social prices of butter and SMP may have an adverse influence on the projected competitiveness of many 'non-intervention' products, and the industry as a whole. On the other hand, however, it is noteworthy that these seemingly high levels of future Euro-social milk prices still lie below the intervention price milk equivalents calculated at the indicative EU costs.

\subsubsection{Projections of private and social profitability}

This section presents and discusses the projection results for future social and private profitability. Only $\mathrm{DRC}_{1}$ and $\mathrm{PCR}_{1}$, i.e. indices with farm milk treated as a tradable input have been used, which means that the focus is on the efficiency of using scarce domestic resources in milk processing activities. All projections are made for the year 2007. Results are presented in Table 4.6. and in Annex Tables 24-28.

Table 4.6. Projections of private and social profitability, 2007, under alternative scenarios for macroeconomic development and technical change.

\begin{tabular}{|c|c|c|c|c|c|c|c|c|}
\hline \multirow{4}{*}{ Activity } & \multicolumn{2}{|c|}{1997} & \multicolumn{6}{|c|}{2007} \\
\hline & \multirow[b]{2}{*}{$\mathrm{PCR}_{1}$} & \multirow[b]{2}{*}{$\mathrm{DRC}_{1}$} & \multicolumn{2}{|c|}{ Low-growth } & \multicolumn{2}{|c|}{ Base } & \multicolumn{2}{|c|}{ High-growth } \\
\hline & & & $\mathrm{PCR}_{1}$ & $\mathrm{DRC}_{1}{ }^{\mathrm{EU}}$ & $\mathrm{PCR}_{1}$ & $\mathrm{DRC}_{1}{ }_{1}^{\mathrm{EU}}$ & $\mathrm{PCR}_{1}$ & $\mathrm{DRC}_{1}{ }^{\mathrm{EU}}$ \\
\hline & & & \multicolumn{6}{|c|}{ Technical Change } \\
\hline Milk processing industry & 0.92 & 1.13 & 1.12 & 1.26 & 1.25 & 1.38 & 1.40 & 1.52 \\
\hline Skimmilk powder & 0.94 & 0.98 & 0.71 & 0.84 & 0.75 & 0.86 & 0.78 & 0.88 \\
\hline Ripening cheese & 0.84 & 0.77 & 2.09 & 2.73 & 2.16 & 2.67 & 2.23 & 2.62 \\
\hline Butter & 1.99 & 2.16 & 1.30 & 1.77 & 1.35 & 1.74 & 1.40 & 1.72 \\
\hline \multirow[t]{2}{*}{ Yoghurts } & 0.67 & 1.15 & 0.98 & 1.04 & 1.12 & 1.18 & 1.29 & 1.34 \\
\hline & & & \multicolumn{6}{|c|}{ No Technical Change } \\
\hline Milk processing industry & 0.92 & 1.13 & 0.82 & 0.86 & 0.92 & 0.96 & 1.01 & 1.05 \\
\hline Skimmilk powder & 0.94 & 0.98 & 0.67 & 0.71 & 0.69 & 0.73 & 0.71 & 0.75 \\
\hline Ripening cheese & 0.84 & 0.77 & 1.24 & 1.28 & 1.33 & 1.36 & 1.42 & 1.46 \\
\hline Butter & 1.99 & 2.16 & 1.18 & 1.24 & 1.21 & 1.26 & 1.24 & 1.29 \\
\hline Yoghurts & 0.67 & 1.15 & 0.84 & 0.89 & 0.93 & 0.97 & 1.03 & 1.08 \\
\hline
\end{tabular}


Two general observations can be made on the basis of the results presented in Table 4.6. First, the divergence between projected PCR and DRC values for the same activity tend to be smaller than in the base year case. This simply reflects limited control over many policy instruments arising from the EU membership, as well as the optimistic assumption made with regard to the elimination of nonpolicy distortions both on the output and input side. It is worth recalling here that to a large degree this assumption incorporated in the DRC and PCR results reflects the expectation that EU membership should have a pro-competitive, distortion reducing effect on markets in which the industry operates. Second, in all analysed cases the projected private profitability is expected to exceed the social one. This effect mainly arises from the assumed divergence in the farm milk market and in capital costs in favour of the industry.

\section{Macroeconomic effects}

Assumptions concerning macroeconomic development have a strong influence on the projected levels of social and private profitability. This can be demonstrated by comparing the DRC and PCR values for 1997 with those projected for 2007 in the scenario No Technical Change. In most cases, future values are worse than those in the base year. The view of the macroeconomic effects free of other influences can be gained by comparing values from different macroeconomic scenarios. For all activities, neglecting the technical change effects, higher rates of economic growth have an adverse effect on social and private profitability. Although the magnitudes of this effect vary, it appears not to have changed the profitability ranks.

Without technical change not only the industry will stay socially unprofitable (as it was in 1997) but it is also expected to lose its private profitability, regardless of the macroeconomic scenario used. Product specific effects of macroeconomic development under the scenario No Technical Change vary significantly. For SMP and butter both social and private profitability is going to improve in any macroeconomic scenario, however, only SMP will be socially and privately profitable in 2007 (as it was in 1997) while butter will remain unprofitable in both social and private terms. Dramatic effects of changes in relative prices have been projected for ripening cheese, namely, in all three macroscenarios the initially positive social and private profitability is expected to become negative in the year 2007. For yoghurt the social profitability also remains negative in 2007, while private profitability substantially deteriorates in all three scenarios and turns negative under Base and Lowgrowth scenarios.

\section{Effects of technical change}

The assumed factor productivity improvement appears to have significant influence on the profitability projections. The magnitude of these improvements is sufficient to guarantee both social and private profitability at industry level in 2007, however only for the Low-growth and Base 
scenarios. For social profitability this means a switch from the initial negative profitability in $1997-$ the technical change more than compensates for the losses incurred due to the price changes. In private terms and in the Base scenario this 2007 profitability is expected to reach a level similar to that in 1997- the technical change just compensates for the adverse effects of price changes.

Although the assumed technical change is expected to bring significant improvements in private and social profitability for all product-specific activities, these improvements do not suffice to offset the dramatic price effects in ripening cheese production or to guarantee either social or private profitability in butter production. In yoghurt production the technical change provides for a positive social profitability under the Low-growth and Base scenarios and for a switch from negative to positive profitability in the Base scenario.

The following interpretation of the technical change effects can be proposed: for products for which favourable development of private profitability has been projected in the scenario No Technical Change, as for SMP and to a lesser extent for yoghurt, one could expect a relatively smaller demand for cost-reducing technical change. At the same time, however, favourable development of relative prices means that an activity may be expected to attract new investment targeted at output expansion. This in turn means that technical change, on average, may be attained because of the economies of rapid growth. In turn, an unfavourable development of relative prices, as in the case of ripening cheese and butter, simply implies high demand for cost-saving technical change, which, expectedly, can be realised given the existing scope for technology transfer and removal of many financial and institutional constraints on investment. Moreover, implicit in the future changes in relative prices, and hence changes in relative profitability of various dairy activities, is a tendency of the industry to accommodate the product structure in favour of products characterised by higher projected profitability. Neglecting this allocation effect in the calculations must have resulted in underestimating the industry-level profitability projections (relative to expected real development). The results suggest that the greatest need for technical change will be faced in ripening cheese and butter production. As suggested by the pace of expansion and allocation of state aid under the PRMM, cheese production has already experienced substantial modernisation in the recent past. Butter, in turn, belongs to the products, which have experienced the smallest technological progress in the past. However, as argued in the previous chapter, profitability projection would probably need to take account of the specific opportunity costs of farm milk used in butter production, the omission of which must have underestimated projected profitability levels. Already in 1997, yoghurt production belonged to the group of dairy products the production capacity of which had been either modernised or newly set up using more updated technologies. In the case of yoghurt production this was very much due to the specific demand conditions and relatively high importance of FDI. 


\section{Sources of product specific developments}

The next important step in interpreting the results is to try to explain product-specific dynamic effects. Generally, differences in the projected profitability levels depend on differences in terms of revenue change, factor intensity in conjunction with the factor-specific price developments and factor-specific productivity gains assumed in the scenario of technical change. These effects have been isolated by estimating matrices of dynamic comparative advantage (Tables 4.7 and 4.8).

Table 4.7: Matrix of dynamic comparative advantage, under Base scenario, in real terms (1997 revenues $=100$ ).

\begin{tabular}{|c|c|c|c|c|c|c|}
\hline \multicolumn{7}{|l|}{ Industry } \\
\hline & \multirow[t]{2}{*}{ Revenues } & \multicolumn{4}{|c|}{ Costs } & \multirow[t]{2}{*}{ Profits } \\
\hline & & Tradables & Farm Milk & Labour & Capital & \\
\hline Euro-social values in 2007 & 96 & 15 & 54 & 17 & 12 & -1 \\
\hline Social values in 1997 & 100 & 18 & 57 & 16 & 11 & -3 \\
\hline Total change & -4 & -3 & -4 & 1 & 0 & 2 \\
\hline Price effect & -8 & -4 & -5 & 10 & -5 & -3 \\
\hline Technical change effect & 4 & 1 & 1 & -9 & 5 & 6 \\
\hline \multicolumn{7}{|l|}{ SMP } \\
\hline & \multirow[t]{2}{*}{ Revenues } & \multicolumn{4}{|c|}{ Costs } & \multirow{2}{*}{ Profits } \\
\hline & & Tradables & Farm Milk & Labour & Capital & \\
\hline Euro-social values in 2007 & 94 & 7 & 66 & 9 & 9 & 4 \\
\hline Social values in 1997 & 100 & 8 & 71 & 8 & 10 & 2 \\
\hline Total change & -6 & -2 & -6 & 0 & -1 & 2 \\
\hline Price effect & -6 & -2 & -8 & 5 & -5 & 4 \\
\hline Technical change effect & 0 & 0 & 2 & -5 & 4 & -2 \\
\hline \multicolumn{7}{|l|}{ Ripening cheese } \\
\hline & \multirow{2}{*}{ Revenues } & \multicolumn{4}{|c|}{ Costs } & \multirow{2}{*}{ Profits } \\
\hline & & Tradables & Farm Milk & Labour & Capital & \\
\hline Euro-social values in 2007 & 81 & 6 & 60 & 16 & 6 & -8 \\
\hline Social values in 1997 & 100 & 8 & 65 & 15 & 6 & 7 \\
\hline Total change & -19 & -1 & -4 & 1 & 0 & -15 \\
\hline Price effect & -24 & -2 & -5 & 9 & -3 & -23 \\
\hline Technical change effect & 5 & 0 & 1 & -8 & 3 & 8 \\
\hline \multicolumn{7}{|l|}{ Butter } \\
\hline & \multirow[t]{2}{*}{ Revenues } & \multicolumn{4}{|c|}{ Costs } & \multirow[t]{2}{*}{ Profits } \\
\hline & & Tradables & Farm Milk & Labour & Capital & \\
\hline Euro-social values in 2007 & 98 & 8 & 78 & 10 & 9 & -7 \\
\hline Social values in 1997 & 100 & 9 & 82 & 10 & 8 & -9 \\
\hline Total change & -2 & -1 & -3 & 0 & 0 & 2 \\
\hline Price effect & -2 & -2 & -4 & 6 & -4 & 2 \\
\hline Technical change effect & 0 & 1 & 0 & -5 & 4 & 0 \\
\hline \multicolumn{7}{|l|}{ Yoghurt } \\
\hline & \multirow[t]{2}{*}{ Revenues } & \multicolumn{4}{|c|}{ Costs } & \multirow[t]{2}{*}{ Profits } \\
\hline & & Tradables & Farm Milk & Labour & Capital & \\
\hline Euro-social values in 2007 & 101 & 32 & 28 & 18 & 23 & 0 \\
\hline Social values in 1997 & 100 & 39 & 30 & 17 & 24 & -10 \\
\hline Total change & 1 & -7 & -2 & 1 & -2 & 10 \\
\hline Price effect & -4 & -8 & -3 & 10 & -12 & 8 \\
\hline Technical change effect & 5 & 2 & 1 & -9 & 10 & 2 \\
\hline
\end{tabular}

Changes in the real value of revenue appear to be dominant source of variation in projected product-specific profitability, both socially and privately. These changes, in terms of percentage of the base-year revenue, including technical change effect on output prices, range between a $19 \%$ decrease (ripening cheese) and a 1\% increase (yoghurt) in social terms, and between a $20 \%$ decrease (ripening cheese) and a $4 \%$ decrease (butter) in private terms. On the cost side price effects partly compensate one another and the net price effect on costs ranges between minus $1 \%$ (ripening cheese) and minus 
$11 \%$ (yoghurt) in social terms, and between minus 9\% (butter) and minus 12\% (SMP) in private terms.

Table 4.8: Matrix of dynamic effects on private profitability, under Base scenario, in real terms $(1997$ revenues $=100)$

\begin{tabular}{|c|c|c|c|c|c|c|}
\hline \multicolumn{7}{|l|}{ Industry } \\
\hline & \multirow[t]{2}{*}{ Revenues } & \multicolumn{4}{|c|}{ Costs } & \multirow[t]{2}{*}{ Profits } \\
\hline & & Tradables & Farm Milk & Labour & Capital & \\
\hline Private values in 2007 & 89 & 14 & 47 & 16 & 10 & 2 \\
\hline Private values in 1997 & 100 & 18 & 54 & 17 & 9 & 2 \\
\hline Total change & -11 & -3 & -6 & -2 & 1 & 0 \\
\hline Price effect & -15 & -4 & -7 & 7 & -3 & -7 \\
\hline Technical change effect & 4 & 1 & 1 & -9 & 4 & 6 \\
\hline \multicolumn{7}{|l|}{ SMP } \\
\hline & \multirow[t]{2}{*}{ Revenues } & \multicolumn{4}{|c|}{ Costs } & \multirow[t]{2}{*}{ Profits } \\
\hline & & Tradables & Farm Milk & Labour & Capital & \\
\hline Private values in 2007 & 92 & 7 & 61 & 9 & 8 & 7 \\
\hline Private values in 1997 & 100 & 9 & 72 & 10 & 7 & 3 \\
\hline Total change & -8 & -2 & -10 & -1 & 1 & 5 \\
\hline Price effect & -8 & -2 & -12 & 4 & -3 & 6 \\
\hline Technical change effect & 0 & 0 & 2 & -5 & 3 & -1 \\
\hline \multicolumn{7}{|l|}{ Ripening Cheese } \\
\hline & \multirow[t]{2}{*}{ Revenues } & \multicolumn{4}{|c|}{ Costs } & \multirow[t]{2}{*}{ Profits } \\
\hline & & Tradables & Farm Milk & Labour & Capital & \\
\hline Private values in 2007 & 80 & 7 & 57 & 16 & 6 & -5 \\
\hline Private values in 1997 & 100 & 8 & 65 & 18 & 5 & 4 \\
\hline Total change & -20 & -1 & -8 & -2 & 1 & -10 \\
\hline $\begin{array}{r}\text { Price effect } \\
\end{array}$ & -25 & -2 & -9 & 7 & -2 & -19 \\
\hline Technical change effect & 5 & 1 & 1 & -9 & 3 & 9 \\
\hline \multicolumn{7}{|l|}{ Butter } \\
\hline & \multirow[t]{2}{*}{ Revenues } & \multicolumn{4}{|c|}{ Costs } & \multirow[t]{2}{*}{ Profits } \\
\hline & & Tradables & Farm Milk & Labour & Capital & \\
\hline Private values in 2007 & 96 & 8 & 73 & 10 & 8 & -3 \\
\hline Private values in 1997 & 100 & 10 & 81 & 11 & 7 & -8 \\
\hline Total change & -4 & -1 & -7 & -1 & 1 & 5 \\
\hline Price effect & -4 & -2 & -8 & 4 & -3 & 5 \\
\hline Technical change effect & 0 & 1 & 0 & -6 & 4 & 1 \\
\hline \multicolumn{7}{|l|}{ Yoghurt } \\
\hline & \multirow[t]{2}{*}{ Revenues } & \multicolumn{4}{|c|}{ Costs } & \multirow[t]{2}{*}{ Profits } \\
\hline & & Tradables & Farm Milk & Labour & Capital & \\
\hline Private values in 2007 & 82 & 27 & 22 & 14 & 17 & 2 \\
\hline Private values in 1997 & 100 & 33 & 25 & 16 & 16 & 10 \\
\hline Total change & -18 & -7 & -3 & -2 & 1 & -7 \\
\hline $\begin{array}{r}\text { Price effect } \\
\end{array}$ & -22 & -8 & -4 & 6 & -6 & -11 \\
\hline Technical change effect & 5 & 1 & 0 & -8 & 7 & 4 \\
\hline
\end{tabular}

As far as the factor intensity in the value added is concerned, dynamic comparative advantages arising from the changes in relative prices appear to be positively affected by high capital intensity (yoghurt) and adversely affected by high labour intensity (ripening cheese). Of importance is the relative factor intensity because price effects for both factors go in opposite directions, are of comparable rates, and hence tend to largely balance out. Relative factor intensity measured by ratio of costs (in social prices) of capital to labour in value added ranges between 1.3 for yoghurts to 0.4 for ripening cheese, in social prices.

Farm milk cost is treated as a tradable cost element $\left(\mathrm{DRC}_{1}\right)$ and behaves similar to costs of tradable inputs, simply because its price is derived from the tradable product prices, SMP and butter, subject to same paramount influence of RER. 
Three effects labelled as technical change effects on dynamic comparative advantages are of major importance. The first is the effect on revenues (quality premia), which is assumed to occur in all non-intervention products. Indeed, this effect proves particularly important for more value added products where it compensates for at least some of the losses incurred due to the negative price effects. The second is the labour saving effect that tends to dominate the total technical change effect on the cost side. The third is an increase in the capital costs attributable both to increased modernisation investments and substitution for labour.

\section{Sensitivity of private profitability to farm milk prices}

A high cost share of farm milk implies high sensitivity of projected profitability to assumption regarding farm milk prices. In sensitivity analysis two alternative price scenarios for farm milk prices have been tested. The first, with the 'full' transmission of the increases in butter and SMP Euro-social prices to farm milk prices, the second, with the price of milk equal to $95 \%$ of the equivalent of butter and SMP Euro-social prices, and the third, equal to $95 \%$ of this equivalent. From the simulation results presented in Table 4.9 one can see that, indeed, the assumed variation in the milk prices has substantial influence on projected private profitability.

Table 4.9. Sensitivity analysis: impact of variation in farm milk price on private profitability (PCR) in 2007 under alternative scenarios (Farm milk price as percentage of SMP and butter price equivalent under the current processing costs).

\begin{tabular}{|c|c|c|c|c|c|c|c|c|c|c|}
\hline \multirow{4}{*}{ Activity } & \multirow[t]{4}{*}{1997} & \multicolumn{9}{|c|}{2007} \\
\hline & & \multicolumn{3}{|c|}{ Low-growth } & \multicolumn{3}{|c|}{ Base } & \multicolumn{3}{|c|}{ High-growth } \\
\hline & & $100 \%$ & $95 \%$ & $90 \%$ & $100 \%$ & $95 \%$ & $90 \%$ & $100 \%$ & $95 \%$ & $90 \%$ \\
\hline & & \multicolumn{9}{|c|}{ No Technical Change } \\
\hline Milk processing industry & 0.92 & 1.25 & 1.12 & 1.01 & 1.39 & 1.25 & 1.14 & 1.53 & 1.40 & 1.29 \\
\hline Skimmilk powder & 0.86 & 0.83 & 0.71 & 0.62 & 0.85 & 0.75 & 0.67 & 0.87 & 0.78 & 0.71 \\
\hline Ripening cheese & 0.84 & 2.83 & 2.09 & 1.66 & 2.76 & 2.16 & 1.78 & 2.70 & 2.23 & 1.90 \\
\hline Butter & 1.84 & 1.80 & 1.30 & 1.02 & 1.77 & 1.35 & 1.09 & 1.75 & 1.40 & 1.16 \\
\hline Yoghurts & 0.77 & 1.01 & 0.98 & 0.94 & 1.16 & 1.12 & 1.08 & 1.34 & 1.29 & 1.25 \\
\hline \multicolumn{11}{|c|}{ Technical Change } \\
\hline Milk processing industry & 0.92 & 0.91 & 0.82 & 0.75 & 1.01 & 0.92 & 0.84 & 1.11 & 1.01 & 0.93 \\
\hline Skimmilk powder & 0.86 & 0.78 & 0.67 & 0.58 & 0.80 & 0.69 & 0.61 & 0.81 & 0.71 & 0.63 \\
\hline Ripening cheese & 0.84 & 1.56 & 1.24 & 1.02 & 1.63 & 1.33 & 1.12 & 1.70 & 1.42 & 1.22 \\
\hline Butter & 1.84 & 1.66 & 1.18 & 0.91 & 1.64 & 1.21 & 0.96 & 1.62 & 1.24 & 1.01 \\
\hline Yoghurts & 0.77 & 0.87 & 0.84 & 0.82 & 0.96 & 0.93 & 0.90 & 1.07 & 1.03 & 1.00 \\
\hline
\end{tabular}

Source: author's estimates based on methods and data described in text.

In particular, the assumed 5\% divergence from the Euro-social price level has resulted in triggering positive profitability is some of the analysed cases including yoghurt in Low-growth and No Technical Change and milk processing industry in Technical Change and both Base and High- 
growth. Further reduction of the price to $90 \%$ of the Euro-social level extends the set of profitable cases by milk processing industry in Technical Change and High-growth scenario and butter in Technical Change and all three macro-scenarios.

These results confirm the expectation that depressing farm milk prices may be seen by the industry as an important means of mitigating competitive pressure. Of course, the choice of such a solution will be contingent on functioning of the farm milk market given the outcomes of the sector restructuring and the decision concerning the future reform of the CAP dairy regime, and the quota system in particular. Higher scope for farmers to switch among buyers and adverse consequences for the farm milk supply in the longer-term may limit the industry's opportunity for and willingness to use such a defence strategy in the future. Nevertheless, the changes in the relative farm prices, arising from the CAP adoption, in favour of milk, may enhance the farmers' readiness to 'tolerate' lower milk prices on condition that the underlying transfers would help the industry to accommodate successfully to the increased competitive pressure arising from EU accession. In fact such a co-operative attitude of farmers would not be very new in the Polish dairy sector. Similar behaviour in many dairy cooperatives was reported between 1991 and 1993, when the industry faced financial problems related to transition reforms (Smoleński, 1998b). 


\section{BROAdENEd VIEW OF DYNAMIC COMPARATIVE AdVANTAGE - A CASE STUdy OF THE YOGHURT MARKET}

In the previous chapters products have been treated in a rather uniform way in terms of the mechanism determining their comparative advantage. Namely, by using the DRC methodology, the observed current input intensities reflecting: (i) relative factor intensity (H-O-S) and (ii) factor productivity (Ricardo) have been confronted with the domestic factor prices (indicative of endowments) and world prices of tradable input and output (indicative of efficiency of foreign competitors). However, it has also been said that the dairy products may differ in terms of the determinants of input productivity improvement, since they are faced with various scope for technology imitation (productivity lag) and various barriers to efficiency improvement (e.g. a barrier of domestic market size to develop scale efficiency, limited mobility of new technologies or institutional constraints). Moreover, as suggested in Chapter 2, dynamic adjustments in the product structure tend to discriminate against certain products with regard to the rate of technology updating (economies of rapid growth), at least in the short/medium term. This may result in relative efficiency of products contradicting the expectations based on the static view of comparative advantages (e.g. higher social profitability of yoghurts compared to butter in the Chapter 3.).

The analysis hitherto also neglected the role of foreign direct investments in determining international competitiveness. Increasingly, FDIs are seen as a means to overcome several constraints typical of the economies of transition (Banse et al., 1998) and are considered a prerequisite for developing international competitiveness of the Agro-food sectors in the CEECs (Josling et al., 1997).

This chapter takes a broadened view of dynamic comparative advantage in the analysed industry. The analysis proceeds by carrying out a case study of the Polish yoghurt market. In the years 19921999 this market was characterised by very dynamic developments in terms of domestic output and consumption growth, intensity of FDI and several other features. As far as trade theory is concerned, the analysis takes into consideration the role of the domestic demand conditions (e.g. Porter, 1990), and the role of FDI in technological and structural change. The focus is placed on motives and consequences of FDI including interaction with the economies of scale and domestic trade policy.

The study starts from a presentation of major developments in the years 1992-1999, follows with identifying salient facts of these developments and concludes with launching and discussing several hypotheses explaining these developments and outlining the prospects for the near future. 


\subsection{Characteristics of Yoghurt and Yoghurt Technology}

Yoghurt is produced through fermentation of milk. It is classified as a fresh dairy product with a relatively short shelf life. There is a wide scope for product differentiation according to: (i) type of bioflora used in fermentation, (ii) milk fat content, (iii) supplementary elements such as fruits, (iv) size, shape and graphic design of packaging as well as (v) shelf-life. Milk contribution to the total production costs is about 20\% (Krell and Wietbrauk, 1993) and is the lowest among the dairy products. Consequently, yoghurt can also be classified as a 'high value added' dairy product with high scope for horizontal and vertical differentiation. Due to the product innovation, yoghurt production tends to be intensive in R\&D and marketing inputs (e.g. advertisements), which make scale economies an important element of cost competitiveness. Thanks to: (i) technological progress in packaging and processing and developments in transport infrastructure and (ii) relatively high unit value, yoghurt is an internationally tradable item, at least, as far as European distances are concerned. In general, trade can be determined by the production efficiency (e.g. due to scale effects) or consumer preference for variety.

\subsection{Developments in the Yoghurt market in Poland (1990-1999)}

\subsubsection{Domestic consumption}

Milk drinks, and yoghurts in particular, represent the most dynamically developing segment of the dairy market in Poland. It is estimated that between 1993 and 1998 consumption of milk drinks (mainly yoghurts and kefirs) increased fivefold. Between 1996 and 1998 alone the per capita consumption of yoghurts increased from $2.3 \mathrm{~kg}$ to $5.2 \mathrm{~kg}^{64}$ (Figure 5.1). Despite this increase, the current consumption level corresponds only to about one third of that in Germany, which is often regarded as an indication of the potential for further increases in yoghurt sales in Poland.

The ongoing consumption growth may be attributed to the following factors:

i. Income effects. Yoghurt with other high value products may be characterised by relatively highincome elasticity of demand. The 1998 real average per capita income exceeded by $16.1 \%$ the 1992 level and by $19.1 \%$ the 1995 level (GUS, 1999c);

ii. Price effect. Growing competition among suppliers in years 1998-1999 may have contributed to the price depression. As suggested by high profit margins (Table 5.3) there may be a scope for further price decreases;

64 This estimate results from the data on the domestic market balance (Figure 5.1). Somewhat lower per capita consumption amounting to 3.72 in 998 has been evidenced by the household budget surveys by the GUS (GUS, 1999c, and IERiGŻ, 1999). 
iii. Changing consumer preferences. First, the economic transition may have merely resulted in revealing hidden consumer preferences by granting access to a variety of new products including new varieties of yoghurts. Second, yoghurts enjoy the reputation of a 'healthy' food, the significance of which may have been strengthened by growing health awareness. Third, yoghurt belongs to the most intensively advertised food product mainly due to the promotional campaigns of the Danone - the leading domestic producer.

Figure 5.1. Production and consumption of yoghurts in Poland 1996-1999, yearly.

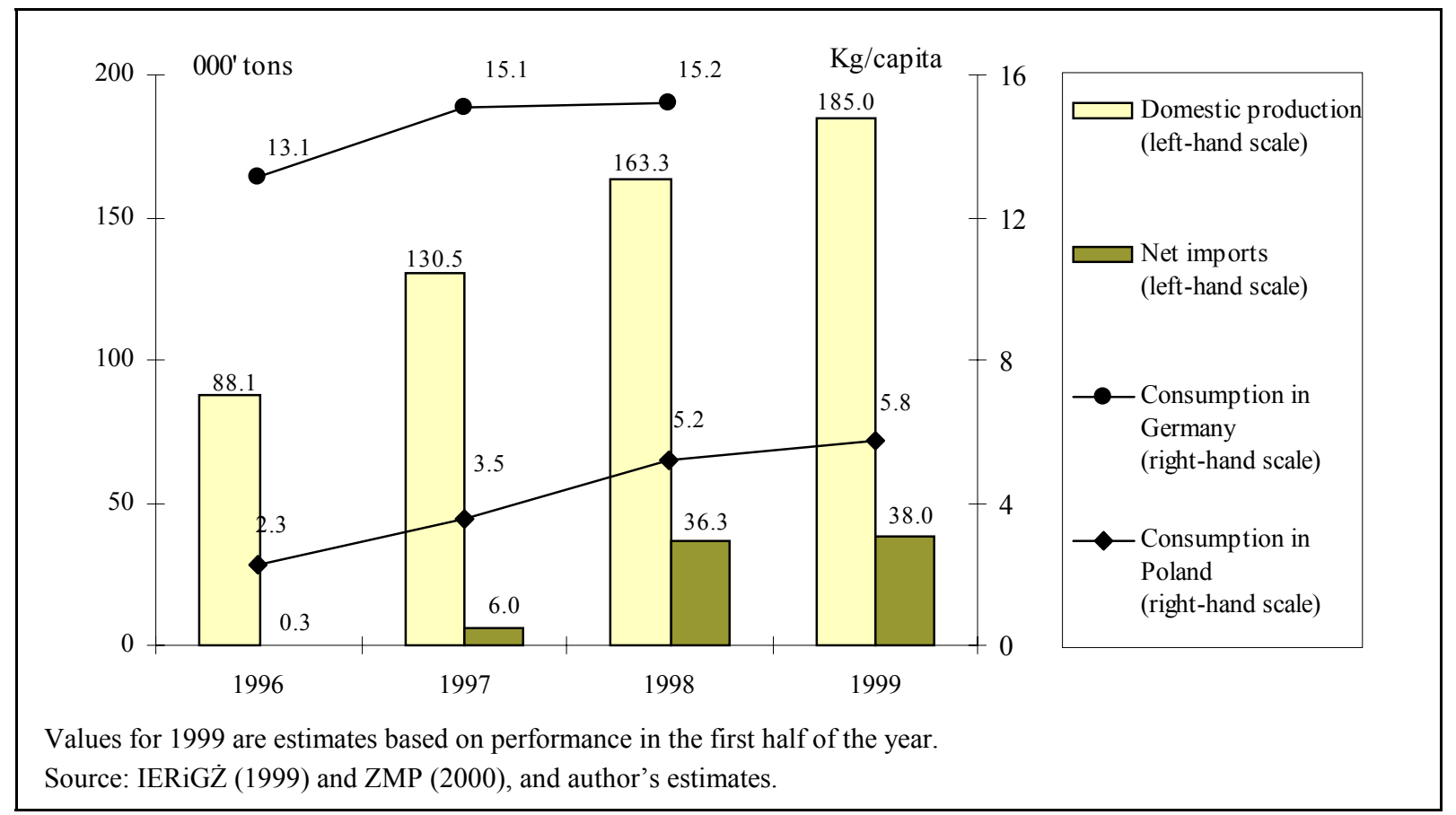

A recent consumer enquiry (Boss Rolnictwo, 1999) indicates that despite the already realised increases, yoghurt consumption still has the highest growth potential among dairy products: about $50 \%$ consumers said that they intended to increase their yoghurt purchasing in the near future, compared to only $20-30 \%$ in the case of other dairy products (cottage cheese, kefir, hard cheeses).

\subsubsection{Domestic production and imports}

Consumption growth in the period 1994-1999 was mainly served by domestic production: imports became significant only in 1998. Between 1996 and 1998, domestic production almost doubled, rising from 88.1 thousand tons to 163.3 thousand tons (Figure 5.1). According to records for the first half of

65 For example in 1996 expenditures on radio advertisements of Danone amounted to $1.38 \%$ of all expenditures on radio advertisement in Poland (Krajweski et al., 1999). Janowicz (1999) reports that advertising campaigns by Danone and Yoplait, two FDI-based yoghurt producers were ranked among the ten most effective in the Polish consumer goods market in January 1999. 
1999, this expansion is to continue: the 1999 production is expected to reach 185 thousand tons (IERiGŻ, 1999).

The number of domestic producers is estimated at around 100 (Boss Rolnictwo, 1999). However, two firms, Danone and Bakoma, account jointly for as much as $60 \%$ of total domestic production and about $50 \%$ of domestic sales (Table 5.1 ). The remaining domestic suppliers can be divided into a group of 10-15 'medium-size' producers, who reach between $1 \%$ and $3 \%$ of the domestic market each, and the group of 'small-scale' suppliers who jointly account for $10 \%-15 \%$ of the domestic market.

Table 5.1. Major suppliers' shares in the domestic yoghurt market in Mai-June 1999.

\begin{tabular}{|c|c|c|c|c|}
\hline \multirow{2}{*}{ Producer clusters } & \multirow{2}{*}{ Producer } & \multirow{2}{*}{ Ownership status } & \multicolumn{2}{|c|}{ Market shares in percentage } \\
\hline & & & by quantity & by value \\
\hline \multirow[t]{3}{*}{ Leaders } & Danone & FDI company & 23 & 26 \\
\hline & Bakoma & Domestic company & 22 & 26 \\
\hline & Zott & Foreign importer & 21 & 22 \\
\hline \multirow[t]{7}{*}{ Medium-scale } & Yoplait & FDI company & 2 & 2 \\
\hline & Łódzkie ZM & Domestic co-operative & 3 & 3 \\
\hline & OSM Krasnystaw & Domestic co-operative & 3 & 2 \\
\hline & OSM Sanok & Domestic co-operative & 3 & 2 \\
\hline & Farma & Domestic company & 2 & 1 \\
\hline & Fromako & Domestic company & 2 & 2 \\
\hline & OSM Opole & Domestic co-operative & 2 & 1 \\
\hline \multirow[t]{2}{*}{ Small-scale } & Other & About 60 co-operatives & 17 & 13 \\
\hline & Total & & 100 & 100 \\
\hline
\end{tabular}

Net imports grew significantly in 1998 reaching about $18 \%$ of domestic sales, which further increased to $21-22 \%$ by the middle of 1999 . Imports expressed in terms of the half-year import volume increased from 2.6 thousand tons in the first half 1997 to 31.4 thousand tons in the first half of 1999 (Figure 5.2). A single foreign supplier, the German firm Zott, accounted for more than $90 \%$ of imports in 1998 and 1999. As a result, about 70\% of sales in 1999 have been realised by 3 firms (Table 5.1).

In years 1996-1998 Poland exported about 3 thousand tons of yoghurts yearly to the FSU countries. Until 1998, both in imports and exports, only one yoghurt variety dominated: flavoured or with fruit with a fat content of between $3 \%$ and $6 \%$ (CN 040310930) (Table 5.2).

The expansion of domestic production has been accompanied by high profitability. In the period 1995-1997 the profitability of the two domestic leaders specialising in yoghurt production exceeded both the profitability of the entire milk processing industry and the profitability of the better performing non-co-operative sub-sector (Table 5.3). 
Table 5.2. Poland's foreign trade in yoghurts, 1994-1998.

\begin{tabular}{|c|c|c|c|c|c|c|c|c|c|}
\hline \multirow{3}{*}{$\begin{array}{l}\text { Commodity } \\
\text { and } \mathrm{CN} \text { code }\end{array}$} & \multirow{3}{*}{ Year } & \multicolumn{4}{|c|}{ Exports } & \multicolumn{4}{|c|}{ Imports } \\
\hline & & \multicolumn{2}{|c|}{ All } & \multicolumn{2}{|c|}{ FSU } & \multicolumn{2}{|c|}{ All } & \multicolumn{2}{|c|}{ EU } \\
\hline & & $\begin{array}{l}\text { Value } \\
\text { Mio } \\
\text { USD } \\
\end{array}$ & $\begin{array}{c}\text { Volume } \\
\text { Thous. } \\
\text { Tons }\end{array}$ & $\begin{array}{l}\text { Value } \\
\text { Mio } \\
\text { USD } \\
\end{array}$ & $\begin{array}{c}\text { Volume } \\
\text { Thous. } \\
\text { Tons }\end{array}$ & $\begin{array}{l}\text { Value } \\
\text { Mio } \\
\text { USD } \\
\end{array}$ & $\begin{array}{c}\text { Volume } \\
\text { Thous. } \\
\text { Tons }\end{array}$ & $\begin{array}{l}\text { Value } \\
\text { Mio } \\
\text { USD } \\
\end{array}$ & $\begin{array}{c}\text { Volume } \\
\text { Thous. } \\
\text { Tons }\end{array}$ \\
\hline Yoghurts & 1994 & 0.210 & 0.15 & 0.200 & 0.14 & 2.392 & 3.05 & 2.391 & 3.05 \\
\hline \multirow[t]{4}{*}{04031} & 1995 & 1.315 & 0.81 & 1.297 & 0.81 & 0.389 & 0.44 & 0.389 & 0.44 \\
\hline & 1996 & 2.910 & 2.37 & 2.877 & 2.35 & 3.076 & 2.74 & 2.998 & 2.71 \\
\hline & 1997 & 1.923 & 2.14 & 1.826 & 2.08 & 7.326 & 8.05 & 6.300 & 6.98 \\
\hline & 1998 & 4.591 & 5.07 & 3.119 & 3.75 & 37.815 & 41.36 & 36.602 & 39.65 \\
\hline \multirow{5}{*}{$\begin{array}{l}\text { Yoghurt: flavoured or } \\
\text { containing added fruit, } \\
\text { nuts, of fat content } \\
\text { between } 3 \% \text { but not } 6 \% \\
040310930\end{array}$} & 1994 & 0.024 & 0,01 & 0.024 & 0.01 & 0.065 & 0.05 & 0.065 & 0.05 \\
\hline & 1995 & 0.413 & 0.34 & 0.412 & 0.34 & 0.009 & 0.00 & 0.009 & 0.00 \\
\hline & 1996 & 1.050 & 1.10 & 1.047 & 1.09 & 0.781 & 0.55 & 0.730 & 0.53 \\
\hline & 1997 & 1.206 & 1.61 & 1.197 & 1.60 & 3.836 & 4.60 & 3.809 & 4.59 \\
\hline & 1998 & 4.029 & 4.58 & 2.873 & 3.53 & 34.788 & 37.79 & 34.786 & 37.79 \\
\hline
\end{tabular}

Table 5.3. Net profitability of yoghurt producers compared to that of the entire milk processing industry (in \% of revenue).

\begin{tabular}{|lcccc|}
\hline & 1995 & 1996 & 1997 & 1998 \\
\hline Milk industry: (1) & -0.29 & -0.21 & 0.90 & -0.47 \\
$\quad$ Co-operatives & n.a. & -0.62 & 0.16 & -1.44 \\
$\quad$ Other & n.a. & 0.93 & 2.37 & 1.77 \\
Yoghurts (market leaders): (2) & & & 11.32 \\
$\quad$ Bakoma & 4.62 & 11.97 & 13.11 & n.a. \\
$\quad$ Danone & & 13.01 & & \\
\hline n.a.- not available. & & & \\
In 1997 revenues from yoghurts accounted for 90\% of total revenue of Bakoma (Rzeczpospolita 25.02.1998). \\
Source: (1) IERiGŻ (1999), (2) Monitor Polski, Dziennik Urzędowy and Rzeczpospolita (20.09.1999). \\
\hline
\end{tabular}

According to a study by Doradztwo mleczarskie (1997), in 1997 all co-operatives producing yoghurts declared their highest profit margin for this activity. Even in 1999, when domestic producers complained about the growing import competition, the average net profitability of yoghurt production in the co-operative sector was estimated at 5\% (Boss Rolnictwo, 1999). High profits and prospects for domestic market growth must have attracted many small-scale investments in yoghurt production in the dairy co-operatives sector. In numerous co-operative enterprises profits from yoghurt production compensate for losses from other product lines (Boss Rolnictwo, 1999). At the same time, many small-scale producers cannot attain the legally required quality standards (PIH, 1998). 


\subsubsection{Characteristics of major suppliers}

Danone. French FDI of Compagnie Gervais Danone (one of the biggest dairy enterprises in the world) in the Dairy Co-operative Wola in Warsaw. In 1991 a French-Polish joint venture was created and in 1995 Danone took over all equity shares. Initial capital invested by the equity purchase amounted to 5 Mio USD (PAIZ, 1998). However, during the first year of its activity alone the modernisation investment amounted to 10 Mio USD. Until 1995 a substantial part of supplies on the Polish market originated from imports from a factory in Belgium (Rzeczpospolita, 14.02.1995). Also in 1995 Danone expanded its activity in Poland by taking over $60 \%$ of Mildes (in Bierun near Katowice), the biggest milk processing firm in south Poland (Rzeczpospolita, 15.02.1995). In 1999 the firm took over $35 \%$ of Bakoma shares - the second biggest domestic producer and its major competitor in the Polish market.

Bakoma. Founded in 1989 by a joint-venture between domestic capital (Z. Komorowski) and foreign direct investment from the USA (E.Mazur). The FDI contribution amounted to 2 Mio USD (PAIZ, 1998) and only had a financial character. The processing capacity has been created by a 'green-field' investment in Elżbietów near Warsaw. In 1999 investment was planned in a dairy cooperative in Kutno where the firm took over 55\% of equity shares. In 1995-1998 the firm managed to realise sales increases from about 27 Mio to 76 Mio USD. The profits generated during that time (about 20 Mio USD) have been reinvested to expand capacity (Rzeczpospolita, 20.09.1999). Since 1995, shares of the enterprise have been traded on the Warsaw Stock Exchange. Bakoma is the second biggest domestic producer with about $21-22 \%$ of the market share in 1999 (Table 5.1).

Zott. The third biggest yoghurt producer in Germany. Two processing plants (Mertingen and Gunzburg) process daily 1.3 Mio 1 of farm-milk and export to 35 countries. In 1998 yearly sales amounted 900 Mio DM (the equivalent of about $20 \%$ of the total sales of the Polish milk processing industry and of about $300 \%$ of sales of the entire Polish yoghurt market). Activity in Poland started in 1991 by establishing a commerce office. Later two storehouses were built: in Wrocław and near Poznań. In 1998 Zott started to expand on the Polish market with its trademark Jogobella, soon reaching about more than $20 \%$ of the market share. In the second half of 1999 negotiation to purchase the dairy co-operative in Opole began with the intention of starting production in Poland (Rzeczpospolita, 24.03.1999).

Other FDI producers. The French Yoplait started to operate on the Polish market in 1997 with imports. After the take-over of the dairy co-operative in Osowa Sień, imports were substituted by domestic production (Rzeczpospolita, 24.03.1999). Campina Bacha is a sister company of two Dutch dairy firms: Bacha Menken and Campina Melkunie (the two biggest world dairy enterprises). Yoghurts are produced in its subsidiary Campina Tojo (Tojo - a brand name) in Toruń. Campina Tojo, together with other three subsidiaries, were transformed into Campina Polska in Mai 1999 (Boss Rolnictwo, 1999). 


\subsection{Reactions to Increased Competition from Imports in 1998}

Rising yoghurt imports became one of the most hotly debated issues in Polish agro-food sector bringing about a variety 'protective' reactions both at the policy and business levels. It has been estimated that the two market leaders (Danone and Bakoma) 'lost' some 20\%-30\% of their market shares ${ }^{6}$ (Rzeczpospolita, 17.04.1999). Most affected has been the group of small-scale producers, who mainly relied on favourable demand trend rather than active marketing strategy (Boss rolnictwo, 1999). In April 1999 the tariff rate for yoghurt was increased.

\subsubsection{Increased tariff rates}

Already in 1998 about 60 dairy co-operatives associated in the Union of Domestic Dairy Cooperatives (KPSM) asked the MAFE for a 'relevant' regulations to limit import competition on the yoghurt market (Rzeczpospolita, 17.04.1999). Two kinds of rationale were put forward. The first indicated the importance of profits generated in yoghurt production for: (i) modernisation investments and (ii) the ability of dairy co-operatives to pay adequate remuneration for quality farm milk, both being considered as fundamental for adjustments to the EU accession requirements. The consequences of the 'lost' profits from yoghurt were exacerbated by the tightened situation in 1998 after losing export outlets in FSU markets (the results of the Russian 'crisis') and decreased exports to the EU (mainly a consequence of the EU ban on Polish imports due to sanitary reasons). The second were complaints about: (i) the apparent 'dumping' price level of imports and (ii) the EU subsidies to the dairy exports to Poland. The 1998 trade report by SAEPR/FAPA (1999) shows that in the first months of expansion on the Polish market unit values of imported yoghurt were about one third below those for the last month of 1997, while at the end of 1998 they increased by 20\%. Figure 5.2 presents this effect with the data for half-year periods in the years 1997-1999.

66 In most available press reports the term market 'loses' is used in reference to the alternative without imports. In fact, sales by domestic producers in 1998 increased relative to 1997 (Figure 5.1). However, cost increases may have appeared if the attainable sales were reduced below the expected level for which the production capacities have been expanded. 
Figure 5.2. Volume and unit value of yoghurt imports to Poland, 1997-1999.

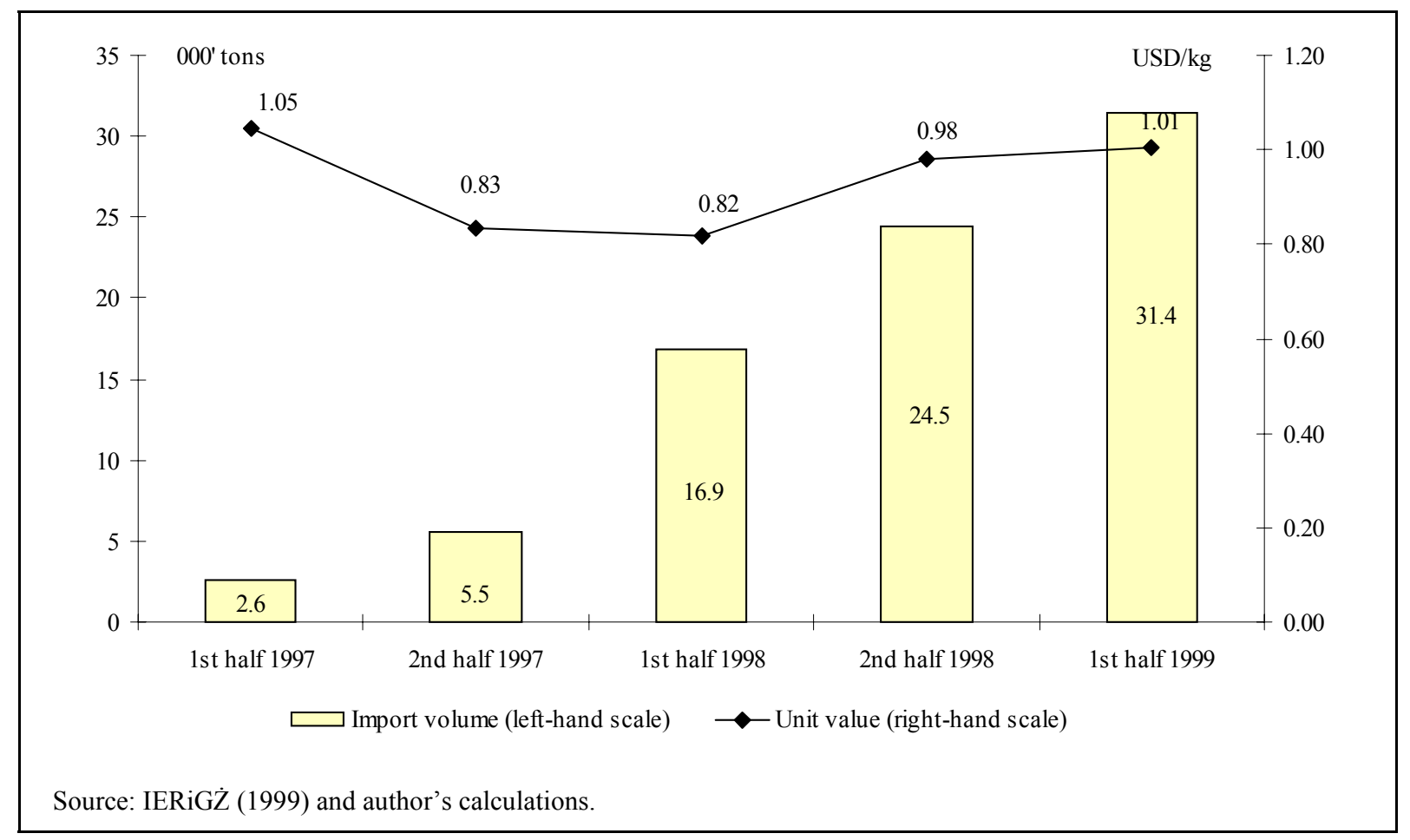

In April 1999 Poland pushed up import tariffs on EU flavoured yoghurts with a fat content of 3\%$6 \%$ (CN 040310930) from 9\% to 35\%. The category of yoghurt affected was that which accounted for more than $90 \%$ of 1998 imports (Table 5.2). This policy change initiated a dispute between Poland and the EU about the consistency of the new tariffs with the Europe Agreement. While the Polish party referred to articles 30 and 33 of the Agreement, 6 the EU Commission claimed that tariff rises on yoghurts and other products introduced by Poland in 1999 were against the 'spirit of the Agreement. Partial settlement of the dispute was communicated in September 1999 after a series of bilateral meetings. Poland was ready to revert to the original $9 \%$ preferential tariff for deliveries from the EU but, however, within a quota of 16 thousand tons (set as the average from the previous 3 -years' import volume). Beyond this volume a higher tariff of $29 \%$ would apply. Preferences towards the EU importers would apply in that the autonomous tariff rates, applicable to third countries, would be elevated up to $175 \%$ (the maximum limit under UR GATT). These new arrangements would apply to all categories of yoghurts and only for two years (2000 and 2001) (Agra Europe East Europe, 1999, and Rzeczpospolita, 03.09.1999).

67 Poland also referred to the precedence of using these articles by the EU to limit imports of Polish cherries in 1992 (Rzeczpospolita, 11.05.1999 and Rzeczposplita 24.03.1999).

68 The complaints from the EU side also indicated the unfortunate momentous of this policy change, in particular because the talks on renewing the trade protocol with the purpose of further liberalising trade between Poland and the EU within the Europe Agreement were due to begin in October 1999. In turn Poland, as far as political argumentation is concerned, stressed that the tariff rises were (apart from any other economic reasons) needed to give Poland the maximum possible margin for negotiation when the next round of WTO talks got underway in Seattle in November 1999 (Agra-Europe, East Europe, September 1999). 


\subsubsection{Response of the major importer (Zott) to the new tariff rates}

In response to the increased tariff rates for the specified yoghurt category (CN 040310930) Zott adjusted by switching to imports of yoghurts with a lower fat content (CN 040310910). In this way, as indicated by the records for first months of 1999 (Figure 5.2), the rate of import increases was not affected in a significant (if any) way. In August 1999 Zott announced intentions to take over a dairy co-operative in Opole, one of the best performing medium-size yoghurt producers. As the future strategic investor, it made a commitment to invest about 30 Mio DM to modernise and expand processing capacity. The offer was accepted by the members of the Co-operative at the end of September 1999.

\subsubsection{Response of domestic leaders (Danone and Bakoma)}

Already in 1995 Danone tried to take over its main competitor on the Polish market by offering 90 Mio USD for its shares. However, only in spring 1999 did the commitment to the concept of capital integration of the two competitors come from the side of Bakoma. By purchasing $35 \%$ of Bakoma's shares for 35-40 million USD, Danone became its second major shareholder. According to Z. Komorowski, founder of the firm and holder of the majority of Bakoma's shares, this merger was a response to the concentration processes in the European food-processing industry and, in particular, to the growing competition on the domestic yoghurt market. He also pointed out the areas of planned cooperation of the two firms: joint input purchases and use of a joint distribution network - both aimed at cost reduction (Rzeczpospolita, 20.09.1999). Nevertheless, it is also obvious that the merger of the two firms is bound to substantially enhance their market power.

\subsubsection{Reaction of other producers to new competitive situation}

Apart from effective lobbying for tariff increases, the smaller scale producers also tried to carry out real adjustments in order to cope with the growing competition. This involved plans to co-operate by launching a joint yoghurt trademark together with a relevant promotional campaign. However, according to several announcements (e.g. Boss Rolnictwo, 1999), only ten co-operative producers and two private firms (Szaflary and Fromako) have been able to make a commitment to enter such a jointventure - a firm had to meet the minimum technological standards imposed. Such a defence strategy was already successfully applied by a group of dairy co-operatives in 1996 when a joint brand of butter 'Dobre' was launched as a reaction to advertisement-driven growth in margarine consumption (major substitute for butter). Figure 5.3 summarises reactions of various firms. 
Figure 5.3. Concentration of yoghurt producers as a response to changing competitive conditions.

Source: author's compilation based on information described in the text.
Sloping rightward: $\begin{aligned} & \text { Init total } \\ & \text { costs } \\ & \text { and price in the size of enterprise due to merger or another form of integration } \\ & \text { conducive to decline in unit costs (decline in the scale inefficiency). } \\ & \text { rate real appreciation (effect of real appreciation on cost is neglected). }\end{aligned}$
Interpretation of arrows.
rise in unit costs experienced by domestic producers due to the increased competition from imports in
leaders

\subsection{Salient Facts on Developments in the Yoghurt Market in Poland}

On the base of the preceding descriptive analysis one can identify the following salient facts of recent development in Polish yoghurt market:

i. Yoghurt belongs to the group of consumer goods characterised by dynamic growth in domestic consumption during the economic transition. Future income growth and increase in competition in this market should promote further growth of yoghurt sales in Poland;

ii. Until 1998 the growing domestic consumption had been almost exclusively served by domestic production. Realising relatively high profitability, producers managed to expand their output quickly without facing substantial competition from imports. The surge in imports in 1998 merely slowed down the rate of domestic production growth and diminished the market shares of domestic producers. With this development the sustainability of the market position of many producers has been jeopardised;

iii. Competitive pressure has risen due to the appearance of new foreign competitors. This prompted an increase in tariff rates and pro-efficiency reactions at production level. The smallest producers, who probably are not scale efficient and whose existence relied on the temporary favourable demand conditions, limited their defence strategy to lobbying for tariff increases; 
iv. Foreign direct investments have had an important contribution to the development of domestic yoghurt production. The leading domestic producer Danone is a FDI of a multinational company specialising in dairy production and thus it has contributed both financial (and the corresponding embedded technological change) as well as non-tangible firm-specific assets. The second biggest producer, Bakoma, benefited only from the financial capital which entered the joint-venture with domestic investors; the consequent development of the firm was based on 'purchasable' technologies and imitation;

v. There has emerged a fairly clear pattern of the FDI settlement in Polish yoghurt production. Foreign firms started with supplies of imports from the home countries and only later moved to production in the host country. This pattern applies for Danone, Yoplait and Zott. While in the case of the two French firms the shift from imports to FDI might have been motivated by trade (transport and transaction) costs and other potential advantages of local production, in the case of Zott the trade policy effect may be a factor;

vi. Structure of the market (survival criterion) and costs structure (high fixed costs related to new product development and marketing activity) suggest that competitiveness of yoghurt production seems to rely heavily on the scale efficiency. The resulting high market concentration implies that firms may face the opportunities and challenges related to imperfect competition (price discrimination or bargaining position against down- and up-stream sectors). Both scale efficiency and the related issue of market power seem to be important factors driving the recent and possibly further developments in the Polish yoghurt market.

\subsection{Explaining the Competitiveness of Yoghurt Production in Poland}

After the presentation of the recent developments in the Polish yoghurt market there remains the task of explaining these developments in terms of the trade theory hypotheses as well as evaluating the prospects for the future international competitiveness of yoghurt production in Poland. This task is performed by launching the following explanatory hypotheses drawing upon the 'traditional' and 'modern' trade theories.

\section{Hypothesis 1.}

There are several theoretically conceivable sources of competitive disadvantage for Polish yoghurt producers vis-a-vis competitors from the EU. The first includes the factor intensity component of comparative advantage - the EU should enjoy a comparative advantage in yoghurt production due to the relatively high capital intensity of this activity $(\mathrm{H}-\mathrm{O}-\mathrm{S})$. The second, and related with the first, is the comparative advantages of the EU due to the relatively high role of technological progress in 
yoghurt production Technological advancements may be characterised by the limited international mobility of some innovations providing for, at least temporary, productivity advantages (neotechnology trade theory). The third is the role of increasing returns to scale equipping the competitors who have evolved in the EU single market with a 'first mover advantage'.

All three hypothesised effects can occur simultaneously. The measures of comparative advantage applied in Chapters 3 and 4 may have embraced these effects.

Only the two first effects are reversible - the pattern of specialisation tends to change with the change in relative factor abundance; at the same time a country may enhance its abilities to imitate and innovate. The third effect, however, may be irreversible - historically determined pattern specialisation due to increasing returns to scale is difficult to change.

Yoghurt production can be classified as an activity in which scale efficiency matters significantly. The differentiated nature of the product and the fact that competition relies heavily on product innovation, rather than only cost reducing innovation, make R\&D and marketing two areas where considerable fixed costs are generated. However, in industries characterised by a high minimum efficient scale the ability to gain scale efficiency depends on the market size - the greater the (domestic) market the more firms have the chance to reach an efficient scale without violating competitive market conditions (Krugman and Obstfeld, 1994). Scale efficiency can provide for the effective entry barriers or sustainable competitive advantage of existing firms over 'potential' ones, even if the latter have superior technology at their disposal (Markusen et al., 1995). This is conducive to a path-dependency in terms of international competitiveness and specialisation. Subsequently, liberalisation of trade between partner countries differing significantly in terms of market size (and hence firm size) may give competitive advantage to firms originating from the partner country with a greater market.

Similarly, the differentiated nature of the product, the importance of R\&D and scale-related managerial skills may foster imperfect mobility of (new) technologies - firms and countries may use technologies which can only be imitated with a substantial time lag or may not be imitated at all (technology/assets specific to firms or country). In yoghurt production the example of the successful Bakoma may suggest that most technology elements are purchasable and that the delay in technology transfer is not substantial. However, it is also possible that the significance of the firm-specific assets/technologies may only become apparent under more competitive environment expected after Poland's accession to the EU. As far as this component of competitiveness is concerned, Polish firms may seem to be in a disadvantageous competitive position mainly because of the shorter time in which the stock of comparable firm-specific assets could have been accumulated.

69 The relation between the capital abundance and the ability to innovate fast consists in that R\&D tends to be capital intensive. 
Although, according to the comparative advantage argument, technological lags responsible only for lower factor productivity can be compensated for by the lower factor prices (e.g. labour or raw material), the scope for such compensation is less possible for those technological advancements, which provide for superior quality. Consequently, the lower quality attainable is penalised with lower prices.

\section{Hypothesis 2.}

The underlying disadvantages listed in hypothesis 1. have been temporarily compensated for by the specific domestic market conditions associated with the transitional character of the economy and fast economic growth. The first is booming domestic consumption. The second includes institutional and other costs of importing. These have provided for a significant location advantages and, thereby positively contributed to the development of domestically located capacities in yoghurt production.

Booming domestic demand has several possible explanations related with the economic transition and growth. These have been accompanied by: (i) the temporary high costs to imports (high transport costs related with distance and lengthy border controls, underdeveloped market infrastructure and high costs of information), and (ii) the advantage of domestic producers in terms of knowledge of how to operate in an immature institutional environment.

These circumstances favoured domestically located production by offering high profitability, because the growth in demand may have exceeded the growth in new investments at high effective import price. These conditions may have had a temporary character because with the flow of time: (i) domestic distribution and retail sectors experience fast development mostly attributable to FDIs in wholesale, supermarket chains and discount operations, ${ }_{0}$ (ii) potential foreign suppliers have gained experience in operating in the Polish market and have developed their own distribution facilities (Zott's two warehouses in Poznań and Wrocław), and (iii) ongoing real appreciation of the Polish złoty has partly 'compensated' for the high costs of importing.

As a result of these temporary conditions three categories of producers have emerged:

i. Domestic-capital-based firms, which have taken advantage of high profitability to develop technologically and technically and also scale efficient productive capacity (Bakoma), thus achieving sustainable competitiveness;

ii. Domestic firms which have entered the yoghurt production to exploit profits offered without, however, developing sufficient technological expertise and economic efficiency to sustain their growth and competitiveness in the future;

iii. Foreign firms, which have established production in Poland to overcome trade costs and to make use of other 'location' advantages (see next hypothesis).

70 See Adamowicz (1997). 
This hypothesis, therefore, stresses the role of favourable domestic demand conditions in a manner similar to that of Linder (Markusen et al., 1995) or Porter (1990), though, in a different macroeconomic context; causal factors here are the demand effects accompanying the economic transition and economic growth (including convergence of consumption patterns). Furthermore, it also implies that favourable (though temporary) demand and competitive conditions have been necessary for domestic production to develop and gain the ability to compete. This dynamic effect resembles the infant industry and strategic trade policy arguments, with the difference, however, that the promotion of domestically located production has been achieved not only with the use of trade policy and input subsidy but also with the 'protection' of the home market via underdeveloped institutions and market infrastructure.

\section{Hypothesis 3.}

The FDI have a crucial contribution to the sustainable overcoming of the competitive disadvantages listed in hypothesis 1. The domestic market conditions described in hypothesis 2. enhanced the rate of FDI.

The first category of beneficial effects of FDI on the competitiveness of domestic yoghurt production can be referred to as direct effects. They consist of the increased efficiency of domestic resources employed in the FDI firms, i.e. labour, farm milk and domestic capital. The effects arise from:

i. Transfer of new technologies based on the (i) knowledge capital often of a firm-specific nature, and (ii) economies of scale available through multinational operation, such as R\&D and marketing inputs, hence providing advantages unattainable by domestic firms;

ii. Transfer of financial capital enabling modernisation of the existing capacities and establishment of new firms (so called 'green-field' investments). Although absolute volumes of the founding FDI capital were relatively small (usually shares of the enterprises taken over), most of the generated profits have been domestically re-invested, thereby, multiplying the initial values.

The second includes indirect or spillover effects conducive to the efficiency gains in the domestic (non-FDI) firms. These include:

i. Improved access to new technologies due to demonstration effects, e.g. an opportunity granted to the managers of domestic firms who can directly observe the business practices of more experienced competitors (also associated with the dissipation of some of the FDI-firm intangible assets);

ii. Promoting elimination of the existing inefficiencies and an increase in the propensity for technological change by exerting competitive pressure in the domestic market. Supposedly monopolistic practices may have been prevented in this way, although, in this regard, evidence is 
mixed. On the one hand, Danone has for long been the only strategic competitor of Bakoma. However, the capital integration of the two, which started in 1999, may threaten the competitive condition in the future;

iii. Contribution to revealing hidden domestic preferences and thereby to spurring the growth of the domestic market. This has been achieved both by introducing a variety of new products and by 'modern' promotional campaigns;

iv. Contribution to improved transparency and clearer incentives in the market for farm milk, in particular in terms of the remuneration for high quality.

\section{Hypothesis 4.}

Domestic sectoral policies have had an ambiguous influence on the emergence of the competitive domestic yoghurt production.

Investment subsidies and positive effective protection have helped to develop profitable yoghurt production by the co-operative sector but most induced investments were rather below the scale assuring long-term viability of projects. Short-term profitability could have been attained at the 'cost' of weakening the pressure for structural adjustment in the dairy co-operative sector.

An increase in import tariffs in 1999 was meant to sustain the favourable conditions (high profitability) experienced in recent years by dairy co-ops. However, this policy may have rather unexpected effects. It seems to have accelerated the decision by the major foreign competitor (Zott) to move production to Poland. For competitive position of co-operative producers, the merger of the Danone and Bakoma may have the same effect. However, the new FDI location by Zott should make a positive contribution to the international competitiveness of the sector.

Nevertheless, the rise in domestic market protection may also enable the two new market leaders (about $80 \%$ of the market is shared by two competitors: Danone integrated with Bakoma, and Zott) to exert market power. This would mean excess profits for the domestic producers, decreased consumption and welfare losses due to the consumer surplus decreases, repatriation of monopoly profits by FDI capital and, possibly, lowered production efficiency. 


\section{SUMMARY AND CONCLUSION}

\subsection{Outline of the Study}

This study addresses the problem of competitiveness of Polish milk processing industry during Poland's integration with the EU. The focus is on the measurement of economic efficiency and incentives in the most recent years, and on projecting efficiency and incentives over the time span until 2010. Reactions of the industry to these incentives, in terms of changes in output and trade patterns, are not analysed.

At the theoretical level, the study employs the concept of comparative advantage of international trade theory. To choose a relevant analytical framework an eclectic approach recommended in recent literature is used. This approach relies on confronting characteristics of broader economic environment and sector-specific technological and structural features with assumptions of various explanatory hypotheses offered by the theory. On this basis a working hypothesis is formulated that changes in comparative advantages, i.e. dynamic comparative advantages, in the entire economy and in the industry will play a crucial role in determining its competitive performance during the period under consideration.

Domestic resource cost (DRC) methodology is used to trace comparative advantages and their components in the most recent past, the year 1997, and to make projections for dynamic comparative advantages in the years 1997-2010. Desegregations of static and dynamic comparative advantages is achieved by applying a set of auxiliary quantitative tools including Policy Analysis Matrix (PAM), and indicators of policy and non-policy effects such as: Nominal Protection Coefficient (NPC), Effective Protection Coefficient (EPC), Coefficient of Divergences in Domestic Factor Cost (CDDFC) and Private Cost Ratio (PCR).

The empirical study starts in Chapter 2 with a descriptive analysis of milk processing technology, in general, and the current state of milk processing technology in Poland, in particular. Next, recent technical change is measured by estimating Tornquist approximation of Divisa indices of total factor productivity. The scope for future changes in productivity, i.e. for reacting to prospected changes in relative prices, is measured by the use of engineering cost calculation (effects of scale and capacity utilisation) and by comparing industry structure and factor productivity with the corresponding values 
in the neighbouring Germany. Investment policy and institutional incentives affecting the pace of modernisation and restructuring are identified and discussed.

In Chapter 3 recent comparative advantages in the sector are analysed by estimating DRCs, PCRs and PAMs, for economic activities: milk processing industry (multi-product activity), SMP, ripening cheese (Gouda), butter, and yoghurt. Extensive data are collected to estimate input-output coefficients, private and social prices, and, policy effects. In the case of output markets, an extension of the conventional approach to the measurement of private-social divergence is used - direct policy and 'unexplained' distortions have been disentangled.

In Chapter 4 dynamic comparative advantages are projected by simulating future DRCs, PCRs and PAMs and by discussing components of the inter-temporal changes using Matrix of Dynamic Comparative Advantages. The input-output model and other estimates from the ex-post analysis of Chapter 3 serve as the base-year case in the ex-ante analysis in Chapter 4. This analysis starts from formulating scenarios for: (i) macroeconomic development, (ii) sectoral policies (including the path of price harmonisation with the CAP) and (iii) future technical change. Three macroeconomic scenarios are used differing in terms of growth rate and in terms of pace of changes in factor prices and real exchange rates. One scenario for sectoral policy harmonisation, with a step-wise price adjustment (2004-2007), and future reformed dairy prices (AGENDA 2000) under the EU membership, is analysed. Two scenarios for technical change are used: one 'without technical change' and second 'with technical change'.

Chapter 5 presents a case study of yoghurt market in Poland. This chapter aims at grasping less quantifiable and more complex developments in the industry that influence comparative advantage. The analysis starts from descriptive presentation of various aspects of the yoghurt market in recent years, including production, consumption, trade, foreign investment, industrial structure, policy instruments and others. In the next step the collected evidence is used to identify salient facts of this market's development and to formulate explanatory hypotheses rooted in the 'modern' trade theory.

\subsection{Findings}

\section{Technology}

Within the range of capacities typical for Poland's milk processing firms, the currently used technologies offer substantial scope for cost reduction by an increase in the average size of processing capacity and in the enterprise size. The underlying minimum efficient scale (MES) of enterprises tends to be enhanced by new technologies. Progressing concentration in the EU dairy industries implies an increasing importance of size effects both in processing and in marketing. 
Between 1993 and 1997 substantial changes have occurred with regards to relative prices in the industry. At the same time, the industry managed to carry out an adjustment in the product composition of output and to improve partial and total factor productivity. The analysis of total factor productivity suggests that directions of these adjustments are consistent with the directions of detected changes in the relative prices.

There is a substantial gap between Polish and German milk processing industries in terms of technology used as measured by the input intensities, in particular, in terms of labour productivity. This gap can be explained by several factors such as: technological lag (use of outdated technologies), technical inefficiency (x-inefficiency, e.g. poorer management skills and organisation, low rates of capacity utilisation), scale inefficiency (too low degree of industrial concentration) but also by the use more labour intensive production techniques. It can be expected that technology improvement will provide for major gains in factor productivity in the medium term. However, there is a strong synergy between the technological change and 'structural' determinants of factor productivity. Hence, the institutional (e.g. ownership attitudes) and policy (distortion of economic incentive structure) impediments to restructuring of existing firms (mainly co-operatives) and to restructuring of industrial structure slow down the technological change and productivity improvements.

On the basis of the collected data it has been hypothesised that recent investment policy in the industry, i.e. interest subsidies on investment credits, might have adversely affected allocative efficiency of new investments. The acquisition of new technologies might have been enhanced at the 'cost' of weakening incentives to rationalise management and industrial structure. In this indirect way private investment funds may partly be displaced while the industry may suffer competitiveness loses due to foregone gains from economies of scale, both in processing and marketing. The last effect could be exacerbated by prospected integration with the EU market, where concentration and integration of the industry play increasingly important role in preventing imbalances in the market bargaining power vis-à-vis foreign competitors and domestic retail sector.

\section{Recent comparative advantage}

The general result of analysis in Chapter 3 is that the Industry treated as one activity is socially unprofitable, whereas its viability, i.e. profitability in private prices, is mainly achieved by a complex set of distorting effects in output and input markets. Policies designed explicitly to mitigate competitive pressure include high tariff rates in output markets, and subsidies to investment capital. Transfers through product market and budget subsidies to investment capital more than compensate for taxation through enhanced wages and for 'low' economic efficiency (lack of comparative advantage at industry-level). 
Variation in product-specific results reflects differences in: (i) policy and non-policy effects in output markets, (ii) input intensity, and (iii) technology/productivity advancement. First, both price enhancing and price depressing divergences in output markets are detected. They are explained through transient 'imbalances' in supply/demand conditions, and policy and other influences. For example, products favoured through output market distortion tend to be those, which have recently experienced high increases in domestic demand (ice cream, fresh cheese, and yoghurt). Second, the most labour intensive and least capital-intensive activity, ripening cheese, proves to be most socially profitable, whereas the least labour intensive and most capital intensive - yoghurt - proved the least socially profitable. This result is consistent with an expectation based on the theory of comparative advantage and on Poland's relative abundance in both factors (relative to major world competitors). At the same time, however, relative labour intensity tends to negatively affect net transfers obtained by an activity through factor market distortions. Third, products differ in terms of productivity gains experienced in most recent years, through so-called economies of rapid growth. This means that even relatively capital-intensive activities may perform relatively well in terms of social profitability, provided that they have experienced capacity expansion and associated productivity gains.

The detected structure of comparative advantages and structure of policy and other incentives mean that industry envisages the need to restructure and modernise. Necessary adjustments include changing the product-structure of output and productivity improvement. The pace and the outcome of the process are difficult to predict - the analysis in Chapter 3 delivers merely a snapshot view of the incentives driving investment. Expected evolution of relative prices that need to be considered in a 'full-blown' investment planning is the subject of Chapter 4.

\section{Dynamic comparative advantages}

During Poland's prospected integration with the EU macroeconomic component of the comparative advantage in the Industry will be shaped by three major economic-political processes. The first one is the progressing economic transition, including privatisation, reforms of legal framework and public sector, and other policies. The second is the 'natural' tendency to economic convergence, i.e. to relatively high rates of economic growth typical to low- and middle- income countries. The third is the policy harmonisation with the EU and its interference with the first two processes.

Possible achievement of relatively high growth rates by Polish economy implies that the analysed industry will be faced with a challenge of competitiveness originating from other economy sectors the ones which realize high productivity improvements and which can effectively compete for scarce domestic resources, labour and capital. This factor-side competition is to be manifested through the increase in real wages and maintained relatively high real interest rates. In addition, changing economy structure leads to real appreciation of domestic currency, which adversely affects the net 
price (output price minus value of tradable inputs) received by tradables industries. The pace of changes in these macroeconomic components of comparative advantage is expected to be positively related with the economic growth rate.

The pace of future macroeconomic changes cannot be precisely predicted or modelled. The recent macroeconomic developments in Poland seem to well accord with the theoretic expectations on the economic convergence. As in the recent past, and as cross-country studies suggest, macroeconomic convergence is contingent on broad economic policy. Therefore, the assumptions on the pace of macroeconomic changes are, to a great extent, policy assumptions. In this respect EU-accession, and merely its perspective, is commonly expected to have a positive influence on the prerequisites of economic convergence, and thereby on the magnitude of macroeconomic forces of dynamic comparative advantages in the analysed Industry.

To a degree, the rationales underlying macroeconomic scenarios may also justify optimistic projections on future technical change in the milk processing industry. Predicting high growth and fast changes in the macroeconomic variables one makes an implicit assumption that 'higher' rates of technical change should also be expected in the activities analysed here. Nevertheless, there are also industry-specific institutional and policy determinants of future responsiveness to the competitive challenges, which deny any certainty about its future competitive performance.

It is often expected that the harmonisation of sectoral policies in Poland with the CAP should play an important role in determining the future competitiveness of the industry. The major result of this study is that despite the assumed 'partial' transmission of CAP price support to farm milk prices, both private and social profitability of the industry in the year 2007 are expected to decrease in relation to 1997. The magnitude of this deteriorating effect appears to be 'positively' related to the rate of economic growth.

Two ways of accommodating future competitive pressure in the industry, arising from deteriorating relative prices, have been demonstrated. The first one is the technical change for which moderate progress has been assumed under the examined scenario. Indeed, as suggested by the magnitude of productivity gaps in Chapter 2 higher rates of productivity improvements are still possible. The second one is the 'flexibility' in adjusting farm milk price. On the one hand, lagged (or partial) transmission of CAP price support to farm level could improve private competitiveness in milk processing. On the other hand, such a strategy may jeopardise the modernisation and restructuring of the farm milk production and restrain future milk supply. The third potential way of mitigating the competitive pressure, i.e. escalation of policy and non-policy transfers, will be limited to a set of effects already embodied into the simulation scenarios, such as subsidies to capital cost within the SAPARD scheme. Scope for such mitigating effects will be limited by the constrained domestic policies (e.g. adherence to the competition policy of the EU), improved institutional 
framework (e.g. adherence to rigid quality and other standards) and increased market competition (free-trade within the enlarged EU), which will be brought about by Poland's accession to the EU.

Product-specific projections depend on the magnitude of (i) revenue effect due to price alignment with CAP and (ii) cost effect due to specific input intensities. The former is determined by the level of Poland's prices in the base period, specific constraints on future prices policy like these arising from WTO commitments, and assumed consequences of quality differences for estimates of price gap. As for the latter, future social and private profitability is favoured by high intensity in capital and traded inputs, i.e. inputs the real unit cost of which is expected to decline with economic growth - an effect of RER appreciation. The adverse effect on future profitability has high intensity in labour and notradable inputs. The most dramatic influence of changes in relative prices was detected here for ripening cheese. Possible changes in the commodity structure of protection in the EU dairy sector due to the WTO constraints on export subsidy may aggravate this effect.

\section{Dynamic effects in yoghurt market}

In the period 1993-1999 yoghurt market in Poland was characterised by a dynamic development. Between 1993-1998 the output volume expanded by $c a$. 400\%. This growth was attained with high reliance on FDI. Industrial structure which has emerged is extremely polarised with two third of sales attributable to only two firms and one third to 20 to 60 diary coops. The years 1998-1999 were marked by high growth in net imports. This growing import competition induced radical policy reaction - the increase of import tariffs in 1999 as well as the initiation of the industrial restructuring process.

The quantitative analysis in Chapter 3 reveals that an average technology in yoghurt production is profitable in private prices, but unprofitable in social ones. At the same time it is shown that certain technological properties of this activity may favour its dynamic comparative advantage, at least relative to other milk processing activities. First, the activity is characterised by relatively small susceptibility to projected changes in relative prices, which is because of high shares of tradable inputs and capital in cost structure. Second, experienced output expansion implies high potential gains from economies of rapid growth, i.e. from instalment of completely new technologies, rather than only modernising and restructuring of existing capacities. This conclusion from Chapters 3 and 4 has been complemented by a closer view of the forces guiding investment and restructuring during the period of dynamic output expansion.

The following explanatory hypotheses are formulated to describe these dynamic developments and to assess prospects for future competitive performance of the activity in terms of trade theory.

There are several conceivable sources of competitive disadvantage of Polish yoghurt producers vis-à-vis competitors from the EU. The first one is the factor intensity component of comparative 
advantage - the EU should enjoy a comparative advantage in yoghurt production due to the relative high capital intensity of this activity (H-O-S). Second, there is the comparative advantage of the EU due to the relatively high role of technological progress in yoghurt production. Technological advancements may be characterised with limited international mobility of some innovations providing for, at least temporary, productivity advantages (neo-technology trade theory). Third, there is the role of increasing return to scale equipping the competitors who evolved in the EU single market with a 'first mover advantage'.

These potential disadvantages have been temporary compensated by the specific domestic market conditions associated with the transitional character of the economy and fast economic growth. These include (i) booming domestic consumption and (ii) institutional and other costs to imports. Both have provided for a significant location advantages and, thereby positively contributed to the development of domestically located capacities in yoghurt production.

The FDI has been a crucial contribution to the sustainable overcoming of the competitive disadvantages listed in the first hypothesis. The domestic market conditions described in the second hypothesis enhanced the rate of FDI.

Domestic sectoral policies have had an ambiguous influence on the emergence of the competitive domestic yoghurt production.

\subsection{General Conclusions}

i. The concept of comparative advantage and the corresponding empirical measures provide for a relevant framework to analyse international competitiveness of agro-food processing industry in Poland during the integration with the EU. The use of the concept makes the analysis consistent with economic theory and provides for guidelines in searching for major sources of competitive challenges.

ii. In the perspective of future economic and institutional development coupled with the accession to the EU Polish milk processing industry faces both competitiveness opportunities and competitiveness challenges. A major opportunity is the high scope for productivity improvement stemming both from the technological lag and from improving investment conditions in stabilising Polish economy. The major challenge is that this productivity improvement needs to catch up with productivity improvements in other economy sectors so as to sustain the industry competitiveness in the markets for scarce domestic resources. In other words, when applied to conditions of a fast growing economy, the concept of dynamic comparative advantage implies that the 'magnitude' of competitive pressure coming from other economy sectors may even exceed that coming from foreign producers of the same products. 
iii. The role of CAP in determining competitive position of the industry should be neutral in a sense that increased output prices should be 'fully' transmitted to higher farm milk prices. Since this transmission is, in general, market-driven, future economic efficiency in the industry will have consequences for farm milk prices, i.e. for the benefits farmers will get from the price support offered by the CAP.

iv. Non-price aspects of competitiveness have been only partly considered in this study. The analysis implicitly assumes that by the moment of accession the industry will manage to adhere to the minimum quality requirements imposed by the EU acquis. The analysis of yoghurt market suggests that full integration between Polish and EU markets for diary products may significantly enhance importance of factors such as product innovation, product differentiation and bargain market power of milk processing enterprises. 


\section{REFERENCES}

Abbott, P.C. and M.E., Bredahl (1994) Competitiveness: Definitions, Useful Concepts, and Issues. In: Bredhal, M.E., Abbott, P.C., Reed, M.R. (eds) Competitiveness in International Food Markets. Westview Press, Boulder, San Francisco, Oxford.

Adamowicz, M. (1997) Inwestycje zagraniczne w przemyśle rolno-spożywczym Polski. Przemyst spożywczy 10. Warsaw.

Agra Europe East Europe (1999) EU alarm over planned tariff rises. Agra Europe, September 1999, LTD. London.

Agra Europe (1999) April 16, 1999, pp. EP/3.

Agra-Europe (1999) CAP Monitor. London.

Agriculture Canada (1991) Growing Together: Report to Ministers of Agriculture. Task Force on Competitiveness in the Agri-food Industry, Ottawa.

Alvensleben, R. (1996) Die Wettbewerbsverhältnisse auf dem Rohmilchmarkt der neuen Bundesländer. Welt der Milch 6, pp. 192-194.

Balassa, B. and D. Schydlowski (1972) Domestic Resource Cost and Effective Protection Once Again. Journal of Political Economy 1, Vol. 80. The University of Chicago Press.

Banse, M. (1999) Macro-economic Implications of the EU-Accession. Draft Final Results of Task 5, The Research Project FAIR1-CT95-0029, Agricultural Implications of CEEC Accession to the $E U$. Institute of Agricultural Economics, Göttingen.

Banse, M., Guba, W. and W. Münch (1998) Eastern Enlargement of the EU: How competitive is the Agri-food Sector in Central and Eastern Europe under EU conditions? The example of Hungary and Poland. Paper presented Paper presented at $59^{\text {th }}$ EAAE Seminar: Understanding competitiveness, Apeldoorn, April 22-24.

Barro, R. J. (1997) Determinants of Economic Growth. A Cross-Country Empirical Study. The MIT Press, Cambridge, Massachusetts, London, England.

Barro, R.J. and X, Sala-I-Martin (1991) Convergence across states and regions. Brooking Papers on Economic Activity, vol.1/91, 107-182.

Barro, R.J., (1991) Economic Growth in a Cross-Section of Countries. Quarterly Journal of Economics, vol. 106, pp. 407-443.

Barzelay, M. and S.R. Pearson (1982) The Efficiency of Producing Alcohol for Energy in Brazil. Economic Development and Cultural Change, vol 8, pp 131-144.

Bazydło, I. and T. Sokołowski (1998) Rozliczanie surowca w zakładach mleczarskich. KPSM, Warszawa.

Behme, G. (1975a) Bestimmung des Kostenverlaufs von Molkereiabteilungen in Abhängigkeit von der Kapazitätsgrösse und-auslastung. IV. Teil: H-Milch-Abtailung. Milchwissenschaft 30 (5), pp. 282-290.

Behme, G. (1975b) Bestimmung des Kostenverlaufs von Molkereiabteilungen in Abhängigkeit von der Kapazitätsgrösse und-auslastung. VI. Teil: Abteilung Betriebsraum. Milchwissenschaft 30 (4), pp.416-422. 
Behme, G. (1975b) Bestimmung des Kostenverlaufs von Molkereiabteilungen in Abhängigkeit von der Kapazitätsgrösse und-auslastung. VI. Teil: Abteilung Betriebsraum. Milchwissenschaft 30 (4), pp.416-422.

Behme, G. and H. Wietbrauk (1975) Bestimung des Kostenverlaufs von Molkereiabteilungen in Abhängigkeit von der Kapazitätsgrösse und-auslastung, II. Teil: Abteilung Sprütrocknung. Milchwissenschaft 30 (3).

Berkum, B. van and H. van Meijl (1998a) A survey of trade theories. Agricultural Economics Research Institute (LEI-DLO), Onderzoekverslag 161.

Berkum, B. van and H. van Meijl (1998b) Usability of trade theories in explaining agricultural trade. Agricultural Economics Research Institute (LEI-DLO), Onderzoekverslag 162.

Biegański, M. (1998) Analiza efektów realizowanego programu restrukturyzacji i modernizacji mleczarstwa w Polsce. Uwarunkowania rozwoju mleczarstwa polskiego w procesie integrowania Polski z Uniq Europejska,. Program badawczy KBN, Draft paper, Poznań.

Biegluk, M. (1999) Mleczna Droga. Businesmen 2, pp.32-35. Warszawa.

Boehlje, M. (1990) Alternative models of structural change in agriculture and related industries. Staff Papers Series, Department of Agricultural and Applied Economics, University of Minnesota, St. Paul.

Bonjec, S., Münch, W. and F.M. Swinnen (1998) Exchange Rates and the Measurement of Agricultural Price Distortions in the CEECs and of CEEC-EU Accession Costs. Working Paper Series of the Joint Research Project: Agricultural Implications of CEEC Accession to the EU, Working Paper 1/3. Institute of Agricultural Economics, Göttingen.

Boss Rolnictwo (1999) Na rynku jogurtów w Polsce wciąż jest o co się bić!. By Białasiewicz M., No. 36, (503), 10.09.1999, Warszawa.

Brandes, W. and M. Odening (1992) Investition Finanzierung und Wachstum in der Landwirtschaft. Verlag Eugen Ulmer.

Brehm, K.P and E.Krell (1975) Bestimmung des Kostenverlaufs von Molkereiabteilungen in Abhängigkeit von der Kapazitätsgrösse und-auslastung. VIII. Teil: Butereiabteilung. Milchwissenschaft 30 (10), pp. 614-622.

Brehm, K.P and E.Krell (1976) Bestimmung des Kostenverlaufs von Molkereiabteilungen in Abhängigkeit von der Kapazitätsgrösse und-auslastung, IX. Teil: Abtelung Edamerkaeserei. Milchwissenschaft 31(2), pp.98-106.

Brorsen, B. W. et al. (1985) Marketing Margings and Price Uncertainty: The case of the U.S. Wheat Market. American Journal of Agricultural Economics 67, pp. 521-528.

Bruno, M. (1972) Domestic Resource Cost and Effective Protection: Clarification and Synthesis. Journal of Political Economy 1, Vol. 80. The University of Chicago Press.

Budny, J., Matyjasek, K. and J. Kaczorek (1986) Kształtowanie się wskazników zużycia energii w przemyśle mleczarskim-energochłonność linii podstawowych. Przeglad Mleczarski, Warszawa.

Caraveli, H. and B. Traill (1998) Technological Developments and Economies of Scale in Dairy Industry. Agribusiness 4, vol. 14, pp. 311-319. John Wiley \& Sons, Inc.

Chambers, R.G. (1988) Applied Production Analysis. Cambridge University Press.

Corden, W. M. (1971) The Theory of Protection. Clarendon Press, Oxford.

Corden, W.M. (1984) The Structure of a Tariff System and the Effective Protection Rate. In: Bhagwati. J. N. (ed) International Trade: Selected Readings. The MIT Press, Cambridge, Massachusetts and London, England. 
Domańska, E. (1994) Podstawowe założenia Programu Restrukturyzacji i Modernizacji Mleczarstwa. Artykuł specjalny w Rynku Mleka 7. IERiGŻ, ARR, MAFA, Warsaw.

Domańska, E. (1999) Finansowanie wspierania procesów restrukturyzacji i modernizacji sektora mleczrskiego. Artykuł specjalny. Rynek mleka 16. IERiGŻ, ARR, MAFA, Warsaw.

Doradztwo Mleczarskie (1997) Polskie spółdzielnie mleczarskie: wyniki ankiet. Know How Fund, Fundusz Spółdzielczości Wiejskiej, The Produce Studies Group, Warsaw.

Dornbusch, R. and S. Fischer (1994) Macroeconomics. Sixth Edition, McGraw-Hill Book Company.

DRI Europe (1996) Food, Drink and Tobacco Processing Machinery Industry-Summary. The Single Market Review Series, DG XV of the EU Commission.

Dutton, J. and T. Grenees (1987) Alternative measures of effective exchange rates for agricultural trade. European Review of Agricultural Economics 14, pp. 427-442.

Early, R. (1998) The Technology of Dairy Products.

Edwards, S. (1989) Real Exchange Rates, Devaluation, and Adjustement. MIT Press, Cambridge, Mass.

Ethier, W.J. (1994) Conceptual Foundations from Trade, Multinational Firms, and Foreign Investment Theory. In: Bredahl, M.E., Abbott, P.C. and M.R Reed (eds) Competitiveness in International Food Markets. Westview Press, Boulder, San Francisco, Oxford.

EU Commission (1988) A survey of the Economies of Scale. In: Pratten (ed) Studies on the Economic Effects of Integration - Basic Findings, vol. 2. Brussels.

EU Commission (1997) The CAP and enlargement-Agri-food price developments in five associated countries. European Economy 2, Brussels.

EU Commission (1998) Regular Report of Commission on Progress towards Accession - Poland. Brussels.

European Commission (1997) Situation and Outlook, Dairy Sector. Brussels.

EUROSTAT (1998) EU Trade Database. CD version.

FAPRI (1998) World Agricultural Outlook 1998. Iowa-Missouri-Columbia. http://www.ag.iastate.edu/card/fapri/fapri98/outlook99/

FAPRI (1999) World Agricultural Outlook 1999. Iowa-Missouri-Columbia. http://www.ag.iastate.edu/card/fapri/fapri98/outlook99/

Filas, A., Szczęsny, J.and J. Kamiński (2000) Gerontokracja III RP. Wprost 3, (16.I.). Warszawa.

Fisher, S., Sahay, R. and C. Vegh (1998) How Far Is Eastern Europe From Brussels? IMF Working Paper, WP/98/53.Electronic version.

Fratz, R.S. (1988) X-Efficiency: Theory, Evidence and Applications. Kluwer Academic Publischers, Boston/Dordrecht/Lanchester.

Frenkel, M. and H.R. Hemmer (1999) Grundlagen der Wachstumstheorie. Verlag Franz Vahlen, München.

Frohberg, K. and M. Hartmann (1997) Comparing Measures of Competitiveness. Discussion Paper 2, Institute of Agricultural Development in Central and Eastern Europe (IAMO), Halle(Saale).

Gardner, B.L. (1975) The Farm-Retail Farm Spread in a Competitive Food Industry. American Journal of Agricultural Economics, August 1975.

Garibaldi, P. and Z. Brixiova (1997) Labour Market Institutions and Unemployment Dynamics in Transition Economies. IMF Working Paper, http://www.imf.org/external/pubs/cat/longres.cfm. 
Glauben, et al. (1998) Empirishe Messung von Politik- und Structureffekten auf Basis eines erweiterten Policy-Analysis-matrix (PAM) Ansatzes am Beispiel des slovakischen Milch- und Molkereisektors. Poster-paper presented at GEWISOLA, 30.09.-02.10.1998, Bonn.

Glöer, E., Schmidt, K. and O.Warnk, (1997) Untersuchungen zur Effizienz staatlicher Fördmassnahmen zur Anpassung und Verbesserung der Strukturen in der Molkerei- und Fleischwirtschaft im Beitrittsgebiet der Bundesrepublik Deutschland. Abschlussbericht. Bundesanstalt für Milchforschung, Kiel.

GISIPAR (1998) Weekly report. Draft version. Warsaw.

GISIPAR (1999) Jakość mleka surowego w skupie i przetworów mlecznych w I pótroczu 1999. Draft paper. Warsaw.

Gopinath, M. et al. (1996) Competitiveness of U.S. Food Processing: Benefits from Primary Agriculture. American Journal of Agricultural Economics 78, pp. 1044-1055.

Gopinath, M., Arnade, C., Shane, M. and T. Roe (1997) Agricultural competitiveness: The case of United States and major EU countries. Agricultural Economics 16, pp. 99-109. Elsevier.

Gornowicz, M. (1983) Technika i organizacja a koszty produkcji masła. PhD dissertation, Olsztyn.

Gornowicz, M. (1987) Koncentracja produkcji masła a koszty transportu surowca. Zagadnienia Ekonomiki Rolnej 3/87, pp. 97-105. Warsaw.

Gornowicz, M. (1996) Koszty i rentowność produkcji wybranych spółdzielni mleczarskich w latach 1991-1994. Zeszty naukowe Akademii Rolniczo-Technicznej w Olsztynie 33. Olsztyn.

Gornowicz, M. and T. Stachowski (1990) Wpływ zmian techniki i ceny czynników produckcji na koszty robocizny i energii w procesie wyrobu sera. Przeglad Mleczarski 3. Warsaw.

Gornowicz, M. and T. Stachowski (1991) Wpływ zmian techniki i ceny czynników produkcji na koszty robocizny i energii w procesie wyrobu sera. Przeglad Mleczarski 4, Warsaw.

Gornowicz, M. Pimpicki, S. and T. Stachowski (1999) Koszty i rentowsność produckcji wyrobów mleczarskich w latach 1994-1997. Paper presented in VII Seminar: Progress in technology, technique and organisation in the dairy sector, Olsztyn, 15-16 February, 1999.

Griliches, Z. (1960) Measuring Inputs in Agriculture: A critical Survey. Journal of Farm Economics 42 (5), pp. 1411-147.

GUS (1997) Rocznik Statystyczny Pracy. GUS, Warsaw.

GUS (1998a) Gospodarka paliwowo-energetyczna 1996-1997. GUS, Warsaw.

GUS (1998b) Income statement database: F01 reports. Draft report, GUS, Warsaw.

GUS (1998c) Naktady i wyniki przemystu w 1997. GUS, Warsaw.

GUS (1998d) Rocznik Statystyczny Przemystu. GUS, Warsaw.

GUS (1998e) Rocznik Statystyczny Rolnictwa. GUS, Warsaw.

GUS (1999a) Statistical Bulletin 1/2000. GUS, Warsaw.

GUS (1999b) Statistical Bulletin 1/1999. GUS, Warsaw.

GUS (1999c) Rocznik Statystyczny. Various issues from years 1990-1999. GUS, Warsaw.

Halpern, L. and Ch. Wyplosz (1996) Equilibrium Exchange Rates in Transition Economies. IMF

Working Paper, Electronic version, http://www.imf.org/external/pubs/cat/longres.cfm.

Hirshleifer, J. (1970) Investment, Interest and Capital. Prentice-Hall, Inc. Englewood Cliffs, N.J.

Hülsemeyer, F. (1999) Welche Zielsetzungen ergeben sich aus der Milchmarktpolitik für die Wissenschaft?... aus Sicht der Ökonomie'. Welt der Milch, 53. 
Hülsemeyer, F. and E. Glöer (1998) Eine Bestandsaufnahmezur Umstrukturierung der ostdeutschen Molkereiwirtschaft unter Zugrundelegung des Sektorgutachtens. Welt der Milch 52.

Hülsen, U. (1996) Ausgewälte Trends in der Molkereitechnologie. Welt der Milch. 50.

IERiGŻ (1999) Rynek mleka. Stan i Perspektywy. Raporty Rynkowe: No. 1- 17. Years: 1992-1999. IERiGŻ, ARR, MAFE, Warsaw.

Janowicz, H. (1999) Rynek mleka i przetworów mlecznych. Życie Handlowe, Warsaw.

Josling, T., Tangermann, S. and P.Walkenhorst (1997) Foreign Direct Investment and Trade in Eastern Europe: The Creation of a Unified European Economy, The Agricultural and Food Sectors. Working Paper Series of the Joint Research Research Project: Agricultural Implication of CEEC Accession to the EU, FAIR project.

Kalaitzandonakes, N.G, Gehrke, B. and M.E. Bredahl (1994) Competitive Pressure, Productivity Growth, and Competitiveness. In: Bredahl, M.E., Abbott, P.C. and M.R. Reed (eds) Competitiveness in International Food Markets. Westview Press.

Kopits, G. (1999) Implications of EMU for Exchange Rate Policy in Central and Eastern Europe. IMF Working Paper, Electronic version: http://www.imf.org/external/pubs/cat/longres.cfm.

Koutsoyiannis, A. (1980) Modern Microeconomics, Second Edition. The Macmillan Press LTD, Hong Kong.

KPSM (1998) Skorygowany Rzqdowy Program Restrukturyzacji i Rozwoju Sektora Mleczarskiego. Draft document, KPSM, Warszawa.

Krajewski, K., Świątkowska, M., and H. Górska-Warsiewicz (1999) Czynniki kształtujące zachowania konsumentów na rynku jogurtow w Polsce. Przegląd Mleczarski 5, Warsaw.

Krajnyak, K and J. Zettelmeyer (1997) Competitiveness in Transition Economies - What Scope for Real Appreciation?. IMF Working Paper, http://www.imf.org/external/pubs/cat/longres.cfm.

Kravis, I.B. and R.E. Lipsey (1988) National Price Levels and the Prices of Tradables and Nontradables. American Economic Review, May 1988, 78, pp. 474-78.

Kray, H. A. (1997) PAM-Analysis of Slovakian Agricultural Policies. Draft version. Technical Report of FAO Research Project TCP/SLO/4552.

Krell, E. and H.Wietbrauk (1993a) Die Kosten der Modellabteilung 'Schnittkäserei' am Beispiel der Herstellung von Gouda-Käse. Veröffentlichungen der Bundesanstalt für Milchforschung, Kiel.

Krell, E. and H.Wietbrauk (1993b) Die Bewertung des Rohstoffes Milch und seine Bedeutung als Kostenfaktor. Deutsche Milchwirtschaft 17, pp. 824-827.

Krell, E., Schmidt, E., Wiedera, H. And U. Höper (1997) Ökonomie der Milchbe- und- verarbeitung. In: Betriebs- und marktwirtschaftliche Studien zur Ernährunswirtschaft. IfBML, Kiel.

Krueger, A. (1972) Evaluating Restrictionist Trade Regimes: Theory and Measurement. Journal of Political Economy 1, Vol. 80, pp. 48-61. The University of Chicago Press.

Krugman, P. (1994) Competitiveness a Dangerous Obsession. Foreign Affairs, March/April 1994, pp. $28-44$.

Krugman, P. and M. Obstfeld (1994) International Economics-Theory and Policy. Addison-Wesley.

Kulawik, J. (1998) Polityka kredytowa w sektorze żywnościowym w latach dziewięćdziesiątych. Zagadnienia Ekonomiki Rolnej 6 (269), Warsaw.

Leibenstein, H. (1966) Allocative Efficiency vs. X-Efficciency. American Economic Review, vol 56, June, pp. 392-415.

Levine, R. and D. Renelt (1992) A sensitivity Analysis of Cross-Country Growth Regression. American Economic Review, Vol. 82, pp. 942-63. 
Longuet D. and H. Wietbrauk (1975) Bestimmung des Kostenverlaufs von Molkereiabteilungen in Abhängigkeit von der Kapazitätsgrösse und-auslastung. V. Teil: Joghurtabtailung. Milchwissenschaft 30 (4), pp. 344-353.

Longuet D.(1975) Bestimmung des Kostenverlaufs von Molkereiabteilungen in Abhängigkeit von der Kapazitätsgrösse und-auslastung. VII. Teil: Trinkmilchabtailung. Milchwissenschaft, 30 (4), pp.548-554.

Longuet, D. and H. Wietbrauk (1975) Bestimmung des Kostenverlaufs von Molkereiabteilungen in Abhängigkeit von der Kapazitätsgrösse und-auslastung. III. Teil: Abteilung Speisequarkabtailung. Milchwissenschaft 30 (4), pp.213-220.

Łoś, K. (1985) Koncentracja i specjalizacja w spółdzielczym przemyśle mleczarskim. Przeglad mleczarski 10, pp. 3-6, Warsaw.

Machowski, E., Nowacki, T. and J. Szarek (1993) Przesłanki wzrostu efektywności systemu gospodarki mleczarskiej. Przeglad mleczarski 5, Warsaw.

MAFE (1996) Lista koncesji udzielonych przez Polske w ramach Porozumienia Rolnego Rundy Urugwajskiej GATT. Draft paper. Warsaw.

MAFE (1998) Biuletyn informacyjny. MAFE, Warsaw.

Marczewski, K. (1998) Szacunek skali efektywnej protekcji w latach 1996-1997. In: Zagraniczna Polityka Gospodarcza Polski 1996-1997. IKiCHZ, Warsaw.

Marczewski, K. and J. Chojna. (1999) Powiqzania cen w polskim handlu zagranicznym z cenami światowymi w latach 1995-1997 (towary surowcowe). Studia i analizy statystyczne. GUS, Warsaw.

Markusen, J. R. Melvin, J.R. and W.H. Kaempfer (1995) International Trade. Theory and Evidence. Mc Graw-Hill, International Edition.

Mashayekhi, A. (1980) Shadow Prices for Project Appraisal in Turkey. World Bank Staff Working Paper, No. 392 (1980). The World Bank, Washington, D.C.

Masters. W.A. and A.Winter-Nelson (1995) Measuring the Comparative Advantage of Agricultural Activities: Domestic Resource Costs Ratio and the Social Cost-Benefit Ratio. American Journal of Agricultural Economics 77, pp. 243-250.

Ministry of Finance (1999) Strategia finansów publicznych i rozwoju gospodarczego, Polska 20002010. Draft document, Warsaw.

Misala, J. (1997) Revealed competitiveness vis-a-vis the EU, Trade flow analysis. In: Tangermann, S. And W. Münch (eds) Analysis of Polish Agriculture and Food Economy's Competitiveness and Complementarily in regard to EEC/EU. Phare-Project, GFA, KOMPAK, FAPA, Warsaw.

Monitor Polski, Dziennik Urzędowy (1999) http://www.abc.com.pl/serwis/publik.htm

Monke, E.A. and S.R. Pearson (1989) The Policy Analysis Matrix for Agricultural Development. Cornell University Press, Ithaca and London.

Münch, W., Safin, M, M. and J. Rajtar (1997) Recent Comparative Advantages of Polish Agri-food Products: Results of the DRC analysis. In: Tangermann, S. And W. Münch (eds) Analysis of Polish Agriculture and Food Economy's Competitiveness and Complementarily in regard to EEC/EU. Phare-Project, GFA, KOMPAK, FAPA, Warsaw.

Nitecka, E. (1998) Jakość i systemy zapewniania jakości w branży mleczarskiej na tle wymagań Unii Europejskiej. In: Korzyści i zagrożenia dla branży mleczarskiej zwiqzane z przystapieniem Polski do Unii Europejskiej. Seminar in Gdynia, 4-5 September 1998, FAPA, Warszawa.

NOBE (1998) Harmonisation: Where we stand. Meeting EU efficiency standards 1996-1998. Centrum Europejskie, Natolin, Warsaw. 
Nowicki, H. (1998)Uwarunkowania prawne przekształceń własnościowych w spółdzielczości mleczarskiej w Polsce. In: Uwarunkowania rozwoju mleczarstwa polskiego w procesie integrowania Polski z Uniq Europejska. Vol. 2, Torun.

O.J. of the EC (1999) Council regulation (EC) No. 1255/1999 of May 1999, L 160/48.

Obrusiewicz, T. (1994) Mleczarstwo. Część 1 i 2. Podręcznik dla zasadniczej szkoły zawodowej. WSiP, Warsaw.

OECD (1992) Main Economic Indicators. December 1992, OECD, Paris.

OECD (1994) Main Economic Indicators. December 1994, OECD, Paris

OECD (1995a) Technological Change and Structural Adjustment in OECD Agriculture. OECD, Paris

OECD (1995b) Review of Agricultural Policies: Poland, OECD, Paris.

OECD (1996) Main Economic Indicators. September 1996. OECD, Paris.

OECD (1998) The OECD Agricultural Outlook. 1998-2003, Paris.

OECD (1999) Main Economic Indicators. May 1999, OECD, Paris.

Orłowski, W. (1996) Droga do Europy. Studia i Prace - Z Prac Zakładu Badań StatystycznoEkonomicznych. GUS, Warsaw.

Orłowski, W. (1998) Problemy Społeczno-gospodarcze Zwiqzane z Wejściem Polski do Unii Europejskiej. Studia i Prace - Z Prac Zakladu Badan Statystyczno-Ekonomicznych. GUS, Warsaw.

PAIZ (1998) Inwestycje zagraniczne w Polsce. PAIZ, Warszawa.

Pearce, D.W. (1995) The MIT Dictionary of Modern Economics. Fourth Edition, The MIT Press, Cambridge, Massachusetts.

Pearson, S.R. et al. (1987) Portuguese Agriculture in Transition. Cornell University Press. Ithaca and London.

Penson, J. B. Jr. and D.A. Lins (1980) Agricultural Finance. Prentice-Hall, Inc. Englewood Cliffs, N.J.

Philips, L. (1983) The economics of price discriminations. Cambridge University Press, Cambridge.

Piesse, J. (1997) Efficincy Issues in Transition Economies. An application to Hungary. Ashgate, Aldershot. Brookfield USA, Singapore, Sydnay.

PIH (1998) Informacja o wynikach kontroli jakości mleka i wyrobów mlecznych w 1997. Draft paper. Warsaw.

Pimpicki, S., Goronowicz, M. and T. Stachowski (1999) Możliwości poprawy organizacji zwózki mleka w wybranym zakładzie mleczarskim. Paper presented in seminar: Progress in technology and organisation of dairy sector, 15-16.February, Olsztyn.

Pitts, E. (1983) Economic Aspects of Seasonality of Milk Production. Situation and Outlook Bulletin No.3. Economics \& Rural Welfare Research Centre, Dublin.

Polish Tariff Schedule (1999) Dziennik Ustaw Rzeczypospolitej Polskiej. Issues from years: 19961999. Warsaw.

Porter, M.E. (1990) Competitive advantage of nations. New York: The Free Press.

Rzeczpospolita (03.09.1999) Kompromis w wojnie jogurtowej. By: Bielecki, J.. http://www.rzeczpospolita.pl.

Rzeczpospolita (11.05.1999) Spór o cło na jogurty. By: Bielecki, J. Warsaw. 
Rzeczpospolita (14.02.1995) Zaczeło sie od importu: Danone kupuje dwie mleczarnie. Warsaw.

Rzeczpospolita (15.02.1995) Po „Woli“ zakład w Bieruniu: Danone na Śląsku. Warsaw.

Rzeczpospolita (17.04.1999) Producenci chcą równej konkurencji. By: Oktaba, L.. Warsaw.

Rzeczpospolita (17.05.1999) Mleczna droga do Brukseli. By: Rojewska, H.. Warsaw.

Rzeczpospolita (20.09.1999) Będą sery i desery: inwestycje i zamiary Bakomy. By: Oktaba, L.. Warsaw.

Rzeczpospolita (23.09.1998) Mleczarnie wracają na europejski rynek. By: Bielecki, J.. Warsaw.

Rzeczpospolita (24.03.1999) Jogobella wyparła Bakomę i Danona. By: Oktaba L. Warsaw.

Rzeczpospolita (25.02.1998) Spółka rodzinna. By Apanowicz, P.. Warsaw.

Rzeczpospolita (25.08.1999) OSM MRAGOWO. Warsaw.

SAEPR/FAPA (1998) Analiza Skutków Liberalizacji Handlu Rolno-spożywczego w Ramach WTO, Uktadu Europejskiego, CEFTA. Draft paper. FAPA, Warsaw.

SAEPR/FAPA: Polish Agri-food Trade. Issues from years: 1995 to 1999.

Sharples, J.A. (1990) Cost of Producing and Productivity in Analyzing Trade and Competitiveness. American Journal of Agricultural Economics, December, 1990.

Shiff, M.and A. Valdes (1998) Agriculture and the Macroeconomy. In: B. Gardner and G. Rausser (eds) Handbook of Agricultural Economics. Elsevier Science.

Skarżyńska, A. and J. Sadowska (1998) Koszty jednostkowe i dochodowość produkcji rolniczej w gospodarstwach indywidualnych w 1997. IERiGŻ, Warsaw.

Smoleński, Z. (1997) Stan i perspektywy przetwórstwa mleka. IERiGŻ. Warsaw.

Smoleński, Z. (1998a) Przeobrażenia spółdzielni mleczarskich i koncepcje nowych zasad statutowych oraz symulacyjne scenariusze rozwoju popytu i podaży produktów mleczarskich. In: Uwarunkowania rozwoju mleczarstwa polskiego w procesie integrowania Polski z Unia Europejskq. Vol. 2, Torun.

Smoleński, Z. (1998b) Situation and Outlook for Dairy Industry. In: Assistance in Preparing a Livestock Action Plan. Animal Production in Poland - A Sectoral Analysis. Report under Technical Cooperation Programme. FAO. Wydawnictwo SGGW, Warsaw.

Smoleński, Z. and Wigier, M. (1997) Analiza porównawcza mleczarstwa w Polsce i w krajach Unii Europejskiej. In: Stowarzyszenie z UE: niezbędne procesy dostosowawcze polskiej gospodarki żywnościowej. IERiGŻ, FAPA, Warsaw.

Sokołowski, T. and I. Bazydło (1999) Zmiany w gospodarce tluszczem i białkiem mleka w wybranych zakladach mleczarskich. Paper presented in seminar: Progress in technology and organisation of dairy sector, 15-16 February, Olsztyn.

Sokołowski, T. and M. Zlotkiewicz-Krasnodębska (1999) Analiza zużycia opakowań w wybranym zaktadzie mleczarskim. Paper presented in seminar: Progress in technology and organisation of dairy sector, 15-16 February, Olsztyn.

Stachowski, T. (1981) Ekonomika i organizacja przemystu spożywczego. Przewodnik do ćwiczeń. Olsztyn.

Stachowski, T. and M. Gornowicz (1998) Wpływ restrukturyzacji gospodarki na ekonomike produkcji i konsumpcji artykułów mleczarskich. Draft paper, Olsztyn.

Stachowski, T. Pimpicki, S. and M. Gornowicz (1999) Koszty i rentowność produkcji wybranych wyrobów mleczarskich w latach 1994-1997. Paper presented in seminar: Progress in technology and organisation of dairy sector, 15-16 February, Olsztyn. 
Stachowski, T., Kozłowski,W., Gornowicz, M. and S. Pimpicki (1995) Koszty wytwarzania i użytkowania czynników energetycznych w zakładzie mleczarskim. Zeszty naukowe Akademii Rolniczo-Technicznej w Olsztynie, No. 31, Olsztyn.

StBA (1996) Kostenstruktur der Unternehmen im Verbrauchsguetter produzierenden Gewerbe und im Nährungs - und Genussmittelgewerbe. Fachreihe 4.3.3, Verlag: W.Kohlhammer GMBH Stuttgart und Mainz.

Steinka, I., et al. (1999) Porównanie jakości twarożków produkowanych w zakładach o zróżnicowanych systemach kontroli jakości. Paper presented in seminar: Progress in technology and organisation of dairy sector, 15-16 February, Olsztyn.

Szteyn, J. and H. Listwon (1999) Jakość mikrobiologiczna produktów mleczarskich z rejonu Ostolęki. Paper presented in seminar: Progress in technology and organisation of dairy sector, 15-16 February, Olsztyn.

TACIS, (1999) UEPLAC, Kiev, Ukraine.

Tangermann, S. (1999) Europe's Agricultural Policies and the Millennium Round. The World Economy 9, December 1999, Vol. 22, pp. 1155-1177. Blackwell Publishers, Oxford, UK \& Boston, USA.

Tangermann, S. and T., Josling (1994) Pre-Accession Agricultural policies for Central Europe and the European Union. Report commissioned by the DG-I of the European Commission. Göttingen/Stanford.

Tomek, W.G. and K. L. Robinson (1990) Agricultural Product Prices. Third Edition, Cornell University Press, Ithaca and London.

Tower, E. (1992) Domestic Resource Cost, Journal of International Economic Integration (7)1, pp. $20-40$.

Traill, B. and J. Gilpin (1998) Changes in Size Distribution of EU Food and Drink Manufactures: 1980 to 1992, Agribusiness 4, Vol. 14, pp. 321-329.

Tsakok, (1990) Agricultural Price Policy. A Practitioner's Guide to Partial-Equilibrium Analysis. Cornell University Press, Ithaca and London.

Tyers, R. and K. Anderson (1990) Disarray in World Food Markets. A Quantitative Assessment. Cambridge University Press.

USDA ERS (1999) The European Union's Common Agricultural Policy: Pressures for Change. Situation and Outlook Series, WRS-99-2, October 1999.

Valdes. A. and B. Schaeffer (1995) Surveillance of Agricultural Price and Trade Policies. A Handbook for Chile. World Bank Technical Paper, No. 291.

Vitrová, R. (1997) Price level and RER development in the Czech Republic in comparison with the EU and CEFTA countries. Paper presented at: Workshop on Macroeconomic Problems of an EU Enlargement to the East, 28 February - 1 March, Halle.

Wei, A., Guba, W., Burcroff II, R. (1998) Why Has Poland Avoided the Price Liberalisation Trap? The case of the Hog-Pork Sector. The World Bank Economic Review 1, Vol. 12, pp. 155-74.

Weiss, S.E. and J. Budny (1999) Podstawowe wielkości występujace przy spalaniu różnych paliw w polskim przemyśle mleczarskim. Paper presented in seminar: Progress in technology and organisation of dairy sector, 15-16 February, Olsztyn.

Williamson, J. (1993) Democracy and the 'Washington Consensus'. World Development 8, pp. 13291336.

Wojdalski, J. Domagała. A.. Kaleta. A.. Janus. P. (1998) Energia i jej użytkowanie w przemyśle rolnospożywczym. Wydawnictwo SGGW, Warsaw. 
WTO (1996-1999) Notification of the European Communities concerning export subsidy commitments. Electronic versions.

Zalewski, A. and L. Nierzurawski (1994) Procesy ewolucji mleczarstwa w Polsce. Projekt badawczy. Zeszyt 49, Raporty IERiGŻ, Warsaw.

Zalewski, R. (1998) Kryteria odbioru jakościowego mleka w Polsce na tle norm europejskich. In: Skawińska E (ed) Uwarunkowania rozwoju mleczarstwa polskiego w procesie integrowania Polski z Uniq Europejska. TNOiK, Torun.

Ziajka, S and W. Dzwolak (1998) Wptyw jakości mleka na proces technologiczny. Paper presented in seminar on dairy production, Łomża.

Ziąbrowski, A. (1997) Stawki Transportowe w Międzynarodowym Przewozie Produktów Rolnych. FAMMU/FAPA, Warsaw.

ZMP (1999) Milch. ZMP Bilanz 1998. ZMP, Bonn.

ZMP (2000) Milch. ZMP Bilanz 1999. ZMP, Bonn. 
ANNEX I: ANNEX TABLES TO CHAPTER 1 
Annex Table 1. Potential Determinants of Industry Competitiveness in Poland vis-à-vis the EU.

\section{Comparative Advantage}

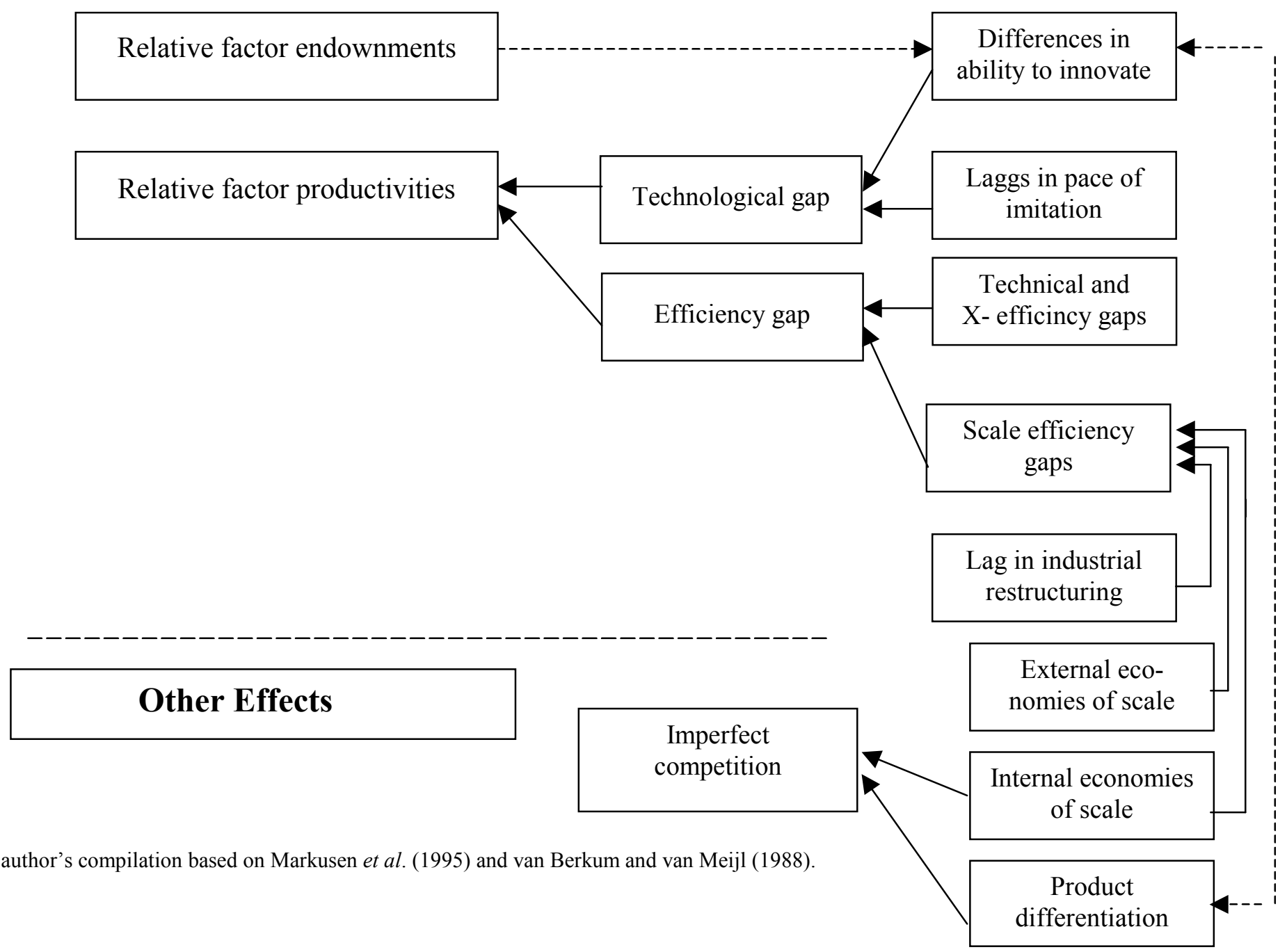

Poland-EU differences implying contribution of various effects:

1. Differences in relative capital/labour endowment

2. Pending effects of liberalisation, privatisation restructuring in Poland

3. Accumulated proefficiency effects of the EU single market

4. Differences in size of domestic markets

5. Differences in income levels and in the pace of income growth 
Annex Table 2. Stylised facts of a macroecomony in transition and applicability of theories in explaining changes in the sector-level competitiveness.

\begin{tabular}{|l|l|}
\hline \multicolumn{1}{|c|}{ Stylised facts } & \multicolumn{1}{c|}{ Applicable explanatory theories } \\
\hline $\begin{array}{l}\text { - Relatively high growth rates } \\
\text { - Inflow of foreign capital } \\
\text { - High interest rates } \\
\text { - Current account deficits } \\
\text { - High sensitivity of economic performance to political } \\
\text { and institutional reforms }\end{array}$ & $\begin{array}{l}\text { - Convergence property of (neo-) classical growth models } \\
\text { - Inter-temporal trade theory } \\
\text { - Conditionality' of economic convergence on economic policy } \\
\text { and institutional development }\end{array}$ \\
\hline $\begin{array}{l}\text { Competitive pressure on tradable industries due to on- } \\
\text { going appreciation of real exchange rate }\end{array}$ & $\begin{array}{l}\text { Labour productivity gains tend to be biased in favour of tradable } \\
\text { sector. This according to Balassa-Samuelson theory translates to } \\
\text { increases in prices of non-tradables relative to prices of tradables. }\end{array}$ \\
\hline $\begin{array}{l}\text { Conclusion: Industries loose or gains in terms of } \\
\text { comparative advantage }\end{array}$ & $\begin{array}{l}\text { Changing relative factor endowments and technological change } \\
\text { influence comparative advantages (H-O-S) and Ricardo } \\
\text { hypotheses). }\end{array}$ \\
$\begin{array}{l}\text { For an activity decisive for its competitiveness are: } \\
\text { scope for technology upgrade compensating wage increases } \\
\text { and appreciation of RER } \\
\text { ability to take advantage of the opening opportunities of } \\
\text { increasing investment and technological change } \\
\text { (privatisation, impediments to FDI, trade policy, other). }\end{array}$ \\
\hline
\end{tabular}

Source: author's compilation based on Krugman and Obstfeld (1994); Markusen et al., (1995); Tyers and Anderson (1990) and others.

Annex Table 3. Technology and product characteristics in milk processing, potential determinants of competitiveness and corresponding trade theory models.

\begin{tabular}{|l|l|l|}
\hline \multicolumn{1}{|c|}{$\begin{array}{c}\text { Product/technology } \\
\text { characteristics }\end{array}$} & \multicolumn{1}{|c|}{$\begin{array}{c}\text { Homogenous } \\
\text { (e.g. butter, SMP and hard cheeses) }\end{array}$} & $\begin{array}{c}\text { Differentiated } \\
\text { (e.g. yoghurt) }\end{array}$ \\
\hline New technologies & $\begin{array}{l}\text { New technologies increasingly automated, } \\
\text { also due to the 'need' to improve process } \\
\text { and quality control }\end{array}$ & $\begin{array}{l}\text { Old and new technologies highly automated } \\
\text { Increasing importance of marketing costs }\end{array}$ \\
\hline $\begin{array}{l}\text { Scope for increasing returns } \\
\text { to scale }\end{array}$ & $\begin{array}{l}\text { Medium. New technologies increase the } \\
\text { minimum efficient scale and offers gains } \\
\text { from production concentration }\end{array}$ & $\begin{array}{l}\text { High. Reliance on scale efficiency associated } \\
\text { with importance of R\&D and marketing inputs }\end{array}$ \\
\hline $\begin{array}{l}\text { Mobility of new } \\
\text { technologies }\end{array}$ & $\begin{array}{l}\text { Both processing and marketing } \\
\text { technologies internationally mobile }\end{array}$ & $\begin{array}{l}\text { Processing technologies mobile internationally, } \\
\text { however, expertise in R\&D and management } \\
\text { (gained through learning) may be firm- specific }\end{array}$ \\
\hline $\begin{array}{l}\text { Nature of technological } \\
\text { change }\end{array}$ & $\begin{array}{l}\text { Process innovations conducive to cost } \\
\text { decreases }\end{array}$ & $\begin{array}{l}\text { Product innovation conducive to wider product } \\
\text { variety (horizontal differentiation) or better } \\
\text { quality of same product (vertical differentiation) }\end{array}$ \\
\hline & $\begin{array}{l}\text { Dominant role of comparative advantage } \\
\text { based on gaps in relative factor } \\
\text { endowments and relative factor } \\
\text { productivity }\end{array}$ & $\begin{array}{l}\text { Comparative advantage based on temporary } \\
\text { technological gaps (e.g. ability to fast exploit the } \\
\text { scope for increasing returns in processing and } \\
\text { marketing offered by new innovations). } \\
\text { Product differentiation, industrial concentration } \\
\text { and fast demand growth offer the scope for } \\
\text { imperfect competition }\end{array}$ \\
\hline Conclusion: & \begin{tabular}{l} 
iens \\
\hline
\end{tabular}
\end{tabular}

Source: author's compilation based on van Berkum, B and H. van Meijl (1998a,b). 
ANNEX II: ANNEX TABLES TO CHAPTER 2 
Annex Table 4. Structure of Polish milk processing industry by selected criteria, 1994.

\begin{tabular}{|c|c|c|c|c|c|c|c|}
\hline \multirow[t]{3}{*}{ Size criterion } & \multirow[t]{3}{*}{ Parameters } & \multirow[t]{3}{*}{ Units } & \multicolumn{4}{|c|}{ Enterprise size classes } & \multirow[t]{3}{*}{ Total } \\
\hline & & & \multicolumn{4}{|c|}{ In thousand tons per year } & \\
\hline & & & Below 20 & $20-50$ & $50-100$ & Above 100 & \\
\hline \multirow{8}{*}{$\begin{array}{l}\text { Farm milk } \\
\text { procurement (1) }\end{array}$} & Number of enterprises & Units & 182 & 119 & 30 & 3 & 334 \\
\hline & Milk procured & Thousand tons & 1600 & 2906 & 1517 & 351 & 6373 \\
\hline & Production per enterprise & Thousand tons & 9 & 24 & 51 & 105 & 19 \\
\hline & Share in : & & & & & & \\
\hline & -enterprise number & Percentage & 55 & 36 & 9 & 1 & 100 \\
\hline & -milk procured & Percentage & 25 & 46 & 24 & 6 & 100 \\
\hline & & & \multicolumn{4}{|c|}{ In Million PLZ per year } & \\
\hline & & & Below 10 & $10-40$ & $40-80$ & Above 80 & \\
\hline \multirow[t]{4}{*}{ Sales value (2) } & Number & Units & 147 & 139 & 26 & 6 & 318 \\
\hline & Share of enterprise number & Percentage & 46 & 44 & 8 & 2 & 100 \\
\hline & & & \multicolumn{4}{|c|}{ In thousand tons per year } & \\
\hline & & & Below 20 & $20-50$ & $50-100$ & Above 100 & \\
\hline \multirow{7}{*}{$\begin{array}{l}\text { Production of } \\
\text { consumption milk } \\
\text { and fresh products (1) }\end{array}$} & Number of enterprises & Units & 317 & 17 & - & - & 334 \\
\hline & Milk procured & Thousand tons & 1506 & 264 & - & - & 1770 \\
\hline & $\begin{array}{l}\text { Production per enterprise } \\
\text { Share in. }\end{array}$ & Thousand tons & 5 & 16 & - & - & 5,3 \\
\hline & -enterprise number & Percentage & 95 & 5 & - & - & 100 \\
\hline & -milk processed & Percentage & 85 & 15 & - & - & 100 \\
\hline & & & \multicolumn{4}{|c|}{ In tons per year } & \\
\hline & & & Below 100 & $100-1000$ & $1000-4000$ & Above 4000 & \\
\hline \multirow{8}{*}{$\begin{array}{l}\text { Hard cheese } \\
\text { production (1) }\end{array}$} & Number of enterprises & Units & 14 & 117 & 46 & 3 & 180 \\
\hline & Production per class & Tons & 762 & 32787 & 74342 & 19189 & 127080 \\
\hline & Production per enterprise & Tons & 55 & 280 & 1613 & 6271 & 706 \\
\hline & Shares in: & & & & & & \\
\hline & -enterprise number & Percentage & 8 & 65 & 26 & 2 & 100 \\
\hline & -total production & Percentage & 1 & 26 & 59 & 15 & 100 \\
\hline & & & \multicolumn{4}{|c|}{ In tons per year } & \\
\hline & & & Below 100 & $100-1000$ & $1000-5000$ & Above 5000 & \\
\hline \multirow{7}{*}{ Butter production (1) } & Number of enterprises & Units & 62 & 174 & 31 & - & 267 \\
\hline & Production per class & Tons & 3041 & 59526 & 54380 & - & 116946 \\
\hline & Production per enterprise & Tons & 49 & 342 & 1756 & - & 438 \\
\hline & Shares in : & Percentage & & & & & \\
\hline & $\begin{array}{l}\text {-enterprise number } \\
\text {-total production }\end{array}$ & $\begin{array}{l}\text { Percentage } \\
\text { Percentage }\end{array}$ & $\begin{array}{r}23 \\
3\end{array}$ & $\begin{array}{l}65 \\
51\end{array}$ & $\begin{array}{l}12 \\
47\end{array}$ & $\begin{array}{l}- \\
-\end{array}$ & $\begin{array}{l}100 \\
100\end{array}$ \\
\hline & & & \multicolumn{4}{|c|}{ In tons per year } & \\
\hline & & & Below 1000 & $1000-5000$ & $5000-20000$ & Above 20000 & \\
\hline \multirow{5}{*}{$\begin{array}{l}\text { Milk powder } \\
\text { production }(1)\end{array}$} & Number of enterprises & Units & 40 & 32 & 3 & - & 75 \\
\hline & Production per class & Tons & 6300 & 86400 & 19800 & - & 112500 \\
\hline & $\begin{array}{l}\text { Production per enterprise } \\
\text { Shares in. }\end{array}$ & Tons & 158 & 2698 & 6600 & - & 1500 \\
\hline & -enterprise number & Percentage & 53 & 43 & 4 & - & 100 \\
\hline & -total production & Percentage & 6 & 77 & 18 & - & 100 \\
\hline
\end{tabular}

(1) Concerns co-operatives only, (2) Concerns all enterprises with more than 50 employees in 1995.

Source: Smoleński, Z. and M. Wigier, (1997), and Smoleński, Z. (1998b) and author's calculations. 
Annex Table 5. Indices of nominal and real values and prices of output and inputs used in TFP estimation, 1993-1997 (1993=1).

\begin{tabular}{|c|c|c|c|c|c|}
\hline & 1993 & 1994 & 1995 & 1996 & 1997 \\
\hline \multicolumn{6}{|l|}{ Nominal values } \\
\hline Output: & 1.00 & 1.20 & 1.78 & 2.28 & 2.92 \\
\hline Farm milk & 1.00 & 1.11 & 1.76 & 2.12 & 2.59 \\
\hline Fuels & 1.00 & 1.43 & 1.63 & 1.87 & 2.16 \\
\hline Other material inputs & 1.00 & 1.81 & 3.02 & 5.33 & 7.29 \\
\hline Electricity & 1.00 & 1.21 & 1.67 & 1.86 & 2.23 \\
\hline Services & 1.00 & 1.18 & 1.51 & 1.87 & 2.72 \\
\hline Labour & 1.00 & 1.20 & 1.64 & 2.02 & 2.69 \\
\hline Capital & 1.00 & 1.33 & 1.79 & 2.24 & 2.68 \\
\hline Other costs & 1.00 & 1.21 & 1.39 & 1.89 & 2.81 \\
\hline \multicolumn{6}{|l|}{ Real values: } \\
\hline Outputs & 1.00 & 0.93 & 1.07 & 1.14 & 1.27 \\
\hline Farm milk & 1.00 & 0.86 & 1.05 & 1.06 & 1.13 \\
\hline Fuels & 1.00 & 1.11 & 0.98 & 0.93 & 0.94 \\
\hline Other material inputs & 1.00 & 1.40 & 1.81 & 2.66 & 3.17 \\
\hline Electricity & 1.00 & 0.93 & 1.00 & 0.93 & 0.97 \\
\hline Services & 1.00 & 0.91 & 0.90 & 0.94 & 1.18 \\
\hline Labour & 1.00 & 0.93 & 0.98 & 1.01 & 1.17 \\
\hline Capital & 1.00 & 1.03 & 1.08 & 1.12 & 1.16 \\
\hline Other costs & 1.00 & 0.93 & 0.83 & 0.94 & 1.22 \\
\hline \multicolumn{6}{|l|}{ Nominal prices: } \\
\hline Outputs & 1.00 & 1.28 & 1.82 & 2.08 & 2.31 \\
\hline Farm milk & 1.00 & 1.18 & 1.90 & 2.21 & 2.51 \\
\hline Fuels & 1.00 & 1.45 & 1.66 & 1.92 & 2.24 \\
\hline Other material inputs & 1.00 & 1.25 & 1.57 & 1.77 & 1.98 \\
\hline Electricity & 1.00 & 1.24 & 1.58 & 1.81 & 2.01 \\
\hline Services & 1.00 & 1.29 & 1.58 & 1.82 & 2.10 \\
\hline Labour & 1.00 & 1.29 & 1.81 & 2.24 & 2.96 \\
\hline Capital & 1.00 & 1.24 & 1.49 & 1.78 & 1.99 \\
\hline Other costs & 1.00 & 1.30 & 1.67 & 2.00 & 2.30 \\
\hline \multicolumn{6}{|l|}{ Real prices: } \\
\hline Output & 1.00 & 0.99 & 1.09 & 1.04 & 1.00 \\
\hline Farm milk & 1.00 & 0.92 & 1.14 & 1.10 & 1.09 \\
\hline Fuels & 1.00 & 1.12 & 1.00 & 0.96 & 0.98 \\
\hline Other material inputs & 1.00 & 0.97 & 0.94 & 0.88 & 0.86 \\
\hline Electricity & 1.00 & 0.95 & 0.95 & 0.90 & 0.87 \\
\hline Services & 1.00 & 1.00 & 0.94 & 0.91 & 0.91 \\
\hline Labour & 1.00 & 0.99 & 1.08 & 1.12 & 1.29 \\
\hline Capital & 1.00 & 0.96 & 0.90 & 0.89 & 0.86 \\
\hline Other costs & 1.00 & 1.00 & 1.00 & 1.00 & 1.00 \\
\hline \multicolumn{6}{|c|}{ Output and input quantities: } \\
\hline Output & 1.00 & 0.94 & 0.98 & 1.10 & 1.26 \\
\hline Farm milk & 1.00 & 0.94 & 0.92 & 0.96 & 1.03 \\
\hline Fuels & 1.00 & 0.99 & 0.98 & 0.97 & 0.96 \\
\hline Other material inputs & 1.00 & 1.45 & 1.92 & 3.02 & 3.68 \\
\hline Electricity & 1.00 & 0.98 & 1.06 & 1.03 & 1.11 \\
\hline Services & 1.00 & 0.91 & 0.96 & 1.03 & 1.30 \\
\hline Labour & 1.00 & 0.93 & 0.91 & 0.90 & 0.91 \\
\hline Capital & 1.00 & 1.07 & 1.20 & 1.26 & 1.35 \\
\hline Other costs & 1.00 & 0.93 & 0.83 & 0.94 & 1.22 \\
\hline
\end{tabular}


Annex Table 6. Role of selected factors of technical performance in the Polish dairy sector. Literature review (part 1.).

\begin{tabular}{|c|c|c|c|c|c|}
\hline No & $\begin{array}{l}\text { Component of } \\
\text { performance }\end{array}$ & Authors, source & Findings & Enterprise sample & $\begin{array}{l}\text { Implied sources of } \\
\text { inefficiency and performance variation } \\
\text { and authors' recommendations }\end{array}$ \\
\hline 1. & $\begin{array}{l}\text { Unit production cost } \\
\text { for major products. }\end{array}$ & $\begin{array}{l}\text { Stachowski and } \\
\text { Gornowicz (1998). }\end{array}$ & 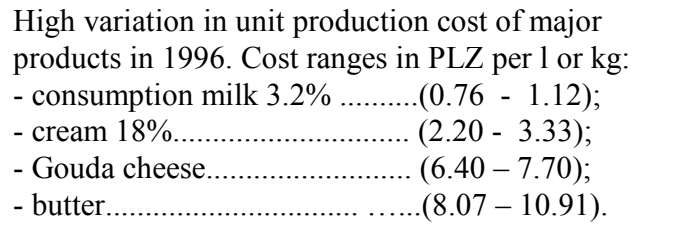 & $\begin{array}{l}\text { Sample of } 12 \text { dairy co-operatives in } \\
\text { the Northeast Poland. }\end{array}$ & $\begin{array}{l}\text { Firms differ in terms of: } \\
\text { degree of capacity utilisation, } \\
\text { prices paid for raw milk, } \\
\text { processing technology, } \\
\text { technical and scale inefficiencies } \\
\text { methods of cost calculation. }\end{array}$ \\
\hline 2. & $\begin{array}{l}\text { Degree of raw milk } \\
\text { utilisation in } \\
\text { processing. }\end{array}$ & $\begin{array}{l}\text { Sokołowski and } \\
\text { Bazydło (1999). }\end{array}$ & $\begin{array}{l}\text { Losses of farm milk. In } 1997 \text { in analysed enterprises } \\
\text { milk fat and proteins were used up (effectively } \\
\text { transferred into products) in } 92,0-95.8 \% \text { and } 93.5- \\
95.4 \% \text { respectively. }\end{array}$ & $\begin{array}{l}\text { Three selected enterprises in the } \\
\text { Northeast Poland. }\end{array}$ & $\begin{array}{l}\text { Excess processing capacities allow for } \\
\text { easy product mix adjustment. Then, } \\
\text { however, instabilities faced on } \\
\text { product markets induce under- } \\
\text { utilisation of milk components. }\end{array}$ \\
\hline 3. & $\begin{array}{l}\text { Farm milk assembly } \\
\text { costs. }\end{array}$ & Machowski et al. (1993) & $\begin{array}{l}\text { Reduction of labour and electricity consumption } \\
\text { of raw milk assembly due to the form indirect (via } \\
\text { collection points) to direct (tank s) way of assembly. }\end{array}$ & Authors' estimates. & $\begin{array}{l}\text { Size efficiency and technology } \\
\text { improvement (process innovation). }\end{array}$ \\
\hline 4. & $\begin{array}{l}\text { Raw milk assembly } \\
\text { costs. }\end{array}$ & Pimpicki et al. (1999). & $\begin{array}{l}\text { Sub-optimal organisation of raw milk assembly } \\
\text { results in up to } 20 \% \text { increase in transport cost. }\end{array}$ & $\begin{array}{l}\text { One of the most successful dairy co- } \\
\text { operatives located in North Poland. }\end{array}$ & $\begin{array}{l}\text { Optimisation of milk assembly is } \\
\text { possible by introduction of new } \\
\text { management support technology based } \\
\text { on computer simulation. }\end{array}$ \\
\hline 5. & Energy consumption. & $\begin{array}{l}\text { Weiss and } \\
\text { Budny (1999). }\end{array}$ & $\begin{array}{l}\text { High variation in energy input. It ranges between } \\
0.89 \text { up to } 2.53 \mathrm{MJ} \text { per } 1 \text { of processed raw milk } \\
\text { according to the type of energy supply system (fuel } \\
\text { and type of heating system). }\end{array}$ & Sample of dairies, 1997/1998. & $\begin{array}{l}\text { Differences in technology of energy } \\
\text { provision. }\end{array}$ \\
\hline 6. & $\begin{array}{l}\text { Packaging material } \\
\text { consumption. }\end{array}$ & $\begin{array}{l}\text { Sokołowski and } \\
\text { Złotkiewicz-Krasnodębska } \\
\text { (1999). }\end{array}$ & $\begin{array}{l}\text { Relatively high }(3.12 \%) \text { losses of packaging } \\
\text { materials. High deviations from norms. }\end{array}$ & A dairy co-operative. & $\begin{array}{l}\text { Failure of packaging technology, poor } \\
\text { quality of packaging materials and } \\
\text { poor management: technological gap } \\
\text { and x-inefficiency. }\end{array}$ \\
\hline
\end{tabular}


Annex Table 6. Role of selected factors of technical performance in the Polish dairy sector. Literature review (part 2.).

\begin{tabular}{|c|c|c|c|c|c|}
\hline No. & Component of performance & Authors, source & Findings & Enterprise sample & $\begin{array}{l}\text { Implied sources of } \\
\text { inefficiency and performance } \\
\text { variation and authors' } \\
\text { recommendations }\end{array}$ \\
\hline 7. & $\begin{array}{l}\text { Accordance with } \\
\text { microbiological quality } \\
\text { norms. }\end{array}$ & $\begin{array}{l}\text { Szteyn and } \\
\text { Listwon (1999). }\end{array}$ & $\begin{array}{l}\text { Decline in the number of questioned samples from } \\
18 \% \text { in } 1993 \text { down to } 6 \% \text { in } 1998 \text {. Best performance } \\
\text { shown by SMP (no questioned samples throughout } \\
\text { the period); worst in case of butter, of which the } \\
\text { quality varies from year to year. High differences } \\
\text { between enterprises (variation from } 0.4 \% \text { to } 33.3 \% \\
\text { of questioned samples). }\end{array}$ & $\begin{array}{l}\text { Systematic veterinary supervision of } \\
10 \text { enterprises in the most } \\
\text { dynamically developing dairy region. }\end{array}$ & $\begin{array}{l}\text { Improvement in the quality control } \\
\text { (management) and introduction of } \\
\text { new processing technology. }\end{array}$ \\
\hline 8. & $\begin{array}{l}\text { Accordance with technical } \\
\text { quality norms. }\end{array}$ & PIH (1998). & $\begin{array}{l}\text { The analysis detected smaller or greater quality } \\
\text { failures in } 33.1 \% \text { of ripening cheese, } 24 \% \text { of butter, } \\
23.4 \% \text { of consumption milk, } 33.7 \% \text { of milk drinks } \\
\text { and } 15.8 \% \text { of cream samples taken in processing } \\
\text { enterprises. The failures result from incorrect } \\
\text { labelling ( } 22 \%) \text {, deviation of physical content from } \\
\text { that legally required ( } 15.9 \%) \text { and underweight } \\
(16.1 \%) \text { (excluding cheeses). }\end{array}$ & $\begin{array}{l}\text { Samples taken in the first quarter or } \\
1998 \text { in } 111 \text { enterprises (around } 33 \% \\
\text { of the total). The samples were not } \\
\text { randomly selected - enterprises were } \\
\text { targeted according to (non-sample) } \\
\text { information, which increases } \\
\text { incidence of failures detected. }\end{array}$ & $\begin{array}{l}\text { Mostly technical }(X) \text { inefficiency } \\
\text { As well as the scale inefficiency and } \\
\text { outdated technologies. }\end{array}$ \\
\hline 9. & $\begin{array}{l}\text { Efficiency of quality } \\
\text { control procedures. }\end{array}$ & Steinka (1999). & $\begin{array}{l}\text { Quality of final product (cottage cheese) depends on } \\
\text { the quality control procedures. Hazard Analysis of } \\
\text { Critical Control Points (HACCP) (instead of } \\
\text { traditional quality control procedures limited to the } \\
\text { final product) allows elimination of quality failures. }\end{array}$ & $\begin{array}{l}\text { Microbial and physical control of } \\
\text { products from } 11 \text { enterprises with } \\
\text { HACCP and } 9 \text { enterprises with } \\
\text { traditional (only final product } \\
\text { control). }\end{array}$ & $\begin{array}{l}\text { Introduction of new process control } \\
\text { HACCP technology as a prerequisite } \\
\text { for meeting new quality standards. }\end{array}$ \\
\hline 10. & $\begin{array}{l}\text { Capital concentration } \\
\text { in co-operative sector. }\end{array}$ & $\begin{array}{l}\text { Rzeczpospolita } \\
(25.08 .1999) .\end{array}$ & $\begin{array}{l}\text { The processes of merging two co-operatives (OSM } \\
\text { Mragowo and Mlekpol Grajewo) have been blocked } \\
\text { by the protests of labour unions. }\end{array}$ & $\begin{array}{l}\text { Two well performing dairy co- } \\
\text { operatives - one pioneering example } \\
\text { of horizontal integration targeted at } \\
\text { reaping economies of scale. }\end{array}$ & $\begin{array}{l}\text { Distorted ownership attitudes and } \\
\text { organisation form conducive to } \\
\text { principal-agent kind of constraints on } \\
\text { restructuring and modernisation. }\end{array}$ \\
\hline 11. & $\begin{array}{l}\text { Role of human capital in } \\
\text { modernisation of co- } \\
\text { operatives. }\end{array}$ & Biegluk (1999). & $\begin{array}{l}\text { Co-operative ownership conducive to significant } \\
\text { internal constraints for most milk processing firms } \\
\text { development can be bridged. }\end{array}$ & $\begin{array}{l}\text { Case study of the most successful } \\
\text { dairy co-operative enterprise } \\
\text { "Mlekovita". }\end{array}$ & $\begin{array}{l}\text { Management skills of co-operative } \\
\text { leader as a way to overcome } \\
\text { institutional constraints on co- } \\
\text { operative development. }\end{array}$ \\
\hline
\end{tabular}


Annex Table 7. Cost structure in milk processing industries in Poland and in German Old and New States (G.O.S. and G.N.S.).

\begin{tabular}{|c|c|c|c|c|c|}
\hline & Units & $\begin{array}{r}\text { G.N.S } \\
1994\end{array}$ & $\begin{array}{c}\text { G.O.S } \\
1994\end{array}$ & $\begin{array}{c}\text { Germany total } \\
1994\end{array}$ & $\begin{array}{c}\text { Poland } \\
1996\end{array}$ \\
\hline 1. Number of enterprises & number & 40 & 154 & 194 & 285 \\
\hline 2. Gross output value & Mio DM & 3809 & 27349 & 31157 & 3665 \\
\hline 3. Net output value & Mio DM & 3558 & 23138 & 26696 & 3206 \\
\hline \multicolumn{6}{|l|}{ 4. Raw milk } \\
\hline volume & '000 tons & 4343 & 21704 & 26047 & 6315 \\
\hline value & Mio DM & 2280 & 12295 & 14575 & 1819 \\
\hline unit cost (price) & $\mathrm{DM} / \mathrm{kg}$ & 0.525 & 0.5665 & 0.560 & 0.288 \\
\hline \multicolumn{6}{|l|}{ 5. Labour } \\
\hline employment & thousand & 4.0 & 31.8 & 35.8 & 56.5 \\
\hline labour cost & Mio DM & 179 & 2269 & 2447 & 437 \\
\hline gross wages & Mio DM & 146 & 1851 & 1997 & 295 \\
\hline average labour cost per employee & '000 DM & 44.5 & 71.3 & 68.3 & 7.7 \\
\hline average gross-wage per employee & ‘000 DM & 36.5 & 58.1 & 55.7 & 5.2 \\
\hline \multicolumn{6}{|l|}{ 6. Capital } \\
\hline depreciation & Mio DM & 84 & 650 & 734 & 101 \\
\hline interest paid on credits & Mio DM & 40 & 162 & 203 & 21 \\
\hline estimated interest on total capital & Mio DM & 121 & 487 & 609 & 83 \\
\hline capital cost equivalent & Mio DM & 246 & 1300 & 1546 & 205 \\
\hline \multicolumn{6}{|l|}{ 7. Materials } \\
\hline including farm milk & with milk & 3329 & 22240 & 25569 & 2738 \\
\hline excluding farm milk & Mio DM & 1049 & 9945 & 10994 & 919 \\
\hline prod excluding farm milk and products & Mio DM & 251 & 4210 & 4461 & 459 \\
\hline other material inputs & Mio DM & 798 & 5735 & 6533 & 459 \\
\hline \multicolumn{6}{|l|}{ 8. Input intensity } \\
\hline \multicolumn{6}{|l|}{ 8.1. Cost per raw milk unit } \\
\hline employment & employment/1000 t & 0.923 & 1.467 & 1.376 & 8.947 \\
\hline labour & $\mathrm{DM} / \mathrm{ton}$ & 41 & 105 & 94 & 69 \\
\hline capital & $\mathrm{DM} /$ ton & 57 & 60 & 59 & 32 \\
\hline other materials & $\mathrm{DM} /$ ton & 184 & 264 & 251 & 73 \\
\hline processing margin & $\mathrm{DM} /$ ton & 294 & 500 & 465 & 220 \\
\hline sales value per $\mathrm{kg}$ of milk & $\mathrm{DM} /$ ton & 295 & 500 & 466 & 220 \\
\hline \multicolumn{6}{|l|}{ 8.2. Share of processing margin } \\
\hline labour cost & $\%$ & 14 & 21 & 20 & 32 \\
\hline capital cost & $\%$ & 19 & 12 & 13 & 15 \\
\hline other materials cost & $\%$ & 62 & 53 & 54 & 33 \\
\hline \multicolumn{6}{|l|}{ 9. Capital/labour relationship } \\
\hline capital/labour ratio & ratio & 1.4 & 0.6 & 0.6 & 0.5 \\
\hline capital cost per employee & '000 DM/employee & 61.4 & 40.8 & 43.1 & 3.6 \\
\hline \multicolumn{6}{|l|}{ 10. Labour productivity } \\
\hline raw milk per employee & tons per employee & 1083.3 & 681.7 & 726.7 & 111.8 \\
\hline net output per employee & '000 DM/employee & 887.4 & 726.8 & 744.8 & 56.7 \\
\hline processing margin per employee & ‘000 DM/employee & 318.8 & 340.6 & 338.2 & 24.5 \\
\hline
\end{tabular}


Annex Table 8. Major characteristics of the Program of Restructuring and Modernisation of Dairy Sector.

Program of Restructuring and Modernisation of Dairy Sector (PRiMM) (1)

\section{Duration: \\ Activity coverage: \\ Objectives:}

Rationale:

Instruments:

Source of financial means:

Eligibility criteria

Formal procedure

Results (2)

\section{4-1997}

Dairy farms and dairy processing enterprises.

Restructuring and modernisation of dairy sector, in particular:

- achieving long-run profitability in farm milk production and milk processing;

- improvement of processing sector competitiveness by increasing capital concentration ;

- stabilisation of dairy market;

- accelerating regional re-allocation of productive capacity.

Since the abandonment of government support to the dairy sector in 1991 most enterprises experienced declining profitability and de-investment. Milk production continued to decline while the sector considered itself unable to finance necessary investments at current market credit conditions.

- Credits with subsidised interest rate applied interest rate equal to $25 \%$ of Central Bank rediscount rate

- Subsidised credit up to $70 \%$ of investment project value (in farm sector up to $80 \%$ )

- However, the subsidised credits can not exceed 2 million PLZ (about 1 million DM) per enterprise; this limit can be raised to 6 million PLZ by a decision of the ARMA president.

- For farm projects the limit amounts to 0.5 million PLZ per farm.

- Deferred payment period: 2 years with 8 -year maturity.

\section{State budget subsidies}

- Eligibility conditions on dairy farms: milk cow herd of minimum 5 head, minimum yearly delivery 18 thousand litres and signed contract for milk delivery with milk processor

- Compliance of the investment project with the regional (voivodship) plan of modernisation and restructuring of milk sector, which considers local natural, economic and other condition and co-ordinates modernisation with broader objectives.

- Preparation of standard business plan.

- Approval of the business plan by the local Extension Centre.

- Submission of the investments (business) plan to the bank.

- Interest rate subsidy payable to bank.

- Value of subsidised credits granted in the years 1994-1997 equals 654 Mio PLZ.

- Out of that sum 300 Mio PLZ were spend on projects in milk processing.

- The subsidised credits correspond to about $24 \%$ of all investments in milk processing in the years $1994-$ 1997.

- The subsidised interest rate yielded negative (-8.3\%) real interest rate compared to market real interest rate (averages for 1996-1998) equal 7.8\%. Considering the structure of investment funds and 8 years maturity this enabled limitation of the annuity (yearly repayment of investment) by $11-12 \%$.

- Average interest rate (on all funds) has been decreased from $7.8 \%$ to $4 \%$.

\section{Corrected Programme for Restructuring of Dairy Programme. Major changes compared to PRiMM (3)}

Projected duration:

Objectives

Rationale

Instruments

Source of financial means

Eligibility criteria (size)
1999-2006

- Improvement of sanitary and hygienic quality standards of farm milk products.

- Improvement of competitiveness and profitability of the dairy sector.

- Upgrade of environmental standards.

Need to meet EU membership requirements.

Not specified.

State budget, EU pre-accession assistance and own firms' resources.

- Farm level: minimum herd size: 10 cows (in mountain areas 5 cows), yearly milk delivery minimum 40 thousand 1 yearly with prospects for herd increase.

- Processing level: yearly milk procurement at least 80 million 1 (in some regions 40 million 1) including firms created by capital integration. Obligation to increase milk procurement during the realisation of projects

Expected results in processing Reduction of the number of processing enterprises to $80-100$ units by increasing average size of each unit.

(3) at the time of the writing of this report the 'Corrected Programme' has been still in the preparation stage.

Source: (1) most information comes from Domańska (1994), (2) own calculations described in Chapter 2 and chapter 3., (3) KPSM (1998). 
Annex Table 9. Major results of the PRiMM in years 1994-1997.

\begin{tabular}{cccc}
\hline $\begin{array}{c}\text { Dairy activities subject to } \\
\text { subsidised investment }\end{array}$ & $\begin{array}{c}\text { Number of units } \\
\text { covered by the Program }\end{array}$ & $\begin{array}{c}\text { Total number of units } \\
\text { (approximate } \\
\text { estimates) }\end{array}$ & $\begin{array}{c}\text { Share } \\
\text { (in percentage) }\end{array}$ \\
\hline A. Milk farms & 23.7 thousand & about 0.8 Mio & 3 \\
Major investment items: & 37.7 thousand & about 2 Mio & 2 \\
milk caws & 31.7 thousand & - & - \\
cooling equipment & 2.1 thousand & - & - \\
milking equipment & & 300 & 82 \\
m. Milk processing enterprises & 247 & 300 & 22 \\
Processing lines: & & 20 & 90 \\
including drinking milk & 67 & 200 & 17 \\
including UHT milk & 18 & 75 & 32 \\
milk drinks and deserts & 148 & 180 & 40 \\
milk powders & 13 & 200 & 34 \\
hard cheeses & 57 & 70 & 31 \\
fresh cheeses & 79 & & 24 \\
processed cheeses & 24 & 300 & - \\
Other equipment: & & 300 & - \\
including: heating systems & 94 & - & \\
sewage systems & 71 & & \\
quality control equipment & 171 & & \\
milk tanks & 520 & & \\
\end{tabular}

Source: Biegański (1999), Doradztwo Mleczarskie (1997) and author's calculations. 
ANNEX III: ANNEX TABLES TO CHAPTER 3 
Annex Table 10. Data used in the estimation of input-output coefficients.

\begin{tabular}{|c|c|c|}
\hline Input/output description & Component of calculations & Data sources \\
\hline Products & $\begin{array}{l}\text { Total Value. Quantities of products: } \\
\text { Prices: }\end{array}$ & $\begin{array}{l}\text { GUS }(1998 b, c, d) \\
\text { IERiGŻ }(1999)\end{array}$ \\
\hline Farm milk & $\begin{array}{l}\text { Total quantity. Milk prices } \\
\text { Prices of fat and non-fat components } \\
\text { Fat/non-fat-intensity for products: }\end{array}$ & $\begin{array}{l}\text { IERiGŻ (1999) } \\
\text { See Annex Table } 17 \\
\text { Bazydło and Sokołowski (1998); Obrusiewicz (1994) }\end{array}$ \\
\hline Labour & Total cost. Employment. Unit cost & GUS $(1997,1998 c)$ \\
\hline Capital & $\begin{array}{l}\text { Capital stock } \\
\text { Interest rates } \\
\text { Capital cost }\end{array}$ & $\begin{array}{l}\text { GUS (1998e) } \\
\text { See Table 3.4. } \\
\text { See Annex Table } 18\end{array}$ \\
\hline Energy & $\begin{array}{l}\text { Total values } \\
\text { Quantities of various energy sources } \\
\text { Prices of fuels }\end{array}$ & $\begin{array}{l}\text { GUS (1998b) } \\
\text { Wojdalski et al. }(1998) \\
\text { GUS (1998a) }\end{array}$ \\
\hline Packaging materials & Cost per unit of output & $\begin{array}{l}\text { Sokołowski and Zlotkiewicz-Krasnodębska (1999) and } \\
\text { Hülsemeyer (1999) }\end{array}$ \\
\hline Other materials & Total value & $\begin{array}{l}\text { Residual from total value (GUS, 1998b) and estimated } \\
\text { intermediate use of milk and packaging materials. }\end{array}$ \\
\hline Services and other costs & Total value & GUS (1998b) \\
\hline Profitability of products & Percentage of revenues & $\begin{array}{l}\text { Gornowicz et al. (1999) } \\
\text { Doradztwo Mleczarskie (1997) }\end{array}$ \\
\hline $\begin{array}{l}\text { Product specific intensities } \\
\text { in capital, labour and other } \\
\text { inputs }\end{array}$ & & $\begin{array}{l}\text { For cost classification method: } \\
\text { Stachowski. T. (1981) } \\
\text { For input intensities: } \\
\text { Budny, et al. (1986); Gornowicz, (1983); Sokolowski } \\
\text { and Złotkiewicz-Krasnodębska (1999) Stachowski, et } \\
\text { al., (1995); Gornowicz, et al., (1999); Gornowicz and } \\
\text { Stachowski (1990); Gornowicz (1996); Wojdalski } \\
\text { et.al. (1998); Brehm and Krell, (1975); Brehm and } \\
\text { Krell (1976); Behme and Wietbrauk (1975); Longuet } \\
\text { and Wietbrauk (1975); Behme (1975a,b); Longuet } \\
\text { (1975); Krell and Wieterbrauk (1993a); Hülsemeyer } \\
\text { (1999). }\end{array}$ \\
\hline
\end{tabular}

Source: author's compilation. 
Annex Table 11. Estimation of product-specific costs in the milk processing industry in Poland, 1997 (per 1000 tons of processed farm milk).

\begin{tabular}{|c|c|c|c|c|c|c|c|c|c|c|c|c|c|}
\hline \multirow{5}{*}{ Product description } & \multicolumn{3}{|c|}{ Output } & \multicolumn{4}{|c|}{ Farm milk input } & \multicolumn{5}{|c|}{ Processing costs } & \multirow[t]{3}{*}{ Profits } \\
\hline & \multirow[t]{2}{*}{ Quantities } & \multirow[t]{2}{*}{ Prices } & \multirow[t]{2}{*}{ Revenue } & \multicolumn{2}{|c|}{ Quantities } & \multicolumn{2}{|c|}{ Values } & \multirow[t]{2}{*}{ Capital } & \multirow[t]{2}{*}{ Labour } & \multirow[t]{2}{*}{ Materials } & \multirow[t]{2}{*}{ Energy } & \multirow[t]{2}{*}{ Services } & \\
\hline & & & & Fat & Non-fat & Fat & Non-fat & & & & & & \\
\hline & Tons & PLZ/Ton & ‘000 PLZ & ‘000 Units & '000 Units & ‘000 PLZ & ‘000 PLZ & ‘000 PLZ & ‘000 PLZ & ‘000 PLZ & ‘000 PLZ & ‘000 PLZ & ‘000 PLZ \\
\hline & (1) & (2) & (3) & (4) & (5) & (6) & (7) & (8) & (9) & (10) & (11) & (12) & (13) \\
\hline 1. Consumption milk & 169.6 & 830.0 & 140.74 & 508.7 & 149.6 & 34.8 & 49.4 & 5.7 & 12.4 & 24.2 & 5.6 & 12.4 & -3.8 \\
\hline 2. Condensed milk and wey & 2.4 & 2490.0 & 5.99 & 23.4 & 5.7 & 1.6 & 1.9 & 0.1 & 0.5 & 1.1 & 0.3 & 0.3 & 0.2 \\
\hline 3. Full milk powder & 7.0 & 15786.6 & 50.75 & 183.7 & 54.3 & 12.6 & 17.9 & 1.7 & 5.0 & 5.5 & 2.6 & 4.9 & 0.5 \\
\hline 4. Skimmed milk powder & 15.2 & 5187.5 & 78.70 & 8.9 & 168.8 & 0.6 & 55.7 & 3.5 & 5.6 & 3.4 & 4.0 & 3.8 & 2.1 \\
\hline 5. Ripening cheese & 20.0 & 8286.5 & 165.96 & 597.9 & 202.2 & 40.9 & 66.7 & 3.0 & 24.1 & 9.8 & 5.0 & 9.1 & 7.3 \\
\hline 6. Non-ripening cheese & 30.0 & 4540.4 & 136.03 & 189.1 & 240.1 & 12.9 & 79.2 & 2.5 & 13.9 & 10.4 & 4.2 & 8.9 & 4.0 \\
\hline 7. Processed cheeses & 5.4 & 8286.5 & 44.59 & 157.9 & 52.8 & 10.8 & 17.4 & 1.2 & 4.2 & 4.3 & 1.8 & 3.0 & 1.9 \\
\hline 8. Ice-creams & 17.3 & 5855.1 & 101.46 & 129.2 & 16.0 & 8.8 & 5.3 & 8.0 & 18.2 & 38.4 & 6.5 & 5.3 & 11.1 \\
\hline 9. Creams & 25.4 & 3265.0 & 82.85 & 314.6 & 22.1 & 21.5 & 7.3 & 4.1 & 17.8 & 13.7 & 6.6 & 16.1 & -4.3 \\
\hline 10. Butter & 17.6 & 7176.3 & 126.26 & 1478.2 & 1.7 & 101.2 & 0.6 & 3.3 & 9.7 & 6.6 & 6.3 & 9.0 & -10.5 \\
\hline 11. Yoghurts and kefirs & 33.6 & 2630.0 & 88.38 & 108.3 & 44.6 & 7.4 & 14.7 & 7.0 & 7.7 & 35.2 & 4.0 & 3.8 & 8.6 \\
\hline 13. Casein & 0.2 & 11252.5 & 1.90 & 0.3 & 5.1 & 0.0 & 1.7 & 0.0 & 0.1 & 0.1 & 0.1 & 0.2 & -0.2 \\
\hline 14. Margin from trade & 38.4 & 1000.0 & 38.39 & & & & & 2.0 & 18.4 & 6.0 & 3.2 & 0.7 & 8.1 \\
\hline Total & & & 1061.99 & 3700.0 & 963.0 & 253.3 & 317.7 & 42.3 & 137.5 & 158.7 & 50.1 & 77.5 & 24.9 \\
\hline
\end{tabular}

Data sources and procedures: author's estimation based on the data and procedure described in Chapter 2.

The output structure presented in columns (1) and (3) has been calculated from the data published in IERiGŻ (1999).

Farm milk intensities in columns (4) and (5) are estimated from technical coefficients for fat and non-fat content in dairy products taken from: Bazydło and Sokołowski (1998) and Obrusiewicz (1994). Based on the assumption that one ton of farm milk contains 3700 units of milk fat and 963 units of milk non-fat components (plasma).

Costs of farm milk in (6) and (7) are calculated from (4) and (5) using implicit prices of fat and non-fat components derived from prices of farm milk, SMP and butter in 1997 (see Annex Table 17).

Product-specific profits in column (13) have been approximated on the basis of data on the relative profitability of dairy production in various enterprise samples by Gornowicz (1999), Doradztwo mleczarskie (1997). The processing costs are calculated as the residuals of: revenues (3) and farm milk costs (6 and 7) and profits (13).

The sub-categories of processing costs (labour, depreciation, materials, energy, services) that are presented here as totals (lowest raw) reflect the levels reported by enterprises to the statistical office in the obligatory financial reports (GUS, 1998c). These totals have been allocated among products according to various criteria and using the information from: Budny, et al. (1986); Gornowicz, (1983); Sokołowski and Złotkiewicz-

Krasnodębska (1999) Stachowski, et al., (1995); Gornowicz, et al., (1999); Gornowicz and Stachowski (1990); Gornowicz (1996); Wojdalski et.al. (1998); Brehm and Krell, (1975); Brehm and Krell (1976); Behme and Wietbrauk (1975); Longuet and Wietbrauk (1975); Behme (1975a,b); Longuet (1975); Krell and Wieterbrauk (1993a,b); Hülsemeyer (1999). 
Annex Table 12. Budget data used in PAM analysis, 1997.

Industry (per1000 tons of farm milk processed)

A. Private costs

\begin{tabular}{|l|c|c|r|r|r|r|r|}
\hline \multicolumn{2}{|c|}{ Input } & Unit & Tradables & F. milk & Labour & Capital & \multicolumn{1}{c|}{ Total } \\
\hline Row cow milk & '000 PLZ & 0.0 & 571.0 & 0.0 & 0.0 & 571.0 \\
\hline \multirow{2}{*}{ Materials: } & packaging & '000 PLZ & 69.7 & 0.0 & 0.0 & 0.0 & 69.7 \\
\cline { 2 - 8 } & other materials & '000 PLZ & 44.4 & 0.0 & 22.2 & 22.2 & 88.9 \\
\hline Electricitv & & '000 PLZ & 13.2 & 0.0 & 0.0 & 0.0 & 13.2 \\
\hline \multirow{4}{*}{ Energy: } & '000 PLZ & 17.8 & 0.0 & 0.0 & 0.0 & 17.8 \\
\cline { 2 - 8 } & coal & '000 PLZ & 3.8 & 0.0 & 0.0 & 0.0 & 3.8 \\
\cline { 2 - 8 } & naturalgas & '000 PLZ & 4.8 & 0.0 & 0.0 & 0.0 & 4.8 \\
\cline { 2 - 8 } & fuel & '000 PLZ & 6.3 & 0.0 & 0.0 & 0.0 & 6.3 \\
\cline { 2 - 8 } & water and sewege & '000 PLZ & 2.2 & 0.0 & 0.0 & 2.2 & 4.3 \\
\hline External services & '000 PLZ & 21.2 & 0.0 & 21.2 & 21.2 & 63.6 \\
\hline Labour & '000 PLZ & 0.0 & 0.0 & 137.5 & 0.0 & 137.5 \\
\hline Canital & '000 PLZ & 0.0 & 0.0 & 0.0 & 42.3 & 42.3 \\
\hline Other costs & '000 PLZ & 4.7 & 0.0 & 4.7 & 4.7 & 14.0 \\
\hline Total & '000 PLZ & 188.0 & 571.0 & 185.6 & 92.5 & 1037.1 \\
\hline
\end{tabular}

Skimmed milk powder (per 1000 tons of output)

A. Private costs

A. Private costs
\begin{tabular}{|l|c|c|r|r|r|r|r|}
\hline \multicolumn{2}{|c|}{ Input } & Unit & Tradables & F. milk & Labour & Capital & Total \\
\hline Row cow milk & '000 PLZ & 0.0 & 3633.5 & 0.0 & 0.0 & 3633.5 \\
\hline \multirow{2}{*}{ Materials: } & packaging & '000 PLZ & 51.9 & 0.0 & 0.0 & 0.0 & 51.9 \\
\cline { 2 - 8 } & other materials & '000 PLZ & 81.0 & 0.0 & 46.9 & 46.9 & 187.5 \\
\hline Electricitv & & '000 PLZ & 75.6 & 0.0 & 0.0 & 0.0 & 75.6 \\
\hline \multirow{4}{*}{ Energy: } & coal & '000 PLZ & 107.5 & 0.0 & 0.0 & 0.0 & 107.5 \\
\cline { 2 - 8 } & oil & '000 PLZ & 22.8 & 0.0 & 0.0 & 0.0 & 22.8 \\
\cline { 2 - 8 } & naturalgas & '000 PLZ & 28.5 & 0.0 & 0.0 & 0.0 & 28.5 \\
\cline { 2 - 8 } & fuel & '000 PLZ & 39.6 & 0.0 & 0.0 & 0.0 & 39.6 \\
\cline { 2 - 8 } & water and sewege & '000 PLZ & 6.9 & 0.0 & 0.0 & 6.9 & 13.9 \\
\hline External services & '000 PLZ & 85.9 & 0.0 & 85.9 & 85.9 & 258.0 \\
\hline Labour & '000 PLZ & 0.0 & 0.0 & 428.3 & 0.0 & 428.3 \\
\hline Capital & '000 PLZ & 0.0 & 0.0 & 0.0 & 192.0 & 192.0 \\
\hline Other costs & '000 PLZ & 69.2 & 0.0 & 19.1 & 19.1 & 57.4 \\
\hline Total & '000 PLZ & 568.9 & 3633.5 & 580.2 & 350.9 & 5096.5 \\
\hline
\end{tabular}

Ripening cheese (per 1000 tons of output)

A. Private costs

A. Private costs
\begin{tabular}{|l|c|c|r|r|r|r|r|}
\hline \multicolumn{2}{|c|}{ Input } & Unit & Tradables & F. milk & Labour & Capital & Total \\
\hline Row cow milk & '000 PLZ & 0.0 & 5358.5 & 0.0 & 0.0 & 5358.5 \\
\hline \multirow{2}{*}{ Materials: } & packaging & '000 PLZ & 82.9 & 0.0 & 0.0 & 0.0 & 82.9 \\
\cline { 2 - 8 } & other materials & '000 PLZ & 324.5 & 0.0 & 136.4 & 136.4 & 545.6 \\
\hline Electricitv & & '000 PLZ & 71.3 & 0.0 & 0.0 & 0.0 & 71.3 \\
\hline \multirow{3}{*}{ Energy: } & coal & '000 PLZ & 96.1 & 0.0 & 0.0 & 0.0 & 96.1 \\
\cline { 2 - 8 } & oil & '000 PLZ & 17.7 & 0.0 & 0.0 & 0.0 & 17.7 \\
\cline { 2 - 8 } & naturalgas & '000 PLZ & 22.1 & 0.0 & 0.0 & 0.0 & 22.1 \\
\cline { 2 - 8 } & fuel & '000 PLZ & 56.1 & 0.0 & 0.0 & 0.0 & 56.1 \\
\cline { 2 - 8 } & water and sewege & '000 PLZ & 17.8 & 0.0 & 0.0 & 17.8 & 35.7 \\
\hline External services & '000 PLZ & 142.0 & 0.0 & 142.0 & 142.0 & 426.3 \\
\hline Labour & '000 PLZ & 0.0 & 0.0 & 920.5 & 0.0 & 920.5 \\
\hline Capital & 000 PLZ & 0.0 & 0.0 & 0.0 & 183.9 & 183.9 \\
\hline Other costs & '000 PLZ & 28.9 & 0.0 & 28.9 & 28.9 & 86.7 \\
\hline Total & '000 PLZ & 859.4 & 5358.5 & 1227.7 & 509.0 & 7903.3 \\
\hline
\end{tabular}

Butter (per 1000 tons of output)

A. Private costs

A. Private costs
\begin{tabular}{|l|l|c|r|r|r|r|r|}
\hline \multicolumn{2}{|c|}{ Input } & Unit & Tradables & F. milk & Labour & Capital & Total \\
\hline Row cow milk & '000 PLZ & 0.0 & 5937.5 & 0.0 & 0.0 & 5937.5 \\
\hline \multirow{2}{*}{ Materials: } & packaging & '000 PLZ & 71.8 & 0.0 & 0.0 & 0.0 & 71.8 \\
\cline { 2 - 8 } & other materials & '000 PLZ & 153.4 & 0.0 & 61.4 & 61.4 & 245.7 \\
\hline \multirow{2}{*}{ Electricitv } & '000 PLZ & 102.4 & 0.0 & 0.0 & 0.0 & 102.4 \\
\hline \multirow{4}{*}{ Energy: } & coal & '000 PLZ & 86.2 & 0.0 & 0.0 & 0.0 & 86.2 \\
\cline { 2 - 8 } & oil & '000 PLZ & 14.4 & 0.0 & 0.0 & 0.0 & 14.4 \\
\cline { 2 - 8 } & naturalgas & '000 PLZ & 18.1 & 0.0 & 0.0 & 0.0 & 18.1 \\
\cline { 2 - 8 } & fuel & '000 PLZ & 61.3 & 0.0 & 0.0 & 0.0 & 61.3 \\
\cline { 2 - 8 } & water and sewege & '000 PLZ & 15.5 & 0.0 & 0.0 & 15.5 & 31.0 \\
\hline External services & '000 PLZ & 134.0 & 0.0 & 134.0 & 134.0 & 402.4 \\
\hline Labour & '000 PLZ & 0.0 & 0.0 & 575.6 & 0.0 & 575.6 \\
\hline Canital & '000 PLZ & 0.0 & 0.0 & 0.0 & 171.4 & 171.4 \\
\hline Other costs & '000 PLZ & 28.1 & 0.0 & 28.1 & 28.1 & 84.3 \\
\hline Total & '000 PLZ & 685.1 & 5937.5 & 799.1 & 410.5 & 7802.0 \\
\hline
\end{tabular}

Yoghurt (per 1000 tons of output)

A. Private costs

\begin{tabular}{|c|c|c|c|c|c|c|}
\hline Input & Unit & Tradables & F. milk & Labour & Capital & Total \\
\hline Row & & & & &
\end{tabular}

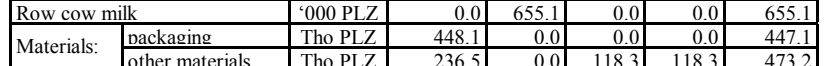

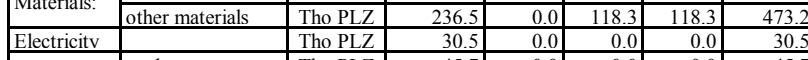

\begin{tabular}{|l|l|l|r|r|r|r|r|}
\hline Electricitv & & Tho PLZ & 30.5 & 0.0 & 0.0 & 0.0 & 30.5 \\
\hline \multirow{3}{*}{ Energy: } & coal & Tho PLZ & 45.7 & 0.0 & 0.0 & 0.0 & 45.7 \\
\cline { 2 - 7 } & oil & Tho PLZ & 10.8 & 0.0 & 0.0 & 0.0 & 10.8 \\
\cline { 2 - 8 } & Natural gas & Tho PLZ & 13.5 & 0.0 & 0.0 & 0.0 & 13.5 \\
\cline { 2 - 7 } & fl & & 0.0 & 0.0 & \\
\hline
\end{tabular}

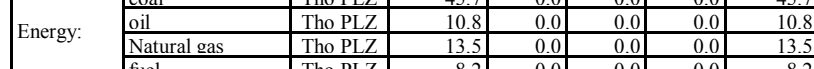

\begin{tabular}{|l|l|r|r|r|r|r|}
\hline fuel & Tho PLZ & 8.2 & 0.0 & 0.0 & 0.0 & 8.2 \\
\hline water and sewege & Tho PLZ & 4.8 & 0.0 & 0.0 & 4.8 & 9.7 \\
\hline
\end{tabular}

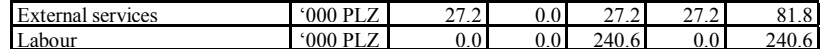

Labour

\begin{tabular}{ll} 
Canital \\
\hline Other costs \\
\hline Total
\end{tabular}

Other costs

'000 PLZ

'000 PLZ

\begin{tabular}{|r|r|r|r|r|r|}
\hline 000 PLZ & 0.0 & 0.0 & 0.0 & 211.3 & 211.3 \\
\hline 600 & 0.0 & 10.0 & 10.0 & 30.1 \\
\hline
\end{tabular}
B. Input prices

\begin{tabular}{|l|r|}
\hline \multicolumn{1}{|c|}{ Units } & \multicolumn{1}{c|}{ Prices } \\
\hline PLZ/T & 571.0 \\
\hline PLZ/Unit & 1.0 \\
\hline PLZ/Unit & 1.0 \\
\hline PLZ/MWh & 154.0 \\
\hline PLZ/T & 177.2 \\
\hline PLZ/T & 643.9 \\
\hline PLZ/m3 & 0.5 \\
\hline PLZ/T & 1100.0 \\
\hline PLZ/T & 1.0 \\
\hline PLZ/Unit & 1.0 \\
\hline PLZ/emnlovee & 19.2 \\
\hline PLZ/Unit & 1.0 \\
\hline PLZ/Unit & 1.0 \\
\hline
\end{tabular}

C. Input quantity

\begin{tabular}{|c|c|c|c|c|c|}
\hline Unit & Tradables & F. milk & Labour & Capital & Total \\
\hline
\end{tabular}

\begin{tabular}{|l|r|r|r|r|r|}
\hline Tons & 0.0 & 1000.0 & 0.0 & 0.0 & 1000.0 \\
\hline Thou units & 69.7 & 0.0 & 0.0 & 0.0 & 69.7 \\
\hline Thou units & 44.4 & 0.0 & 22.2 & 22.2 & 88.9 \\
\hline MWh & 85.7 & 0.0 & 0.0 & 0.0 & 85.7 \\
\hline Tons & 100.5 & 0.0 & 0.0 & 0.0 & 100.5 \\
\hline Tons & 5.9 & 0.0 & 0.0 & 0.0 & 5.9 \\
\hline Thou m3 & 8.9 & 0.0 & 0.0 & 0.0 & 8.9 \\
\hline Tons & 5.7 & 0.0 & 0.0 & 0.0 & 5.7 \\
\hline Thou tons & 2.2 & 0.0 & 0.0 & 2.2 & 4.3 \\
\hline Thou units & 21.2 & 0.0 & 21.2 & 21.2 & 63.6 \\
\hline Emnlovees & 0.0 & 0.0 & 7.1 & 0.0 & 7.1 \\
\hline Thou units & 0.0 & 0.0 & 0.0 & 42.3 & 42.3 \\
\hline Thou units & 4.7 & 0.0 & 4.7 & 4.7 & 14.0 \\
\hline
\end{tabular}

B. Input prices

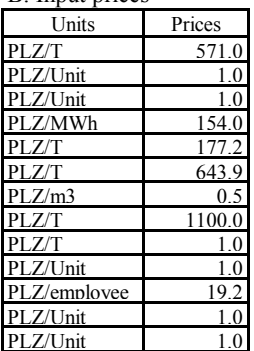

C. Inputs quantity

\begin{tabular}{|l|l|l|l|l|l|}
\hline Units & Tradables & F. milk & Labour & Capital & Total \\
\hline
\end{tabular}

\begin{tabular}{|l|r|r|r|r|r|}
\hline Tons & 0.0 & 6.4 & 0.0 & 0.0 & 6.4 \\
\hline Thou units & 51.9 & 0.0 & 0.0 & 0.0 & 51.9 \\
\hline
\end{tabular}

\begin{tabular}{|r|r|r|r|r|r|}
\hline Thou units & 81.0 & 0.0 & 46.9 & 46.9 & 187.5 \\
\hline
\end{tabular}

\begin{tabular}{|l|r|r|r|r|r|}
\hline MWh & 490.9 & 0.0 & 0.0 & 0.0 & 490.9 \\
\hline
\end{tabular}

\begin{tabular}{|l|r|r|r|r|r|}
\hline Tons & 606.6 & 0.0 & 0.0 & 0.0 & 606.6 \\
\hline Tons & 35.3 & 0.0 & 0.0 & 0.0 & 35.3 \\
\hline
\end{tabular}

\begin{tabular}{|l|r|r|r|r|r|}
\hline Thou m3 & 53.3 & 0.0 & 0.0 & 0.0 & 53.3 \\
\hline
\end{tabular}

\begin{tabular}{|l|r|r|r|r|r|}
\hline Tons & 36.0 & 0.0 & 0.0 & 0.0 & 36.0 \\
\hline Thou tons & 6.9 & 0.0 & 0.0 & 6.9 & 13.9 \\
\hline
\end{tabular}

\begin{tabular}{|r|r|r|r|r|r|}
\hline Thou units & 85.9 & 0.0 & 85.9 & 85.9 & 258.0 \\
\hline
\end{tabular}

\begin{tabular}{|c|r|r|r|r|r|}
\hline Thou units & 0.0 & 0.0 & 22.3 & 0.0 & 22.3 \\
\hline Then & 0.0 & 0.0 & 0.0 & 192.0 & 192.0 \\
\hline
\end{tabular}

\begin{tabular}{|l|r|r|r|r|r|}
\hline Thou units & 0.0 & 0.0 & 0.0 & 192.0 & 192.0 \\
\hline Thou units & 69.2 & 0.0 & 19.1 & 19.1 & 57.4 \\
\hline
\end{tabular}

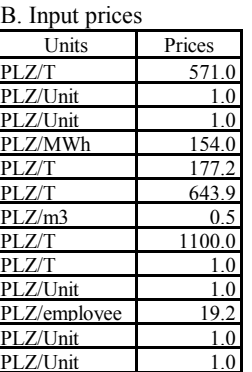

C. Inputs quantity

\begin{tabular}{|c|c|c|c|c|c|}
\hline Units & Tradables & F. milk & Labour & Capital & Total \\
\hline
\end{tabular}

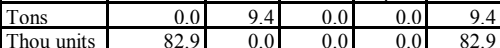

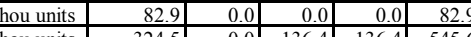
\begin{tabular}{|r|r|r|r|r|r|}
\hline Thou units & 324.5 & 0.0 & 136.4 & 136.4 & 545.6 \\
\hline
\end{tabular} \begin{tabular}{l|r|r|r|r|r|}
\hline MWh & 463.3 & 0.0 & 0.0 & 0.0 & 463.3 \\
\hline Tons & 542.4 & 0.0 & 0.0 & 0.0 & 542.4 \\
\hline
\end{tabular}

\begin{tabular}{l|r|r|r|r|r|}
\hline ons & 27.4 & 0.0 & 0.0 & 0.0 & 27.4 \\
\hline
\end{tabular}
\begin{tabular}{|l|r|r|r|r|r|}
\hline Thou m3 & 41.4 & 0.0 & 0.0 & 0.0 & 41.4 \\
\hline
\end{tabular} \begin{tabular}{|l|r|r|r|r|r|}
\hline Tons & 51.0 & 0.0 & 0.0 & 0.0 & 51.0 \\
\hline Thou tons & 17.8 & 0.0 & 0.0 & 17.8 & 35.7 \\
\hline
\end{tabular}

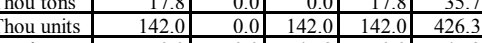
\begin{tabular}{|r|r|r|r|r|r|}
\hline Emblovees & 0.0 & 0.0 & 47.9 & 0.0 & 47.9 \\
\hline
\end{tabular} \begin{tabular}{|l|r|r|r|r|r|}
\hline Thou units & 0.0 & 0.0 & 0.0 & 183.9 & 183.9 \\
\hline Thou units & 28.9 & 0.0 & 28.9 & 28.9 & 86.7 \\
\hline
\end{tabular}

B.

B. Input prices
\begin{tabular}{|l|r|}
\hline \multicolumn{1}{|c|}{ Units } & Prices \\
\hline PLZ/T & 571.0 \\
\hline PLZ/Unit & 1.0 \\
\hline PLZ/Unit & 1.0 \\
\hline PLZ/MWh & 154.0 \\
\hline PLZ/T & 177.2 \\
\hline PLZ/T & 643.9 \\
\hline PLZ/m3 & 0.5 \\
\hline PLZ/T & 1100.0 \\
\hline PLZ/T & 1.0 \\
\hline PLZ/Unit & 1.0 \\
\hline PLZ/emnlovee & 19.2 \\
\hline PLZ/Unit & 1.0 \\
\hline PLZ/Unit & 1.0 \\
\hline
\end{tabular}

C. Inputs quantity

\begin{tabular}{|l|r|r|r|r|r|}
\hline Units & Tradables & F. milk & Labour & Capital & Total \\
\hline
\end{tabular}

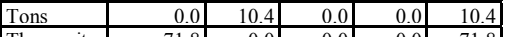

\begin{tabular}{|r|r|r|r|r|r|}
\hline Thou units & 71.8 & 0.0 & 0.0 & 0.0 & 71.8 \\
\hline
\end{tabular}

\begin{tabular}{|l|r|r|r|r|r|}
\hline Thou units & 153.4 & 0.0 & 61.4 & 61.4 & 245.7 \\
\hline MWh & 664.7 & 0.0 & 0.0 & 0.0 & 664.7 \\
\hline
\end{tabular}

\begin{tabular}{|l|r|r|r|r|r|}
\hline MWh & 664.7 & 0.0 & 0.0 & 0.0 & 664.7 \\
\hline Tons & 486.3 & 0.0 & 0.0 & 0.0 & 486.3 \\
\hline
\end{tabular}

\begin{tabular}{|l|r|r|r|r|r|}
\hline Tons & 486.3 & 0.0 & 0.0 & 0.0 & 486.3 \\
\hline Tons & 22.4 & 0.0 & 0.0 & 0.0 & 22.4 \\
\hline
\end{tabular}

\begin{tabular}{|l|r|r|r|r|r|}
\hline Thou m3 & 33.8 & 0.0 & 0.0 & 0.0 & 33.8 \\
\hline Tons & 55.8 & 0.0 & 0.0 & 0.0 & 55.8 \\
\hline
\end{tabular}

\begin{tabular}{|l|r|r|r|r|r|}
\hline Thou tons & 55.8 & 0.0 & 0.0 & 0.0 & 55.8 \\
\hline The & 15.5 & 0.0 & 0.0 & 15.5 & 31.0 \\
\hline
\end{tabular}

\begin{tabular}{|l|r|r|r|r|r|}
\hline Thou units & 134.0 & 0.0 & 134.0 & 134.0 & 402.4 \\
\hline
\end{tabular}

\begin{tabular}{|l|r|r|r|r|r|}
\hline Emnlovees & 0.0 & 0.0 & 29.9 & 0.0 & 29.9 \\
\hline Thou units & 0.0 & 0.0 & 0.0 & 171.4 & 171.4 \\
\hline
\end{tabular}

\begin{tabular}{|l|r|r|r|r|r|}
\hline Thou units & 0.0 & 0.0 & 0.0 & 171.4 & 171.4 \\
\hline Thou units & 28.1 & 0.0 & 28.1 & 28.1 & 84.3 \\
\hline
\end{tabular}

B. Input prices

C. Inputs quantity

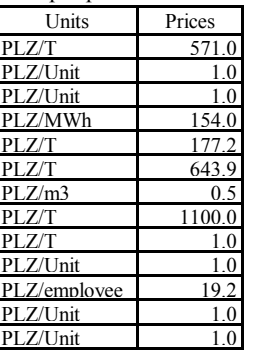

\begin{tabular}{|l|r|r|r|r|r|}
\hline Units & Tradables & F. milk & Labour & Capital & Total \\
\hline
\end{tabular}

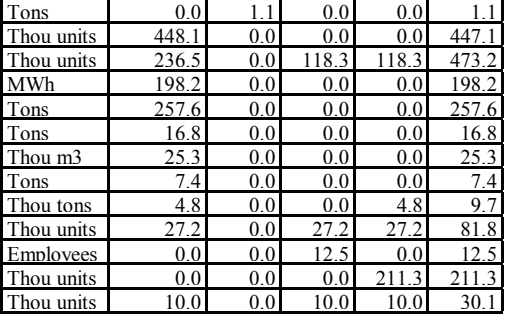

Thou units
Thou units 
Annex Table 13. Nominal, real and effective real exchange rates, Poland, 1993-1998 (1993=1)

\begin{tabular}{|c|c|c|c|c|c|c|c|}
\hline & 1993 & 1994 & 1995 & 1996 & 1997 & 1998 & $\begin{array}{c}\text { Average rate } \\
\text { of change, } \\
\text { per year } \\
\end{array}$ \\
\hline \multicolumn{8}{|c|}{ Nominal Exchange Rtaes } \\
\hline NER (PLZ/USD) & 1.00 & 1.25 & 1.78 & 1.98 & 2.41 & 2.56 & \\
\hline NER (PLZ/DM) & 1.00 & 1.28 & 1.93 & 2.05 & 2.16 & 2.38 & \\
\hline NER (PLZ/RUR) & 1.00 & 0.44 & 0.22 & 0.23 & 0.24 & 0.18 & \\
\hline NER (PLZ/Hrn) & 1.00 & 0.21 & 0.08 & 0.07 & 0.09 & 0.06 & \\
\hline \multicolumn{8}{|l|}{ Real Exchange Rates } \\
\hline RER (PLZ/USD) & 1.00 & 0.96 & 0.83 & 0.79 & 0.83 & 0.77 & $-4.8 \%$ \\
\hline RER (PLZ/DM) & 1.00 & 0.98 & 0.94 & 0.83 & 0.77 & 0.76 & $-5.3 \%$ \\
\hline RER (PLZ/RUR) & 1.00 & 1.32 & 1.53 & 2.01 & 2.03 & 1.51 & $10.9 \%$ \\
\hline RER (PLZ/Hrn) & 1.00 & 1.64 & 2.61 & 2.78 & 2.97 & 2.28 & $22.7 \%$ \\
\hline \multicolumn{8}{|c|}{ Effective Real Exchange Rtaes (1) } \\
\hline $\mathrm{ERER}_{\mathrm{T}}^{\mathrm{EX}}$ & 1.00 & 1.03 & 1.04 & 1.01 & 0.99 & 0.90 & $-2.1 \%$ \\
\hline $\mathrm{ERER}_{\mathrm{T}}^{\mathrm{IM}}$ & 1.00 & 1.00 & 0.96 & 0.91 & 0.89 & 0.82 & $-3.8 \%$ \\
\hline $\mathrm{ERER}_{\mathrm{F}}^{\mathrm{EX}}$ & 1.00 & 1.12 & 1.19 & 1.29 & 1.29 & 1.08 & $2.1 \%$ \\
\hline ERER $_{\mathrm{F}}{ }^{\mathrm{IM}}$ & 1.00 & 0.98 & 0.90 & 0.84 & 0.83 & 0.79 & $-4.7 \%$ \\
\hline $\mathrm{EREC}_{\mathrm{D}}^{\mathrm{EX}}$ & 1.00 & 1.07 & 1.10 & 1.15 & 1.17 & 1.00 & $0.3 \%$ \\
\hline $\mathrm{ERER}_{\mathrm{D}}{ }^{\mathrm{IM}}$ & 1.00 & 1.04 & 1.06 & 1.03 & 1.02 & 0.91 & $-1.7 \%$ \\
\hline \multicolumn{8}{|c|}{ Average for imports and exports (1) } \\
\hline ERER $_{T}$ & 1.00 & 1.02 & 1.00 & 0.96 & 0.94 & 0.86 & $-2.9 \%$ \\
\hline ERER $_{\mathrm{F}}$ & 1.00 & 1.05 & 1.05 & 1.06 & 1.06 & 0.93 & $-1.2 \%$ \\
\hline ERER $_{\mathrm{D}}$ & 1.00 & 1.06 & 1.08 & 1.09 & 1.09 & 0.96 & $-0.7 \%$ \\
\hline \multicolumn{8}{|l|}{ Trade weights in 1997} \\
\hline & \multicolumn{2}{|c|}{ Dairy (D) } & \multicolumn{2}{|c|}{ Agro-food (F) } & \multicolumn{2}{|c|}{ Total $(\mathrm{T})$} & \\
\hline & Exports & Imports & Exports & Imports & Exports & Imports & \\
\hline Russia & 0.183 & 0.084 & 0.279 & 0.012 & 0.084 & 0.063 & \\
\hline Ukraine & 0.063 & 0.057 & 0.071 & 0.007 & 0.047 & 0.010 & \\
\hline Germany & 0.065 & 0.292 & 0.182 & 0.144 & 0.329 & 0.242 & \\
\hline Other EU & 0.183 & 0.321 & 0.206 & 0.316 & 0.312 & 0.396 & \\
\hline Other & 0.506 & 0.246 & 0.262 & 0.522 & 0.228 & 0.289 & \\
\hline Total & 1.000 & 1.000 & 1.000 & 1.000 & 1.000 & 1.000 & \\
\hline
\end{tabular}


Annex Table 14. Producer prices of dairy products, 1993-1998 (PLZ/kg, in current prices).(1)

\begin{tabular}{|c|c|c|c|c|c|c|c|}
\hline Products & 1993 & 1994 & 1995 & 1996 & 1997 & 1998 & $\begin{array}{c}\text { Relative change } \\
1993=100\end{array}$ \\
\hline \multicolumn{8}{|l|}{ Milk } \\
\hline milk $2-2.5 \%$ & 0.36 & 0.43 & 0.67 & 0.76 & 0.83 & 0.89 & 247 \\
\hline milk 3-3.5\% & 0.42 & 0.50 & 0.78 & 0.86 & 0.91 & 0.97 & 231 \\
\hline UHT & 0.63 & 0.78 & 1.04 & 1.15 & 1.31 & 1.42 & 226 \\
\hline \multicolumn{8}{|l|}{ Milk powders } \\
\hline SMP & 2.30 & 3.24 & 4.75 & 5.01 & 5.19 & 4.77 & 207 \\
\hline WMP & 3.00 & 3.60 & 5.33 & 5.99 & 6.39 & 6.34 & 211 \\
\hline \multicolumn{8}{|l|}{ Fresh cheeses } \\
\hline fat & 2.36 & 2.95 & 4.31 & 5.06 & 5.58 & 5.97 & 252 \\
\hline medium -fat & 2.17 & 2.73 & 4.05 & 4.77 & 5.20 & 5.51 & 254 \\
\hline low-fat & 1.77 & 2.32 & 3.54 & 4.31 & 4.54 & 4.77 & 269 \\
\hline \multicolumn{8}{|l|}{ Ripening cheeses: } \\
\hline Gouda & 3.78 & 4.80 & 6.40 & 7.40 & 8.43 & 8.54 & 226 \\
\hline Edam & 3.72 & 4.61 & 6.37 & 7.27 & 8.32 & 8.48 & 228 \\
\hline Tylżycki & 3.59 & 4.52 & 6.30 & 7.05 & 8.29 & 8.80 & 245 \\
\hline Mazurski & 3.68 & 4.66 & 6.41 & 7.46 & 8.61 & 8.34 & 227 \\
\hline Puławski & 3.53 & 4.26 & 5.99 & 7.09 & 7.78 & 8.23 & 233 \\
\hline Fresh cheese & 2.11 & 2.58 & 3.48 & 4.34 & 4.83 & 5.01 & 237 \\
\hline Flavoured cheeses & 2.76 & 3.19 & 4.13 & 4.87 & 5.21 & 5.43 & 197 \\
\hline \multicolumn{8}{|l|}{ Cream } \\
\hline $30 \%$ fat & 1.98 & 2.48 & 2.98 & 3.51 & 3.98 & 4.18 & 212 \\
\hline $18 \%$ fat & 1.55 & 1.85 & 2.50 & 2.86 & 3.27 & 3.47 & 224 \\
\hline \multicolumn{8}{|l|}{ Butter } \\
\hline \multicolumn{8}{|l|}{ 'śmietankowe' } \\
\hline Yoghurt & 1.45 & 2.02 & 2.66 & 3.12 & 3.51 & 3.55 & 245 \\
\hline Kefir & 0.53 & 0.72 & 1.15 & 1.47 & 1.75 & 1.91 & 361 \\
\hline Casein & 4.75 & 7.05 & 11.09 & 10.58 & 11.25 & 12.86 & 271 \\
\hline \multicolumn{8}{|c|}{$\begin{array}{l}\text { (1) Prices exc. VAT. Based on questionnaire surveys by IERiGŻ conducted twice a year. Average yearly calculated on the } \\
\text { base of December and July prices as 'moving average' whereby weights used: } 0.25 \text { for previous year December and } \\
\text { current year December and } 0.5 \text { for current year July. }\end{array}$} \\
\hline Source: IERiGŻ (19 & $\mathrm{ca}$ & & & & & & \\
\hline
\end{tabular}


Annex Table 15. Data and assumptions used in the estimations of social prices for tradables: taxes, subsidies and transport costs.

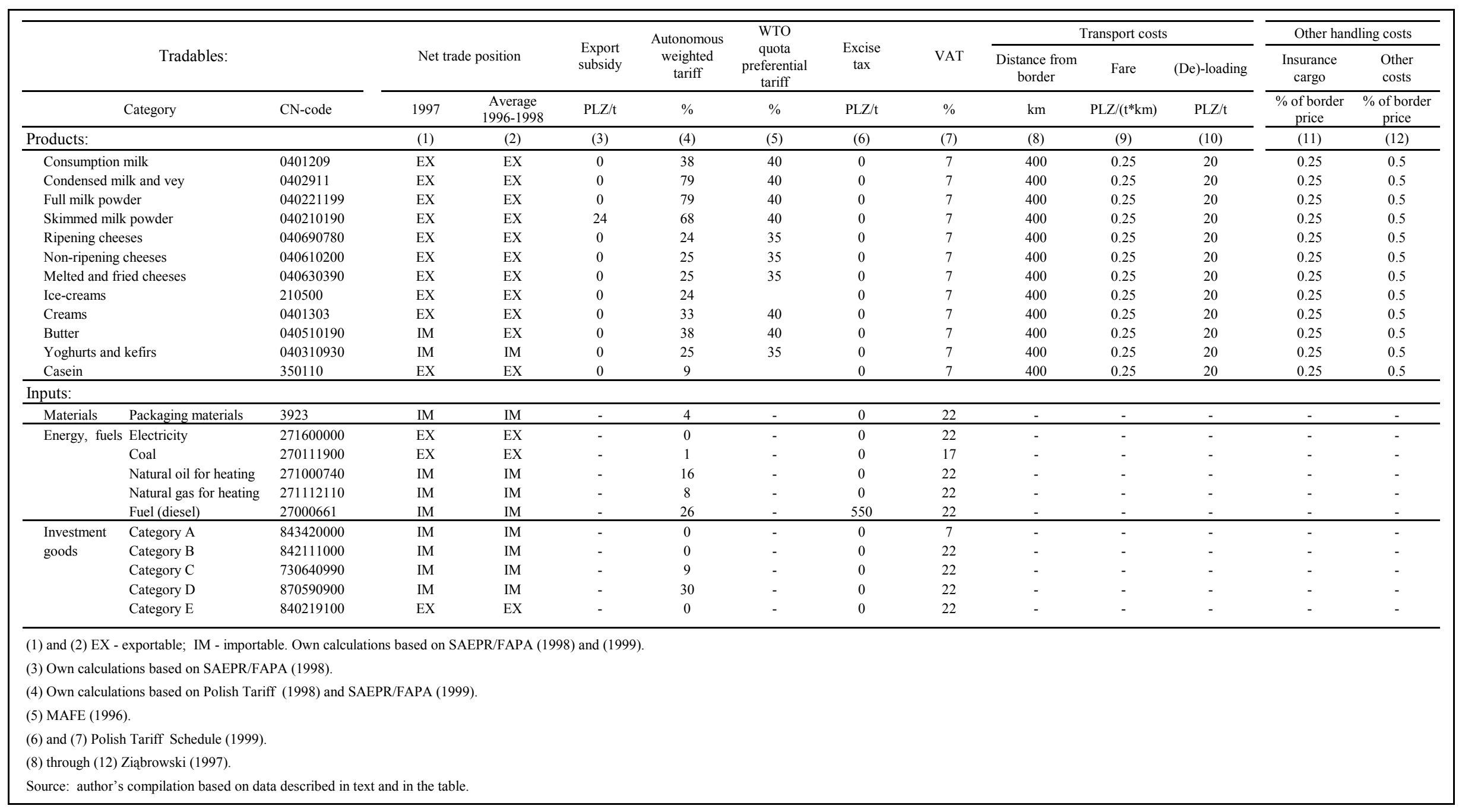


Annex Table 16. Data used in the estimation of social values for tradables: unit values in the trade for representative dairy commodities.

\begin{tabular}{|c|c|c|c|c|c|c|c|c|c|c|c|c|c|c|c|}
\hline \multirow{4}{*}{$\begin{array}{l}\text { Commodity } \\
\text { and } C N \text { code }\end{array}$} & \multirow{4}{*}{ Year (1) } & \multicolumn{4}{|c|}{ Total } & \multicolumn{4}{|c|}{ FSU } & \multicolumn{4}{|c|}{$\mathrm{EU}$} & \multirow{4}{*}{$\begin{array}{c}\text { FSU } \\
\text { share of } \\
\text { Polish } \\
\text { exports }\end{array}$} & \multirow{4}{*}{$\begin{array}{c}\text { EU } \\
\text { share of } \\
\text { Polish } \\
\text { imports }\end{array}$} \\
\hline & & \multicolumn{2}{|c|}{ Exports } & \multicolumn{2}{|c|}{ Imports } & \multicolumn{2}{|c|}{ Exports } & \multicolumn{2}{|c|}{ Imports } & \multicolumn{2}{|c|}{ Exports } & \multicolumn{2}{|c|}{ Imports } & & \\
\hline & & Value & $\begin{array}{c}\text { Unit } \\
\text { value }\end{array}$ & Value & $\begin{array}{c}\text { Unit } \\
\text { value }\end{array}$ & Value & $\begin{array}{c}\text { Unit } \\
\text { value }\end{array}$ & Value & $\begin{array}{c}\text { Unit } \\
\text { value }\end{array}$ & Value & $\begin{array}{c}\text { Unit } \\
\text { value }\end{array}$ & Value & $\begin{array}{c}\text { Unit } \\
\text { value }\end{array}$ & & \\
\hline & & Mio USD & $\mathrm{USD} / \mathrm{kg}$ & Mio USD & $\mathrm{USD} / \mathrm{kg}$ & Mio USD & USD $/ \mathrm{kg}$ & Mio USD & USD $/ \mathrm{kg}$ & Mio USD & USD $/ \mathrm{kg}$ & Mio USD & USD $/ \mathrm{kg}$ & & \\
\hline Liquid milk & 1997 & 0.66 & 0.50 & 0.03 & 0.69 & 0.55 & 0.51 & 0.00 & - & 0.05 & 0.31 & 0.03 & 0.70 & $83 \%$ & $99 \%$ \\
\hline 0401209 & 1996-1998 & 1.44 & 0.54 & 0.07 & 0.64 & 1.11 & 0.53 & 0.00 & - & 0.08 & 0.43 & 0.07 & 0.64 & $77 \%$ & $99 \%$ \\
\hline Concentrated milk & 1997 & 2.95 & 1.13 & 0.81 & 1.68 & 0.07 & 1.52 & 0.00 & - & 0.01 & 2.00 & 0.81 & 1.68 & $2 \%$ & $100 \%$ \\
\hline 0401303 & 1996-1998 & 3.35 & 1.19 & 2.66 & 1.78 & 0.13 & 1.53 & 0.00 & - & 0.02 & 1.98 & 2.66 & 1.78 & $4 \%$ & $100 \%$ \\
\hline 040210190 & 1996-1998 & 442.50 & 1.57 & 25.36 & 1.29 & 2.28 & 1.68 & 22.57 & 1.26 & 160.66 & 1.56 & 0.94 & 1.63 & $1 \%$ & $4 \%$ \\
\hline Skimmed milk powder & 1997 & 2.79 & 1.85 & 0.26 & 2.10 & 0.28 & 2.04 & 0.05 & 3.50 & 2.24 & 1.84 & 0.21 & 1.92 & $10 \%$ & $81 \%$ \\
\hline 040221199 & 1996-1998 & 7.12 & 1.86 & 0.56 & 1.92 & 2.64 & 1.88 & 0.05 & - & 3.17 & 1.88 & 0.51 & 1.84 & $37 \%$ & $91 \%$ \\
\hline Condensed milk & 1998 & 0.17 & 0.76 & 0.10 & 0.93 & 0.17 & 0.75 & 0.00 & - & 0.00 & 1.98 & 0.10 & 0.93 & $97 \%$ & $100 \%$ \\
\hline 0402991 & 1996-1998 & 0.64 & 0.94 & 0.11 & 1.13 & 0.56 & 0.97 & 0.00 & - & 0.00 & 2.08 & 0.11 & 1.07 & $87 \%$ & $99 \%$ \\
\hline Yoghurt & 1997 & 1.21 & 0.75 & 3.84 & 0.83 & 1.20 & 0.75 & 0.00 & 1.42 & 0.00 & 1.10 & 3.81 & 0.83 & $99 \%$ & $99 \%$ \\
\hline 040310930 & 1996-1998 & 6.29 & 0.87 & 39.41 & 0.92 & 5.12 & 0.83 & 0.00 & - & 0.00 & 1.25 & 39.32 & 0.92 & $81 \%$ & $100 \%$ \\
\hline Kefir and milk drinks & 1997 & 0.05 & 1.08 & 0.86 & 1.00 & 0.05 & 1.07 & 0.00 & - & 0.00 & 1.98 & 0.86 & 1.00 & $99 \%$ & $100 \%$ \\
\hline 40390910 & 1996-1998 & 2.13 & 0.97 & 3.80 & 1.02 & 2.12 & 0.97 & 0.00 & - & 0.00 & 1.79 & 3.80 & 1.02 & $100 \%$ & $100 \%$ \\
\hline Fresh cheese & 1997 & 7.64 & 1.13 & 4.88 & 1.70 & 3.36 & 1.20 & 0.00 & - & 0.02 & 1.08 & 4.59 & 1.66 & $44 \%$ & $94 \%$ \\
\hline 040610200 & 1996-1998 & 24.09 & 1.14 & 14.57 & 1.60 & 9.84 & 1.20 & 0.03 & - & 0.04 & 1.16 & 14.13 & 1.58 & $41 \%$ & $97 \%$ \\
\hline Processed (melted) cheeses & 1997 & 4.22 & 2.90 & 5.55 & 2.85 & 2.51 & 2.80 & 0.00 & - & 0.00 & 4.71 & 5.28 & 2.89 & $60 \%$ & $95 \%$ \\
\hline 040630390 & 1996-1998 & 10.62 & 2.86 & 11.41 & 3.03 & 7.00 & 2.76 & 0.00 & - & 0.00 & 5.44 & 11.14 & 3.05 & $66 \%$ & $98 \%$ \\
\hline Ripening cheeses & 1997 & 6.13 & 2.60 & 0.55 & 3.77 & 5.63 & 2.61 & 0.00 & - & 0.28 & 2.35 & 0.52 & 4.02 & $92 \%$ & $94 \%$ \\
\hline 040690780 & 1996-1998 & 15.66 & 2.59 & 1.63 & 3.97 & 13.42 & 2.59 & 0.00 & - & 1.29 & 2.52 & 1.60 & 4.06 & $86 \%$ & $98 \%$ \\
\hline Ice-creams & 1997 & 43.00 & 1.89 & 4.20 & 2.10 & n.a. & n.a. & n.a. & n.a. & n.a. & n.a. & n.a. & n.a. & n.a. & n.a. \\
\hline 210500 & 1996-1998 & 111.50 & 1.83 & 11.60 & 2.18 & n.a. & n.a. & n.a. & n.a. & n.a. & n.a. & n.a. & n.a. & n.a. & n.a. \\
\hline Casein & 1997 & 20.90 & 3.31 & 22.80 & 3.26 & n.a. & n.a. & n.a. & n.a. & n.a. & n.a. & n.a. & n.a. & n.a. & n.a. \\
\hline 350110 & 1996-1998 & 85.80 & 3.57 & 84.40 & 3.33 & n.a. & n.a. & n.a. & n.a. & n.a. & n.a. & n.a. & n.a. & n.a. & n.a. \\
\hline
\end{tabular}


Annex Table 17. Estimation of implicit prices of fat and non-fat components of farm milk, example of Polish market prices in the years 1995-1997 and alternative processing costs.

\begin{tabular}{|c|c|c|c|c|c|c|}
\hline Steps of the estimation procedure & Products & Units & 1995 & 1996 & 1997 & Notes \\
\hline \multirow[t]{3}{*}{ A. Prices } & Milk & $\mathrm{PLZ} / \mathrm{T}$ & 432 & 501 & 571 & (1) \\
\hline & Butter & $\mathrm{PLZ} / \mathrm{kg}$ & 5151 & 5794 & 7176 & (2) \\
\hline & SMP & $\mathrm{PLZ} / \mathrm{kg}$ & 4745 & 5005 & 5188 & (3) \\
\hline \multirow[t]{2}{*}{$\begin{array}{l}\text { B. Quantities of butter and SMP produced } \\
\text { from } 1000 \mathrm{~kg} \text { of milk }\end{array}$} & Butter & $\mathrm{kg}$ & 43.5 & 43.5 & 43.5 & (4) \\
\hline & SMP & $\mathrm{kg}$ & 81.2 & 81.2 & 81.2 & (5) \\
\hline \multirow{2}{*}{$\begin{array}{l}\text { C. Revenue from butter and SM per one Ton } \\
\text { of milk processed }\end{array}$} & Butter & PLZ & 224 & 252 & 312 & (6) \\
\hline & SMP & PLZ & 385 & 406 & 421 & (7) \\
\hline \multirow{7}{*}{$\begin{array}{l}\text { D. Processing margins per one ton of } \\
\text { processed milk }\end{array}$} & \multicolumn{5}{|c|}{ Actual margin } & \\
\hline & Total & PLZ & 177 & 157 & 162 & (8) \\
\hline & Butter & PLZ & 63 & 56 & 58 & (9) \\
\hline & SMP & PLZ & 113 & 101 & 104 & (10) \\
\hline & \multicolumn{5}{|l|}{$E U$ margin } & \\
\hline & Butter & PLZ & 35 & 38 & 41 & (11) \\
\hline & SMP & PLZ & 61 & 66 & 72 & (12) \\
\hline \multirow{6}{*}{$\begin{array}{l}\text { E. Milk value in butter and SMP obtained } \\
\text { from one Ton of milk processed }\end{array}$} & \multicolumn{5}{|c|}{ Actual margin } & \\
\hline & Butter & PLZ & 160 & 196 & 254 & (13) \\
\hline & SMP & PLZ & 272 & 306 & 317 & (14) \\
\hline & \multicolumn{5}{|l|}{$E U$ margin } & \\
\hline & Butter & PLZ & 189 & 214 & 271 & (15) \\
\hline & SMP & PLZ & 324 & 341 & 349 & (16) \\
\hline \multirow{6}{*}{$\begin{array}{l}\text { F. Implicit prices of fat and non-fat milk } \\
\text { components }\end{array}$} & \multicolumn{5}{|c|}{ Actual margin } & \\
\hline & Fat & PLZ/Unit & 0.043 & 0.053 & 0.068 & (17) \\
\hline & Non-fat & PLZ/Unit & 0.283 & 0.319 & 0.330 & (18) \\
\hline & \multicolumn{5}{|l|}{$E U$ margin } & \\
\hline & Fat & PLZ/Unit & 0.051 & 0.058 & 0.073 & (19) \\
\hline & Non-fat & PLZ/Unit & 0.338 & 0.355 & 0.363 & (20) \\
\hline
\end{tabular}

A. (1) to (3) - the prices on the Polish market are taken from IERIGŻ (1999).

(4) and (5) - the quantities of butter and SMP, are calculated from the content of fat and non-fat units per kg of a product. The values taken from Bazydlo and Sokolowski (1999) are:

- farm milk: 3.700 fat units and 0.963 non-fat units;

- butter: 84.023 fat units and 0.260 non-fat units;

- SMP: 0.586 fat units and 11.721 non-fat units.

C. (6) and (7) - the revenues from butter and SMP, are calculated from prices and volumes, i.e. $(6)=(4) *(2)$ and $(7)=(5) *(3)$

(8) the total actual processing margin is calculated as a difference between the revenue from butter and SMP and farm milk cost, i.e.

$(8)=(6)+(7)-(1)$

(9) and (10) - the product-specific costs are obtained by splitting the total costs (8) using the information on unit processing costs in production of butter and SMP quoted by Bazydlo and Sokolowski (1999).

(11) and (12) - EU processing costs are calculated as a product of volumes (4) and (5) and unit processing costs used in the calculation of Intervention Milk Price Equivalent quoted in Agra-Europe (1999).

E. (13) to(16) - milk values of butter and SMP, are defined as the difference between product specific revenues (6) and (7) and the corresponding product specific processing costs (9) to (12).

F. (17) to (20) - implicit prices for fat and non-fat are calculated from: i) milk value of butter and SMP, (13) to (16), ii) quantities of butter and SMP obtained from the unit of milk, (4) and (5), and iii) product-specific contents of fat and non-fat components (see note to step C). The milk values of butter (13) and SMP (14) must equal the sum of fat and non-fat values. The (17) and (18) are two unknowns in the system of two equations:

$(13)=(17) *(4) * 84.023+(18) *(4) * 0.260$

$(14)=(17) *(5) * 0.586+(18) *(5) * 11.721$

For the case of EU processing costs (19) and (20) are calculated from the following system of two equations:

$(15)=(19) *(4) * 84.023+(20) *(4) * 0.260$

$(16)=(19) *(5) * 0.586+(20) *(5) * 11.721$

Source: author's estimations based on methods described in Bazydło and Sokołowski (1999) and Krell et al. (1997). 
Annex Table 18. Costs of direct capital in milk processing industry, Poland, 1993-1997.

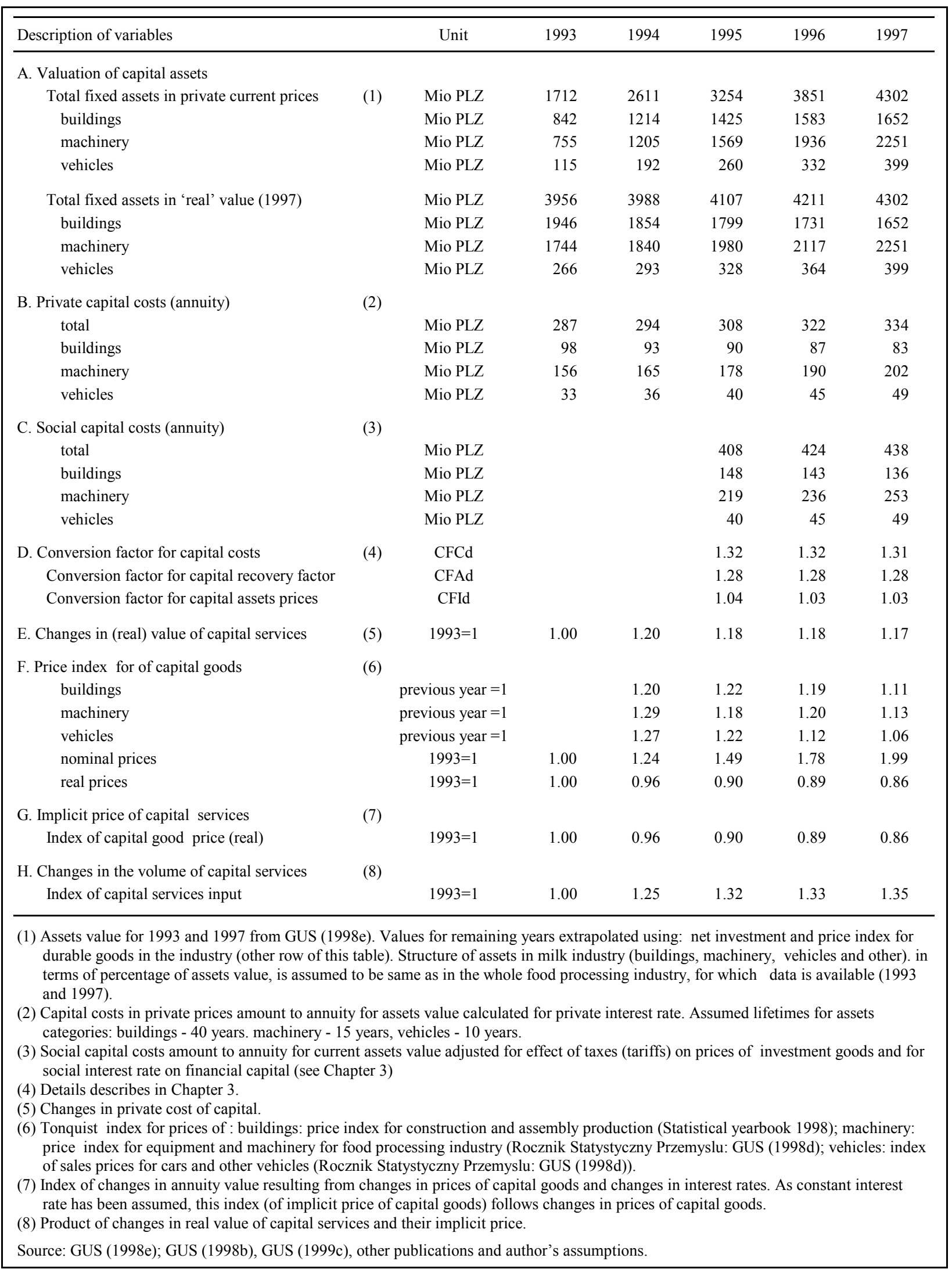


Annex Table 19. Hypothesised effects of economies of rapid growth on the desired product structure of the industry, stylised representation based on production-possibility curve.

\section{OTHER DAIRY PRODUCTS}

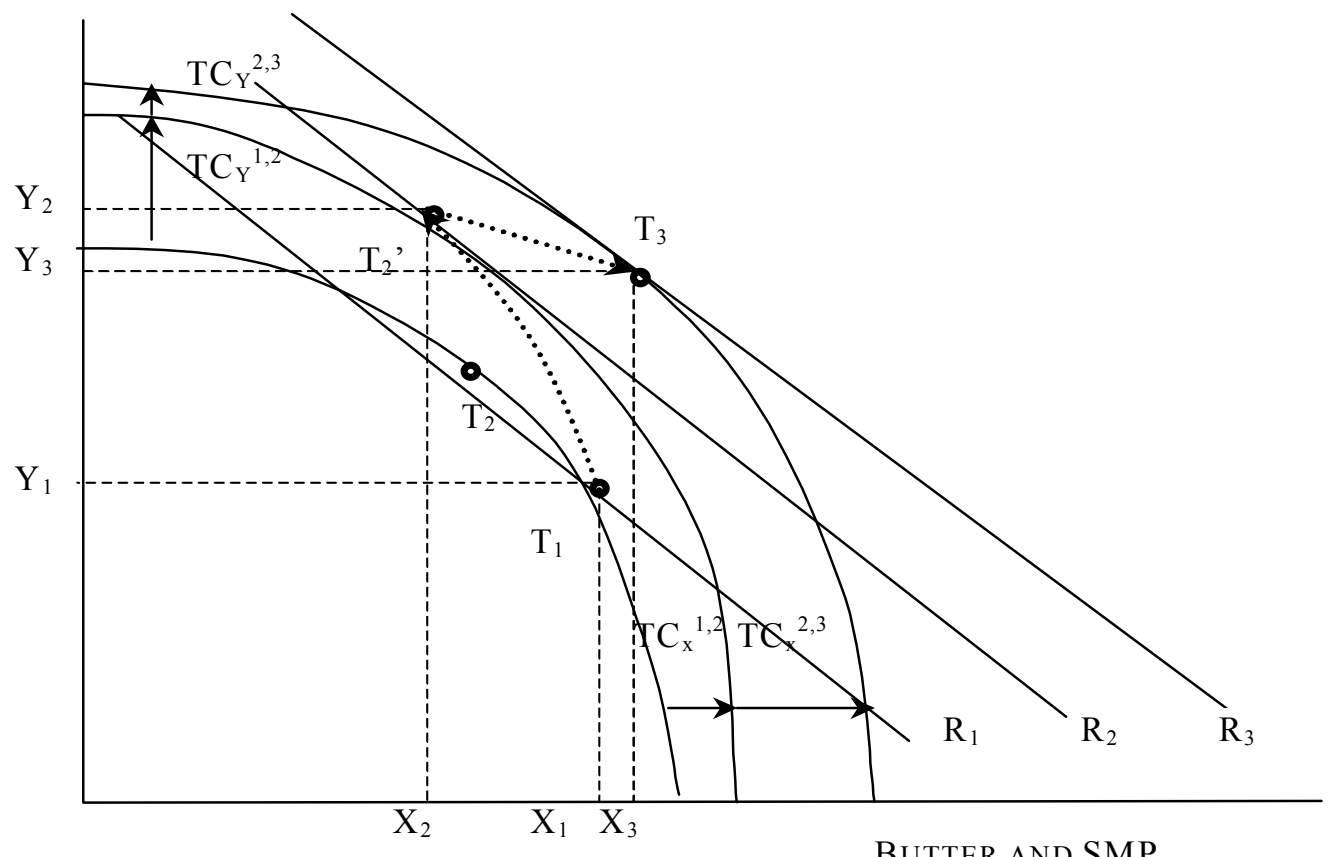

BUTTER AND SMP

Notation: 1, 2,3 - superscripts denoting time of observation

$\mathrm{X}$ - quantities of "Butter and SMP"

$\mathrm{Y}$ - quantities of "Other dairy products"

$\mathrm{R}$ - isorevenue curves

$\mathrm{T}$ - combinations of two products in the industry output

$\mathrm{TC}_{\mathrm{y}}{ }^{1.2}$ - technical change realised between time 1 to 2 in 'Other dairy products'

$\mathrm{TC}_{\mathrm{x}}{ }^{1.2}$ - technical change realised between time 1 and 2 in 'Butter and SMP'

By economies of rapid growth are meant here the gains in input productivity (and unit costs reductions) resulting from technological change, which accompany the expansion of an activity (e.g. induced by the initial change in the relative prices). This change in productivity are fostered by rapid growth because new investments are inherently related with more productive technology. At the same time declining activities (here, for simplicity, butter and SMP) attract few new investments and hence experience limited technological change and input productivity. This is, however, a temporary situation since in the longer-run the scope for technological change will also be exploited in the "declining" activities. During the time of adjustment of product structure, however, the output of expanding activities (here, other dairy products) may overshoot the long-run equilibrium level. At the initial technology the relative prices (reflecting here relative profitability) would suggest that the industry would reach the equilibrium in point $T_{2}$. With the technological change biased in favour of expanding activities, the equilibrium moves to $T_{2}$ '. However in the longer run the technological change will also ultimately be realised in the declining activities, which shifts the equilibrium to the point $T_{3}$. The deviation of the $T_{2}$ ' from the $T_{3}$ may e.g. depend on the i) scope for technological change and ii) the constraints on the financing, which postpone the time when technical change will be realised in the declining activities.

Source: author's compilation based on discussion presented in the text. 
ANNEX IV: ANNEX TABLES TO CHAPTER 4 
Annex Table 20. Development of selected macroeconomic variables of Polish economy, 1990-1998.

\begin{tabular}{|c|c|c|c|c|c|c|c|c|c|c|}
\hline Variables & Units & 1990 & 1991 & 1992 & 1993 & 1994 & 1995 & 1996 & 1997 & 1998 \\
\hline \multirow[t]{2}{*}{ GDP } & $1990=100$ & 100.0 & 93.0 & 95.4 & 99.0 & 104.1 & 111.4 & 118.1 & 126.1 & 132.2 \\
\hline & Rate of change in $\%$ & & -7.0 & 2.6 & 3.8 & 5.2 & 7.0 & 6.0 & 6.8 & 4.8 \\
\hline Gross capital formation & $\%$ share of GDP & 25.6 & 19.9 & 15.2 & 15.6 & 15.9 & 19.8 & 21.9 & 24.7 & 26.4 \\
\hline Gross investment outlets & $1990=100$ & 100 & 97 & 96 & 98 & 105 & 123 & 147 & 179 & 206 \\
\hline Gross value of fixed assets & $1990=100$ & 100 & 101 & 102 & 104 & 106 & 109 & 114 & 118 & 123 \\
\hline Exports & $1990=100$ & 100 & 138 & 157 & 186 & 211 & 254 & 325 & 397 & 452 \\
\hline Imports & $1990=100$ & 100 & 98 & 95 & 94 & 111 & 129 & 142 & 161 & 176 \\
\hline $\begin{array}{l}\text { Share of tradables in } \\
\text { Gross Value Added }\end{array}$ & \multicolumn{3}{|c|}{$\begin{array}{l}\text { VA in manufacturing, maining and } \\
\text { agriculture per total value added }\end{array}$} & 39 & 39 & 39 & 35 & 33 & 32 & 29 \\
\hline Propensity to trade & \multicolumn{2}{|c|}{$\begin{array}{l}\text { (Imports+Exports)/ } \\
\text { Gross output of tradables }\end{array}$} & & 37 & 41 & 44 & 46 & 50 & 57 & 61 \\
\hline Current account & Mio USD & & & & & & 5455 & -1352 & -4312 & -6858 \\
\hline Direct foreign investment (net) & Mio USD & & & & & & 1134 & 2741 & 3041 & 4966 \\
\hline Portfolio foreign investemnt (net) & Mio USD & & & & & & 1171 & 241 & 2098 & 1330 \\
\hline $\begin{array}{l}\left.\operatorname{RER}^{(2)}\right)_{\text {PLZ/USD }}= \\
\text { NERRLZ/USD }^{*}\left(\mathrm{PPI}_{\text {US }} / \mathrm{CPI}_{\mathrm{Pol}}\right)\end{array}$ & $1990=100$ & 100 & 66 & 60 & 60 & 57 & 49 & 47 & 50 & 46 \\
\hline $\mathrm{RER}^{(2)}{ }_{\mathrm{PLZ} / \mathrm{DM}}=\mathrm{NER}_{\mathrm{PLZ} / \mathrm{DM}} *\left(\mathrm{PPI}_{\mathrm{Ger}} / \mathrm{CPI}_{\mathrm{Pol}}\right)$ & $1990=100$ & 100 & 65 & 64 & 59 & 58 & 56 & 49 & 45 & 45 \\
\hline $\mathrm{RER}^{(1)}{ }_{\mathrm{Pol}}=\mathrm{PPI}_{\mathrm{Pol}} / \mathrm{CPI}_{\mathrm{Pol}}$ & $1990=100$ & 100 & 83 & 78 & 76 & 72 & 71 & 66 & 65 & 62 \\
\hline CPI & Rate of change in $\%$ & & 70.3 & 42.3 & 35.3 & 32.2 & 27.8 & 19.9 & 14.9 & 11.8 \\
\hline GDP Price Index & Rate of change in $\%$ & & 55.3 & 38.5 & 30.5 & 28.4 & 27.9 & 18.7 & 14.0 & 11.7 \\
\hline PPI manufacturing & Rate of change in $\%$ & & 40.9 & 34.5 & 31.9 & 25.3 & 25.4 & 12.4 & 12.2 & 7.3 \\
\hline \multirow[t]{2}{*}{ Net real wage } & $1990=100$ & 100 & 99.7 & 97 & 94.2 & 94.6 & 97.4 & 103 & 110.5 & 115.4 \\
\hline & Rate of change in $\%$ & & -0.3 & -2.7 & -2.9 & 0.4 & 3.0 & 5.7 & 7.3 & 4.4 \\
\hline \multirow[t]{2}{*}{ Employment } & ‘000 & 16280 & 15326 & 14677 & 14330 & 14475 & 14735 & 15021 & 15439 & 15800 \\
\hline & $1990=100$ & 100.0 & 94.1 & 90.2 & 88.0 & 88.9 & 90.5 & 92.3 & 94.8 & 97.1 \\
\hline Unemployment rate & Percentage & 6.5 & 12.2 & 14.3 & 16.4 & 16 & 14.9 & 13.2 & 10.3 & 10.4 \\
\hline \multirow[t]{2}{*}{ GDP/employee } & $1990=100$ & 100.0 & 98.8 & 105.8 & 112.5 & 117.1 & 123.1 & 128.0 & 133.0 & 136.2 \\
\hline & & & -1.2 & 7.1 & 6.3 & 4.1 & 5.1 & 4.0 & 3.9 & 2.4 \\
\hline
\end{tabular}




\section{Annex Table 21. Deriving the Relation Between GDP Growth and the Change in the RER ${ }^{(1)}$}

Kravis and Lipsey (1988) have used the following structural relationship in their empirical studies on determination of domestic price level with cross-country data: $\mathrm{PL}=\mathrm{a}+\mathrm{b} * \mathrm{R}+\mathrm{c} * \mathrm{OP}+\mathrm{d}^{*} \mathrm{SN}$, where: $\mathrm{PL}$ is a price level, the dependent variable, defined as the ratio of the PPP of a currency to its NER, both taken relative to USD as the numeraire currency; $\mathrm{R}$ is real GDP per capita; OP is openness of the economy measured by the exports plus imports divided by GDP (or by output of tradables); SN is the share of nontradables in the final expenditure on GDP; a,b,c,d are estimated coefficients.

The rationale underlying this model can be summarised as follows: international price comparisons suggest that the law of one price, which gave rise to the PPP theory, only holds for the tradable goods, while the prices of non-tradables are determined domestically and differ substantially among countries. Real per capita income level (R) is expected to be a predominant factor because it determines the demand side of the market for nontradables $^{(2)}$ as well as the labour costs in their production (and hence total costs and supply schedule) ${ }^{(3)}-$ both resulting in a positive relationship between the income level and i) price level for non-tradables and ii) the general price level. Countries may, however, even differ in terms of the level of tradable prices because of different propensity to trade (OP), which pulls a country's prices towards the world average - upward for poor countries and downward for rich countries, whereby trade not only directly affects the prices of tradables but also affects the prices of non-tradables by tending to raise the prices of relatively abundant factors (e.g. labour in poor country) and lowering the prices of those which are relatively scarce (e.g. labour in rich countries). Moreover general price levels of two countries with the same prices of both tradables and non-tradables may differ due to the differences in their shares in the GDP (SN) (weights in GDP price index).

Empirical results have shown that the above outlined model is able to explain up to $80 \%$ of observed variations in the national price levels and that structural parameters also hold true for the changes of the PL over

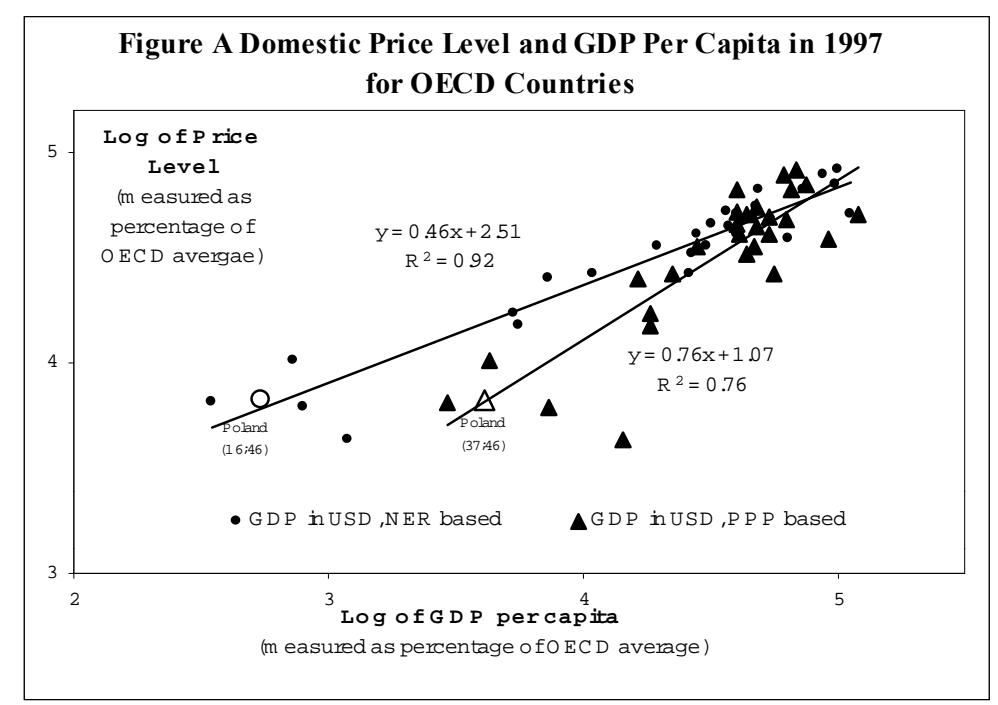
time. At the same time the values and degree of significance of estimated coefficients vary among various country samples and over time. For countries with a similar level of openness, shares of non-tradables in GDP and similarities in terms of institutional conditions, the income level is the major factor responsible for the cross-country price level differences and price level increases over time.

According to these rationales, future development of Poland's price level and hence the real exchange rate should mainly be determined by the changes in GDP/capita and the functional relationship between the two should be approximated by the relationship derived from a cross-sectional analysis of countries similar in terms of the 'non-income' determinants of domestic price level. For this purpose the group of OECD countries seems to be well suited. The simple statistical exercise conducted here consists of regressing the price levels (PL) on GDP 
per capita in 1997 in 29 OECD countries. Both variables are defined as in the Kravis and Lipsey (1988) studies, i.e. PL is the ratio of PPP to NER, while GDP per capita is expressed in real terms (measured by PPP exchange rate) or in nominal value USD-denominated (i.e. using NER), both relative to the average for OECD countries, which here represent a numeraire 'country'. Moreover, both variables are used in the logarithmic form, which provides for a useful property of the reaction coefficients - rates of growth in price level are proportionally linked with the rates of changes in GDP per capita (elasticity of price level with respect to income level) (Figure A). It is significant that, for the 'forecasting' purpose of the estimated coefficients the importance of the omission of other variables is diminished since it can be argued that they are related with the GDP level in a systematic way (openness and trade dependence and the share of non-tradables in the GDP tend to increase with the increase in GDP).

Although the estimates are constructed with the data on relative levels of GDP and prices they hold true for the absolute changes in the GDP over time. For example, to arrive at the temporal changes in the price level relative to the OECD average (rate of convergence of NER to PPP) one needs to use the relative growth rates (because with the growth rates in OECD countries their price level increases, thus diminishing dollar purchasing power and Polish PPP). In turn, by applying the coefficient for the absolute rate of growth one obtains a change in the domestic price level or relative to the OECD level in the base year i.e. 1997.

In the next step the same relation has been estimated for the available (unfortunately short) time series data for Poland covering years 1993-1998. The data used pertains to the changes in the real GDP relative to the OECD (i.e. moving) average since PPP exchange rates specific for each year are used. The same is, hence, true for the price levels. The changes in the GDP in USD terms are made relative to the (moving) OECD average too.

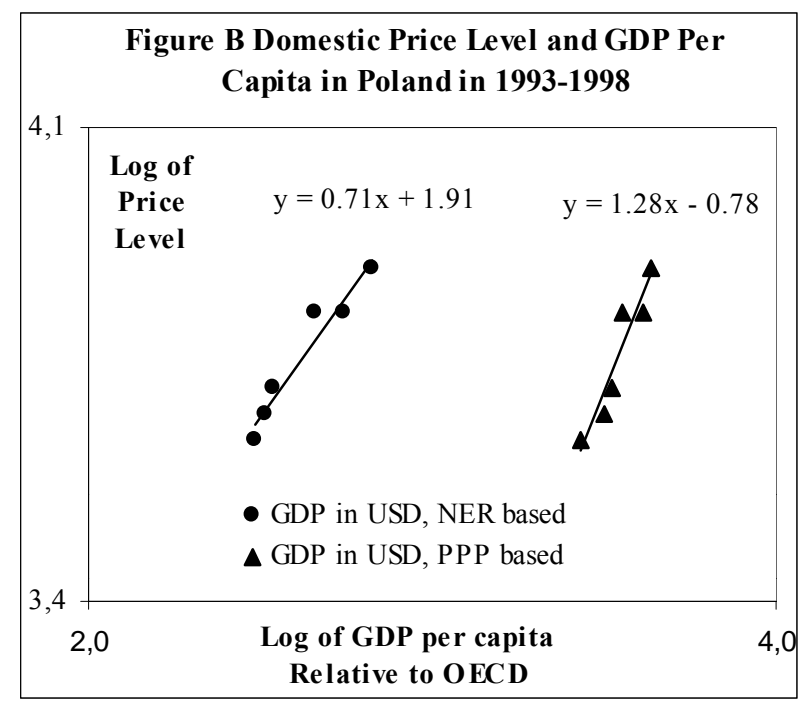

The next question concerns the interpretation of the differences between the coefficients derived from cross-sectional (cross-country) data and those for the most recent time series in Poland (Figure B). In general, these differences are consistent with the above outlined theory. Namely, the high rates of price increases in Poland have been experienced during the period characterised by: i) an increasing degree of openness of the economy (e.g. the variable $\mathrm{OP}$ - ratio of trade value to the value of tradables domestically produced increased from 0.37 to 0.61 between 1992 and 1998); ii) the increasing share of tradables in the GDP (the share of manufacturing and agriculture in the GDP declined from $39 \%$ in 1992 to $29 \%$ in 1998) (see Annex Table 20), and iii) possible increases in the general quality of products that may have found reflection in higher prices. Thus, the detected magnitude of the price pulling effect of these factors may have been temporary, specific to the economic transition and, hence, diminishing in the long term (future).

The last problem related with quantifying the relation between the growth rate and the RER is the link between the domestic price level PL and alternative indices of RER used in temporal analysis. The general rule is that the inter-temporal index of PL (RER(3)) and the RER are reciprocals, provided that the same price indices 
are used in constructing the two measures (Kravis and Lipsey, 1988). Since the PL used in estimates are based on the GDP basket of domestic goods and services the RER(1) and RER(2) with GDP price index in the denominator are the adequate indices.

Taking the relations between the PL and RER indices for the years 1993-1998, one arrives at the following results (Figure C): the RER(1) indices yield lower reaction coefficients (in terms of absolute value) compared to

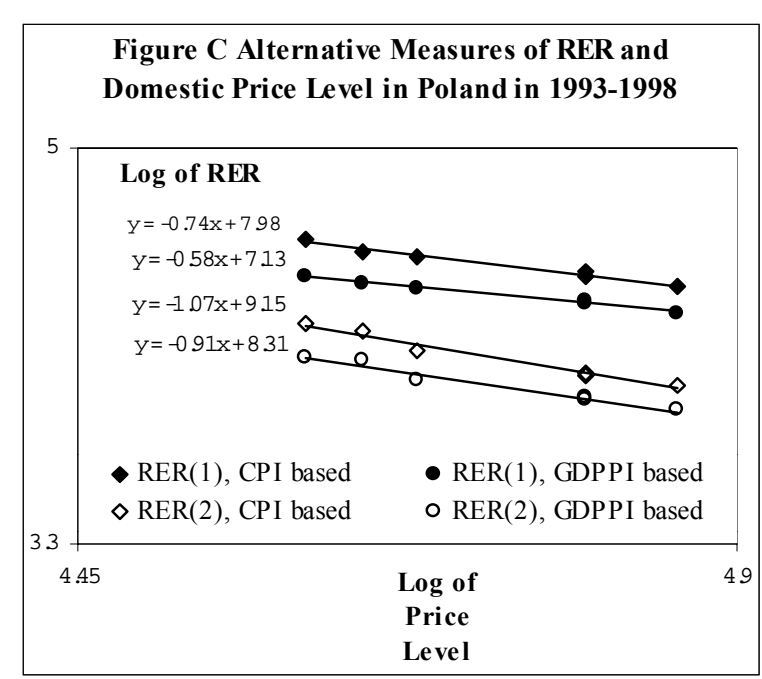

the RER(2) because the nominator of the former reflects the domestic prices of tradables (domestic PPI) which, as already argued, rose relative to the nominator of RER(2) i.e. index of foreign prices of tradables (PPI in US and Germany) - due to the increasing propensity to trade (openness) and because a certain share of the activities covered by the domestic PPI may be of a non-tradable character (measurement error). Probably, the coefficients of the $\operatorname{RER}(1)$ and $\operatorname{RER}(2)$ denominated in the CPI have higher absolute values compared to their counterparts denominated in GDPPI because of the faster rising share of non-tradables in

the CPI basket during the analysed period. With time, however, the CPI and GDPPI started to converge (Annex Table 20). Thus, in the longer term, the convergence of the domestic prices of tradables to their international levels and the convergence of the CPI to the GDPPI means that the values of all alternative measures will also converge.

In conclusion, the rate of the domestic price increases in response to the GDP/per capita growth in the longterm can be assumed to approximate to 0.76 , the value derived from the cross-country regression for OECD countries in 1997. Furthermore, assuming that in the analysed industry perfect alignment of domestic prices to their international levels has already been achieved the $\operatorname{RER}(1)$ and $\operatorname{RER}(2)$ measured in terms of domestic GDPPI are equivalently good measures (changes in foreign prices of tradables will be fully and immediately transmitted to the domestic market) and they are equal to the reciprocal of the changes in price level (PPP/NER). Ultimately, the rate of changes in the real prices of tradable components in such industry is assumed to equal 0.76 of the rate of GDP/capita growth rate.

\section{Notes:}

(1) The figures A,B and C in this annex are based on author's own calculations made with the used of the data from OECD $(1994,1996,1999)$ and GUS (1999c).

(2) High incomes are conductive to high prices of non-tradables because of the relatively lower scope for productivity differences (or improvements in the temporal context) in non-tradables sector. High incomes mainly result from the differences in productivity in the tradables sectors. This effect is known as the Balassa-Samuelson theory for explaining why prices of non-tradables are lower in poor countries (Krugman and Obstfeld, 1994).

${ }^{(3)}$ High incomes lead to an upward shift in the marginal costs because non-tradables, which consist largely of services, are naturally labour intensive relative to tradables. This explanation for the differences in price levels between rich countries (with a high capital-labour ratio and high marginal labour productivity and high wages) and poor countries (with a low capital labour ratio and low marginal labour productivity and low wages) is known as a Bhagwati-Kravis-Lipsey theory (Krugman and Obstfeld, 1994). 
Annex Table 22. Projections of world market prices for dairy products, 1997-2010 (F.O.B. export price, northern Europe).

\begin{tabular}{|c|c|c|c|c|c|c|c|c|c|c|c|c|c|c|c|}
\hline & & 1997 & 1998 & 1999 & 2000 & 2001 & 2002 & 2003 & 2004 & 2005 & 2006 & 2007 & 2008 & 2009 & 2010 \\
\hline \multicolumn{16}{|l|}{ Cheese } \\
\hline OECD (1) & USD $/ 100 \mathrm{~kg}$ & 220 & 216 & 215 & 218 & 225 & 230 & 235 & & & & & & & \\
\hline FAPRI (2) & $\mathrm{USD} / 100 \mathrm{~kg}$ & 243 & 247 & 250 & 252 & 251 & 251 & 252 & 255 & 258 & & & & & \\
\hline FAPRI (3) & USD $/ 100 \mathrm{~kg}$ & & 223 & 232 & 235 & 244 & 244 & 245 & 246 & 247 & 247 & 249 & 249 & & \\
\hline Applied & $1997=1$ & 1.00 & 0.92 & 0.95 & 0.97 & 1.00 & 1.01 & 1.01 & 1.01 & 1.02 & 1.02 & 1.02 & 1.02 & 1.03 & 1.03 \\
\hline \multicolumn{16}{|l|}{ Butter } \\
\hline OECD (1) & USD $/ 100 \mathrm{~kg}$ & 179 & 179 & 175 & 167 & 166 & 171 & 176 & & & & & & & \\
\hline FAPRI (2) & USD $/ 100 \mathrm{~kg}$ & 172 & 185 & 188 & 189 & 190 & 192 & 194 & 196 & 197 & & & & & \\
\hline FAPRI (3) & $\mathrm{USD} / 100 \mathrm{~kg}$ & & 185 & 180 & 176 & 178 & 180 & 183 & 185 & 188 & 189 & 188 & 188 & & \\
\hline Applied & $1997=1$ & 1.00 & 1.08 & 1.05 & 1.02 & 1.03 & 1.05 & 1.06 & 1.07 & 1.09 & 1.10 & 1.09 & 1.09 & 1.09 & 1.08 \\
\hline \multicolumn{16}{|l|}{ SMP } \\
\hline OECD (1) & $\mathrm{USD} / 100 \mathrm{~kg}$ & 176 & 169 & 172 & 182 & 195 & 198 & 200 & & & & & & & \\
\hline FAPRI (2) & $\mathrm{USD} / 100 \mathrm{~kg}$ & 174 & 163 & 176 & 182 & 187 & 190 & 195 & 202 & 211 & & & & & \\
\hline FAPRI (3) & USD $/ 100 \mathrm{~kg}$ & & 145.3 & 126 & 128.9 & 141.3 & 146 & 148.6 & 151.8 & 154 & 156.8 & 160.4 & 164 & & \\
\hline Applied & $1997=1$ & 1.00 & 0.84 & 0.72 & 0.74 & 0.81 & 0.84 & 0.85 & 0.87 & 0.89 & 0.90 & 0.92 & 0.94 & 0.96 & 0.99 \\
\hline \multicolumn{16}{|l|}{ WMP } \\
\hline OECD (1) & USD $/ 100 \mathrm{~kg}$ & 185 & 181 & 181 & 185 & 192 & 195 & 198 & & & & & & & \\
\hline FAPRI (2) & $\mathrm{USD} / 100 \mathrm{~kg}$ & 183 & 187 & 197 & 203 & 206 & 208 & 211 & 216 & 222 & & & & & \\
\hline Applied & $1997=1$ & 1.00 & 0.84 & 0.72 & 0.74 & 0.81 & 0.84 & 0.85 & 0.87 & 0.89 & 0.90 & 0.92 & 0.94 & 0.96 & 0.99 \\
\hline
\end{tabular}


Annex Table 23. Estimation of benchmark levels for dairy price alignment due to the integration with the CAP.

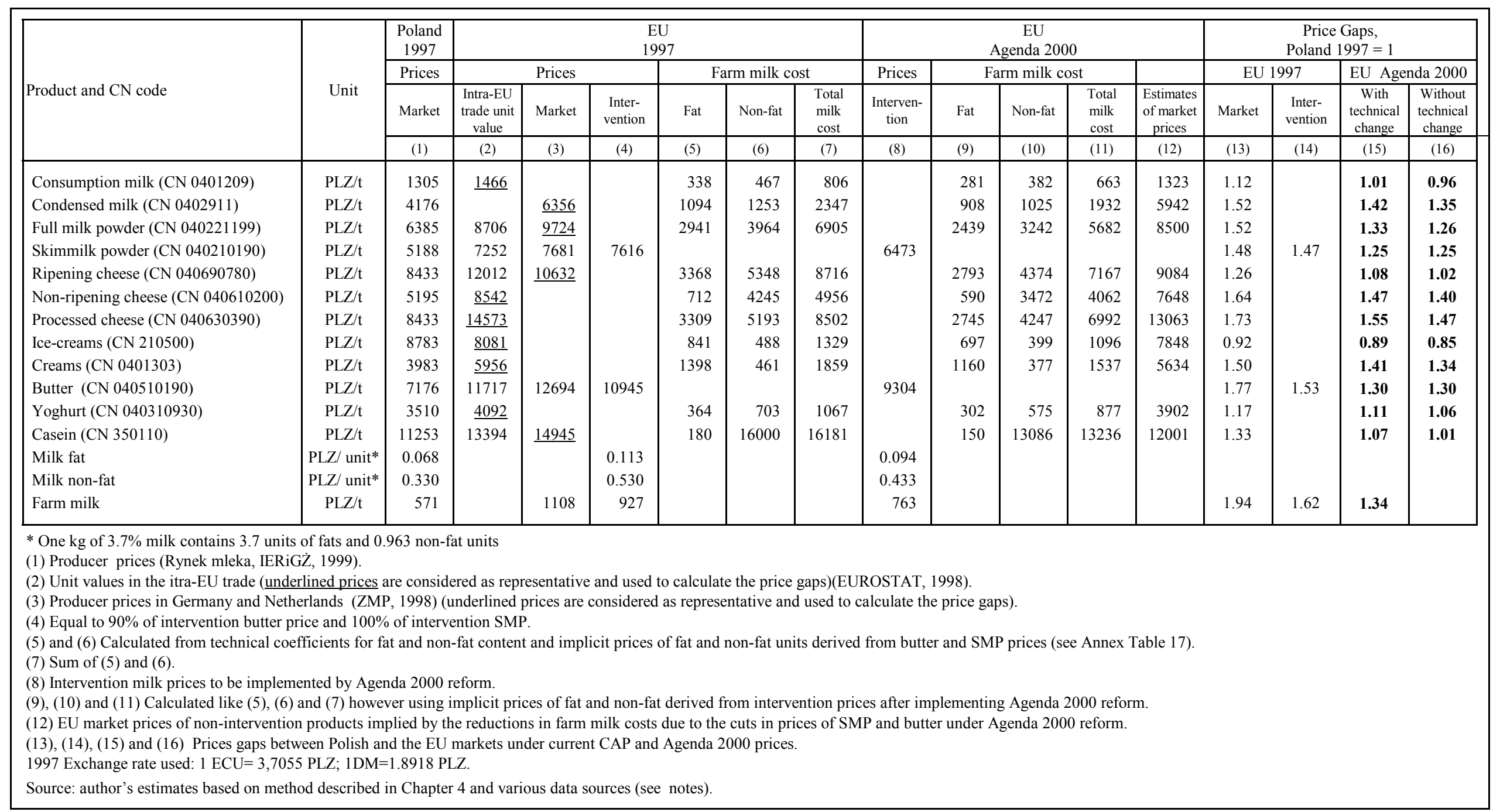


Annex Table 23. Milk processing industry, ex-post and ex-ante PAMs and decomposition of dynamic effects (in real terms, PLZ/ton of farm milk processed).

\begin{tabular}{|c|c|c|c|c|c|c|}
\hline \multicolumn{7}{|l|}{997} \\
\hline & \multirow[t]{2}{*}{ Revenues } & \multicolumn{4}{|c|}{ Costs } & \multirow[t]{2}{*}{ Profits } \\
\hline & & Tradables & Farm Milk & Labour & Capital & \\
\hline Private prices & 1062 & 188 & 571 & 186 & 92 & 25 \\
\hline Social prices & 981 & 178 & 564 & 158 & 112 & -30 \\
\hline Total divergence & 81 & 10 & 7 & 28 & -20 & 55 \\
\hline Direct policy distortion & 36 & 10 & 7 & 28 & -20 & 11 \\
\hline Remaining divergence & 44 & 0 & 0 & 0 & 0 & 44 \\
\hline \multirow[t]{2}{*}{ NPC } & 1,08 & 1,06 & 1,01 & 1,18 & 0,82 & \\
\hline & Prv. VA/T & Soc. VA/T & EPC & DRC & PRC & DDFC \\
\hline Milk as tradable $\left(\mathrm{DRC}_{1}\right)$ & 303 & 240 & 1,26 & 1,13 & 0,92 & 1,03 \\
\hline Milk as domestic reresource $\left(\mathrm{DRC}_{2}\right)$ & 874 & 804 & 1,09 & 1,04 & 0,97 & 1,02 \\
\hline
\end{tabular}

PAM, 2007, Base scenario and No Technical Change

\begin{tabular}{|c|c|c|c|c|c|c|}
\hline & \multirow[t]{2}{*}{ Revenues } & \multicolumn{4}{|c|}{ Costs } & \multirow[t]{2}{*}{ Profits } \\
\hline & & Tradables & Farm Milk & Labour & Capital & \\
\hline Private values & 909 & 145 & 493 & 275 & 65 & -69 \\
\hline Eurosocial values & 909 & 142 & 519 & 275 & 72 & -99 \\
\hline Total divergence & 0 & 3 & -26 & 0 & -7 & 31 \\
\hline NPC & 1,00 & 1,02 & 0,95 & 1,00 & 0,90 & \\
\hline & Prv. VA/T & Eurosoc. VA/T & EPC & DRC & PRC & DDFC \\
\hline Milk as tradable $\left(\mathrm{DRC}_{1}\right)$ & 271 & 248 & 1,09 & 1,40 & 1,25 & 0,98 \\
\hline Milk as domestic resource $\left(\mathrm{DRC}_{2}\right)$ & 764 & 767 & 1,00 & 1,13 & 1,09 & 0,96 \\
\hline
\end{tabular}

PAM, 2007, Base scenario and Technical Change

\begin{tabular}{|c|c|c|c|c|c|c|}
\hline & Revenues & & & & & Profits \\
\hline & & Tradables & Farm Milk & Labour & Capital & \\
\hline Private values & 946 & 153 & 503 & 165 & 102 & 24 \\
\hline Eurosocial values & 946 & 150 & 529 & 165 & 113 & -10 \\
\hline Total divergence & 0 & 3 & -26 & 0 & -11 & 34 \\
\hline NPC & 1,00 & 1,02 & 0,95 & 1,00 & 0,90 & \\
\hline & Prv. VA/T & Eurosoc. VA/T & EPC & DRC & PRC & DDFC \\
\hline Milk as tradable $\left(\mathrm{DRC}_{1}\right)$ & 268 & 268 & 1,09 & 1,04 & 0,92 & 0,96 \\
\hline Milk as domestic resource $\left(\mathrm{DRC}_{2}\right)$ & 793 & 797 & 1,00 & 1,01 & 0,97 & 0,95 \\
\hline
\end{tabular}

Matrix of Dynamic Effects on Social Profitability

\begin{tabular}{|c|c|c|c|c|c|c|}
\hline & \multirow[t]{2}{*}{ Revenues } & \multicolumn{4}{|c|}{ Costs } & \multirow[t]{2}{*}{ Profits } \\
\hline & & Tradables & Farm Milk & Labour & Capital & \\
\hline Social values in 2007 without T.CH. & 946 & 150 & 529 & 165 & 113 & -10 \\
\hline Social values in 2007 without T.TCH. & 909 & 142 & 519 & 275 & 72 & -99 \\
\hline Social Values in 1997 & 981 & 178 & 564 & 158 & 112 & -30 \\
\hline Total Change & -35 & -28 & -35 & 7 & 1 & 20 \\
\hline Price Effect & -74 & -37 & -45 & 94 & -51 & -34 \\
\hline Technical Change Effect & 39 & 9 & 10 & -86 & 52 & 55 \\
\hline
\end{tabular}

\section{Matrix of Dynamic Effects on Private Profitability}

\begin{tabular}{|c|c|c|c|c|c|c|}
\hline & \multirow[t]{2}{*}{ Revenues } & \multicolumn{4}{|c|}{ Costs } & \multirow[t]{2}{*}{ Profits } \\
\hline & & Tradables & Farm Milk & Labour & Capital & \\
\hline Private values in 2007 with T.CH. & 946 & 153 & 503 & 165 & 102 & 24 \\
\hline Private values in 2007 without T.CH. & 909 & 145 & 493 & 275 & 65 & -69 \\
\hline Private values in 1997 & 1062 & 188 & 571 & 186 & 92 & 25 \\
\hline Total Change & -116 & -35 & -68 & -21 & 10 & -1 \\
\hline Price Effect & -156 & -44 & -78 & 71 & -35 & -69 \\
\hline Technical Change Effect & 40 & 10 & 10 & -92 & 45 & 68 \\
\hline
\end{tabular}

Source: author's estimates based on methods and data described in text. 
Annex Table 24. Skimmed milk powder, ex-post and ex-ante PAMs and decomposition of dynamic effects (in real terms, PLZ/ton of product).

\begin{tabular}{|c|c|c|c|c|c|c|}
\hline \multicolumn{7}{|l|}{997} \\
\hline & \multirow[t]{2}{*}{ Revenues } & \multicolumn{4}{|c|}{ Costs } & \multirow[t]{2}{*}{ Profits } \\
\hline & & Tradables & Farm Milk & Labour & Capital & \\
\hline Private prices & 5188 & 463 & 3711 & 501 & 371 & 142 \\
\hline Social prices & 5089 & 429 & 3635 & 426 & 512 & 87 \\
\hline Total divergence & 98 & 34 & 76 & 75 & -142 & 54 \\
\hline Direct policy distortion & 24 & 34 & 76 & 75 & -142 & -20 \\
\hline Remaining dstortion & 74 & 0 & 0 & 0 & 0 & 74 \\
\hline \multirow[t]{2}{*}{ NPC } & 1,02 & 1,08 & 1,02 & 1,18 & 0,72 & \\
\hline & Prv. VA/T & Soc. VA/T & EPC & DRC & PRC & DDFC \\
\hline Milk as tradable $\left(\mathrm{DRC}_{1}\right)$ & 1014 & 1026 & 0,99 & 0,91 & 0,86 & 1,00 \\
\hline Milk as domestic reresource $\left(\mathrm{DRC}_{2}\right)$ & 4725 & 4661 & 1,01 & 0,98 & 0,97 & 0,93 \\
\hline
\end{tabular}

\section{PAM, 2007, Base scenario and No Technical Change}

\begin{tabular}{|c|c|c|c|c|c|c|}
\hline & \multirow[t]{2}{*}{ Revenues } & \multicolumn{4}{|c|}{ Costs } & \multirow[t]{2}{*}{ Profits } \\
\hline & & Tradables & Farm Milk & Labour & Capital & \\
\hline \begin{tabular}{|l|} 
Private values \\
\end{tabular} & 4798 & 361 & 3095 & 742 & 260 & 338 \\
\hline Eurosocial values & 4798 & 333 & 3258 & 742 & 297 & 167 \\
\hline Remaining divergence & 0 & 29 & -163 & 0 & -37 & 171 \\
\hline NPC & 1,00 & 1,09 & 0,95 & 1,00 & 0,88 & \\
\hline & Prv. VA/T & Eurosoc. VA/T & $\mathrm{EPC}$ & DRC & PRC & DDFC \\
\hline Milk as tradable $\left(\mathrm{DRC}_{1}\right)$ & 1341 & 1207 & 1,11 & 0,86 & 0,75 & 0,96 \\
\hline Milk as domestic resource $\left(\mathrm{DRC}_{2}\right)$ & 4436 & 4465 & 0,99 & 0,96 & 0,92 & 0,95 \\
\hline
\end{tabular}

PAM, 2007, Base scenario and Technical Change

\begin{tabular}{|c|c|c|c|c|c|c|}
\hline & \multirow[t]{2}{*}{ Revenues } & \multicolumn{4}{|c|}{ Costs } & \multirow[t]{2}{*}{ Profits } \\
\hline & & Tradables & Farm Milk & Labour & Capital & \\
\hline Private values & 4798 & 376 & 3186 & 445 & 404 & 386 \\
\hline Eurosocial values & 4798 & 340 & 3354 & 445 & 460 & 199 \\
\hline Total divergence & 0 & 36 & -168 & 0 & -56 & 187 \\
\hline \multirow[t]{2}{*}{ NPC } & 1,00 & 1,11 & 0,95 & 1,00 & 0,88 & \\
\hline & Prv. VA/T & Eurosoc. VA/T & EPC & DRC & PRC & DDFC \\
\hline Milk as tradable $\left(\mathrm{DRC}_{1}\right)$ & 1104 & 1104 & 1,12 & 0,82 & 0,69 & 0,94 \\
\hline Milk as domestic resource $\left(\mathrm{DRC}_{2}\right)$ & 4422 & 4458 & 0,99 & 0,96 & 0,91 & 0,95 \\
\hline
\end{tabular}

Matrix of Dynamic Effects on Social Profitability

\begin{tabular}{|c|c|c|c|c|c|c|}
\hline & \multirow[t]{2}{*}{ Revenues } & \multicolumn{4}{|c|}{ Costs } & \multirow[t]{2}{*}{ Profits } \\
\hline & & Tradables & Farm Milk & Labour & Capital & \\
\hline Social values in 2007 without T.CH. & 4798 & 340 & 3354 & 445 & 460 & 199 \\
\hline Social values in 2007 without T.TCH. & 4798 & 333 & 3258 & 742 & 297 & 167 \\
\hline Social Values in 1997 & 5089 & 429 & 3635 & 426 & 512 & 87 \\
\hline Total Change & -291 & -88 & -281 & 19 & -52 & 112 \\
\hline Price Effect & -291 & -97 & -382 & 253 & -273 & 208 \\
\hline Technical Change Effect & 0 & 9 & 101 & -234 & 221 & -97 \\
\hline
\end{tabular}

\section{Matrix of Dynamic Effects on Private Profitability}

\begin{tabular}{|l|c|c|c|c|c|c|}
\hline \multirow{2}{*}{} & \multirow{2}{*}{ Revenues } & \multicolumn{4}{c|}{ Costs } & \multicolumn{2}{c|}{ Profits } \\
\cline { 3 - 6 } & & Tradables & Farm Milk & Labour & Capital & 404 \\
\hline Private values in 2007 with T.CH. & 4798 & 376 & 3186 & 445 & 386 \\
\hline Private values in 2007 without T.CH. & 4798 & 361 & 3095 & 742 & 260 & 338 \\
\hline Private values in 1997 & 5188 & 463 & 3711 & 501 & 371 & 142 \\
\hline Total Change & -390 & -87 & -525 & -56 & 34 & 245 \\
\hline Price Effect & -390 & -104 & -625 & 193 & -141 & 287 \\
\hline Technical Change Effect & 0 & 17 & 100 & -249 & 174 & -42 \\
\hline
\end{tabular}

Source: author's estimates based on methods and data described in text 
Annex Table 25. Ripening cheese, ex-post and ex-ante PAMs and decomposition of dynamic effects (in real terms, PLZ/ton of product).

\begin{tabular}{|c|c|c|c|c|c|c|}
\hline \multicolumn{7}{|l|}{ РАМ, 1997} \\
\hline & \multirow[t]{2}{*}{ Revenues } & \multicolumn{4}{|c|}{ Costs } & \multirow[t]{2}{*}{ Profits } \\
\hline & & Tradables & Farm Milk & Labour & Capital & \\
\hline Private prices & 8287 & 672 & 5375 & 1454 & 418 & 367 \\
\hline Social prices & 8213 & 620 & 5301 & 1236 & 505 & 552 \\
\hline Total divergence & 74 & 53 & 74 & 218 & -87 & -185 \\
\hline Direct policy distortion & 0 & 53 & 74 & 218 & -87 & -258 \\
\hline Remaining divergence & 74 & 0 & 0 & 0 & 0 & 74 \\
\hline \multirow[t]{2}{*}{ NPC } & 1,01 & 1,08 & 1,01 & 1,18 & 0,83 & \\
\hline & Prv. VA/T & Soc. VA/T & EPC & DRC & PRC & DDFC \\
\hline Milk as tradable $\left(\mathrm{DRC}_{1}\right)$ & 2239 & 2292 & 0,98 & 0,76 & 0,84 & 1,03 \\
\hline Milk as domestic reresource $\left(\mathrm{DRC}_{2}\right)$ & 7614 & 7593 & 1,00 & 0,93 & 0,95 & 1,08 \\
\hline
\end{tabular}

\section{PAM, 2007, Base scenario and No Technical Change}

\begin{tabular}{|c|c|c|c|c|c|c|}
\hline & \multirow[t]{2}{*}{ Revenues } & \multicolumn{4}{|c|}{ Costs } & \multirow[t]{2}{*}{ Profits } \\
\hline & & Tradables & Farm Milk & Labour & Capital & \\
\hline Private values & 6285 & 534 & 4621 & 2152 & 294 & -1316 \\
\hline Eurosocial values & 6285 & 506 & 4864 & 2152 & 326 & -1563 \\
\hline Total divergence & 0 & 28 & -243 & 0 & -33 & 248 \\
\hline NPC & 1,00 & 1,06 & 0,95 & 1,00 & 0,90 & \\
\hline & Prv. VA/T & Eurosoc. VA/T & $\mathrm{EPC}$ & DRC & PRC & DDFC \\
\hline Milk as tradable $\left(\mathrm{DRC}_{1}\right)$ & 1131 & 916 & 1,23 & 2,71 & 2,16 & 0,99 \\
\hline Milk as domestic resource $\left(\mathrm{DRC}_{2}\right)$ & 5751 & 5779 & 1,00 & 1,27 & 1,23 & 0,96 \\
\hline
\end{tabular}

PAM, 2007, Base scenario and Technical Change

\begin{tabular}{|c|c|c|c|c|c|c|}
\hline & \multirow[t]{2}{*}{ Revenues } & \multicolumn{4}{|c|}{ Costs } & \multirow[t]{2}{*}{ Profits } \\
\hline & & Tradables & Farm Milk & Labour & Capital & \\
\hline Private values & 6616 & 576 & 4714 & 1291 & 470 & -435 \\
\hline Eurosocial values & 6616 & 540 & 4962 & 1291 & 519 & -696 \\
\hline Total divergence & 0 & 36 & -248 & 0 & -49 & 261 \\
\hline \multirow[t]{2}{*}{$\mathrm{NPC}$} & 1,00 & 1,07 & 0,95 & 1,00 & 0,91 & \\
\hline & Prv. VA/T & Eurosoc. VA/T & EPC & DRC & PRC & DDFC \\
\hline Milk as tradable $\left(\mathrm{DRC}_{1}\right)$ & 1114 & 1114 & 1,19 & 1,62 & 1,33 & 0,97 \\
\hline Milk as domestic resource $\left(\mathrm{DRC}_{2}\right)$ & 6040 & 6076 & 0,99 & 1,11 & 1,07 & 0,96 \\
\hline
\end{tabular}

Matrix of Dynamic Effects on Social Profitability

\begin{tabular}{|l|c|c|c|r|r|r|}
\hline \multirow{2}{*}{} & \multirow{2}{*}{ Revenues } & \multicolumn{3}{|c|}{ Costs } & \multicolumn{2}{c|}{ Profits } \\
\cline { 3 - 7 } & & Tradables & Farm Milk & \multicolumn{2}{c|}{ Labour } & \multicolumn{2}{c|}{ Capital } \\
\hline Social values in 2007 without T.CH. & 6616 & 540 & 4962 & 1291 & 519 & -696 \\
\hline Social values in 2007 without T.TCH. & 6285 & 506 & 4864 & 2152 & 326 & -1563 \\
\hline Social Values in 1997 & 8213 & 620 & 5301 & 1236 & 505 & 552 \\
\hline Total Change & -1597 & -79 & -339 & 55 & -1248 & -14 \\
\hline Price Effect & -1978 & -117 & -441 & 733 & -231 & -1922 \\
\hline Technical Change Effect & 382 & 38 & 102 & -678 & 245 & 674 \\
\hline
\end{tabular}

\section{Matrix of Dynamic Effects on Private Profitability}

\begin{tabular}{|l|c|c|c|c|c|c|}
\hline \multirow{2}{*}{} & \multirow{2}{*}{ Revenues } & \multicolumn{4}{|c|}{ Costs } & \multicolumn{2}{c|}{ Profits } \\
\cline { 3 - 6 } & & Tradables & Farm Milk & Labour & Capital & \\
\hline Private values in 2007 with T.CH. & 6616 & 576 & 4714 & 1291 & 470 & -435 \\
\hline Private values in 2007 without T.CH. & 6285 & 534 & 4621 & 2152 & 294 & -1316 \\
\hline Private values in 1997 & 8287 & 672 & 5375 & 1454 & 418 & 367 \\
\hline Total Change & -1670 & -96 & -661 & -163 & 52 & -802 \\
\hline Price Effect & -2054 & -143 & -762 & 559 & -162 & -1545 \\
\hline Technical Change Effect & 383 & 47 & 101 & -721 & 214 & 744 \\
\hline
\end{tabular}

Source: author's estimates based on methods and data described in text 
Annex Table 26. Butter, ex-post and ex-ante PAMs and decomposition of dynamic effects (in real terms, PLZ/ton of product).

\begin{tabular}{|c|c|c|c|c|c|c|}
\hline \multicolumn{7}{|l|}{997} \\
\hline & \multirow[t]{2}{*}{ Revenues } & \multicolumn{4}{|c|}{ Costs } & \multirow[t]{2}{*}{ Profits } \\
\hline & & Tradables & Farm Milk & Labour & Capital & \\
\hline Private prices & 7176 & 685 & 5784 & 823 & 481 & -597 \\
\hline Social prices & 7044 & 641 & 5769 & 699 & 585 & -651 \\
\hline Total divergence & 132 & 44 & 15 & 123 & -104 & 54 \\
\hline Direct policy distortion & 0 & 44 & 15 & 123 & -104 & -79 \\
\hline Remaining divergence & 132 & 0 & 0 & 0 & 0 & 132 \\
\hline \multirow[t]{2}{*}{ NPC } & 1,02 & 1,07 & 1,00 & 1,18 & 0,82 & \\
\hline & Prv. VA/T & Soc. VA/T & EPC & DRC & PRC & DDFC \\
\hline Milk as tradable $\left(\mathrm{DRC}_{1}\right)$ & 707 & 634 & 1,12 & 2,03 & 1,84 & 1,00 \\
\hline Milk as domestic reresource $\left(\mathrm{DRC}_{2}\right)$ & 6491 & 6403 & 1,01 & 1,10 & 1,09 & 1,02 \\
\hline
\end{tabular}

\section{PAM, 2007, Base scenario and No Technical Change}

\begin{tabular}{|c|c|c|c|c|c|c|}
\hline & \multirow[t]{2}{*}{ Revenues } & \multicolumn{4}{|c|}{ Costs } & \multirow[t]{2}{*}{ Profits } \\
\hline & & Tradables & Farm Milk & Labour & Capital & \\
\hline Private values & 6896 & 526 & 5217 & 1218 & 338 & -403 \\
\hline Eurosocial values & 6896 & 493 & 5492 & 1218 & 377 & -684 \\
\hline Total divergence & 0 & 33 & -275 & 0 & -39 & 281 \\
\hline \multirow[t]{2}{*}{ NPC } & 1,00 & 1,07 & 0,95 & 1,00 & 0,90 & \\
\hline & Prv. VA/T & Eurosoc. VA/T & EPC & DRC & PRC & DDFC \\
\hline Milk as tradable $\left(\mathrm{DRC}_{1}\right)$ & 1153 & 911 & 1,27 & 1,75 & 1,35 & 0,98 \\
\hline Milk as domestic resource $\left(\mathrm{DRC}_{2}\right)$ & 6370 & 6403 & 0,99 & 1,11 & 1,06 & 0,96 \\
\hline
\end{tabular}

PAM, 2007, Base scenario and Technical Change

\begin{tabular}{|c|c|c|c|c|c|c|}
\hline & \multirow[t]{2}{*}{ Revenues } & \multicolumn{4}{|c|}{ Costs } & \multirow[t]{2}{*}{ Profits } \\
\hline & & Tradables & Farm Milk & Labour & Capital & \\
\hline \begin{tabular}{|l|} 
Private values \\
\end{tabular} & 6896 & 590 & 5250 & 731 & 547 & -221 \\
\hline Eurosocial values & 6896 & 550 & 5526 & 731 & 605 & -516 \\
\hline Total divergence & 0 & 39 & -276 & 0 & -58 & 295 \\
\hline \multirow[t]{2}{*}{ NPC } & 1,00 & 1,07 & 0,95 & 1,00 & 0,90 & \\
\hline & Prv. VA/T & Eurosoc. VA/T & EPC & DRC & PRC & DDFC \\
\hline Milk as tradable $\left(\mathrm{DRC}_{1}\right)$ & 820 & 820 & 1,29 & 1,63 & 1,21 & 0,96 \\
\hline Milk as domestic resource $\left(\mathrm{DRC}_{2}\right)$ & 6306 & 6346 & 0,99 & 1,08 & 1,04 & 0,95 \\
\hline
\end{tabular}

Matrix of Dynamic Effects on Social Profitability

\begin{tabular}{|l|c|c|c|r|r|r|}
\hline \multirow{2}{*}{} & \multirow{2}{*}{ Revenues } & \multicolumn{3}{|c|}{ Costs } & \multicolumn{2}{c|}{ Profits } \\
\cline { 3 - 6 } & & Tradables & Farm Milk & Labour & \multicolumn{2}{c|}{ Capital } \\
\hline Social values in 2007 without T.CH. & 6896 & 550 & 5526 & 731 & 605 & -516 \\
\hline Social values in 2007 without T.TCH. & 6896 & 493 & 5492 & 1218 & 377 & -684 \\
\hline Social Values in 1997 & 7044 & 641 & 5769 & 699 & 585 & -651 \\
\hline Total Change & -148 & -91 & -243 & 31 & 20 & 135 \\
\hline Price Effect & -148 & -157 & -278 & 415 & -271 & 143 \\
\hline Technical Change Effect & 0 & 66 & 35 & -384 & 291 & -8 \\
\hline
\end{tabular}

\section{Matrix of Dynamic Effects on Private Profitability}

\begin{tabular}{|c|c|c|c|c|c|c|}
\hline & \multirow[t]{2}{*}{ Revenues } & \multicolumn{4}{|c|}{ Costs } & \multirow[t]{2}{*}{ Profits } \\
\hline & & Tradables & Farm Milk & Labour & Capital & \\
\hline Private values in 2007 with T.CH. & 6896 & 590 & 5250 & 731 & 547 & -221 \\
\hline Private values in 2007 without T.CH. & 6896 & 526 & 5217 & 1218 & 338 & -403 \\
\hline Private values in 1997 & 7176 & 685 & 5784 & 823 & 481 & -597 \\
\hline Total Change & -280 & -96 & -534 & -92 & 65 & 376 \\
\hline Price Effect & -280 & -170 & -568 & 316 & -187 & 328 \\
\hline Technical Change Effect & 0 & 74 & 34 & -408 & 253 & 48 \\
\hline
\end{tabular}

Source: author's estimates based on methods and data described in text 
Annex Table 27. Yoghurt, ex-post and ex-ante PAMs and decomposition of dynamic effects (in real terms, PLZ/ton of product).

\begin{tabular}{|c|c|c|c|c|c|c|}
\hline & \multirow{2}{*}{ Revenues } & \multicolumn{4}{|c|}{ Costs } & \multirow{2}{*}{ Profit } \\
\hline & & Tradables & Farm Milk & Labour & Capital & \\
\hline Private prices & 2630 & 877 & 659 & 427 & 411 & 257 \\
\hline Social prices & 2150 & 836 & 649 & 363 & 517 & -215 \\
\hline Total divergence & 480 & 41 & 10 & 64 & -106 & 472 \\
\hline Direct policy distortion & 679 & 41 & 10 & 64 & -106 & 671 \\
\hline Remaining divergence & -199 & 0 & 0 & 0 & 0 & -199 \\
\hline \multirow[t]{2}{*}{ NPC } & 1,22 & 1,05 & 1,01 & 1,18 & 0,79 & \\
\hline & Prv. VA/T & Soc. VA/T & EPC & DRC & PRC & DDFC \\
\hline Milk as tradable $\left(\mathrm{DRC}_{1}\right)$ & 1095 & 665 & 1,65 & 1,32 & 0,77 & 0,98 \\
\hline Milk as domestic reresource $\left(\mathrm{DRC}_{2}\right)$ & 1753 & 1314 & 1,33 & 1,16 & 0,85 & 0,95 \\
\hline
\end{tabular}

\section{PAM, 2007, Base scenario and No Technical Change}

\begin{tabular}{|c|c|c|c|c|c|c|}
\hline & \multirow[t]{2}{*}{ Revenues } & \multicolumn{4}{|c|}{ Costs } & \multirow[t]{2}{*}{ Profits } \\
\hline & & Tradables & Farm Milk & Labour & Capital & \\
\hline Private values & 2059 & 671 & 564 & 632 & 289 & -98 \\
\hline Eurosocial values & 2059 & 674 & 594 & 632 & 316 & -157 \\
\hline Total divergence & 0 & -2 & -30 & 0 & -28 & 60 \\
\hline \multirow[t]{2}{*}{ NPC } & 1,00 & 1,00 & 0,95 & 1,00 & 0,91 & \\
\hline & $\begin{array}{l}\text { Prv. VA/T } \\
\end{array}$ & Eurosoc. VA/T & EPC & DRC & PRC & DDFC \\
\hline Milk as tradable $\left(\mathrm{DRC}_{1}\right)$ & 823 & 791 & 1,04 & 1,20 & 1,12 & 0,97 \\
\hline Milk as domestic resource $\left(\mathrm{DRC}_{2}\right)$ & 1387 & 1385 & 1,00 & 1,11 & 1,07 & 0,96 \\
\hline
\end{tabular}

\section{PAM, 2007, Base scenario and Technical Change}

\begin{tabular}{|c|c|c|c|c|c|c|}
\hline & \multirow[t]{2}{*}{ Revenues } & \multicolumn{4}{|c|}{ Costs } & \multirow[t]{2}{*}{ Profits } \\
\hline & & Tradables & Farm Milk & Labour & Capital & \\
\hline Private values & 2167 & 704 & 576 & 379 & 444 & 64 \\
\hline Eurosocial values & 2167 & 707 & 606 & 379 & 485 & -10 \\
\hline Total divergence & 0 & -2 & -30 & 0 & -41 & 74 \\
\hline \multirow[t]{2}{*}{ NPC } & 1,00 & 1,00 & 0,95 & 1,00 & 0,91 & \\
\hline & Prv. VA/T & Eurosoc. VA/T & EPC & DRC & PRC & DDFC \\
\hline Milk as tradable $\left(\mathrm{DRC}_{1}\right)$ & 854 & 854 & 1,04 & 1,01 & 0,93 & 0,95 \\
\hline Milk as domestic resource $\left(\mathrm{DRC}_{2}\right)$ & 1463 & 1461 & 1,00 & 1,01 & 0,96 & 0,95 \\
\hline
\end{tabular}

Matrix of Dynamic Effects on Social Profitability

\begin{tabular}{|l|c|c|c|c|c|c|}
\hline \multirow{2}{*}{} & \multirow{2}{*}{ Revenues } & \multicolumn{3}{|c|}{ Costs } & \multicolumn{2}{c|}{ Profits } \\
\cline { 3 - 7 } & & Tradables & Farm Milk & Labour & Capital & \\
\hline Social values in 2007 without T.CH. & 2167 & 707 & 606 & 379 & 485 & -10 \\
\hline Social values in 2007 without T.TCH. & 2059 & 674 & 594 & 632 & -157 \\
\hline Social Values in 1997 & 2150 & 836 & 649 & 363 & 517 & -215 \\
\hline Total Change & 17 & -129 & -43 & 16 & -32 & 205 \\
\hline Price Effect & -93 & -166 & -56 & 215 & -254 & 168 \\
\hline Technical Change Effect & 111 & 37 & 13 & -199 & 222 & 38 \\
\hline
\end{tabular}

\section{Matrix of Dynamic Effects on Private Profitability}

\begin{tabular}{|c|c|c|c|c|c|c|}
\hline & \multirow[t]{2}{*}{ Revenues } & \multicolumn{4}{|c|}{ Costs } & \multirow[t]{2}{*}{ Profits } \\
\hline & & Tradables & Farm Milk & Labour & Capital & \\
\hline Private values in 2007 with T.CH. & 2167 & 704 & 576 & 379 & 444 & 64 \\
\hline Private values in 2007 without T.CH & 2059 & 671 & 564 & 632 & 289 & -98 \\
\hline Private values in 1997 & 2630 & 877 & 659 & 427 & 411 & 257 \\
\hline Total change & -463 & -173 & -83 & -48 & 33 & -193 \\
\hline Price effect & -586 & -210 & -95 & 164 & -155 & -290 \\
\hline Technical change effect & 123 & 38 & 13 & -212 & 188 & 97 \\
\hline
\end{tabular}

Source: author's estimates based on methods and data described in text 